ANDREIA CAROLINA ROSA

DESEMPENHO DOS CIRCUITOS DE MOAGEM DIRETO E INVERSO DA SAMARCO 
ANDREIA CAROLINA ROSA

DESEMPENHO DOS CIRCUITOS DE MOAGEM DIRETO E INVERSO DA SAMARCO

Dissertação apresentada à Escola Politécnica da Universidade de São Paulo para obtenção do título de Mestre em Engenharia

SÃO PAULO

2013 
ANDREIA CAROLINA ROSA

\section{DESEMPENHO DOS CIRCUITOS DE MOAGEM DIRETO E INVERSO} DA SAMARCO

Dissertação apresentada à Escola Politécnica da Universidade de São Paulo para obtenção do título de Mestre em Engenharia

Área de Concentração: Engenharia Mineral

Orientador: Prof. Dr. Homero Delboni Junior

SÃO PAULO

2013 
Este exemplar foi revisado e alterado em relação à versão original, sob responsabilidade única do autor e com a anuência de seu orientador.

São Paulo, 18 de fevereiro de 2013.

Assinatura do autor

Assinatura do orientador

FICHA CATALOGRÁFICA

Rosa, Andréia Carolina

Desempenhos dos circuitos de moagem direto e inverso da Samarco / A.C. Rosa. -- ed.rev. -- São Paulo, 2013.

$132 \mathrm{p}$.

Dissertação (Mestrado) - Escola Politécnica da Universidade de São Paulo. Departamento de Engenharia de Minas e de Petróleo.

1. Cominuição (Estudo comparativo) 2. Moagem 3. Ferro I. Universidade de São Paulo. Escola Politécnica. Departamento de Engenharia de Minas e de Petróleo II. t. 


\section{AGRADECIMENTOS}

Agradeço a todos que me apoiaram na realização deste trabalho e em especial:

à Samarco Mineração S.A, pela oportunidade e pelo suporte;

ao professor Homero Delboni Jr., pela orientação, suporte e por todo aprendizado;

ao meu gestor, Denilson Rodrigues de Araujo, pelo apoio e confiança;

às equipes dos laboratórios de Controle de Processos e Químico de Germano, pela dedicação e presteza na realização das amostragens e nas análises laboratoriais;

às equipes de produção e processo dos Concentradores I e II de Germano, por me "abrirem sua casa" e pelas discussões enriquecedoras;

a Vladimir Figueiredo, Geraldo Batisteli, Lamartine Freitas e Ernane Gonzaga, pelo apoio na realização das amostragens;

aos colegas da antiga GGDT e aos novos companheiros da GGTE pela torcida. Em especial, a José Pedro da Silva e Duilio Carvalho, cuja convivência muito me ensinou;

ao eterno tutor e amigo, Joaquim Donizetti Donda, pela paciência, ensinamentos e crescimento profissional proporcionado. 


\section{RESUMO}

Este trabalho analisou, comparativamente, os aspectos operacionais entre as configurações de circuito fechado de moagem em moinhos de bolas, quais sejam, os circuitos direto e inverso. Foram realizadas amostragens no circuito industrial de prémoagem e moagem primária do Concentrador I de Germano, da Samarco Mineração, ora operando sob a configuração inversa, ora sob a configuração direta. Os históricos de dados industriais entre os circuitos dos Concentradores I e II de Germano foram também comparados, para complementação desta análise. Por fim, foram realizados ensaios de moagem em escala de laboratório, simulando ambas as condições. As comparações entre diferentes índices de desempenho selecionou o consumo de energia por tonelada de material gerado abaixo da malha de controle como o mais adequado para avaliar o desempenho dos circuitos. A comparação entre os históricos dos dados industriais dos Concentradores I (operando sob circuito inverso) e do Concentrador II (operando sob circuito direto) mostrou um histórico consistente em que o circuito do Concentrador II apresenta menor consumo energético por tonelada de material gerado abaixo da malha de controle do circuito. Estes resultados foram diferentes daqueles obtidos a partir das amostragens realizadas no circuito industrial da Samarco, os quais indicaram melhor desempenho do circuito inverso. A diferença foi atribuída à etapa de classificação, cujo desempenho determina a alteração ou até mesmo anula os benefícios, conforme demonstram os resultados de simulação posteriores.

Palavras chave: minério de ferro, moagem, classificação. 


\begin{abstract}
This work compared the performance associated to both direct and reverse ball mill closed circuit configurations. Survey campaigns were carried out in both Samarco Mineração industrial plants ie. Concentrator I and Concentrator II. The former includes reverse configured ball mill closed grinding circuit, while the latter is equipped with ball mills under a direct closed configuration. The study comprised laboratory jar tests as well as comparisons between historical data obtained for both industrial plants. The energy consumption per ton of generated product was selected as the most adequate parameter to access the circuit performance. Comparisons based on historical data indicated that the Concentrator II, configured in a direct mode, showed a better performance than Concentrator I. Such a conclusion contrasts with the results obtained from the survey campaign which indicated a better performance for the reverse configuration. Such a difference was associated to the performance of the classification, carried out in cyclones, as demonstrated by simulations conducted on the basis of previously calibrated models.
\end{abstract}

Key words: iron ore, grinding, classification. 


\section{SUMÁRIO}

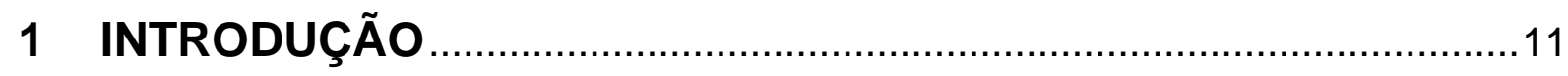

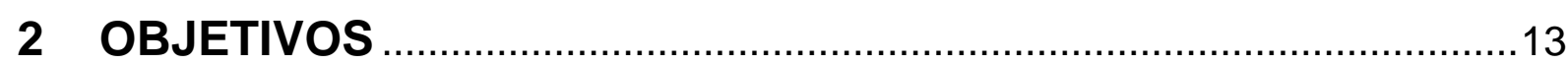

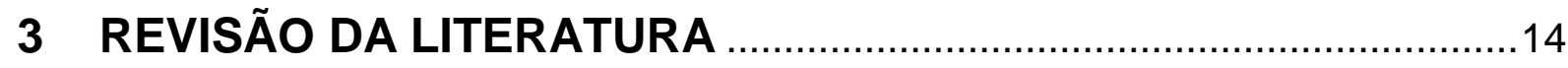

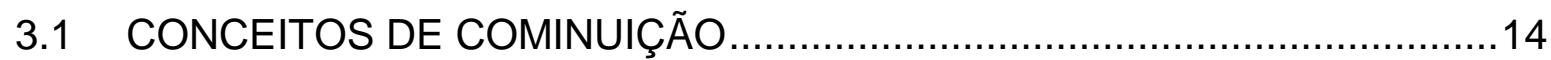

3.2 CONCEITOS DE EFICIÊNCIA DE MOAGEM .........................................17

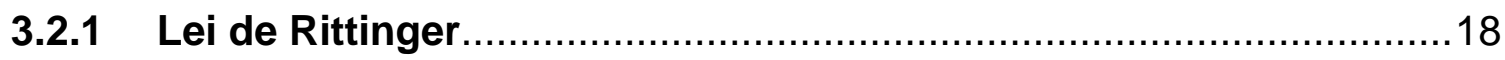

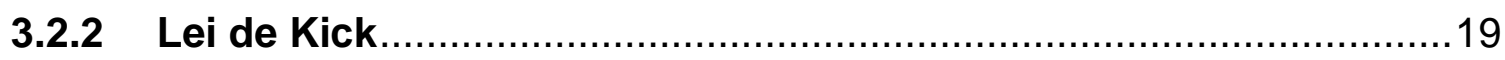

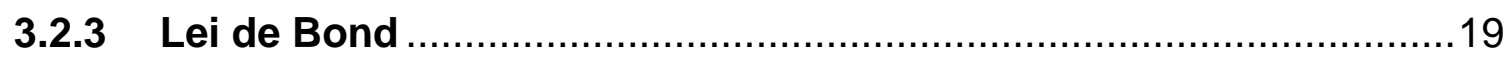

3.2.4 Forma genérica das "leis" de moagem .....................................23

3.2.5 Críticas ao conceito de eficiência ligado ao consumo de energia..24

3.3 AS DIFERENTES CONFIGURAÇÕES DE CIRCUITO DE MOAGEM .........25

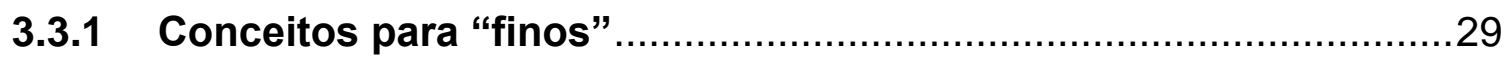

3.3.2 Efeitos da classificação e da carga circulante nos circuitos de moagem

3.3.3 Efeitos da retirada de finos na alimentação do circuito e sua avaliação 36

3.4 MODELAMENTO MATEMÁTICO DA OPERAÇÃO DE HIDROCICLONES 38

3.5 MÉTODO PARA ENSAIOS DE MOAGEM..............................................42

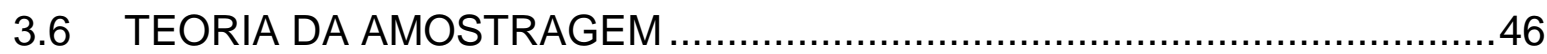

3.6.1 Erros de delimitação dos incrementos .........................................

3.6.2 Erros de extração dos incrementos ……...................................52

3.6.3 Aspectos práticos para amostragens de circuitos de moagem .......53

4 A SAMARCO MINERAÇÃO E OS CIRCUITOS DE MOAGEM

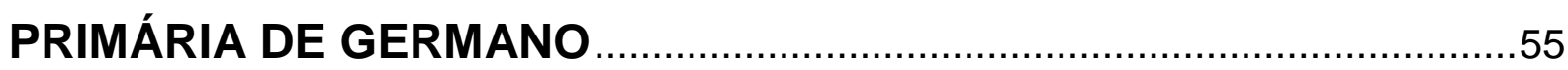

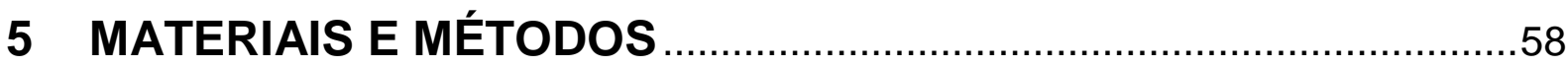

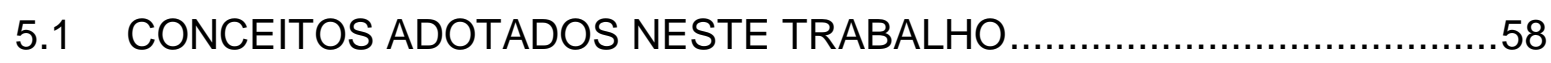

5.2 AMOSTRAGENS EM CIRCUITO INDUSTRIAL ....................................59

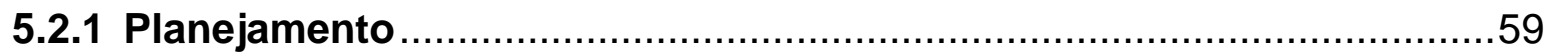

5.2.2 Variabilidade das características dos materiais e fluxos amostrados ..60 


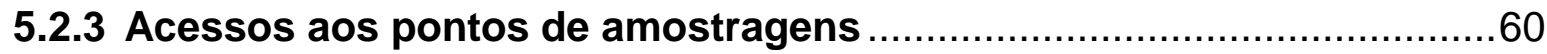

5.2.4 Levantamento de parâmetros operacionais do circuito ........................65

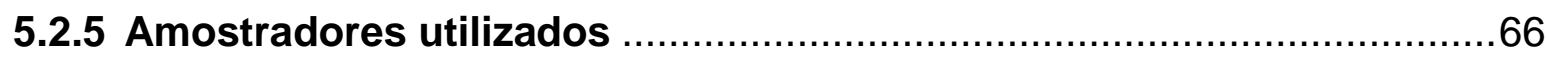

5.3 AMOSTRAGENS REALIZADAS NO CIRCUITO DE MOAGEM DO

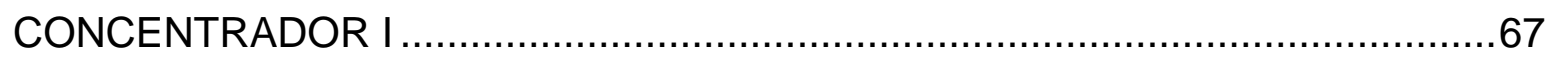

5.3.1 Cálculo dos parâmetros utilizados para análise dos circuitos

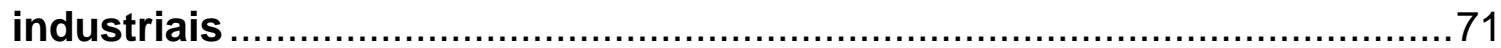

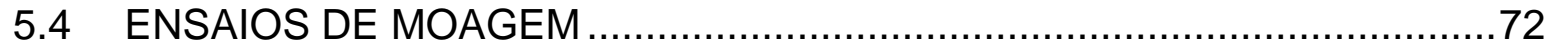

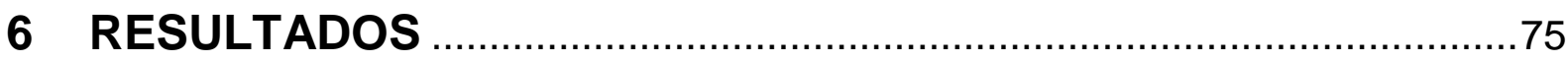

6.1. AMOSTRAGENS NO CIRCUITO INDUSTRIAL …...............................75

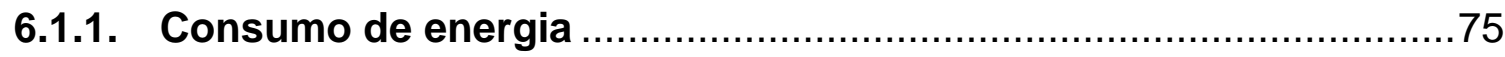

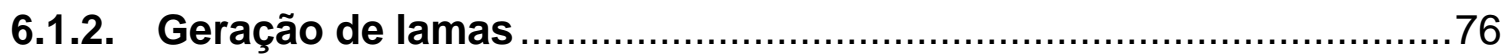

6.2. ENSAIOS DE MOAGEM EM LABORATÓRIO ..........................................76

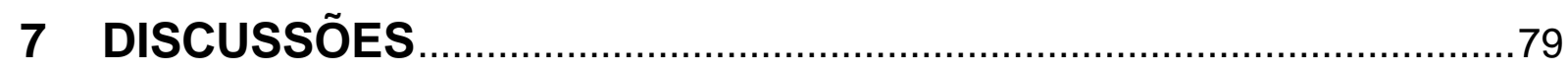

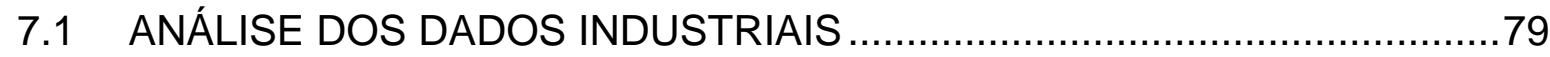

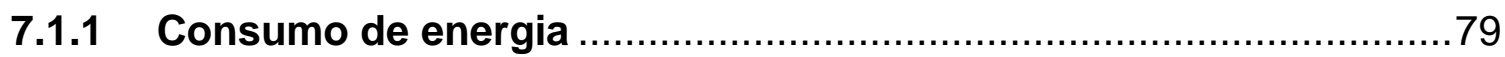

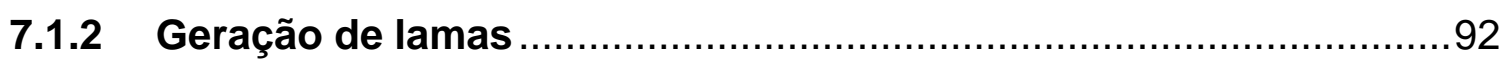

7.2 ANÁLISE DOS ENSAIOS DE LABORATÓRIO........................................93

7.2.1 Utilização de peneiras para fechamento de circuitos de moagem..97

7.3 VANTAGENS PRÁTICAS DA CONFIGURAÇÃO DIRETA .........................99

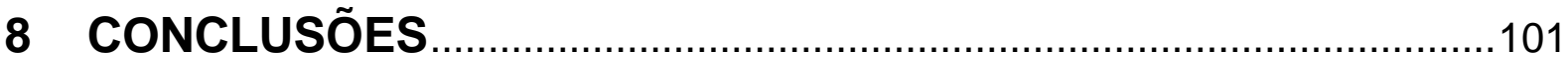

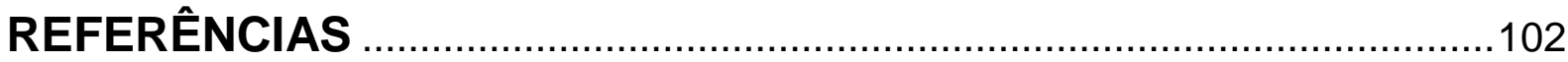

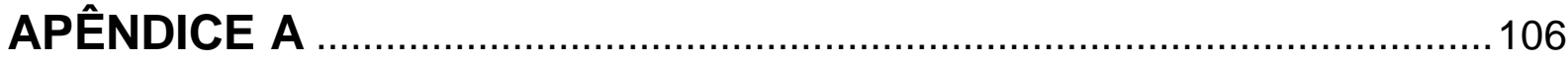

APÊNDICE B

APÊNDICE C 


\section{LISTA DE FIGURAS}

Figura 3.1 - Curvas de partição: (a) comparação entre curvas real e ideal; (b) curva real e corrigida

Figura 3.2 - Perfis de descarga no ápex dos hidrociclones: A - operação normal; B operação em corda (GUPTA; YAN, 2006)

Figura 3.3 - Inversão nas curvas de partição dos ciclones secundários de Germano.

Figura 3.4 - Condições de operação adequadas para o circuito direto e inverso.

(Adaptado de Sepúlveda, 2009).... 38

Figura 3.5 - Influência do parâmetro a na curva de partição. (GUPTA; YAN, 2006) .41

Figura 3.6 - Comparação entre curvas de partição real e teórica para minério de magnetita (Lynch, 1977)

Figura 3.7 - Fluxograma do circuito de moagem primária no início da operação do

Concentrador I de Germano.

Figura 3.8 - Fluxograma do circuito atual de moagem primária do Concentrador I de

Germano.

Figura 3.9 - Relação entre consumo específico de energia industrial e previsto em laboratório após mudança no circuito do Concentrador I.

Figura 3.10 - Representação do caixilho para delimitação de amostra em

transportador de correia.

Figura 3.11 - Amostragem de fluxos contínuos: (A) Amostrando todo o fluxo periodicamente: 1,2,3 estão corretos; 4 e 5 incorretos. (B) Amostrando parte do fluxo continuamente - sempre incorreto. (C) Amostrando parte do fluxo periodicamente sempre incorreto.

Figura 4.1 - Fluxograma do Concentrador I de Germano......................................56

Figura 5.1 - Coleta de amostra em transportador de correia....................................62

Figura 5.2 - Amostrador para a coleta da descarga de moinho...............................63

Figura 5.3 - Coleta de amostras na descarga dos moinhos primários.......................63

Figura 5.4 - Transferência do incremento (descarga do moinho) do coletor para o recipiente. 
Figura 5.5 - Pontos de amostragem no circuito industrial para a configuração inversa.

Figura 5.6 - Pontos de amostragem no circuito industrial para a configuração direta.

Figura 5.7 - Fluxograma para tratamento das amostras coletadas em circuito industrial 71

Figura 5.8 - Relação entre dados de moagem industriais e de laboratório. .73

Figura 5.9 - Fluxograma das etapas de preparação de amostras e execução dos ensaios de moagem.

Figura 6.1 - Distribuições granulométricas para as alimentações dos ensaios de moagem.

Figura 6.2 - Resultados dos ensaios de moagem.

Figura 7.1 - Comparação entre Work Index operacional para os circuitos direto e inverso.

Figura 7.2 - Perfil da curva de cinética de moagem.

Figura 7.3 - Comparação entre os Work Indexes operacionais corrigidos.

Figura 7.4 - Granulometria para a alimentação nova do circuito inverso durante as amostragens.

Figura 7.5 - Comparação entre os Work Indexes ajustados para os circuitos inverso e direto.

Figura 7.6 - Comparação entre o parâmetro "kWh/t $\mathrm{t}_{\text {<00\#" }}$ para os circuitos inverso e direto.

Figura 7.7 - Relação entre potência do moinho e a percentagem de sólidos na descarga.

Figura 7.8 - Partições de água para o underflow...................................................

Figura 7.9 - Circuito de moagem primária do Concentrador II.................................90

Figura 7.10 - Comparação entre dados industriais dos concentradores I e II. ..........91

Figura 7.11 - Percentagem de lamas no overflow dos ciclones primários..................92

Figura 7.12 - Percentagem de lamas para a descarga dos moinhos primários.........93

Figura 7.13 - Resultados da simulação: balanço de massas.

Figura 7.14 - Granulometrias estimadas para produtos da classificação com hidrociclones. 


\section{LISTA DE TABELAS}

Tabela 3.1 - Fator de ineficiência para o circuito aberto......................................21

Tabela 3.2 - Condições dos ensaios de moagem. ............................................43

Tabela 5.1 - Abertura dos amostradores utilizados. ........................................66

Tabela 6.1 - Resultados das amostragens em circuito industrial...........................75

Tabela 6.2 - Percentual de lamas obtido nas amostragens. ...............................76

Tabela 7.1 - Dados utilizados para a calibração do modelo de Nageswararao.........95 


\section{INTRODUÇÃO}

O estudo de circuitos de cominuição tem sido uma constante ao longo da história do tratamento de minérios. Dentre as muitas razões, destaca-se a importância deste processo nas usinas de beneficiamento, seja para se obter a liberação necessária ao ótimo desempenho das etapas posteriores de concentração, ou para adequar a granulometria de produtos e subprodutos ao transporte e/ou processamentos subsequentes.

Além do papel estratégico no beneficiamento da matéria prima mineral, a cominuição é, em geral, responsável por parcela significativa dos custos operacionais de uma usina, o que justifica os múltiplos trabalhos encontrados na literatura visando a escolha, dimensionamento e manutenção de um circuito o mais eficiente possível.

Embora diversas tecnologias tenham sido desenvolvidas nas últimas décadas, os circuitos de cominuição típicos persistem na combinação de britadores e moinhos de bolas com classificadores. Os hidrociclones são largamente empregados na classificação de circuitos de moinhos de bolas, devido, especialmente, à sua praticidade operacional e sua grande capacidade. Há duas configurações possíveis para estas operações, os chamados circuitos inverso e direto.

No primeiro, a classificação é localizada antes do moinho e, portanto, somente a fração grosseira (undersize) da alimentação nova é efetivamente direcionada a moagem; no segundo ocorre o oposto, ou seja, toda alimentação nova passa pelo moinho antes da classificação.

As vantagens e desvantagens de ambas as configurações têm sido longamente debatidas. O circuito inverso evita a passagem do material já adequado às especificações granulométricas do produto pelo moinho, evitando, deste modo, a sobremoagem. Por outro lado, o circuito inverso oferece maiores facilidades operacionais, evitando, por exemplo, a necessidade de empolpamento, uma operação bastante crítica, especialmente para minérios muito densos. 
Apesar das discussões geradas em diferentes fóruns, são poucos os estudos sobre este assunto encontrados na literatura e, principalmente, existem poucos dados industriais disponíveis para balizar estes estudos.

Neste contexto, o circuito de moagem do Concentrador I de Germano - Samarco Mineração S.A. - oferece uma oportunidade relevante. Ele é composto por seis moinhos de bolas, sendo dois pré-primários e quatro primários (primeira e segunda etapas de moagem, respectivamente). Os moinhos pré-primários recebem diretamente o minério britado, operando em circuito aberto. A descarga de cada prémoinho alimenta dois moinhos primários, os quais, por sua vez, operam em circuito fechado e inverso.

$\mathrm{Na}$ ocasião de paradas dos pré-moinhos, porém, o minério britado é alimentado diretamente na etapa de moagem primária. Deste modo, é possível agregar dados de um mesmo equipamento industrial funcionando ora em circuito inverso, ora em circuito direto.

Este trabalho baseia-se na coleta e tratamento dos dados deste circuito, sob ambas as configurações, de forma a proporcionar uma análise comparativa de desempenho. 


\section{OBJETIVOS}

O objetivo deste trabalho é analisar as vantagens e desvantagens relativas dos circuitos de moagem sob configuração direta e inversa, para as condições de operação dos concentradores de Germano, por meio de:

- realização de campanhas de amostragem no circuito de pré-moagem/ moagem primária do Concentrador I de Germano quando em operação sob as configurações direta e inversa;

- análise de dados industriais para a comparação de ambas as configurações;

- análise das variáveis operacionais que possam influenciar os dados obtidos nas campanhas de amostragem;

- realização de ensaios de moagem, com amostras dos circuitos industriais, em situações que simulem as condições operacionais das configurações direta e inversa. 


\section{REVISÃO DA LITERATURA}

$\mathrm{Na}$ literatura especializada, poucas são as referências sobre a comparação entre as configurações direta e inversa para circuitos de moagem. Deste modo, a revisão bibliográfica do presente trabalho cercou-se dos assuntos que permeiam esta avaliação.

A seguir é apresentado um resumo sobre os conceitos de cominuição e das teorias "clássicas" de moagem. O propósito deste primeiro capítulo foi fazer uma introdução sobre o tema do trabalho sem a pretensão de incorrer detalhadamente sobre os assuntos tratados.

Os capítulos seguintes tratam sobre os diferentes tipos de circuito de moagem e sobre o papel da etapa de classificação nas operações do circuito como um todo.

Por fim, foi feito um resumo sobre o modelamento matemático da operação de hidrociclones, o método para os ensaios de moagem utilizados na Samarco Mineração e sobre as teorias de amostragem, recursos importantes para a realização deste trabalho.

\subsection{CONCEITOS DE COMINUIÇÃO}

A cominuição é, geralmente, a operação primária no beneficiamento mineral, definida por Taggart ${ }^{1}$ e Wills ${ }^{2}$ como o processo gradual de redução de tamanho de partículas que se presta, principalmente, a:

- liberar o mineral de interesse para as operações posteriores de concentração;

- preparar a superfície das partículas minerais para reações químicas, processos de concentração, filtragem e pelotização;

- adequar um material para transporte ou segundo as características exigidas para um certo produto.

As operações de cominuição são, normalmente, estagiadas e podem ser divididas entre britagem e moagem. Tradicionalmente, são divididas pela faixa granulométrica de alimentação e do produto, cabendo à britagem os primeiros estágios de 
cominuição, ou seja, a fragmentação de materiais mais grosseiros. A moagem, por outro lado, refere-se aos últimos estágios, determinando produtos mais finos e, por outro lado, recebendo alimentações com menores tamanhos de partículas. Existe, contudo, uma "zona de transição" entre ambos os processos, pouco definida.

Beraldo ${ }^{3}$ define a faixa de operação de britagem tendo, como tamanho máximo de alimentação, partículas de $1 \mathrm{~m}$ e mínimo de $10 \mathrm{~mm}$. A moagem, por sua vez, compreende alimentações com tamanho máximo de até $100 \mathrm{~mm}$, considerando-se os moinhos autógenos e semiautógenos (respectivamente, moinhos que utilizam partículas do próprio minério ou uma combinação destas com bolas, como carga moedora).

Taggart ${ }^{1}$ enfatiza três faixas de operação, de acordo com o tamanho máximo de partículas de alimentação:

- britagem: ROM (Run of Mine) - $20 \mathrm{~mm}$;

- moagem: abaixo de $20 \mathrm{~mm}$;

- "zona de transição": 10 - 15 mm.

Por outro lado, Taggart enfatiza que, em geral, a razão de redução (razão entre os tamanhos da alimentação e do produto da etapa) na moagem é maior que na britagem.

Nenhuma destas propostas, contudo, é suficientemente clara, especialmente ao se considerar o avanço tecnológico dos equipamentos, a qual só ampliou as faixas granulométricas de trabalho possíveis a cada operação.

Atualmente é comum encontrar, por exemplo, moinhos autógenos ou semiautógenos alimentados diretamente com ROM, por vezes, realizando toda redução de tamanho requerida em um único estágio. Por outro lado, britadores de impacto produzem alta quantidade de produto fino, podendo, inclusive, reduzir o trabalho nas operações subsequentes de moagem.

Contudo, alguns autores também enfatizam as diferenças entre os mecanismos de quebra predominantes em cada etapa.

Wills ${ }^{2}$ afirma que na britagem os principais mecanismos de quebra são a compressão das partículas entre superfícies rígidas e o impacto contra superfícies cujo movimento é, de alguma forma, restrito. Na moagem, porém, a quebra é promovida por forças de abrasão e impacto, causadas pela ação de uma carga em movimento livre. 
Chaves e Peres ${ }^{4}$ argumentam que os mecanismos de quebra são os fatores mais importantes para caracterizar cada etapa de cominuição, sendo a moagem autógena, um caso especial a qual, a rigor, não constitui uma etapa de moagem. Segundo estes autores:

- a britagem está restrita a quebra de partículas acima de 3/4" (19,1 mm) em que predominam as forças de compressão e impacto;

- a moagem refere-se a cominuição de partículas inferiores a 3/4" (19,1 mm) em que predominam os mecanismos de abrasão e "arredondamento" (quebra de arestas).

Kelly e Spottiswood ${ }^{5}$ apontam, como principal motivo para o uso do tamanho de partículas para distinguir ambos os processos, o design necessário aos equipamentos de cada operação: se a partícula é grande, a energia necessária para causar sua fratura também o é, mas a energia aplicada por unidade de massa é baixa; se a partícula é pequena, ocorre o contrário. Deste modo, britadores devem ser estruturalmente resistentes, enquanto moinhos precisam ser capazes de dispersar energia sobre uma grande área de partículas.

A moagem industrial geralmente é feita em tambores rotativos, com uma carga cadente, movimentada pela rotação do tambor. Estes equipamentos são conhecidos como moinhos tubulares de carga cadente e os corpos moedores podem ser de diversas formas e materiais. A denominação moinhos de bolas refere-se, comumente, ao equipamento cuja carga moedora é composta por corpos de ferro fundido ou aço, não necessariamente esferas. Se partículas do próprio minério são utilizadas como carga moedora, os moinhos são denominados autógenos, ou semiautógenos (caso seja empregada uma pequena percentagem de bolas), casos bastante particulares de moagem.

Pryor $^{6}$ alega que, nos moinhos tubulares de carga cadente, a energia fornecida ao equipamento é utilizada para manter o corpo cilíndrico, a carga moedora e a massa de minério em rotação e a energia é transmitida às partículas por:

- colisão interpartículas e entre elas e os corpos moedores;

- pressão exercida pela corpos moedores (se a partícula estiver nos interstícios da carga moedora) ou entre as bolas e o revestimento da carcaça;

- abrasão e impacto, por ação do movimento dos corpos moedores;

- "choque" originado pelas bolas cadentes e transmitido pela carga. 
Além do papel estratégico no beneficiamento da matéria prima mineral, a moagem é, em geral, responsável por parcela significativa dos custos operacionais de um concentrador, devido, especialmente, a dois fatores: o alto desgaste de revestimentos e corpos moedores, inerentes aos mecanismos de quebra das partículas e o elevado consumo energético desta operação.

Por este motivo, a moagem é estudada, tradicionalmente, sob o viés da relação entre o consumo de energia e as granulometrias da alimentação e do produto desta etapa. Desta forma, associa-se aos parâmetros normalmente utilizados para o controle industrial desta operação (granulometria, superfície específica) com um dado essencial para o seu gerenciamento econômico (consumo energético). A seguir este conceito foi desenvolvido em mais detalhes.

\subsection{CONCEITOS DE EFICIÊNCIA DE MOAGEM}

A busca pela "eficiência" de um circuito de moagem tem diversos objetivos, tal como resume Pryor ${ }^{6}$ :

- redução da percentagem dos minerais de interesse nos rejeitos dos processos de concentração;

- redução da participação dos minerais de ganga nos concentrados;

- redução no desgaste dos corpos moedores e dos revestimentos;

- diminuição do consumo de energia;

- aumento da quantidade de mineral liberado;

- redução dos custos operacionais.

Todos os objetivos supracitados estão inter-relacionados. Por exemplo: o aumento da liberação é um fator importante para se alcançar os dois primeiros objetivos, os quais, por outro lado, consistem no aumento da recuperação do concentrador e, portanto, na redução de custos operacionais. Por outro lado, uma das maneiras de se aumentar a quantidade de mineral liberado é aumentar a vazão de alimentação do circuito, reduzindo, assim, a sobremoagem, mas mantendo-se o controle do tamanho máximo de partículas no produto. Esta ação tem, por consequência, a redução do consumo específico de energia (energia por massa 
alimentada no moinho). Por sua vez, o desgaste de corpos moedores e revestimentos são proporcionais ao consumo específico de energia e, portanto, serão reduzidos, diminuindo também os custos operacionais.

Desta forma, conforme observado anteriormente, os conceitos mais tradicionais de eficiência de moagem estão ligados ao seu consumo energético e à granulometria do produto.

Taggart ${ }^{1}$ propõe um eficiente raciocínio sobre o porquê desta escolha: suposto que o objetivo primordial da moagem seja a liberação do mineral de interesse, o desempenho desta operação deveria ser, primariamente, medida a partir do grau de liberação alcançado e, em segundo lugar, pelos custos requeridos para se atingir este fim. Contudo, duas dificuldades se apresentam a este parecer:

- o grau de liberação não é facilmente medido de maneira que se possa utilizar este parâmetro em um sistema de controle operacional; por esta razão, normalmente associa-se o controle do circuito de moagem à malha em que se obtém o grau de liberação desejado;

- o consumo de energia corresponde à maior parcela dos custos operacionais de concentradores industriais (cerca de 60\%); o segundo maior custo associado, o consumo de revestimentos e corpos moedores, está intimamente ligado ao consumo energético da operação.

Deste modo, Taggart define "eficiência de um circuito de moagem" como a razão entre a energia consumida nesta operação pela vazão mássica de material moído em determinada granulometria.

As três primeiras teorias sobre moagem também relacionam a eficiência ao consumo de energia e este, por sua vez, à granulometria. Elas estão resumidas a seguir.

\subsubsection{Lei de Rittinger}

A primeira "lei" sobre moagem foi proposta por Rittinger em 1867 e afirma que a energia necessária à cominuição é proporcional à nova área de superfície gerada nas partículas. Tomando-se as partículas por esferas, a área superficial é 
proporcional ao seu diâmetro e, desta forma, a "lei" de Rittinger pode ser descrita pela equação:

$$
E=k\left(\frac{1}{D_{2}}-\frac{1}{D_{1}}\right), \text { onde: }
$$

$\mathrm{E}=$ energia consumida por unidade de massa alimentada no circuito;

$D_{2}$ e $D_{1}=$ respectivamente, diâmetros do produto e da alimentação do circuito, tomados normalmente como a percentagem passante na malha de controle do mesmo.

$\mathrm{k}=$ constante que define a proporcionalidade entre o consumo específico de energia e 0 diâmetro das partículas.

A constante $\mathrm{k}$ é atribuída às características do minério, ou seja, a dificuldade que o minério oferece à quebra.

\subsubsection{Lei de Kick}

A segunda "lei" foi elaborada por Kick em 1885 e afirma que a energia é proporcional ao tamanho das partículas cominuídas. Novamente, tomando-se as partículas por esferas, esta lei pode ser traduzida na equação:

$$
E=k \ln \left(\frac{D_{1}}{D_{2}}\right) \text { onde: }
$$

$E, k, D_{2}$ e $D_{1}$ têm as mesmas definições anteriores.

\subsubsection{Lei de Bond}

Fred Bond responde pela terceira "lei" de moagem, descrita em 1952, que pode ser descrita por:

$$
E=k\left(\frac{1}{\sqrt{D_{2}}}-\frac{1}{\sqrt{D_{1}}}\right) .
$$

Novamente, as definições para $E, k, D_{2}$ e $D_{1}$ permanecem iguais às anteriores. 
Neste caso, $D_{2}$ e $D_{1}$ se referem ao $D_{80}$, ou seja, as malhas, em micrômetros, que permitem a passagem de $80 \%$ das partículas no produto e na alimentação, respectivamente.

Bond também atribuiu à constante da equação, o valor de $10 \mathrm{Wi}$. O Wi, ou Work Index é intrínseco ao minério tratado e foi definido como a energia necessária para se reduzir o material a partir de um tamanho teórico infinito até um $D_{80}$ de $100 \mu \mathrm{m}$. A equação genérica, apresentada anteriormente, toma então a seguinte forma:

$$
E=10 W i\left(\frac{1}{\sqrt{P}}-\frac{1}{\sqrt{F}}\right)
$$

O Wi é determinado experimentalmente, a partir de ensaios de laboratório desenvolvidos por Bond. Há também a possibilidade de se calcular o Wi, a partir da equação anterior, tomando-se os dados de energia consumida e granulometria de circuitos industriais. Neste caso é chamado de Work Index operacional (Wio) e sua comparação com o Wi obtido a partir dos ensaios de laboratório é, segundo, Rowland ${ }^{7}$, uma medida da eficiência operacional de circuitos industriais.

O trabalho de Bond se baseou em dados empíricos e está sujeito a desvios se aplicado a operações cujos parâmetros se desviam das condições por ele estudadas, quais sejam: moinhos de oito pés de diâmetro, operando a úmido e em circuito fechado - para moinhos de bolas - e em circuito aberto - para moinhos de barras.

Deste modo, Bond e Rowland, posteriormente, sugeriram uma série de fatores de correção que devem ser aplicados para operações com características distintas daquelas estudadas por Bond. Tais fatores, também empíricos, são:

$E_{1}$ - Moagem a seco: neste caso, deve-se multiplicar a energia calculada a partir da equação proposta por Bond por 1,3, ou seja, considera-se a operação a seco $30 \%$ menos eficiente se comparada a moagem a úmido.

$E_{2}-$ Moagem em circuito aberto (moinhos de bolas): Bond e Rowland atribuíram a esta configuração um fator de "ineficiência" dependente do grau de controle exigido para a granulometria do produto, segundo a Tabela 3.1 . 
Tabela 3.1 - Fator de ineficiência para o circuito aberto.

\begin{tabular}{cc}
\hline $\begin{array}{c}\text { \% Passante na malha de } \\
\text { controle }\end{array}$ & "Fator de ineficiência" \\
\hline 50 & 1,035 \\
60 & 1,05 \\
70 & 1,10 \\
80 & 1,20 \\
90 & 1,40 \\
92 & 1,46 \\
95 & 1,57 \\
98 & 1,70 \\
\hline
\end{tabular}

$\mathrm{EF}_{3}$ - Diâmetro do moinho: para equipamentos cujo diâmetro difere do estudado por Bond (8 pés), o fator de correção deve ser calculado por:

$$
E F_{3}=\left(\frac{2,44}{D}\right)^{0,2} \text { onde: }
$$

$\mathrm{D}$ = diâmetro do equipamento, em metros.

$\mathrm{EF}_{4}$ - Granulometria de alimentação: Bond-Rowland consideram que cada equipamento possui uma faixa granulométrica ideal de alimentação. $O \mathrm{~F}_{80}$ (malha que permite a passagem de $80 \%$ das partículas presentes na alimentação do circuito) ideal (Fo, em micrômetros) é calculado por,

$$
F o=16000 \sqrt{\frac{13}{W I}}
$$

para moinhos de barras, e

$$
F o=4000 \sqrt{\frac{13}{W I}}
$$

para moinhos de bolas.

Se $\circ F_{80}$ do circuito estudado for maior que Fo, deve-se aplicar o quarto fator de correção, calculado a partir da equação:

$$
E F_{4}=\frac{R_{r}+(W I-7)\left(\frac{F-F o}{F_{O}}\right)}{R_{r}} \text { em que: }
$$


$\mathrm{R}_{\mathrm{r}}=$ razão de redução;

$\mathrm{F}=\mathrm{F}_{80}$

Rowland recomenda a não utilização deste fator, caso o Wi seja inferior a 7 kWh/st.

$\mathrm{EF}_{5}$ - Granulometria do produto: aplicado em circuitos cujo $\mathrm{P}_{80}$ (malha que permite a passagem de $80 \%$ das partículas do produto do circuito - P) é inferior a 0,075 mm e definido pela equação:

$$
E F_{5}=\frac{P+10,3}{1,145 P}
$$

$E_{6}$ - Razão de redução: este fator deve ser aplicado apenas para moagem em moinhos de barras, quando a razão de redução for inferior ou superior a ideal $\left(R_{\text {ro }}\right)$. Esta razão pode ser calculada por:

$$
R_{r o}=8+\frac{5 L}{D}, \text { sendo: }
$$

L e D, respectivamente, o comprimento das barras e o diâmetro do moinho.

O sexto fator deve ser aplicado se a razão de redução do circuito não estiver no intervalo $R_{r}=R_{r o} \pm 2$ e é determinado por meio da equação:

$$
E F_{6}=\frac{1+\left(R_{r}-R_{r o}\right)^{2}}{150} .
$$

$\mathrm{EF}_{7}$ - Razão de redução para moinhos de bolas: aplicável nas ocasiões em que a razão de redução for inferior a 6 e calculado por:

$$
E F_{7}=\frac{2\left(R_{r}-1,35\right)+0,26}{2\left(R_{r}-1,35\right)} .
$$

$\mathrm{EF}_{8}$ - Fator de dimensionamento para moinhos de barras: para dimensionar moinhos de barras, com base em resultados dos testes de moabilidade desenvolvidos por Bond, recomenda-se os seguintes fatores de "ineficiência":

- para moinhos de barras operando em estágio único deve-se usar o fator de 1,4, se alimentação do moinho advir de circuitos abertos de britagem, e 1,2, se a britagem operar em circuito fechado; 
- para moinhos de barras operando em conjunto com moinhos de bolas, o fator é de 1,2, caso a alimentação do moinho venha de um circuito aberto de britagem; para alimentações originárias de circuitos fechados de britagem, ou em caso da alimentação do moinho conter muitos finos (pelo menos $80 \%$ passante em $1 / 2$ polegada), a aplicação deste fator não é necessária.

\subsubsection{Forma genérica das "leis" de moagem}

As três relações apresentadas anteriormente podem ser resumidas, matematicamente, em uma única equação.

Charles, apud Chaves e Peres ${ }^{4}$, propôs a seguinte relação:

$$
d E=-K \frac{d x}{x^{n}}, \text { em que: }
$$

$E=$ consumo específico de energia;

$\mathrm{X}=$ diâmetro da partícula.

Deste modo, integrando-se a equação anterior com o expoente $n$ igual a 1 , obtém-se a relação proposta por Kick; caso o expoente seja igual a 2, obtém-se a equação de Rittinger e, por sua vez, com o expoente igual a 1,5 a equação é igual a proposta por Bond.

Uma segunda equação, proposta por Hukki (apud $\left.\operatorname{Lynch}^{8}\right)$, é dada por:

$$
d E=-K \frac{d x}{x^{f(x)}} .
$$

A equação de Hukki sugere, portanto, que a constante de proporcionalidade é dependente do tamanho da partícula e que a energia requerida para a fragmentação de uma partícula aumenta à medida que seu diâmetro diminui. Este é o conceito mais aceito por Lynch $^{8}$ e outros estudiosos que se basearam em seu trabalho.

Bond $^{9}$ também reconhece a variação do parâmetro Wi com o diâmetro das partículas e atribui, como principal causa, a presença de finos na alimentação e no produto da moagem. 


\subsubsection{Críticas ao conceito de eficiência ligado ao consumo de energia}

Os conceitos de eficiência de moagem apresentados até o momento são alvos de diversas críticas, devido às suas inerentes limitações.

Taggart ${ }^{1}$ lembra que, por este conceito, a "eficiência" está ligada também às características de cada minério tais como tenacidade e dispersão do mineral de interesse na ganga. Contudo, é bastante útil para se realizar comparações entre diferentes equipamentos (ou circuitos) tratando o mesmo material ou entre diferentes minérios processados em um mesmo circuito.

Além disto, este tipo de definição relaciona ao menos três variáveis que são, na verdade, independentes: a tenacidade do minério (a dificuldade que o material apresenta ao processo de cominuição), a razão de redução, ou seja, a relação entre as granulometrias da alimentação e do produto da etapa e a eficiência do equipamento utilizado, ou seja, as perdas de energia inerentes aos mecanismos deste.

Lynch $^{8}$ evidencia outras limitações deste conceito:

- o consumo de energia nos moinhos tubulares (não autógenos) é quase independente da ocorrência de quebra, ou seja, a carga moedora mantém a potência destes equipamentos relativamente constante, independentemente de acontecerem, em maior ou menor número, eventos que promovam a quebra de partículas;

- em moinhos de bolas, o consumo de energia é pouco sensível a variações na vazão de alimentação do circuito; contudo, como a quebra das partículas é um evento probabilístico nestes equipamentos, ao se variar o número de partículas dentro do moinho, a probabilidade de ocorrência de quebra também variará.

Por estas razões, Lynch recomenda para a avaliação do processo de moagem a relação entre as distribuições granulométricas da alimentação e do produto do moinho, em contrapartida ao enfoque energético proposto pelas teorias tradicionais. Outras variáveis operacionais, como a vazão de alimentação, o diâmetro do moinho e a velocidade de rotação, são também relevantes e devem ser consideradas.

As sugestões de Lynch serviram como base para diversos estudos e novas teorias de moagem que estão disponíveis atualmente. 
Independentemente das restrições aqui apontadas, porém, a praticidade de se relacionar a granulometria e consumo de energia ao conceito de eficiência de moagem, transformou esta relação em uma linguagem comum, difundida entre os usuários e estudiosos do assunto. Este conceito, portanto, por mais limitado que o seja, ainda não foi superado, na prática, pelas teorias mais recentes.

O principal motivo para se adotar este conceito é que ele está intimamente ligado à importância econômica que os circuitos de cominuição representam para quaisquer usinas de beneficiamento, razão pela qual foram, historicamente, alvo de atenção de estudiosos no mundo todo.

\subsection{AS DIFERENTES CONFIGURAÇÕES DE CIRCUITO DE MOAGEM}

Um dos principais fatores para a escolha da configuração dos circuitos de moagem envolve as características a que o produto se destina. Conforme discutido anteriormente, os papéis da moagem estão ligados, normalmente, à diminuição da granulometria e a geração de novas superfícies. O circuito de moagem deve ser concebido, tendo-se em vista as características necessárias à alimentação das etapas subsequentes, as quais, como resume Pryor $^{6}$, podem envolver:

- concentração gravítica: liberação dos minerais de interesse na maior granulometria possível e minimização do aparecimento de ultrafinos;

- lixiviação: geração de novas superfícies, para facilitar a reação química do solvente; neste caso, o surgimento de ultrafinos pode ser favorável;

- flotação: o mineral de interesse deve ser, ao menos parcialmente, exposto à ação dos reagentes e a geração de ultrafinos é prejudicial.

Por esta razão, os equipamentos de classificação exercem um papel tão primordial no circuito quanto o moinho em si. Esta associação é importante para:

- possibilitar o descarte de partículas de ganga o mais rápido possível do processo;

- evitar que partículas de interesse sejam reduzidas a um tamanho menor que o ideal para sua liberação, ou seja, reduzir a sobremoagem do mineral de 
interesse, muitas vezes deletéria para o desempenho das operações de concentração;

- permitir maior controle da granulometria do produto da moagem.

Deste modo, os circuitos de moagem são, primariamente, divididos em duas configurações:

- quando o material realiza apenas um passe pelo moinho, ou seja, não há classificação do produto da moagem, o circuito é chamado de aberto;

- quando o material "pronto" (abaixo da malha de controle do produto) é retirado do circuito por um classificador e as partículas maiores que o estipulado retornam ao moinho, o circuito é chamado de fechado.

Naturalmente, ambos os tipos possuem peculiaridades, mas alguns autores ${ }^{(1-8,10)}$ concordam que o circuito aberto é uma configuração menos eficiente, entre outras razões, por dificultar o controle na distribuição granulométrica do produto.

Wills $^{2}$ e Beraldo ${ }^{3}$ apontam como desvantagens do circuito aberto, a necessidade de controle da taxa de alimentação, de modo a garantir um tempo efetivo de quebra a todas as partículas dentro do moinho. O consequente maior tempo de residência das mesmas provoca maior sobremoagem e desperdício da energia aplicada.

Lembram ainda que, no circuito fechado, a carga circulante (ou seja, a fração retornada ao moinho) tem um papel importante pois, dentre outros fatores:

- reduz a granulometria média da alimentação total do moinho;

- melhora a relação entre a granulometria média da alimentação e o diâmetro da carga de bolas;

- aumenta a quantidade de partículas "prontas" na descarga do moinho.

Deste modo, o fechamento do circuito leva, em geral, a um aumento da capacidade de processamento como um todo.

Taggart $^{1}$ aponta ainda como principais alterações mediante o fechamento do circuito:

- a diminuição do tempo de residência no moinho;

- maior uniformidade ao longo do comprimento do moinho, para a relação entre o tamanho dos corpos moedores e o diâmetro médio das partículas;

- a diminuição do diâmetro máximo das partículas para o produto do circuito.

Estas mudanças contribuem para as vantagens do circuito fechado sobre o aberto.

Pryor $^{6}$ assinala outros efeitos relativos ao fechamento do circuito de moagem: 
- diminui o tamanho (top size) das bolas, em consequência da redução da granulometria da alimentação do moinho;

- melhor acomodação das partículas entre os interstícios da carga moedora;

- melhor ajuste da diluição da polpa no interior do moinho.

Nappier-Munn et al. ${ }^{10}$ afirmam que as desvantagens do circuito aberto estão relacionadas à baixa eficiência de classificação interna dos moinhos de bolas, com descarga por overflow: em equipamentos com descarga por diafragma, a grelha consiste em uma barreira para saída de partículas grosseiras do moinho; em moinhos de barras, o espaço entre elas também exerce, em parte, um controle sobre o tamanho máximo das partículas. Nestes casos, os moinhos podem operar sem uma etapa de classificação. Contudo, é comum encontrar uma etapa subsequente de moagem com bolas, em circuito fechado. Esta última operação é, portanto, a responsável pelo controle da granulometria do produto final.

Rowland ${ }^{7}$ também enfatiza a ineficiência energética do circuito aberto em relação ao circuito fechado. $O$ "fator de ineficiência" do primeiro depende da percentagem passante na malha de controle requerida no produto do circuito, conforme já mostrado na Tabela 3.1.

Por outro lado, há duas configurações possíveis para o circuito fechado: a etapa de classificação pode ser feita antes da moagem ou, em outros termos, retira-se da alimentação nova do circuito, as partículas "prontas" antes de direcioná-las ao moinho, ou a classificação é realizada após o processo de quebra. O primeiro arranjo é chamado de circuito inverso (ou reverso) e o segundo, circuito direto.

Tradicionalmente, circuitos diretos costumam ser empregados na etapa de moagem primária, tanto para proteção dos classificadores de entupimento por partículas grosseiras, quanto para evitar operações de empolpamento do minério britado, dificultadoras do controle do circuito. Já o circuito inverso é prática comum em processos cuja alimentação é o produto de uma etapa anterior de moagem ou concentração, como lembram Napier-Munn et al. ${ }^{10}$.

As distribuições granulométricas e a vazão de sólidos da alimentação do moinho serão distintas em cada caso. No circuito inverso, a retirada dos "finos" presentes na alimentação nova, resulta em uma menor variação no tamanho das partículas e diminui a vazão de sólidos enviados ao moinho. Por outro lado, devido à presença de partículas finas, a granulometria média da alimentação do moinho do circuito direto será menor e, por consequência, o produto do moinho também o será. 
A comparação entre as duas configurações de circuito fechado são, entretanto, tema de controvérsia. Uma primeira análise indica ser natural a retirada das partículas que já se encontram em granulometria adequada ao produto do circuito, antes da alimentação do moinho, evitando, deste modo, "desperdício" de energia e sobremoagem. Contudo, a presença de partículas "finas" na alimentação do moinho, é alvo de diversos trabalhos.

Diversos autores ${ }^{(1-8,10-12)}$ concordam que nos moinhos tubulares, o impacto dos corpos moedores sobre as partículas é aleatório. Por consequência, a distribuição de energia aplicada, para cada fração granulométrica, é proporcional à concentração destas frações. Deste modo, para maximizar a aplicação da energia às partículas grosseiras, é necessário garantir maior quantidade delas no interior do moinho, ou seja, reduzir a presença de finos na alimentação. Por este mesmo princípio, para evitar a sobremoagem, a quantidade de partículas finas no interior do moinho deve ser a mínima possível.

De acordo com Pryor 6 , grandes quantidades de "finos" no interior do moinho podem diminuir a eficiência de moagem, pois estas partículas tendem a formar um filme na superfície dos corpos moedores, cuja ação aumenta o "escorregamento" entre as diversas camadas de bolas e diminui o impacto.

Sepúlveda ${ }^{(11,12)}$ postulou uma "quarta lei de moagem", afirmando que, para uma ótima eficiência energética de moagem, deve-se manter a menor quantidade possível de finos no interior do moinho.

Por outro lado, Bond ${ }^{13}$ recomendou que os circuitos fechados de cominuição fossem avaliados como "caixa preta", ou seja, considerando-se apenas a alimentação nova e o produto final do circuito - especialmente para circuitos de moagem - pois, na carga circulante e na descarga do moinho, as partículas mais resistentes à quebra tendem a se acumular. Para o autor, a distinção entre a eficiência de configurações diretas ou inversas somente se justifica, se a quantidade de finos retirada previamente da alimentação nova seja significativa.

Donda $^{14}$ estudou o circuito de moagem primária do primeiro concentrador de Germano, originalmente configurado como direto, ainda que tenha sido projetado para o tratamento de um minério com alta percentagem de finos naturais. Sua aprovação ao longo dos anos deve-se, entre outros fatores, à simplicidade operacional. 
Deste modo, para melhor estudar as configurações direta e inversa, é preciso avaliar dois pontos:

- o conceito de "finos" nos circuitos de moagem;

- o papel da classificação nos circuitos.

A seguir, estes tópicos foram abordados com mais detalhes.

\subsubsection{Conceitos para "finos"}

A definição de "finos" depende, sobretudo, das características exigidas para a alimentação das operações subsequentes à moagem, especialmente as de concentração.

Para Bond ${ }^{9}$, esta denominação se enquadra a todas as frações abaixo da malha de controle do circuito. Neste caso, a malha de controle é definida pelo $P_{80}$, ou seja, a malha abaixo da qual se encontram $80 \%$ das partículas que constituem o produto do circuito.

Beraldo $^{3}$ e McIVOR ${ }^{15}$ sustentaram a definição proposta por Bond, embora possam ser atribuídas malhas variadas para o controle do produto.

Outro conceito, porém, desvincula o significado dos finos com as características do produto requerido em determinada etapa de moagem: as partículas finas são aquelas cujo comportamento nas etapas de classificação segue o da água. Kelsall (apud Lynch ${ }^{8}$ ) sugeriu este conceito ao afirmar que a fração de finos que se reporta ao underflow dos ciclones corresponde à fração de água na alimentação do ciclone que segue o mesmo destino.

É fácil intuir que, neste caso, a definição de finos está ligada à eficiência da etapa de classificação e, deste modo, existe uma dificuldade maior para uma definição de "finos" por um simples tamanho de partículas. A eficiência dos diversos métodos de classificação depende de outros fatores como a densidade da polpa, as diferenças entre as densidades dos minerais de interesse e os de ganga e a forma das partículas. Por consequência, faz-se necessário convencionar uma malha, abaixo da qual se assume que as partículas terão o comportamento de "finos" para cada caso estudado. 
Sepúlveda ${ }^{(11,12)}$ e Napier-Munn e Asomah ${ }^{16}$, por exemplo, convencionaram os "finos" como as partículas menores que a última malha comumente utilizada para a análise granulométrica do produto da moagem $(0,037 \mathrm{~mm})$.

\subsubsection{Efeitos da classificação e da carga circulante nos circuitos de moagem}

Uma vez discutido o conceito de "finos", é conveniente analisar o papel da classificação nos circuitos de moagem.

Os equipamentos de classificação influenciam a granulometria final do produto, a carga circulante e a capacidade do circuito. Conforme discutido anteriormente, as vantagens do circuito fechado estão ligadas à influência que a etapa de classificação exerce sobre a moagem.

De acordo com Nappier-Munn et al. ${ }^{10}$, os classificadores possuem um papel operacional importante nos circuitos de cominuição, dada a relativa facilidade de atuação em seus parâmetros, se comparados a modificações no equipamento de cominuição. Deste modo, o controle operacional dos circuitos de moagem se dá, na prática, pela atuação nos classificadores.

Os hidrociclones são, geralmente, os classificadores empregados no fechamento de circuitos de moagem. Dentre suas vantagens, destacam-se o menor espaço para instalação, menores custos de manutenção, menor consumo de energia (desconsiderando-se os sistemas de bombeamento) e facilidade de parada para manutenção, mesmo quando estão sob carga total.

O controle da granulometria do produto pela etapa de classificação, promove o retorno das partículas grosseiras à alimentação do moinho, as quais constituem a carga circulante do circuito. O papel da carga circulante é o de controlar:

- o tempo de residência no moinho;

- a granulometria na alimentação "real" do moinho (alimentação nova + material recirculado).

A carga circulante reduz o percentual de partículas grosseiras na alimentação do moinho, além de estreitar a faixa granulométrica das partículas no interior do mesmo. Com a diminuição da granulometria é possível aumentar a vazão 
alimentada no moinho, ou seja, o aumento da carga circulante promove o aumento da capacidade de processamento de um circuito..$^{(1-8,10-12)}$

Taggart ${ }^{1}$ ainda aponta como consequências do aumento da carga circulante:

- o aumento do tamanho médio do produto - mesmo mantendo-se constante a percentagem passante na malha de controle do circuito;

- melhor resposta (maior estabilidade operacional) do circuito às flutuações na granulometria da alimentação nova.

Schlepp e Turner ${ }^{17}$ propõem um raciocínio: se a vazão de alimentação do circuito aumenta, a quantidade de partículas grosseiras dentro do moinho também cresce; logo, a quantidade de material recirculado deve aumentar, caso seja mantida a granulometria para o produto.

Deste modo, em princípio, com o aumento da carga circulante há um expressivo aumento da capacidade do circuito (aumento da vazão alimentada), o qual, após certo ponto, diminui gradativamente. $O$ aumento da capacidade de processamento se deve a dois fatores, promovidos pela carga circulante:

- diminuição do tempo de residência no moinho;

- presença de uma carga de minério mais "bitolada" que se enquadra melhor nos interstícios da carga de corpos moedores.

Contudo, à medida que a recirculação aumenta, a capacidade do sistema de manuseio de polpa e dos equipamentos de classificação passa a ser um limitador para o circuito. Neste contexto, a densidade de polpa na alimentação do ciclone cresce (o que prejudica a eficiência de classificação) e, gradativamente, a quantidade de partículas "prontas" que se reporta a classificação, diminui. Por fim, a densidade de polpa no interior do moinho atinge um limite e provoca a "expulsão" das bolas menores.

Assim, a operação dos circuitos de moagem deve buscar um ponto ótimo de carga circulante, correspondente à máxima capacidade do circuito. Este ponto dependerá, dentre outros fatores:

- da relação comprimento/ diâmetro do moinho, a qual influencia o tempo de residência no mesmo;

- das capacidades do sistema de bombeamento e dos equipamentos de classificação. 
Mclvor $^{15}$ alega que quanto maior o diâmetro do moinho, menor será a "carga circulante limite" para o circuito, ou seja, mais rapidamente se dará o ponto de inversão, a partir do qual o aumento da carga circulante se torna deletério.

Conforme exposto no item 3.2.3, Bond e Rowland sugeriram uma série de fatores empíricos para o ajuste do consumo específico de energia industrial de circuitos de moagem. Dentre eles, um se refere ao diâmetro do moinho e outro à operação em circuito aberto. Segundo Mclvor ${ }^{15}$, estes dois fatores são, na verdade, observações experimentais da influência da classificação nos circuitos de moagem: a eficiência do circuito depende do tempo de residência e da vazão de polpa pelo moinho. Estas variáveis, por sua vez, são intimamente relacionadas à percentagem de carga circulante e à densidade de polpa no interior do moinho.

Beraldo ${ }^{3}$ propôs uma equação para o cálculo da carga circulante "ideal", ou seja, a carga circulante correspondente à máxima capacidade, conjuntamente, das etapas de moagem e classificação. Esta equação corresponde a:

$$
C L=66 \times \frac{D}{L} \times \sqrt[4]{R_{r}} \times \sqrt{W i}, \text { em que: }
$$

$C L$ = carga circulante (percentagem da alimentação nova do circuito);

$\mathrm{D}$ = diâmetro do moinho $(\mathrm{m})$, interno aos revestimentos;

$\mathrm{L}=$ comprimento interno do moinho $(\mathrm{m})$;

$R_{r}=$ razão de redução, ou seja, a fração entre o $F_{80}$ e o $P_{80}$ do circuito;

$\mathrm{Wi}=$ Work Index $(\mathrm{kWh} / \mathrm{st})$.

A equação descrita por Beraldo leva em conta, portanto:

- o tempo de residência no moinho, fortemente influenciado pela relação $D / L$ do moinho;

- a quantidade de partículas "prontas" na alimentação do circuito, definida pela razão de redução;

- as características do minério, definidas pelo Wi de Bond.

Outro papel pertinente à classificação é o controle da quantidade de "finos" no interior do moinho. A quantidade de partículas finas retornadas ao moinho depende da operação de classificação cuja eficiência é definida pela curva de partição.

As curvas de partição são uma maneira de se representar, graficamente, a probabilidade de cada partícula de se reportar ao underflow ou ao overflow. No eixo das abscissas ficam os diâmetros de partículas, em escala logarítma. No eixo das ordenadas ficam representadas as percentagens, para cada tamanho de partícula 
presente na alimentação do hidrociclones que se reporta ao underflow, ou seja, ao produto "grosseiro" da classificação. Esta razão, denominada partição para o underflow, é calculada por:

$$
\operatorname{Pr}=\frac{u \times M_{u}}{a \times M_{a}}, \text { onde: }
$$

$\mathrm{P}_{\mathrm{r}}=$ partição real para o underflow;

$\mathrm{u}, \mathrm{a}=$ percentagem, para cada tamanho de partícula, presente, respectivamente, no underflow e na alimentação do hidrociclone;

$M_{\mathrm{u}}, \mathrm{M}_{\mathrm{a}}=$ respectivamente, vazão mássica no underflow e na alimentação.

O principal parâmetro da curva de partição é o $d_{50}$, ou seja, o ponto da curva que corresponde ao diâmetro das partículas, cuja probabilidade de serem reportadas ao underflow ou ao overflow é de $50 \%$. Por este conceito, em uma curva de partição ideal, todas as partículas cujo diâmetro for superiores ao $d_{50}$ vão para o underflow e todas cujo diâmetro for inferior serão enviadas ao overflow.

Conforme lembra Kelsall (apud Lynch $^{8}$ ), contudo, as partículas que se reportam ao underflow podem vir de dois fenômenos distintos: por classificação, devido às forças que ocorrem no interior do ciclone, ou por curto-circuito, ou seja, partículas que são arrastadas pela água e, portanto, não estão sujeitas à classificação.

O curto-circuito, ou by-pass, de partículas finas para o underflow, é a razão atribuída para o fato de a curva de partição real não passar pela origem. Kelsall (apud Lynch $^{8}$ ) sugeriu que a fração de partículas presentes na alimentação do hidrociclone, que são curto-circuitadas, corresponde à fração de água na alimentação reportada ao underflow. Assim, descontando-se o by-pass, forma-se a curva de partição corrigida, a qual representa a fração que se reporta ao produto grosseiro devido apenas à ação classificatória do equipamento. A partição corrigida é obtida pela equação:

$$
P_{c}=\frac{\left(\operatorname{Pr}-R_{f}\right)}{\left(100-R_{f}\right)} \times 100, \text { onde: }
$$

$P_{c}=$ partição corrigida;

$R_{f}=$ by-pass, ou a percentagem de água presente na alimentação que se reporta ao underflow.

A Figura 3.1 mostra um exemplo para as curvas de partição real e corrigida. 


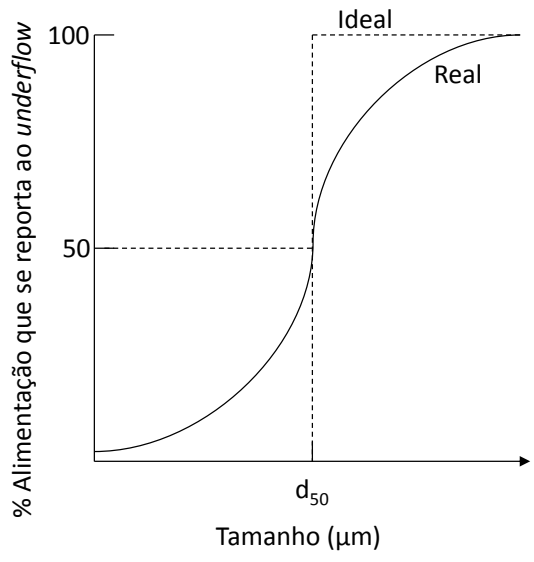

(a)

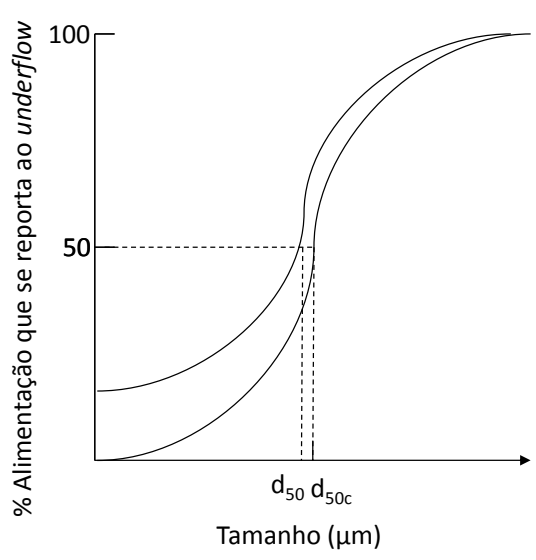

(b)

Figura 3.1 - Curvas de partição: (a) comparação entre curvas real e ideal; (b) curva real e corrigida. (Adaptado de Wills, 2007)

A curva de partição é relacionada por vários autores ${ }^{(2,3,5,6,8,10)}$, à eficiência da etapa de classificação. Chaves ${ }^{18}$ critica, contudo, alguns conceitos desta relação: 0 primeiro ponto é o entendimento da curva de partição como uma medida da qualidade de separação, tendo-se em vista, a curva de partição "ideal". Ou seja, o conceito do $d_{50}$ é teórico, não sendo possível na prática que todas as partículas superiores a este diâmetro sejam reportadas ao underflow e vice-versa. Chaves alerta que a "ineficiência" relatada na curva de partição pode não estar ligada, necessariamente, à qualidade de separação do equipamento, ou a erros operacionais.

Além disto, devido ao uso da curva de partição como parâmetro de "eficiência", o termo $d_{50}$ é referenciado como o diâmetro de corte do ciclone, o que, segundo Chaves, não é conceitualmente correto. Para este autor, o diâmetro de corte do ciclone corresponde ao $d_{95}$ da fração que se reporta ao overflow, não sendo relacionado, portanto, com a curva de partição.

Segundo o conceito proposto por Kelssall para o curto-circuito de partículas finas para o underflow, para garantir o mínimo retorno de finos ao moinho é necessário manter máxima densidade de polpa no underflow dos ciclones. obtém-se a diminuição do fluxo de água e, portanto, o montante de partículas finas que são carregadas por ela para o apex. Em alguns casos a montagem dos hidrociclones sob um determinado ângulo ou a utilização de equipamentos do tipo "fundo plano" 
pode permitir a operação com maiores densidades no underflow, antes da condição de "corda".

A condição de "corda" se caracteriza pela alteração do perfil de descarga no apex do ciclone, normalmente com formato de um cone, para o formato de um cordão, conforme mostra a Figura 3.2:

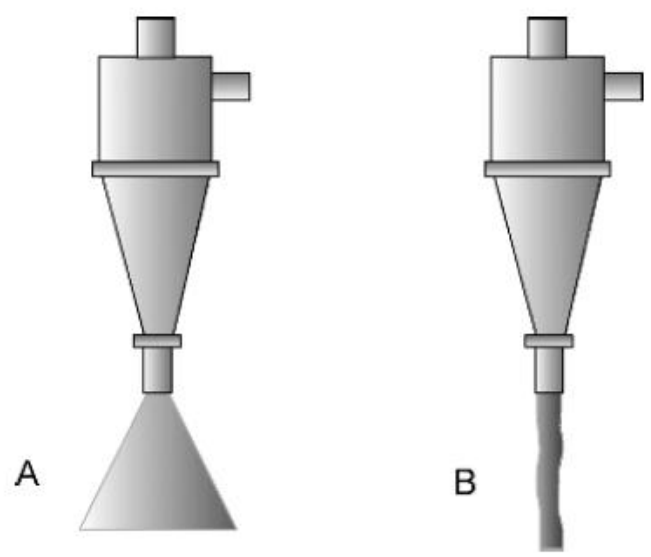

Figura 3.2 - Perfis de descarga no ápex dos hidrociclones: A - operação normal; B - operação em corda (GUPTA; YAN, 2006)

A condição de corda sinaliza que o diâmetro do apex do ciclone está subdimensionado e pode ocasionar o envio de partículas grosseiras ao vortex. Apesar disto, quando o underflow dos ciclones é direcionado ao moinho, pode-se buscar um perfil próximo ao de regime de cordão, para assegurar o controle da reologia de polpa no interior deste último.

É importante frisar que o controle da reologia da polpa recirculada no moinho afeta o comportamento dos corpos moedores. De acordo com Pryor ${ }^{6}$ a eficiência de moagem depende do equilíbrio de água na carga: em polpas muito diluídas, o minério não cobre a superfície das bolas e revestimentos e a energia cinética é dispersada com o choque entre metais. Por outro lado, água insuficiente torna a carga muito pastosa e, neste caso, a energia é desperdiçada em vencer a viscosidade e a polpa não flui adequadamente pelo moinho. Polpas muito densas podem, ainda, resultar na expulsão prematura de bolas do moinho. Este fato é especialmente crítico para a etapa de remoagem e pode ser determinante para a escolha do diâmetro de reposição de corpos moedores.

Por fim, convém lembrar que a "classificação diferencial", ou seja, o comportamento particular de cada mineral durante esta operação, afeta as operações subsequentes, podendo exercer efeitos negativos ou positivos. 
Em alguns casos, a classificação diferencial dos hidrociclones pode ser benéfica, pois os minerais de interesse se concentram em uma faixa granulométrica estreita, facilitando a flotação, como lembram Schlepp e Turner ${ }^{17}$.

Por outro lado, Donda ${ }^{19}$ reportou os efeitos negativos da classificação diferencial no circuito de moagem secundária de Germano, que causava o envio de partículas grosseiras de quartzo ao overflow dos ciclones, como mostra a Figura 3.3.

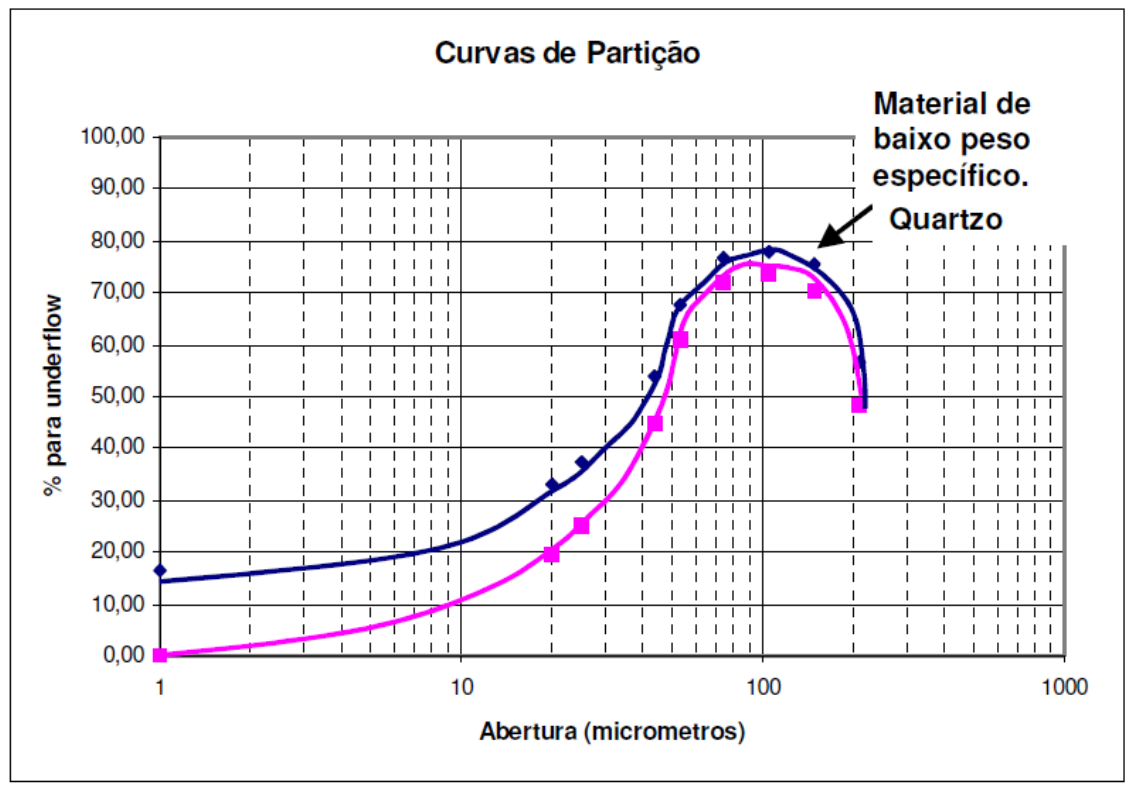

Figura 3.3 - Inversão nas curvas de partição dos ciclones secundários de Germano.

Este efeito foi atribuído à carga circulante com alta percentagem de sólidos do circuito, a qual aumentava a densidade de polpa na alimentação dos ciclones e, por sua vez, prejudicava a eficiência da classificação. Ocorria o envio de partículas grosseiras de quartzo para o overflow dos ciclones, o que prejudicava a seletividade das colunas de flotação, posteriores ao circuito de remoagem. Em virtude deste fato, o circuito foi modificado, passando a operar em regime semiaberto, ou seja, a alimentação nova é classificada, sendo apenas o underflow reportado ao moinho; a descarga do moinho segue diretamente para a flotação.

\subsubsection{Efeitos da retirada de finos na alimentação do circuito e sua avaliação}


Poucas são as referências na literatura sobre a avaliação das configurações direta e inversa, dada a dificuldade de se estabelecer um parâmetro adequado para avaliação de circuitos com características tão peculiares.

Bond $^{(13,20)}$ propõe a correção do $F_{80}$ para o cálculo do Wi de materiais cujos finos tenham sido escalpados. $O \mathrm{~F}_{80}$ corrigido, ou $\mathrm{Fe}$, é encontrado por meio da seguinte equação:

$$
F e=\frac{F}{\left(\frac{2-(F c / F)^{1 / \sqrt{2}}}{2}\right)^{\sqrt{2}}}
$$

onde $F$ é o $F_{80}$ para a alimentação escalpada; Fc é a malha na qual a alimentação foi classificada (malha abaixo da qual os finos foram retirados).

Sepúlveda ${ }^{(11,12)}$ propõe uma comparação entre ambas as configurações por meio do balanço de massas das frações finas na alimentação nova, descarga do moinho e produto do circuito. Deste modo, o balanço de massas para a configuração direta seria:

$$
F_{\mathrm{d}}=F_{o f} \frac{(1+C C)}{\left(1-B_{p f}\right)}
$$

em que $F_{d}$ é a percentagem de finos na descarga do moinho; $F_{\text {of }}$ é a percentagem de finos no overflow dos ciclones; CC é a carga circulante; $\mathrm{B}_{\mathrm{pf}}$ é o by pass de partículas finas, ou seja, o percentual de partículas finas remetidas ao underflow da classificação.

O mesmo balanço, para a configuração inversa, seria:

$$
F_{d}=\left(F_{o f} \frac{C C}{\left(1-B_{p f}\right)}\right)-\frac{F_{A N}}{C C}
$$

onde $F_{A N}$ é a percentagem de finos na alimentação nova do circuito.

A configuração inversa será preferível a direta se:

$$
F_{d}^{\text {inversa }}<F_{d}^{\text {direta }} \text {, }
$$

ou seja:

$$
F_{A N}>F_{o f} \frac{(1+C C)}{\left(1-B_{p f}\right)},
$$

supondo a operação de ambos os circuitos sob valores similares de carga circulante e de by pass de finos. 
Sepúlveda usou valores "típicos" para estes dois parâmetros (3,5 para a carga circulante e 0,4 para o by pass de finos) para estimar a quantidade de finos mínima na alimentação nova, de maneira a tornar a configuração inversa contra a direta interessante. Neste contexto é necessário que a alimentação nova tenha, pelo menos, $30 \%$ de finos para se observar ganhos com o circuito inverso. Deste modo, somente em casos muito específicos, a configuração inversa permite melhor desempenho que a direta. Com este exercício foi construído o gráfico a seguir, que delimita as "zonas" de operação adequadas a cada configuração:

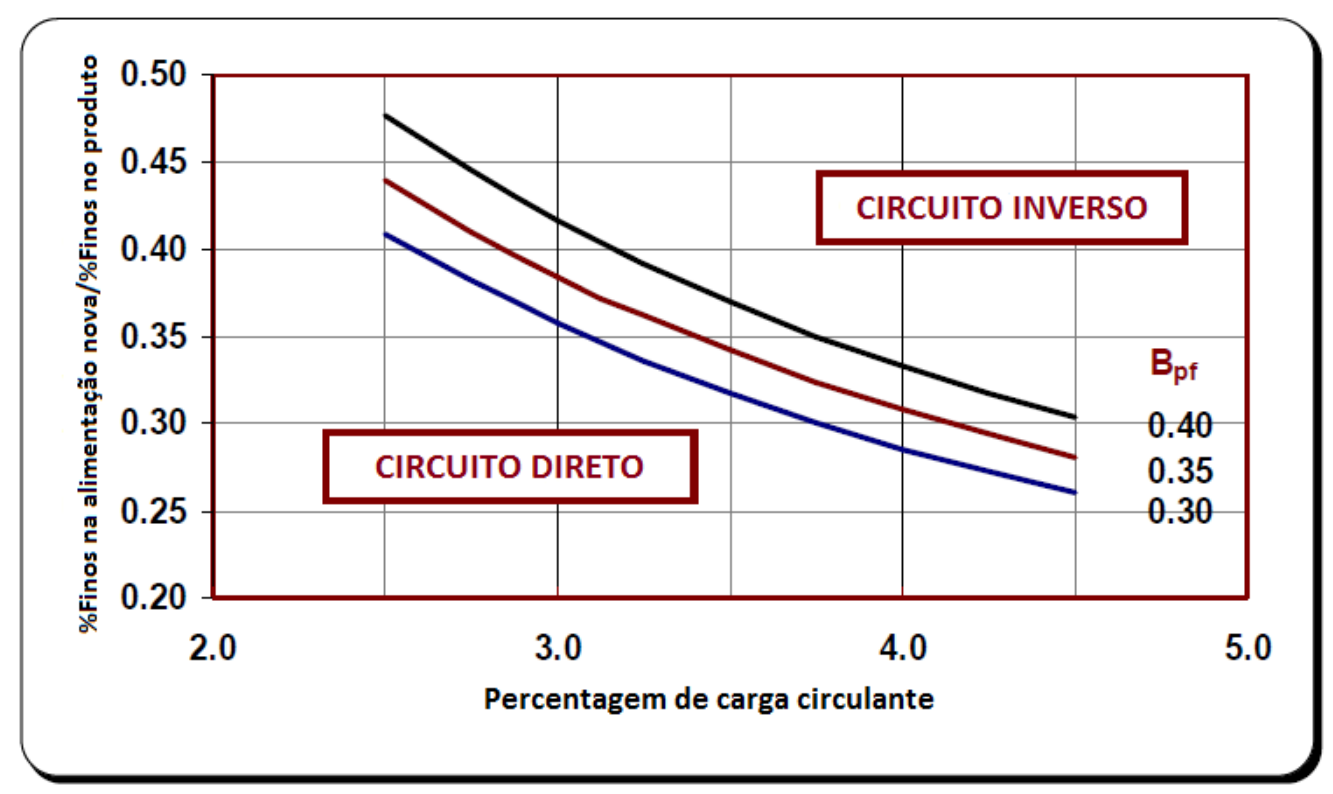

Figura 3.4 - Condições de operação adequadas para o circuito direto e inverso. (Adaptado de Sepúlveda, 2009)

\subsection{MODELAMENTO MATEMÁTICO DA OPERAÇÃO DE HIDROCICLONES}

Neste capítulo abordou-se o modelo matemático de Nageswararao para a operação de hidrociclones, o qual foi utilizado neste trabalho.

Segundo Lynch $^{8}$, um modelo matemático de hidrociclones deve relacionar as variáveis operacionais (pressão, vazão e percentagem de sólidos na alimentação) e as características construtivas do mesmo (diâmetro do hidrociclone, diâmetro do vortex e apex) à respectiva separação. 
O modelo proposto por Nageswararao ${ }^{21}$ é baseado no estudo de Lynch e tem por base a curva padrão de partição, a qual será explicada em maiores detalhes a seguir.

Conforme exposto no item 3.3.2, as curvas de partição são a maneira mais convencional de se representar a eficiência de classificação em hidrociclones e representam a parcela, para cada malha estudada, presente na alimentação que se reporta ao underflow. Contudo, as partículas que se dirigem ao underflow têm, na verdade, duas origens:

- partículas arrastadas pela água, ou seja, que não sofreram a ação classificatória - correspondentes ao by pass;

- partículas efetivamente classificadas e dirigidas ao underflow.

A curva de partição real representa a fração global da alimentação do ciclone dirigida ao underflow, incluindo aquelas curto-circuitadas. Por sua vez, a curva de partição corrigida representa apenas as partículas classificadas, ou seja, corresponde à partição real, descontando-se o by-pass, conforme indicado na Figura 3.1 .

Finalmente, a curva de partição padrão é obtida a partir da corrigida, dividindo-se cada malha pelo $d_{50}$ corrigido. A curva de partição padrão independe das condições operacionais e do diâmetro do ciclone, tal como apontam estudos relatados por Lynch $^{8}$.

O modelo matemático de Nageswararao ${ }^{21}$ baseia-se no conceito da curva de partição padrão proposto por Lynch. Consiste em uma série de equações para descrever a capacidade do hidrociclone (e sua relação com a pressão de operação), a curva de partição padrão, a vazão de água e o $d_{50}$ corrigido.

A equação que relaciona a capacidade do hidrociclone e a pressão na alimentação do mesmo é:

$$
Q=K_{Q o} \times\left(\frac{D_{i}}{D_{c}}\right)^{0,45} \times \theta^{-0,1} \times\left(\frac{L_{c}}{D_{c}}\right)^{0,2} \times D_{c}^{2} \times\left(\frac{P}{\rho_{p}}\right)^{0,5} \times\left(\frac{D_{o}}{D_{c}}\right)^{0,68} \text { onde: }
$$

$\mathrm{Q}=$ vazão volumétrica na alimentação do ciclone $\left(\mathrm{m}^{3} / \mathrm{h}\right)$;

$D_{i}=$ diâmetro do círculo cuja área é equivalente à área do inlet (alimentação do ciclone), em metros;

$D_{c}=$ diâmetro do ciclone $(m)$;

$\theta$ = ângulo da parte cônica do ciclone (graus); 
$\mathrm{L}_{\mathrm{c}}=$ comprimento da parte cilíndrica $(\mathrm{m})$;

$\mathrm{P}=$ pressão na alimentação $(\mathrm{kPa})$;

$\rho_{p}=$ densidade de polpa na alimentação $\left(\mathrm{t} / \mathrm{m}^{3}\right)$;

$D_{0}=$ diâmetro do vortex $(m)$.

A constante $\mathrm{K}_{\mathrm{Qo}}$ é dependente das dimensões do ciclone e das características do material classificado, como densidade e granulometria.

A partição de água para o underflow $\left(\mathrm{R}_{\mathrm{f}}\right)$ é calculada pela relação:

$$
R_{f}=K_{w o} \times\left(\frac{D_{i}}{D_{c}}\right)^{-0,5} \times \theta^{-0,24} \times\left(\frac{L_{c}}{D_{c}}\right)^{0,22} \times\left(\frac{D_{o}}{D_{c}}\right)^{-1,19} \times\left(\frac{D_{u}}{D_{c}}\right)^{2,4} \times\left(\frac{P}{\rho_{p} g D_{c}}\right)^{-0,53} \times \lambda^{0,27} \text { onde: }
$$

$\mathrm{g}$ = aceleração da gravidade $\left(\mathrm{m} / \mathrm{s}^{2}\right)$;

$D_{\mathrm{u}}=$ diâmetro do apex $(\mathrm{m})$;

$\lambda=\frac{10^{1,82 C v}}{\left(8,05 \times(1,0-C v)^{2}\right)}$, onde $C_{v}$ é a percentagem de sólidos na alimentação do ciclone, em volume.

Por sua vez, a partição de polpa para o underflow $\left(R_{v}\right)$ é dada por:

$$
R_{v}=K_{v o} \times\left(\frac{D_{i}}{D_{c}}\right)^{-0,25} \times \theta^{-0,24} \times\left(\frac{L_{c}}{D_{c}}\right)^{0,22} \times\left(\frac{D_{o}}{D_{c}}\right)^{-0,94} \times\left(\frac{D_{u}}{D_{c}}\right)^{1,83} \times\left(\frac{P}{\rho_{p} g D_{c}}\right)^{-0,31} .
$$

As constantes $\mathrm{K}_{\text {wo }}$ e $\mathrm{K}_{\mathrm{vo}}$ são dependentes apenas das características do minério.

$O d_{50}$ corrigido é calculado pela equação:

$$
d_{50}=K_{D o} \times\left(D_{c}\right)^{0,35} \times\left(\frac{D_{i}}{D_{c}}\right)^{-0,5} \times\left(\frac{L_{c}}{D_{c}}\right)^{0,2} \times \theta^{0,15} \times\left(\frac{D_{o}}{D_{c}}\right)^{0,52} \times\left(\frac{D_{u}}{D_{c}}\right)^{-0,47} \times \lambda^{0,93} \times\left(\frac{P}{\rho_{p} g D_{c}}\right)^{-0,22} .
$$

Novamente, a constante da equação, $\mathrm{K}_{\mathrm{Do}}$, é dependente apenas das características do minério, como distribuição granulométrica e densidade.

Por fim, é necessária uma equação que descreva a curva de partição padrão. No modelo computacional aqui descrito, a equação que define a partição para o overflow é dada por:

$$
E o(x)=\frac{C\left(1+\beta \beta^{*} x\right)(\exp (\alpha)-1)}{\left(\exp \left(\alpha \beta^{*} x\right)+\exp (\alpha)-2\right)} \text { onde: }
$$

$x=d / d_{50 c} ;$

$\mathrm{C}=100-\mathrm{R}_{\mathrm{f}}$

Nota-se, primeiramente, que a equação descreve a curva de partição para o overflow. O conceito é similar ao da curva de partição para o underflow, sendo ambas as curvas imagens espelhadas uma da outra. 
Os parâmetros $\alpha$ e $\beta$ são, respectivamente, a inclinação da curva no ponto $x=1 \mathrm{e}$ o ponto de inflexão superior da curva de partição para o overflow. Estes parâmetros estão associados às características do minério. O parâmetro $\alpha$, particularmente, é tido como uma medida da "eficiência" da classificação. A Figura 3.5 mostra o efeito do parâmetro a na curva de partição.

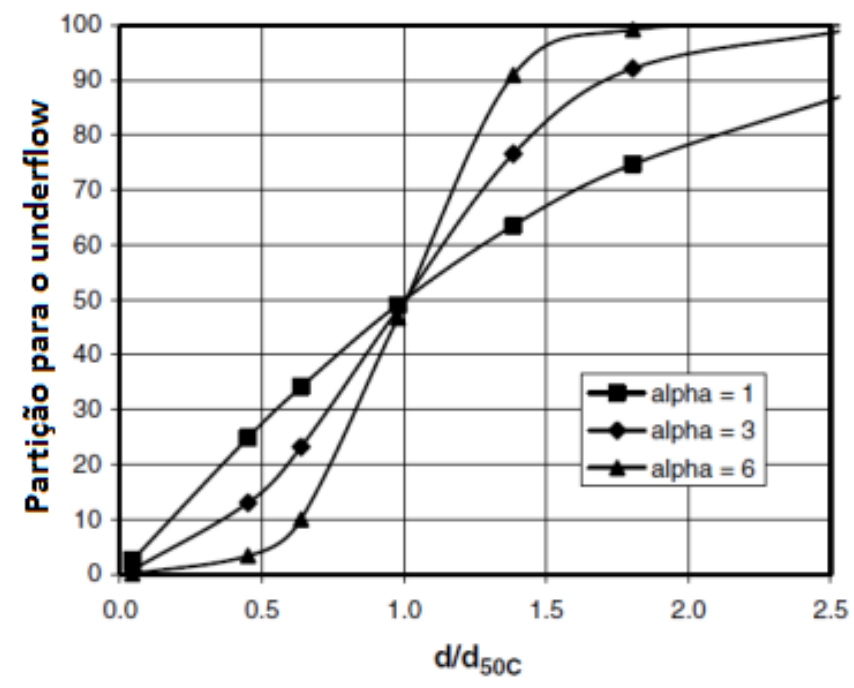

Figura 3.5 - Influência do parâmetro a na curva de partição. (GUPTA; YAN, 2006)

As constantes $C$ e $\beta^{*}$ por sua vez, são calculadas a partir $\alpha$ e $\beta$. Deste modo, para a calibração do modelo é necessário possuir dados operacionais que permitam o cálculo das constantes mencionadas acima.

Uma vez calibrado o modelo, as constantes podem ser utilizadas para a simulação de diferentes condições, desde que as dimensões do hidrociclone não variem muito das dimensões originais.

Chaves $^{18}$ alerta, contudo, que os modelos matemáticos de hidrociclones devem ser aplicados com cautela para a simulação de operações brasileiras. As particularidades do clima fazem com que os minérios no Brasil possuam grandes quantidades de ultrafinos, que afetam a forma da curva de partição. Além disto, Chaves lembra que os modelos matemáticos propostos por Lynch e Rao, foram desenvolvidos com base em experimentos realizados com minérios homogêneos, caso bastante divergente dos itabiritos, compostos de minérios com densidades muito distintas.

Lynch $^{8}$ também alerta para este segundo fato e reconhece que a forma da curva de partição, nestes casos, deve ser analisada com base no comportamento dos diferentes minerais que a constituem. Este autor apresenta uma curva de partição 
composta a partir de dados industriais de uma usina de beneficiamento de minério composto, basicamente, por magnetita e sílica cuja forma sugere, em primeira análise, baixa eficiência de classificação. Contudo, ao se comparar a curva industrial com uma teórica, calculada a partir da soma da classificação individual dos diferentes componentes do minério, nota-se grande concordância, como mostra a Figura 3.6.

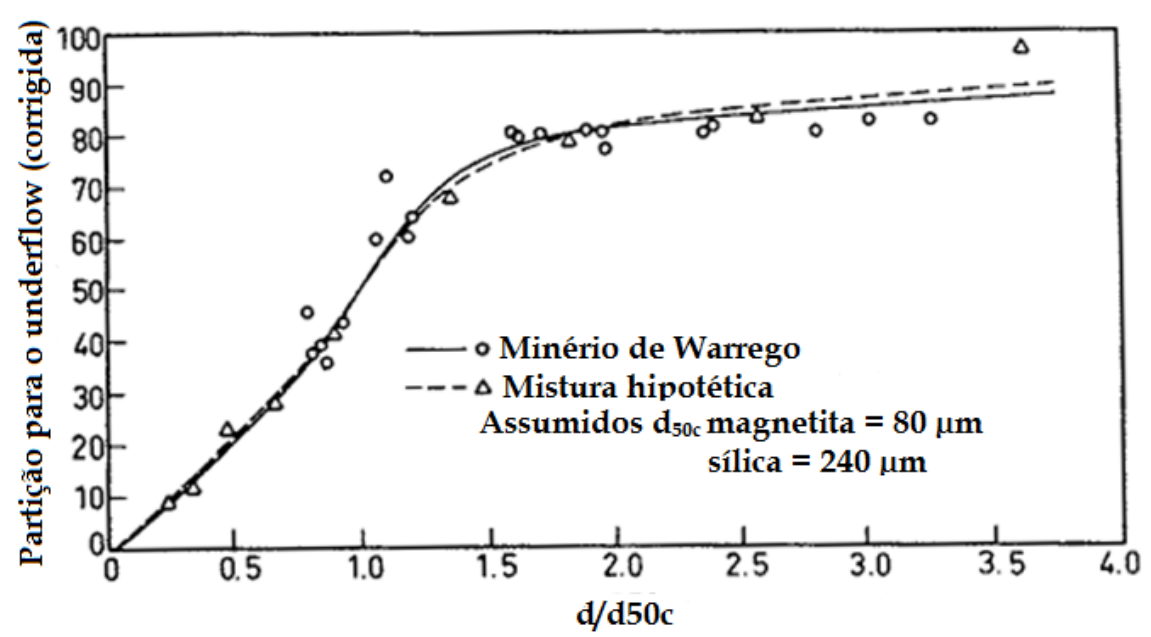

Figura 3.6 - Comparação entre curvas de partição real e teórica para minério de magnetita (Lynch, 1977).

Os modelos computacionais são, portanto, uma ferramenta útil, contanto que seus resultados sejam analisados com nível crítico adequado à realidade industrial estudada.

\subsection{MÉTODO PARA ENSAIOS DE MOAGEM}

Nos concentradores de Germano são realizados rotineiramente ensaios de moagem em laboratório para a previsão do consumo específico de energia dos moinhos industriais. O método foi desenvolvido por Donda ${ }^{22}$, buscando-se substituir o tradicional teste proposto por Bond ${ }^{13}$, tendo-se em vista dois objetivos principais:

- utilização de quantidade mínima possível de amostras, de modo a possibilitar o estudo de materiais advindos de testemunhos de sondagem;

- simplicidade, ou seja, realização dos ensaios com duração mais curta. 
Além disto, observou-se uma dificuldade de previsão do consumo específico de energia do circuito industrial a partir do método proposto por Bond. Esta dificuldade foi atribuída a razão de redução do circuito estudado, inferior a 6 . De acordo com Rowland $^{23}$, para a correta previsão do consumo de energia industrial por meio do ensaio de moabilidade proposto por Bond, é necessário que a razão de redução no teste seja, em média, de 6:1.

O método dos ensaios de moagem utilizados na Samarco Mineração é baseado na equação de Rowland ${ }^{24}$ para a previsão do consumo de energia em moinhos de pequeno diâmetro, qual seja

$$
k W b=6,3 \times D^{0,3} \times \operatorname{sen}\left(51-22\left(\frac{2,44-D}{2,44}\right)\right) \times\left(3,2-3 V_{p}\right) \times C_{s} \times\left(1-\frac{0,1}{2^{\left(9-10 C_{s}\right)}}\right) \text { onde }
$$

kWb: potência $(\mathrm{kW})$ por tonelada de bolas, no eixo pinhão;

D: diâmetro interno do moinho $(\mathrm{m})$;

$V_{p}$ : fração do volume do moinho ocupada pelas bolas;

$\mathrm{C}_{\mathrm{s}}$ : fração da velocidade crítica.

No ensaio, a amostra é toda britada a menos $9,52 \mathrm{~mm}$ e são efetuadas diversas moagens, em tempos sucessivamente mais longos. A equação de Rowland é utilizada para o cálculo da potência consumida no eixo pinhão do moinho utilizado em laboratório, uma vez que as condições dos ensaios são padronizadas. A Tabela 3.2 resume estas condições:

Tabela 3.2 - Condições dos ensaios de moagem.

\begin{tabular}{lc}
\hline Alimentação & amostra britada a $-9,52 \mathrm{~mm}$ \\
Moinho & $12 " \times 12 "$ \\
Rotação & $53,5 \mathrm{rpm}(70 \%$ da velocidade crítica $)$ \\
Carga de bolas & $30,6 \mathrm{~kg}$, escalonada entre 63 a $25 \mathrm{~mm}$ \\
Percentagem de enchimento do moinho & $30 \%$ \\
$\%$ Sólidos da polpa & $80 \%$ \\
Massa de amostra por ciclo & $5,664 \mathrm{~kg}$ \\
\hline
\end{tabular}

De acordo com as informações apresentadas na Tabela 3.2, a potência por tonelada de bolas, calculada a partir da equação de Rowland para o moinho de laboratório, é de 3,643 kW/t de bolas. Deste modo, o consumo específico de energia para este moinho é obtido por: 


$$
\begin{gathered}
\text { Potência }=(3,643 \times 30,6) / 1000=0,1114 k W, \text { logo, } \\
\text { Energia }=\frac{(0,1114 \times 1000 \times t)}{(5,664 \times 60)}=0,3278 \times t, \text { onde: }
\end{gathered}
$$

t é o tempo de cada moagem, em minutos.

Assim, cada tempo de moagem é convertido em consumo específico de energia. São realizados ciclos sucessivos até que se obtenha um produto mais fino do que a especificação para o produto do circuito industrial.

Os resultados dos ensaios são apresentados em um gráfico cujas ordenadas são as percentagens retidas na malha de controle, para os diversos produtos, e as abcissas referem-se ao consumo específico de energia para cada ciclo.

O ensaio foi, primariamente, desenvolvido para prever o consumo de energia do circuito original de moagem primária do Concentrador I, o qual consistia de um circuito fechado direto, conforme mostra a Figura 3.7.

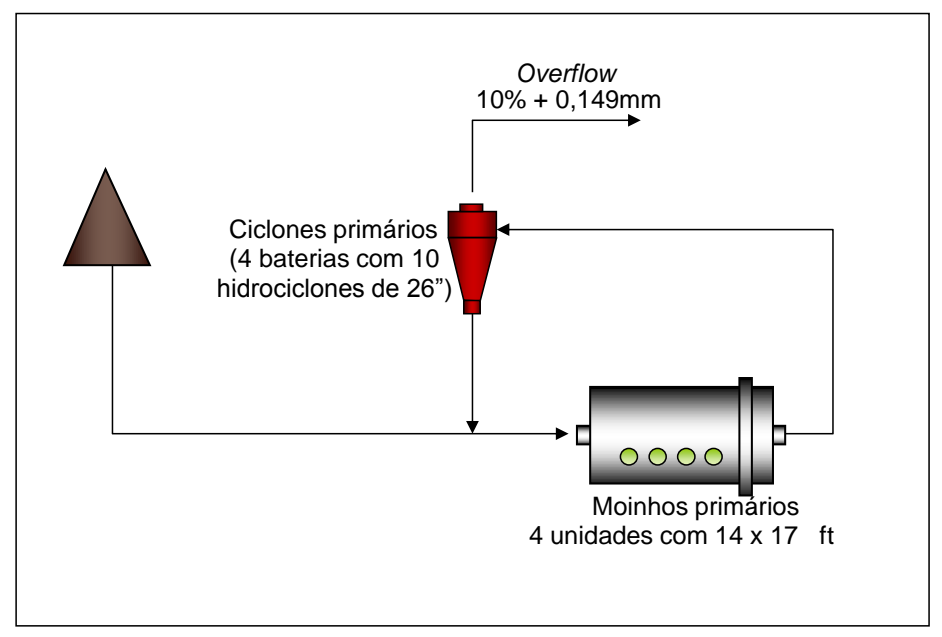

Figura 3.7 - Fluxograma do circuito de moagem primária no início da operação do Concentrador I de Germano.

Para a comparação entre o consumo específico de energia previsto em laboratório e o observado industrialmente, descontava-se, do valor industrial, a fração referente às perdas de energia entre motor e engrenagem, qual seja, para os moinhos primários do Concentrador I, 6\%.

Com a modificação do circuito de moagem do Concentrador I e a inclusão da etapa de pré-moagem, a qual é realizada em circuito aberto, passou-se a descontar 
dos dados industriais, além dos fatores supracitados, o fator de ineficiência proposto por Rowland, para o consumo de energia relativo aos pré-moinhos.

A Figura 3.8 mostra o fluxograma do circuito de moagem do Concentrador I, após a inclusão da etapa de pré-moagem:

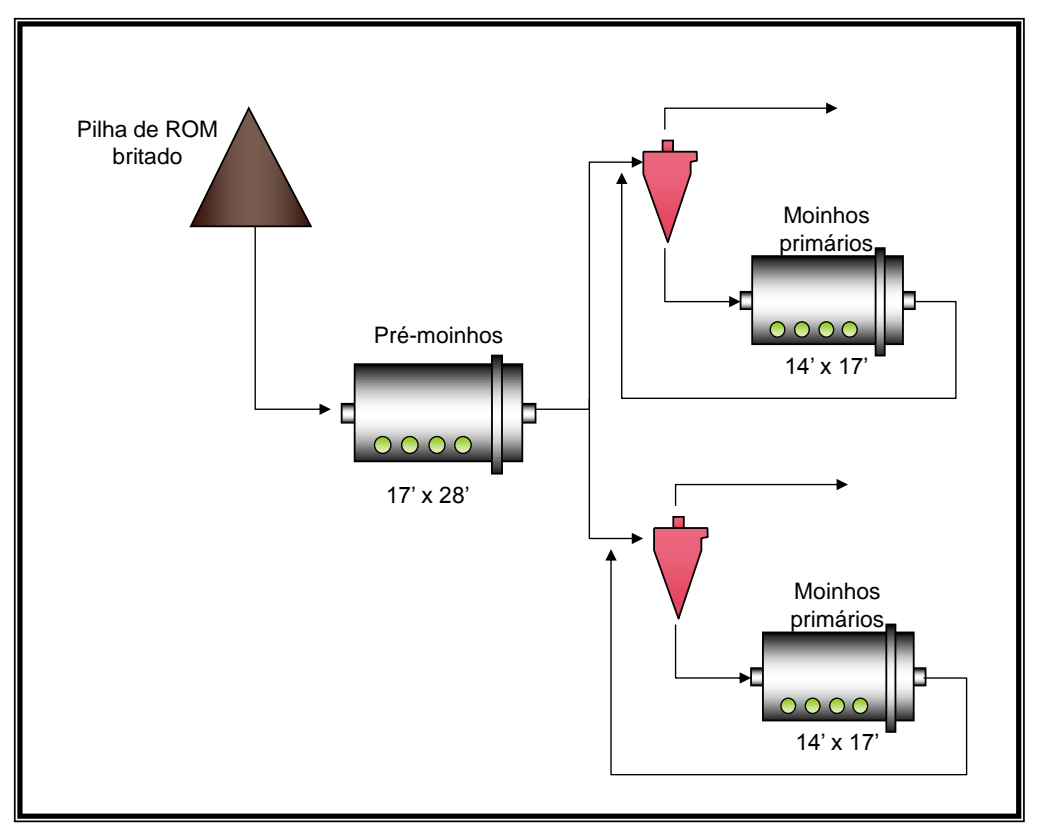

Figura 3.8 - Fluxograma do circuito atual de moagem primária do Concentrador I de Germano.

Conforme exposto no item 3.2.3, Rowland afirma que o fator de eficiência para moagem em circuito aberto depende do controle requerido para o produto. Como o produto dos pré-moinhos é cerca de $70 \%$ passante na malha de controle $(0,149 \mathrm{~mm})$, adotou-se o fator de ineficiência de $10 \%$ para este circuito na Samarco.

Donda, Galinari e Rabelo ${ }^{25}$ demonstraram que existe boa correlação entre os dados industriais e os obtidos em laboratório, conforme mostra a Figura 3.9. 


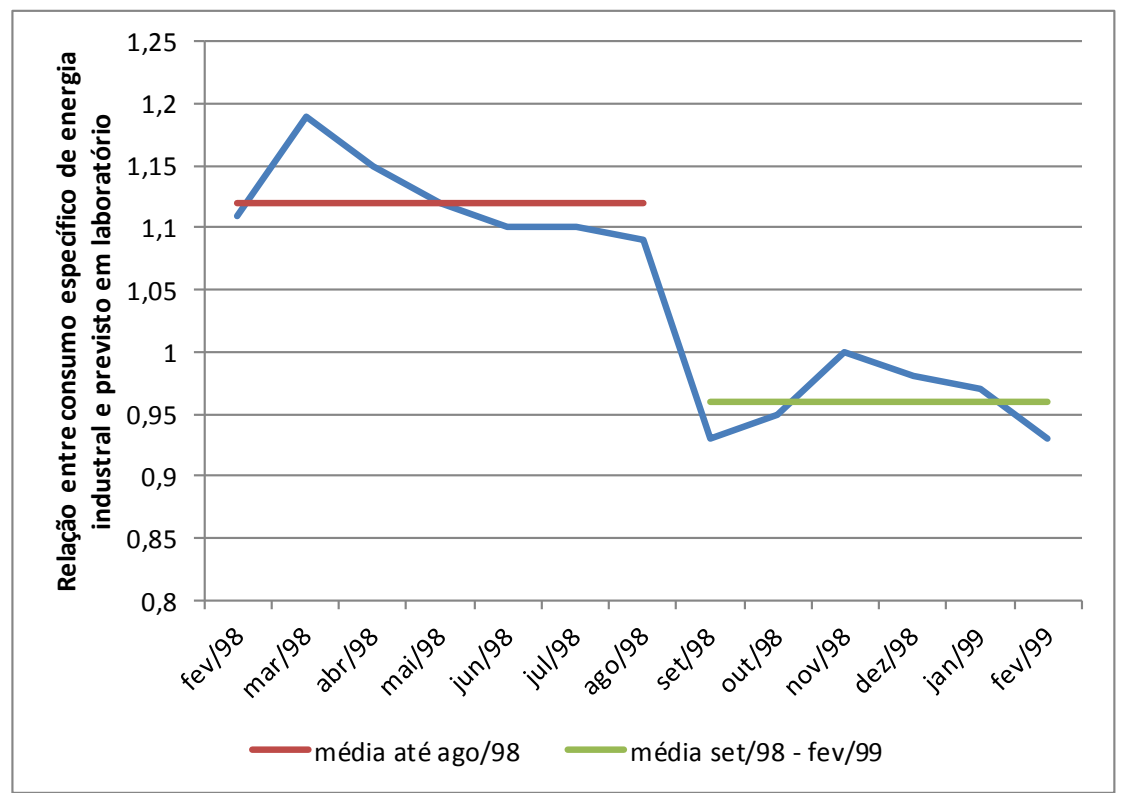

Figura 3.9 - Relação entre consumo específico de energia industrial e previsto em laboratório após mudança no circuito do Concentrador I.

Conforme mostra a Figura 3.9 no período de fevereiro a agosto de 1998, a relação entre o consumo específico de energia industrial e o previsto em laboratório se manteve acima de 1. Foram realizadas investigações no circuito industrial do Concentrador I, as quais levaram a implementação de ações de melhoria de processo e arranjo, tais como a alteração do distribuidor de polpa e a diminuição do tamanho de bolas de reposição nos pré-moinhos e moinhos primários. Após as modificações, o consumo industrial passou a ser inferior ao previsto em laboratório, demonstrando que os ensaios de moagem são uma ferramenta importante para o controle operacional dos circuitos de moagem primária de Germano, além de servir ao dimensionamento dos moinhos dos novos projetos.

\subsection{TEORIA DA AMOSTRAGEM}

A seguir, os conceitos teóricos sobre amostragem foram tratados resumidamente. A teoria mais aceita sobre este tema foi proposta por Pierre Gy em 1976. Os estudos de Gy foram revistos por Pitard ${ }^{26}$ em 1993, e serão o alvo deste capítulo. 
Segundo Pitard, a amostragem "ideal" é aquela em que todos os fragmentos do lote a ser amostrado têm igual probabilidade de serem coletados e todos os objetos estranhos ao lote têm probabilidade zero de serem selecionados.

Contudo, uma série de fatores pode perturbar a realização de uma amostragem "ideal" e comprometer a qualidade dos dados, como afirmam Nappier-Munn et al. ${ }^{10}$ :

- instabilidade do processo;

- características dos amostradores utilizados;

- procedimentos para preparação das amostras;

- erros analíticos;

- precisão dos instrumentos de campo;

- propagação de erros na estimativa de quantidades, teores, etc.

Deste modo, da amostragem até a análise de dados, existem uma série de fatores que podem incorrer em erros e seu melhor entendimento pode levar a minimização destes desvios.

Pitard aponta quatro princípios para o correto planejamento de uma amostragem:

- os materiais são, por natureza, heterogêneos;

- não se deve assumir que quaisquer porções do lote amostrado terão a mesma composição do lote como um todo;

- a fração do lote que está mais acessível a coleta de amostras não é, necessariamente, representativa do todo;

- para a correta amostragem é preciso buscar a minimização dos erros de delimitação (DE), extração (EE) e preparação das amostras (PE), ou seja, deve-se buscar

$$
D E=E E=P E=0 .
$$

A seguir estes conceitos foram desenvolvidos em mais detalhes.

Mesmo em uma amostragem "perfeita", ou seja, em que todos os procedimentos para a minimização de erros de seleção e preparação de amostras foram seguidos, existem erros intrínsecos ao processo de amostragem em si e as caraterísticas do lote os quais não podem ser eliminados.

O primeiro deles é chamado de "erro fundamental" (FE) e está ligado às heterogeneidades do material amostrado, tais como composição química, forma, liberação e distribuição granulométrica. O FE pode ser considerado secundário 
quando a amostra se presta a análises químicas de elementos com altas concentrações, mas é muito importante para a análise de elementos traços.

O erro fundamental pode ser estimado segundo a equação:

$$
\sigma_{(F E)}^{2}=\left(\frac{1}{M S}-\frac{1}{M_{L}}\right) c l f g d^{3}, \text { onde: }
$$

$\mathrm{M}_{\mathrm{S}}=$ massa da amostra;

$\mathrm{M}_{\mathrm{L}}=$ massa do lote amostra;

$\mathrm{d}$ = diâmetro máximo das partículas, definido como a abertura da peneira em que fica retido, no máximo, $5 \%$ da massa total analisada.

Os demais fatores são dependentes das características do material amostrado:

- fator de forma das partículas (f): a equação acima considera que as partículas são cubos perfeitos; deste modo f é um fator corretivo que depende da forma das partículas. Segundo experimentos relatados por Pitard, para a maioria dos materiais $\mathrm{f}$ pode ser assumido como 0,5;

- fator de granulometria (g) que pode ser igual a:

○ 0,25 , para materiais não bitolados;

- 0,55, para materiais bitolados cuja faixa granulométrica se encontre, por exemplo, entre as aberturas de duas peneiras consecutivas;

- 0,75 para materiais naturalmente bitolados, como cereais, por exemplo;

- fator de mineralogia (c), calculado por:

$$
c=\lambda_{m} \frac{\left(1-a_{L}\right)}{a_{L}}+\lambda_{g}\left(1-a_{L}\right), \text { onde: }
$$

$\lambda_{m}$ e $\lambda_{g}=$ respectivamente, densidades do mineral de interesse e da ganga;

$\mathrm{a}_{\mathrm{L}}=$ teor do mineral de interesse no lote amostrado.

- fator de liberação (I), cujos valores podem ser:

- 0,8 para materiais muito heterogêneos;

- 0,4 para materiais heterogêneos;

- 0,2 para materiais medianos;

- 0,1 para materiais homogêneos;

- 0,05 para materiais muito homogêneos.

Como o erro fundamental é proporcional ao diâmetro da partícula, elevado à terceira potência, quanto menor for o diâmetro máximo no lote amostrado, menor 
será o erro incorrido. Por esta razão, sempre que possível, deve-se planejar as operações de amostragem e cominuição da amostra de maneira a minimizar o FE.

De acordo com a máxima variância pretendida, também se deve calcular, previamente, as massas mínimas, para cada etapa de amostragem, de modo a produzir dados confiáveis.

Contudo, conforme Nappier-Munn et al. ${ }^{10}$, a massa mínima teórica, estimada segundo a relação anterior, nem sempre é prática: para materiais grosseiros, este cálculo pode resultar em amostras de toneladas em massa, o que não é viável economicamente. Deste modo, deve-se buscar um equilíbrio entre a teoria e a praticidade de realização da amostragem.

Quando o principal objetivo da amostragem é análise granulométrica, o FE é estimado pela equação ${ }^{26}$ :

$$
s_{F E}^{2}=\left(\frac{1}{M S}-\frac{1}{M_{L}}\right) f \lambda\left[\left(\frac{1}{a_{L c}}-2\right) d_{F L c}^{3}\right]+g d^{3} \text {, onde: }
$$

$\mathrm{f}, \mathrm{g}=$ fatores de forma e granulometria, tal como definidos anteriormente;

$\lambda=$ densidade do minério;

$a_{\mathrm{Lc}}=$ proporção da faixa granulométrica de interesse no lote amostrado;

$\mathrm{d}_{\mathrm{FLc}}=$ diâmetro médio da faixa granulométrica de interesse;

$\mathrm{d}$ = diâmetro máximo, tal como definido anteriormente.

O segundo tipo de erro intrínseco é relativo à segregação natural que as partículas tendem a sofrer dentro de um lote e é chamado de "erro de agrupamento" (GE). Como cada incremento coletado corresponde a um grupo de partículas, a amostra não é composta por uma série de partículas escolhidas ao acaso, mas de grupos de partículas escolhidos ao acaso. Estes grupos trazem desvios probabilísticos em relação à amostra ideal. Para a minimização do GE é recomendado tomar um grande número de incrementos os quais devem conter a menor massa possível.

O quarteamento de amostras também pode favorecer a minimização do GE: o procedimento por pilha cônica não é adequado, pois, a partir dele, são gerados apenas dois incrementos. Por outro lado, os procedimentos de "pazada" alternada e o quarteador tipo Jones são mais assertivos.

Por fim, o erro contínuo (CE) refere-se às flutuações naturais de processo, ou seja, as variações nos fluxos amostrados. 
A materialização da amostra, por sua vez, tem duas fontes de erros: a delimitação, ou seja, o estabelecimento de limites para que se proceda à coleta do incremento, e a extração do incremento. Os desvios de delimitação (DE) e extração (EE) da amostra correspondem, portanto, ao erro total da fase de obtenção da amostra.

Por fim, também devem ser contabilizados, no erro total dos dados obtidos por amostragem, os desvios oriundos das operações de preparação de amostras (PE) e análises de dados (AE), embora estas operações não façam parte da amostragem em si.

Pitard aponta as etapas de delimitação e extração da amostra como as duas potenciais fontes de erros para os dados. Segundo o autor, mais do que estimar estes desvios é preciso tomar cuidados para evitá-los. Os principais aspectos apontados pelo autor para a correção dos erros de delimitação estão apresentados a seguir.

\subsubsection{Erros de delimitação dos incrementos}

a) Materiais granulados em pilhas e em transportadores de correia:

Materiais granulados podem ser considerados um lote unidimensional, ou seja, lotes cuja espessura e largura são muito inferiores ao comprimento. É o caso de pilhas alongadas e materiais amostrados em correias transportadoras paradas. Nestes casos, para uma delimitação adequada do incremento devem-se utilizar dois planos simétricos e paralelos, os quais precisam atravessar inteiramente o lote.

Para a retirada de amostras em correias paradas, contudo, este procedimento é válido se, além do paralelismo, os planos limites se encaixem perfeitamente na curvatura do tapete do transportador. A Figura 3.10 mostra esquematicamente este procedimento: 


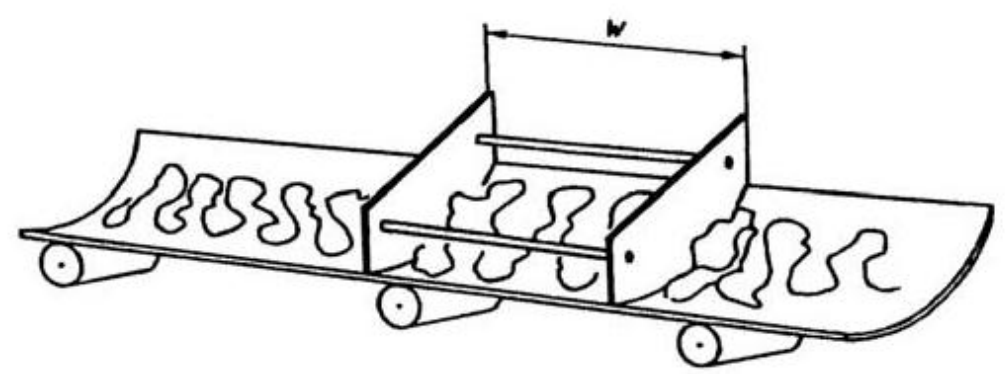

Figura 3.10 - Representação do caixilho para delimitação de amostra em transportador de correia. Fonte: (http://geologia.fc.ul.pt/PosGrad/EstudosCaso0708/MarianaRosaApresentacao.pdf)

As pilhas alongadas devem ser construídas de modo a possuir largura e espessura constantes ao longo de todo o comprimento. Para operação de homogeneização em pilha alongada em laboratório, recomenda-se o uso de pás de secção quadrada para a retirada dos incrementos.

b) Materiais em fluxos contínuos:

Nestes casos, os amostradores devem satisfazer duas condições:

- obter uma "fatia" de material com espessura constante durante toda a coleta do incremento;

- atravessar o fluxo por completo.

A Figura 3.11 ilustra estes dois princípios.
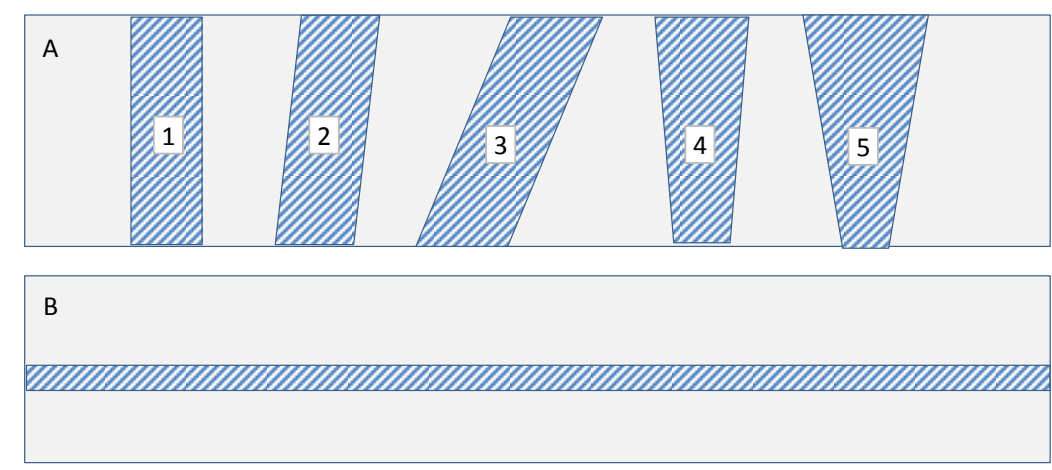

C

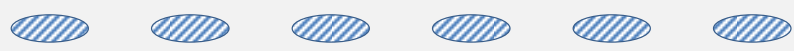

Figura 3.11 - Amostragem de fluxos contínuos: (A) Amostrando todo o fluxo periodicamente: 1,2,3 estão corretos; 4 e 5 incorretos. (B) Amostrando parte do fluxo continuamente - sempre incorreto. (C) Amostrando parte do fluxo periodicamente - sempre incorreto.

(Adaptado de Pitard, 1993).

Para atender aos princípios ilustrados na Figura 3.11, os amostradores devem possuir secção retangular, ou seja, extremidades retas e paralelas entre si. Em 
amostradores do tipo "vezin", que descrevem uma trajetória circular, a secção deve ser perfeitamente radial. É também importante que os amostradores possuam largura suficiente para garantir que atravessem todo o fluxo.

\subsubsection{Erros de extração dos incrementos}

Em amostragens de fluxos contínuos é preciso garantir, além da correta delimitação do fluxo, que as partículas não sejam ricocheteadas pelas paredes do amostrador, para fora do recipiente de coleta.

O desenho do amostrador deve, então, obedecer as seguintes observações:

- as extremidades devem ser perfeitamente ajustadas e simétricas;

- a largura deve ser suficiente para permitir que partículas desviadas do fluxo, ainda caiam dentro dos limites do amostrador.

Via de regra, Pitard recomenda que a largura do amostrador não seja inferior a 3 vezes a espessura do fluxo amostrado.

É também importante observar a largura da abertura do amostrador, em relação ao diâmetro da partícula amostrada.

A norma $\mathrm{ABNT}^{27}$ para amostragem de minérios de $\mathrm{Fe}$, recomenda o máximo entre:

a) a abertura de três vezes o diâmetro máximo de partículas para o fluxo coletado;

b) $30 \mathrm{~mm}$.

Para amostragens em correia parada, a mesma Norma recomenda, ainda, que o comprimento de correia do qual a amostra será retirada seja, ao menos, três vezes maior que o diâmetro da maior partícula a ser coletada.

Pitard recomenda uma abertura superior à mínima, calculada pelas equações:

$$
\begin{gathered}
W o=3 d, \text { para } \mathrm{d}<3 \mathrm{~mm}, \text { ou } \\
W o=3 d+10, \text { para } \mathrm{d}>3 \mathrm{~mm}, \text { onde: }
\end{gathered}
$$

Wo = abertura mínima recomendada $(\mathrm{mm})$;

$\mathrm{d}$ = diâmetro máximo de partículas para o fluxo coletado. 
Pitard alerta, contudo, que estas regras não foram desenvolvidas para fluxos com grandes vazões ( $1000 \mathrm{~m}^{3} / \mathrm{h}$ ), para os quais, ainda não há teorias estabelecidas. Nestes casos é importante utilizar a experiência de campo.

\subsubsection{Aspectos práticos para amostragens de circuitos de moagem}

Nappier-Munn et al. ${ }^{10}$ fizeram um estudo sobre campanhas de amostragens cujo objetivo é a obtenção de dados para a calibração de modelos computacionais para simulação de circuitos de cominuição, incluindo circuitos de moagem em moinhos de bolas.

Alguns aspectos práticos relevantes analisados por estes autores incluem:

a) coleta de dados industriais: devem ser coletados tantos dados quanto forem possíveis, pois a redundância de dados é importante para a verificação de possíveis erros. Dados disponíveis nos sistemas automáticos de controle da planta devem ser registrados periodicamente, sendo a média dos registros considerada representativa do período da amostragem;

b) flutuações no processo: uma vez estabelecidas as condições operacionais alvo do estudo, os autores recomendam que se observe um intervalo de, pelo menos uma hora, antes de se proceder a amostragem, o que corresponde a múltiplos do tempo de residência do moinho. Este cuidado é uma garantia para que o circuito esteja sob operação em regime, ou seja, as condições operacionais devem ser as mais estáveis possíveis. Um bom indicativo desta condição é a estabilidade da corrente elétrica das bombas de alimentação dos hidrociclones;

c) obtenção das amostras: a coleta de todas as amostras deve ser realizada simultaneamente. Se este procedimento não for possível, deve-se proceder à coleta em uma ordem "lógica", que respeite os tempos de residência em cada etapa.

Para o caso de uma grande perturbação ocorrer no processo durante a amostragem, as amostras devem ser descartadas ou, se a campanha estiver próxima do fim, não se devem coletar mais incrementos.

Para amostras obtidas em transportadores de correia, de materiais granulados grosseiros, estes autores recomendam uma alternativa: 
- coletar manualmente, logo após a parada do transportador, pelo menos 50 fragmentos visualmente maiores que $75 \mathrm{~mm}$; estes fragmentos servirão à análise do top size da amostra;

- proceder a coleta do material contido em um 2-5 m de correia, para análise das frações mais finas;

O comprimento de correia, de onde foi retirada a amostra e a velocidade da mesma, devem ser registrados. De posse destes dados e da massa de amostra, é possível calcular a vazão mássica do fluxo e confrontar com a leitura dos instrumentos de campo.

Para a coleta de amostras da alimentação de ciclones, dois procedimentos são destacados. Primeiramente, por meio de uma válvula conectada ao distribuidor da bateria de ciclones. Segundo, utilizando-se um ciclone que não se encontre em operação no momento da amostragem: abrindo-se, lentamente, a válvula de alimentação deste ciclone, todo o fluxo irá, em princípio, se reportar ao underflow, até que o mesmo esteja cheio. Deste modo é possível coletar, durante este intervalo, uma amostra do que se constitui a alimentação do ciclone, na descarga do apex do mesmo. Caso se opte pela obtenção da amostra por meio de uma mangueira conectada ao distribuidor da bateria, recomenda-se a coleta de apenas dois incrementos, para evitar entupimentos no mangote.

Para amostras relativas ao underflow dos ciclones, é preciso garantir que o amostrador corte todo o spray correspondente a este fluxo. Amostras relativas ao overflow, por sua vez, devem ser obtidas na calha de coleta deste fluxo para todos os ciclones. 


\section{A SAMARCO MINERAÇÃO E OS CIRCUITOS DE MOAGEM PRIMÁRIA DE GERMANO}

A Samarco Mineração S.A. é uma joint venture dos grupos Vale e BHP Billiton e atua no mercado internacional de pelotas de minério de ferro. Possui duas unidades industriais, uma situada em Mariana - MG, denominada Unidade Mina de Germano, onde estão localizadas suas jazidas e dois concentradores, e uma situada em Anchieta - ES, denominada Unidade Ponta Ubú, onde ficam suas quatro usinas de pelotização e o terminal marítimo.

O Concentrador I de Germano possui 34 anos de operação, nos quais uma série de modificações de circuito foi realizada. O seu fluxograma original era bastante simples e compreendia duas etapas de moagem em moinhos de bolas, sendo a primeira alimentada diretamente com o ROM, um circuito de deslamagem e uma etapa de flotação, em células convencionais. Este fluxograma foi desenhado para o

minério de Germano que, dentre outras vantagens, era bastante fino e pouco resistente à fragmentação, além de possuir cinética de flotação muito favorável.

Com a exaustão da Mina de Germano, em 1992, e a entrada dos minérios do Complexo Alegria, a operação do concentrador se deparou com novas dificuldades e, em consequência, o circuito foi ajustado. As mudanças incluíram uma etapa de britagem, além de serem incorporados novos estágios de deslamagem e flotação.

Além destas adequações, o concentrador também foi modificado visando 0 aumento de produção de pelotas, de acordo com os projetos de expansão da empresa em 1997. O fluxograma do circuito atual do Concentrador I de Germano é mostrado na Figura 4.1. 


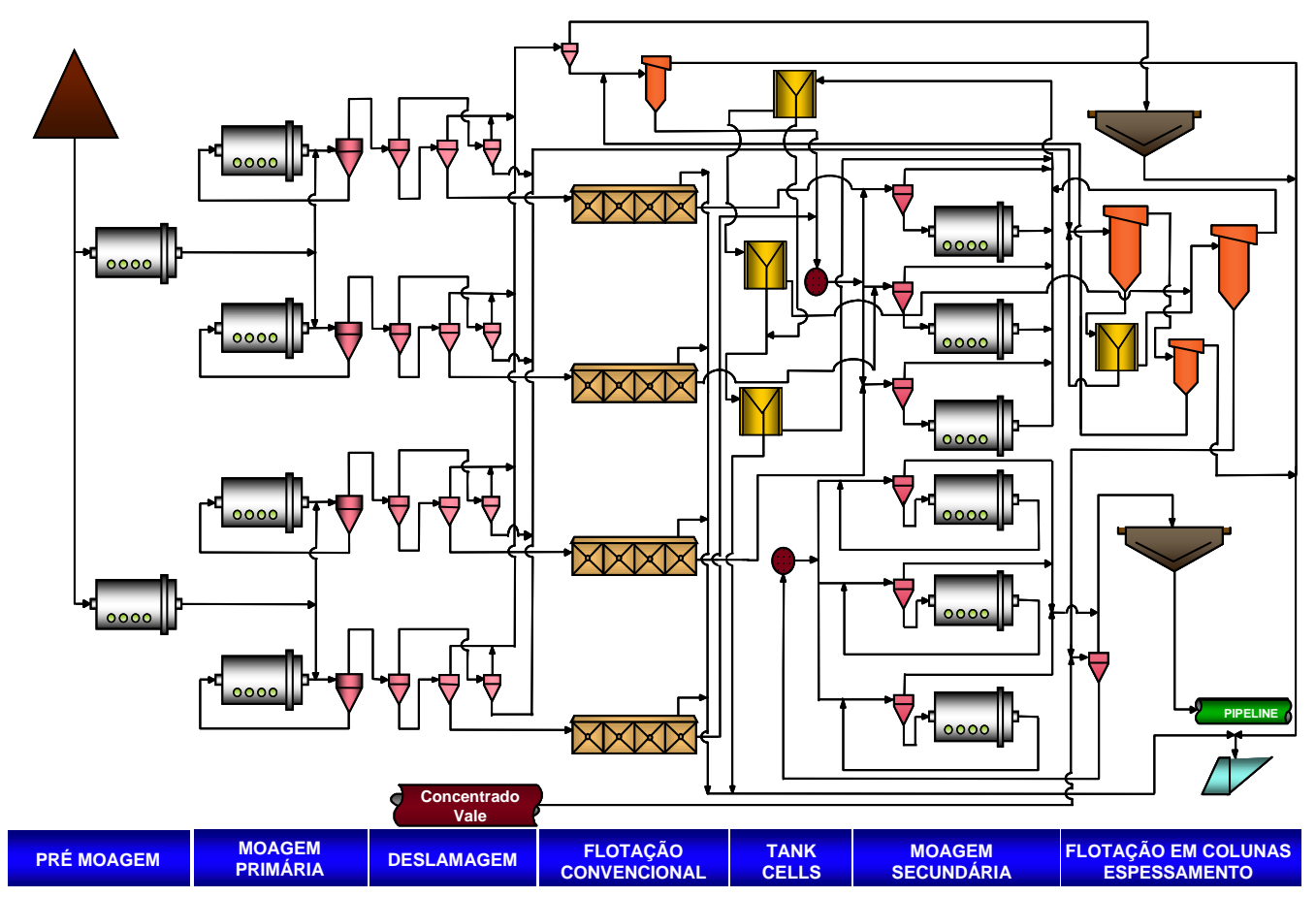

Figura 4.1 - Fluxograma do Concentrador I de Germano.

Como pode ser visto, a configuração atual do concentrador difere bastante de seu fluxograma original, especialmente sob a ótica da simplicidade e facilidade de fluxo. Destaca-se a incorporação das etapas britagem e pré-moagem, além da adição de novos moinhos secundários, necessária ao processamento de minérios de maior dureza e granulometria mais grosseira.

A etapa de pré-moagem foi uma solução desenvolvida por Donda para viabilizar a expansão da capacidade produtiva em 1997, oferecendo, ao mesmo tempo, um circuito de britagem mais simples do que o então vigente. Antes da instalação dos pré-moinhos, a energia disponível na primeira etapa de moagem era insuficiente para processar os minérios de Alegria, o que requeria uma alimentação bastante fina no circuito. Devido a este fato, a usina de britagem operava a úmido, de modo a garantir a granulometria adequada para a operação da moagem primária, trazendo diversos transtornos. Havia necessidade de bombeamento da fração menor que $1 \mathrm{~mm}$ para as caixas de descarga da moagem primária e havia dificuldade no controle tanto da vazão quanto da granulometria na alimentação da moagem.

A alternativa encontrada foi o aumento da energia disponível na moagem, para tornar factível uma alimentação mais grosseira neste circuito. Isto se deu pela inclusão de dois grandes moinhos de bolas, denominados de pré-moinhos, os quais 
passaram a receber o minério britado e cuja descarga alimenta os quatro moinhos já existentes.

O circuito de moagem primária do segundo concentrador de Germano, cujo projeto incorporou todo aprendizado e experiência adquiridos com a operação do Concentrador I, não dispõe de pré-moinhos, pois o conceito básico foi o de manter a facilidade de fluxo, tal como era o primeiro concentrador em sua concepção original. Os moinhos primários do Concentrador II de Germano foram, portanto, dimensionados adequadamente para o processamento do minério britado atual em um único estágio de moagem.

A despeito das diferentes configurações, as primeiras etapas de moagem dos concentradores de Germano têm como objetivo a preparação do minério britado para a flotação mecânica, ou seja, a liberação dos minerais de ferro. A malha de controle deste circuito é $0,150 \mathrm{~mm}$ (100 \#, série Tyler), ou seja, há um limite para a percentagem em massa do produto que pode estar acima desta granulometria.

Entretanto, o controle do produto da moagem primária sobrepõe as especificações para a liberação, uma vez que a geração de partículas ultrafinas (lamas) nos minérios de Alegria é alta. As lamas são prejudiciais ao desempenho da flotação e, por este motivo, um circuito de deslamagem antecede esta etapa, como pode ser visto na Figura 4.1. Contudo, o descarte de partículas finas representa perdas em massa e metálicas no processo global e, portanto, sua geração deve ser controlada. Logo, o circuito formado por pré-moagem e moagem primária tem por objetivo, preparar a alimentação da flotação na granulometria adequada, originando a menor quantidade de lamas possível, de modo a garantir máximos índices de recuperação. A Figura 3.8, mostrada anteriormente, destaca este circuito. Ao todo são seis moinhos, conforme descrito:

- dois pré-primários, operando em circuito aberto, com dimensões de $17 \times 28$ pés e potência instalada de $3800 \mathrm{~kW}$ cada;

- quatro primários, com dimensões de $14 \times 17$ pés e potência instalada de $1430 \mathrm{~kW}$ cada; os moinhos primários operam em circuito fechado inverso, com baterias de 6 hidrociclones de 26" de diâmetro cada. 


\section{MATERIAIS E MÉTODOS}

\subsection{CONCEITOS ADOTADOS NESTE TRABALHO}

Conforme discutido nas seções 3.2 e 3.3, os conceitos de "eficiência de moagem" e "finos" são subjetivos, dependendo do enfoque dado ao estudo. Por esta razão, faz-se necessário convencionar os conceitos adotados neste trabalho.

O consumo de energia nos circuitos de moagem representa uma parcela de grande importância nos custos operacionais de um concentrador. Além disto, o conceito de eficiência energética é um enfoque bastante prático, já que os moinhos são ainda hoje dimensionados pelo consumo de energia e os minérios do mundo todo, referenciados pelo Wi de Bond. Deste modo, adotou-se neste trabalho o conceito mais tradicional para "eficiência", que alia o consumo de energia e granulometria da alimentação e do produto do circuito.

Por outro lado, reconhece-se a importância de se avaliar outros aspectos influentes na operação de circuitos de moagem para se obter uma análise mais abrangente dos mesmos. Este trabalho procurou ir de encontro às críticas da tradicional lei de Bond ao:

- analisar as distribuições granulométricas da alimentação e do produto; não se atendo somente ao $\mathrm{D}_{80}$;

- avaliar o papel de outras variáveis operacionais nos resultados, conforme será explicitado mais adiante.

Quanto à definição de finos, o objetivo principal do presente trabalho é avaliar se a sua retirada na alimentação do circuito de moagem (configuração inversa) oferece maior eficiência energética em relação ao circuito direto. Considerando-se as críticas ao circuito direto - de que a energia empregada para a moagem de partículas abaixo da malha de controle do circuito não seja útil - o conceito de "finos" aqui adotado foi: todas as frações do produto abaixo da malha de controle. No caso dos circuitos de moagem primária de Germano portanto, "finos" são as frações granulométricas passantes em $0,149 \mathrm{~mm}$ (100\# da série Tyler). 


\subsection{AMOSTRAGENS EM CIRCUITO INDUSTRIAL}

Conforme discutido na seção 3.6, o conceito de uma amostragem "ideal" é aquela em que todas as partículas de um determinado lote possuem igual probabilidade de serem coletadas.

Contudo, conforme bem definido neste conceito, a amostragem é um evento probabilístico e, por consequência, seus resultados são influenciados por todas as dificuldades oferecidas à sua realização. Os circuitos industriais estão longe de se constituírem em um ambiente controlado. Mesmo considerando a coleta de amostras apenas em situações de operação "em regime", não é possível evitar as flutuações nas vazões do circuito e nas características físico-químicas dos fluxos tais como, densidade de sólidos, densidade, viscosidade de polpa, etc.

Deste modo, a "amostragem ideal" não é possível, mesmo tomando-se todos os cuidados recomendados na literatura para sua realização. Este capítulo procura resumir as dificuldades encontradas na realização de amostragens em circuitos de moagem industriais e alguns cuidados que foram relevantes para a coleta de dados nos quais se baseou o presente trabalho.

\subsubsection{Planejamento}

Amostragens em circuitos industriais devem ser, primariamente, bem planejadas, para a garantia da obtenção de dados confiáveis e suficientes ao estudo requerido. Este passo é importante para que dados cruciais à pesquisa não sejam esquecidos ou coletados erroneamente.

Além disto, é importante contar sempre com equipe composta por profissionais experientes e conhecedores do circuito amostrado, para garantir confiabilidade no cumprimento dos procedimentos e normas de segurança. A rotatividade natural dos membros da equipe de laboratório pode ser um desafio para o estabelecimento de padrões e o bom cumprimento dos procedimentos. É importante, portanto, o acompanhamento da obtenção de amostras e a verificação sistemática das análises laboratoriais para a garantia da confiabilidade dos dados obtidos. 
Outro ponto crucial para o planejamento de uma amostragem é a verificação dos instrumentos de área. É importante verificar, previamente, seu funcionamento e calibração para evitar a perda de dados operacionais durante a coleta das amostras.

\subsubsection{Variabilidade das características dos materiais e fluxos amostrados}

Conforme já abordado, este é um desafio inerente a quaisquer estudos em circuitos industriais. A dinâmica das operações de lavra normalmente dita a heterogeneidade da alimentação de um concentrador. A existência ou não de pilhas para a regularização destas características, também é importante. Particularmente, os circuitos de Germano são alimentados por uma composição oriunda de diversas minas. O minério é alimentado diretamente nas usinas de britagem por um sistema de correias de longa distância, ou seja, não há pilhas de regularização que permitam a maior uniformidade do minério que chega aos concentradores. O recurso mais utilizado para contornar esta dificuldade é a formação de uma amostra por diversos incrementos que possam absorver parte desta variabilidade inerente à alimentação dos concentradores. Neste trabalho, as amostras em polpa foram compostas por seis incrementos, tomados sob intervalos de 10 minutos, durante um período total de uma hora, segundo o procedimento padrão dos laboratórios de Germano.

\subsubsection{Acessos aos pontos de amostragens}

Circuitos industriais raramente são projetados, tendo-se em vista a facilidade de acesso aos pontos de obtenção de amostras, ainda que elas forneçam importantes dados sobre os mesmos. Ao se considerar também a evolução das normas de segurança do trabalho, que impõem uma série de guarda-corpos, grades para proteção contra partes rotativas, etc, os acessos aos equipamentos tornam-se ainda mais difíceis e o trabalho para a tomada manual de amostras, maior. Em circuitos de moagem, três pontos requerem atenção especial: 
- Amostragem de material granulado em correias transportadoras - este ponto requer, normalmente, a parada (e bloqueio) do equipamento e a varredura do material correspondente a um comprimento pré-determinado do tapete. A parada e o bloqueio de segurança de um equipamento industrial são, geralmente morosas, requerendo a participação de profissionais especializados como, por exemplo, a presença de um técnico eletricista para bloqueio do painel do equipamento na sala elétrica. Por esta razão, é necessário que a amostra global deste ponto seja toda coletada em um único momento, ao contrário do que recomenda a literatura como a norma ABNT ISO3082 ${ }^{(27)}$. Em Germano, o procedimento é realizar a parada do transportador de correia após a coleta dos incrementos das amostras em polpa. Contudo, há a desvantagem de não se poder garantir que o lote coletado seja representativo de todo o período de amostragem. A maior dificuldade, porém, está associada à granulometria do material a ser coletado. Quanto maior for o diâmetro correspondente à maior partícula do lote, maior será a quantidade de amostra a ser coletada para garantir sua representatividade. Conforme discutido na seção 3.6, a literatura recomenda que seja delimitado um comprimento mínimo de correia do qual será obtida a amostra. Contudo, é preciso ter em mente que o local de coleta deve ter espaço suficiente para que os operadores possam se posicionar sobre o tapete e para o manuseio das amostras. Nem sempre o espaço disponível permite a observação desta regra: chutes de alimentação, sistemas de proteção contra partes rotativas e outros dispositivos podem representar barreiras para a realização deste trabalho. A Figura 5.1 ilustra esta operação. 


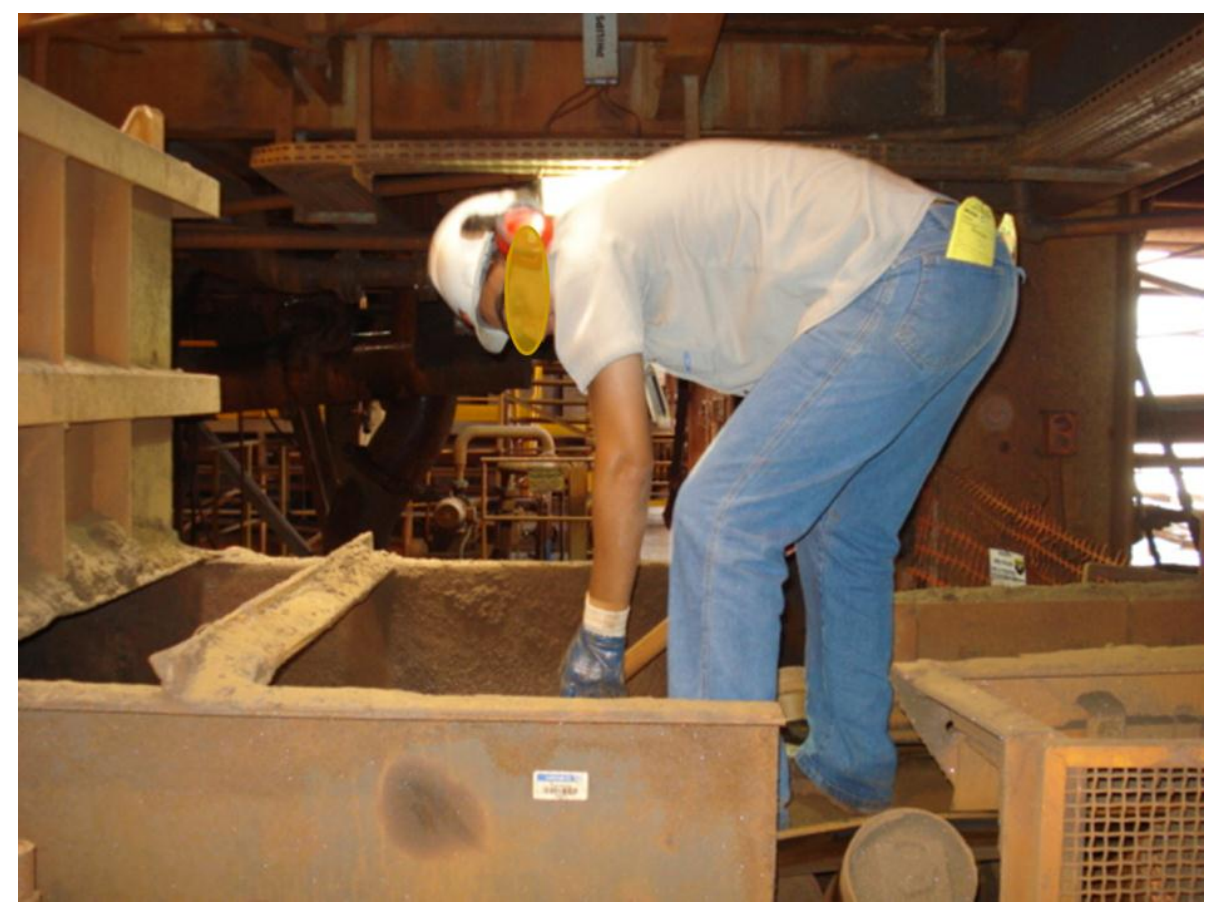

Figura 5.1 - Coleta de amostra em transportador de correia.

- Amostragem da descarga dos moinhos - a descarga dos moinhos constitui um ponto de difícil acesso pois, em geral, o espaço entre a caixa de polpa e o trommel dos moinhos é limitado. Além disto, trata-se de um ponto em que tanto a vazão de polpa quanto a pressão do fluxo são altas, o que dificulta:

- o manuseio dos coletores de amostra: requerendo cuidado para que o intenso fluxo de polpa sobre o cortador de amostra não disperse o material já coletado, dentro dele;

- a possibilidade de se "varrer" efetivamente o fluxo, ao longo de toda a sua extensão.

A Figura 5.2 mostra o coletor usado em Germano para este ponto. Observa-se que a abertura é estreita para evitar que a polpa já coletada seja "expulsa" do coletor enquanto este é manuseado através do fluxo. O cabo longo facilita o acesso ao ponto de coleta e permite que o fluxo seja coletado em toda sua extensão. Contudo, como mostram a Figura 5.3 e a Figura 5.4, seu manuseio é difícil e requer dois laboratoristas para realizar a operação, além de dificultar a transferência do incremento coletado para o recipiente da amostra. Este é um desafio também inerente às características da polpa obtida neste ponto - em geral, com alta percentagem de sólidos. Como a lavagem do amostrador com 
água alteraria a densidade da polpa coletada, é preciso cuidado para garantir que a maior parcela do incremento presente no amostrador seja transferido.

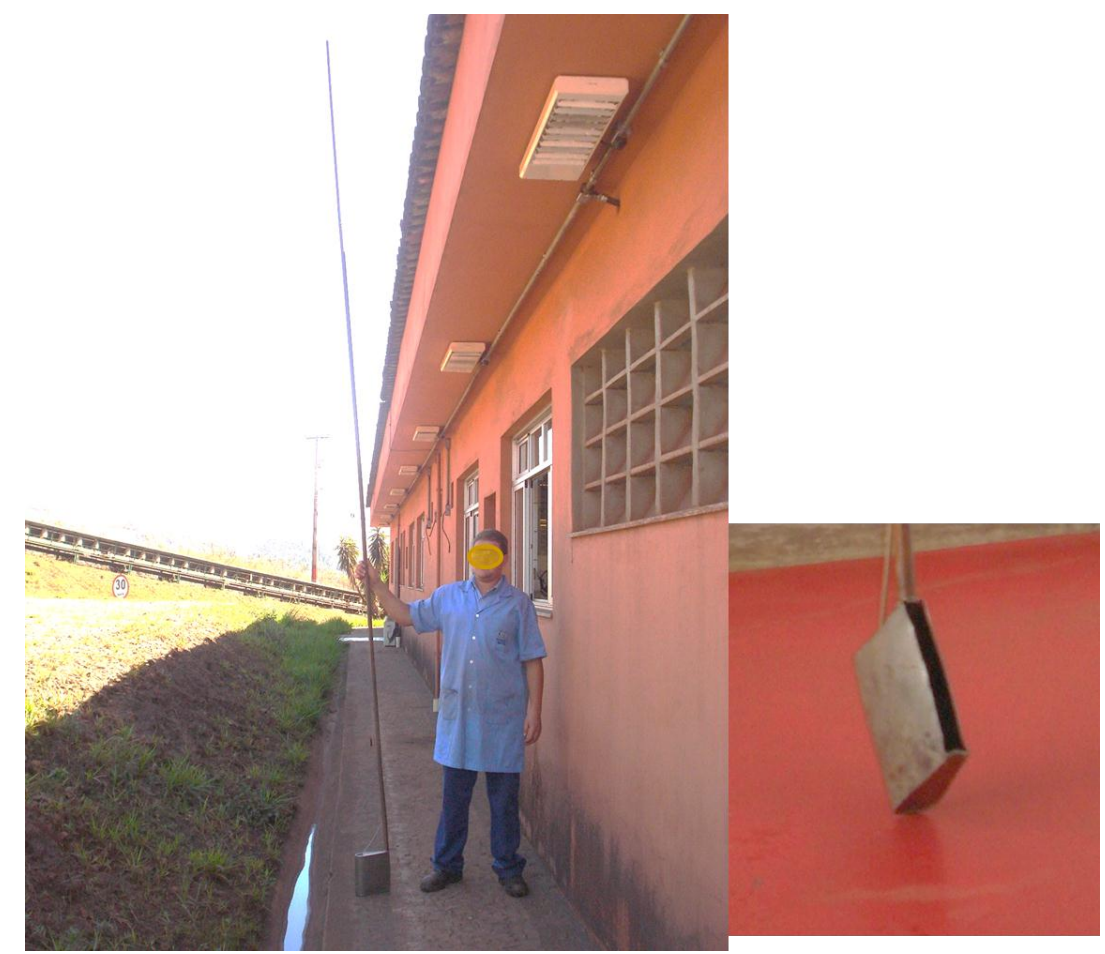

Figura 5.2 - Amostrador para a coleta da descarga de moinho.

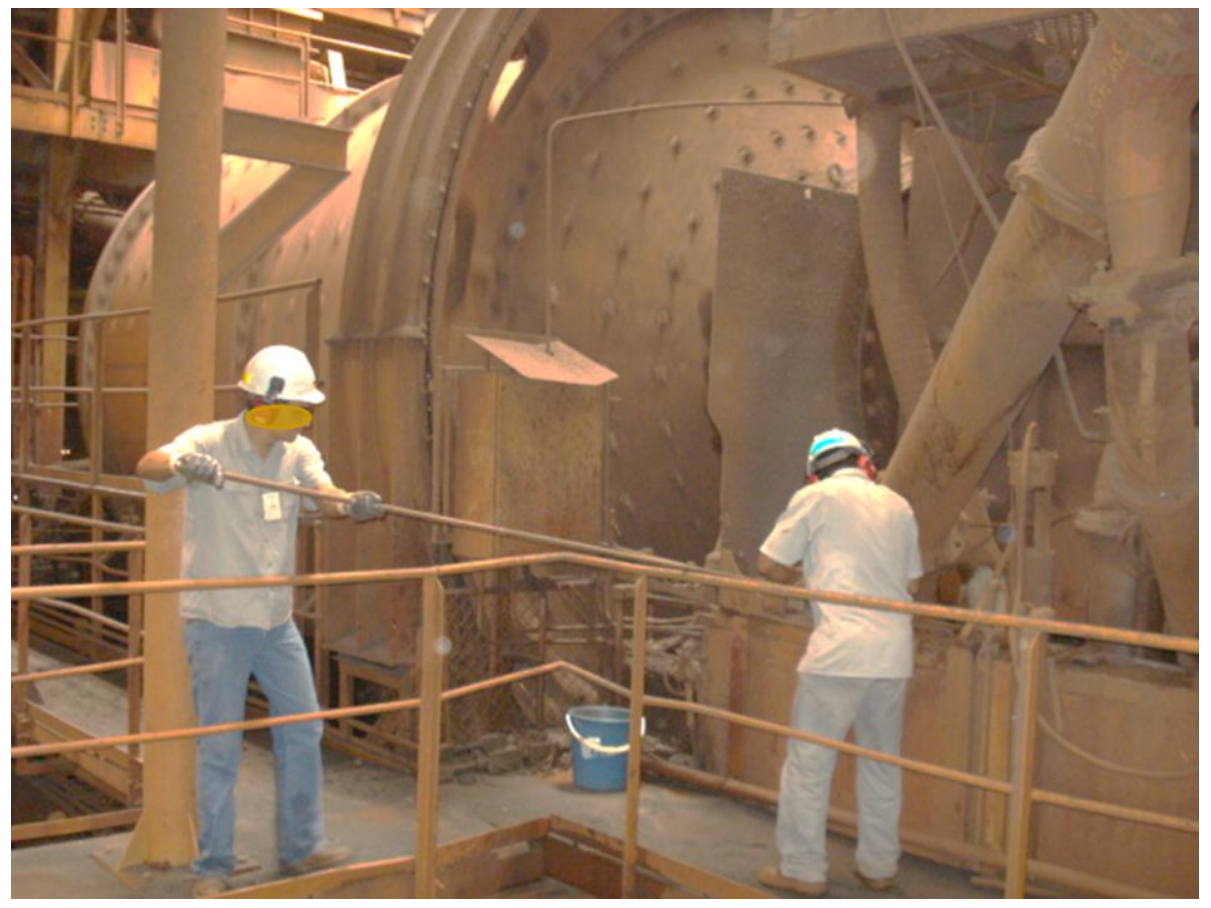

Figura 5.3 - Coleta de amostras na descarga dos moinhos primários. 


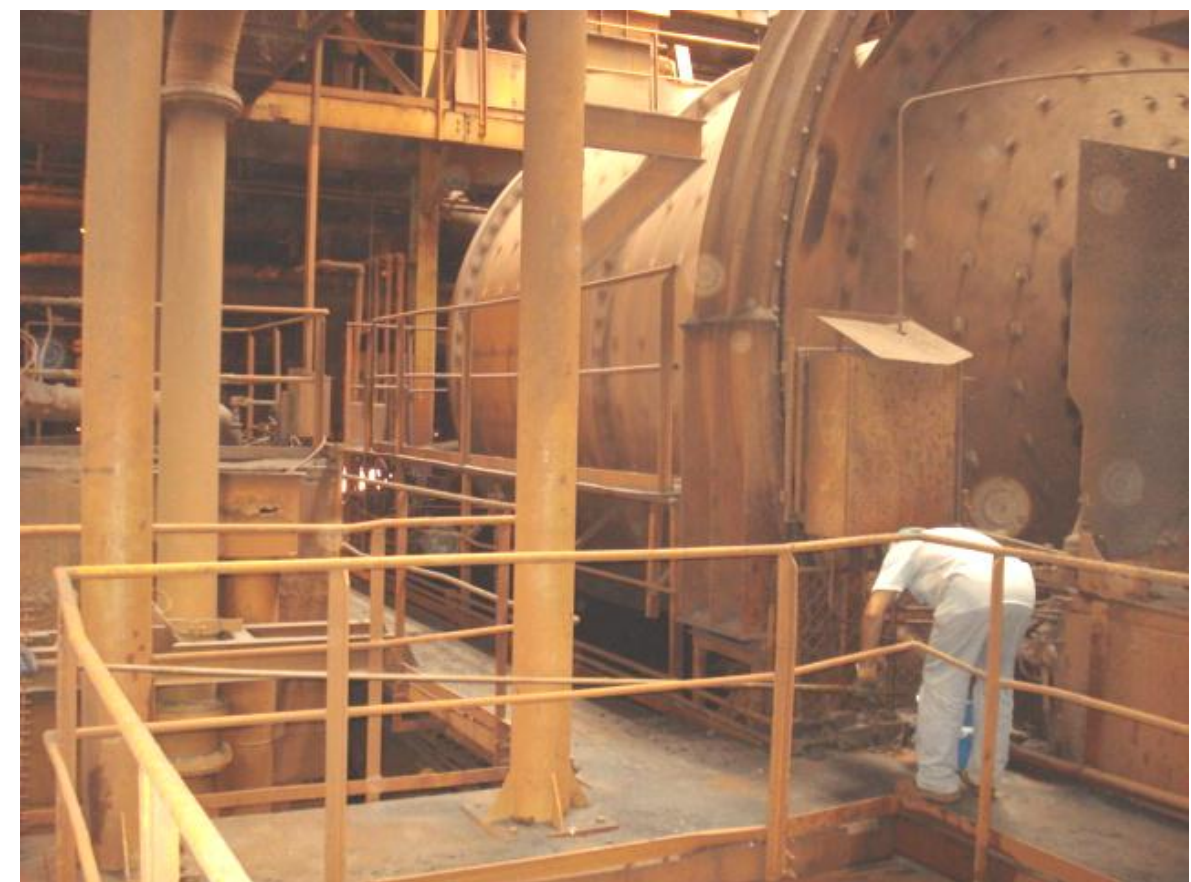

Figura 5.4 - Transferência do incremento (descarga do moinho) do coletor para o recipiente.

- Amostragem da alimentação dos hidrociclones - conforme discutido na seção 3.6, esta amostra pode ser coletada com o uso de um mangote conectado ao distribuidor da bateria de ciclones, ou utilizando-se um ciclone que não se encontre em operação no momento da amostragem. Este segundo procedimento conduz, em geral, a amostras mais representativas. Porém, em circuitos operando à máxima capacidade - como é o caso dos concentradores de Germano - muitas vezes, todos os ciclones estão em operação e não é possível seguir tal procedimento. Além disto, as válvulas instaladas nos ciclones primários são do tipo "on/off”, ou seja, não é possível a abertura parcial da válvula. A alternativa, portanto, é a conexão de um mangote a uma válvula, previamente instalada, no distribuidor de polpa da bateria de ciclones. Não são raros, porém, os entupimentos desta mangueira e, por vezes, da própria válvula, devido à alta densidade de polpa deste fluxo. Se o intervalo entre uma amostragem e outra é grande, o planejamento do trabalho torna-se importante também, neste caso, para garantir que estes pontos estejam em boas condições no momento da coleta. As válvulas instaladas nos distribuidores dos ciclones primários do Concentrador I possuem 2" de diâmetro; contudo, normalmente a coleta da amostra é feita sem a abertura total das válvulas, pois a vazão de polpa seria muito alta e dificultaria o manuseio do coletor. Este fato também contribui para o entupimento do 
mangote, além de diminuir a probabilidade de coleta de todo o fluxo, tal como recomenda a literatura. Por outro lado, o distribuidor pressurizado permite boa homogeneização da polpa amostrada, vindo de encontro às dificuldades aqui discutidas.

\subsubsection{Levantamento de parâmetros operacionais do circuito}

Durante o período de amostragem é importante o registro de informações sobre a operação do circuito estudado. Estas informações auxiliam na análise dos dados de amostragem, fornecem bases para a determinação de erros e completam o entendimento de como se encontrava a operação do circuito no momento da amostragem. O cuidado no registro destas informações é, portanto, tão importante quanto a observação de procedimentos para a tomada de amostras. O desafio, neste momento, é garantir que os instrumentos de campo estejam em funcionamento e bem calibrados. Dada a dificuldade desta tarefa, sempre que possível, é interessante o registro redundante de dados, mediante a verificação de informações. O conhecimento das instalações e, em consequência, das fontes de dados mais confiáveis, é também de grande auxílio. Nos circuitos de moagem primária de Germano, por exemplo, o registro da vazão mássica de alimentação nova do circuito é complicado. A calibração das balanças instaladas nas correias transportadoras de minério britado é "duvidosa", a despeito dos esforços dos técnicos instrumentistas. Por este motivo, esta vazão foi calculada a partir da vazão volumétrica, medida a partir dos medidores de vazão instalados na alimentação do circuito de deslamagem, para onde se destina o produto do circuito de moagem primária. Neste ponto, além dos medidores de vazão, também estão instalados medidores de densidade, permitindo o controle da vazão mássica deste fluxo. Em contrapartida, foram registrados os comprimentos de correia dos quais as amostras da alimentação nova foram retiradas. A vazão mássica foi, novamente, calculada a partir da velocidade dos transportadores e da massa da amostra global coletada.

A calibração dos instrumentos dos ciclones primários do Concentrador I é realizada com frequência. Medidores de vazão e densidade de polpa, por exemplo, 
são aferidos semanalmente pela equipe do Laboratório de Controle de Processos (LCP) de Germano.

\subsubsection{Amostradores utilizados}

O cuidado com os amostradores é um fator decisivo para a diminuição dos erros de amostragem. Além de cuidados com a forma dos recipientes, a literatura é incisiva quanto ao cuidado com a abertura adequada à granulometria do material amostrado. Contudo, aberturas demasiadamente largas podem levar a perdas de material, caso o fluxo amostrado seja muito intenso, ou a contaminações. Por vezes, estes fatores impedem que as normas para amostradores sejam respeitadas. É relevante a análise do ambiente a ser amostrado e, nestes casos, a experiência de campo se torna considerável.

A Tabela 5.1 compara a abertura dos amostradores utilizados para a coleta de amostras analisadas neste trabalho, com o máximo diâmetro médio para cada fluxo. Nota-se que nem sempre foram respeitadas as normas supracitadas, pelas razões já discutidas.

Tabela 5.1 - Abertura dos amostradores utilizados.

\begin{tabular}{|c|c|c|c|c|c|}
\hline Tipo & $\begin{array}{c}\text { Abertura } \\
(\mathrm{mm})\end{array}$ & $\begin{array}{c}\text { Amostra } \\
\text { coletada }\end{array}$ & $\begin{array}{c}\text { Diâmetro } \\
\text { máximo de } \\
\text { partícula }(\mathrm{mm})\end{array}$ & $\begin{array}{c}\text { Abertura } \\
\text { recomendada } \\
\text { pela ABNT } \\
(\mathrm{mm})\end{array}$ & $\begin{array}{c}\text { Abertura } \\
\text { recomendada } \\
\text { por Pitard }\end{array}$ \\
$(\mathrm{mm})$
\end{tabular}




\subsection{AMOSTRAGENS REALIZADAS NO CIRCUITO DE MOAGEM DO CONCENTRADOR I}

Para efeito deste trabalho, uma série de amostragens foi realizada no circuito industrial de pré-moagem/moagem primária do Concentrador I de Germano, em duas condições distintas e consecutivas:

- coleta de dados relativos à operação sob o circuito direto: nas ocasiões de parada programada de um dos pré-moinhos para manutenção;

- coleta de dados relativos à operação sob o circuito inverso: realizadas após a posta em marcha do pré-moinho que se encontrava em manutenção.

Cabe ressaltar que, em ambos os casos, foi observado um período mínimo de uma hora entre a entrada em operação do circuito e a tomada das amostras, para garantir que o circuito estivesse em regime sob a condição amostrada.

Em todas as amostragens, as amostras de polpa foram tomadas durante 0 período de uma hora, sendo cada amostra global constituída de incrementos tomados a cada 10 minutos. As amostras de correia foram coletadas em uma única vez, mediante a parada do equipamento e retirada de todo material sobre um comprimento de correia pré-determinado.

A Figura 5.5 e a Figura 5.6 mostram os pontos de tomada de amostras, para ambos as condições descritas acima.

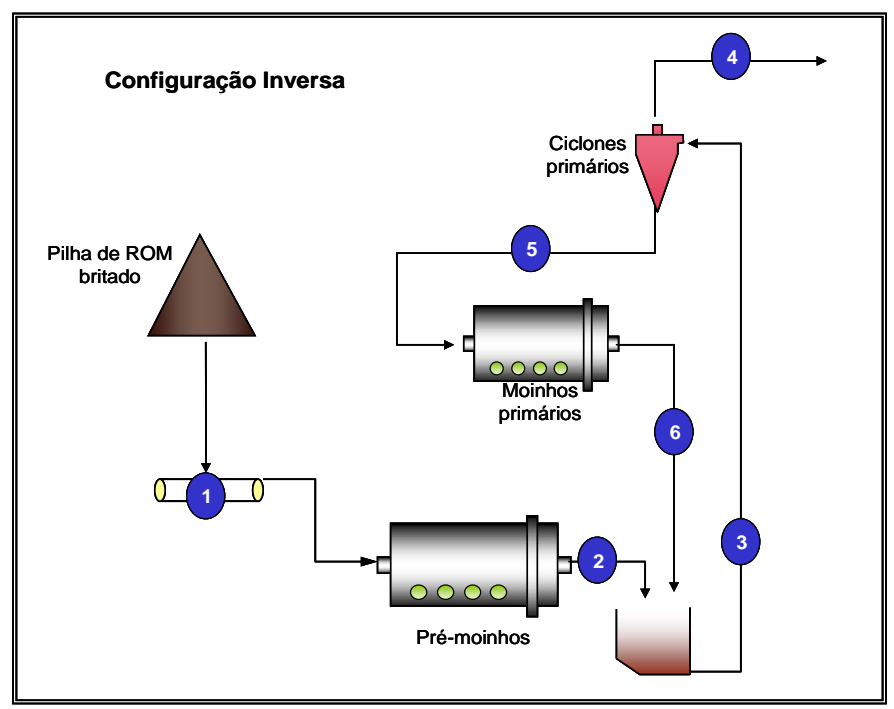

Figura 5.5 - Pontos de amostragem no circuito industrial para a configuração inversa. 


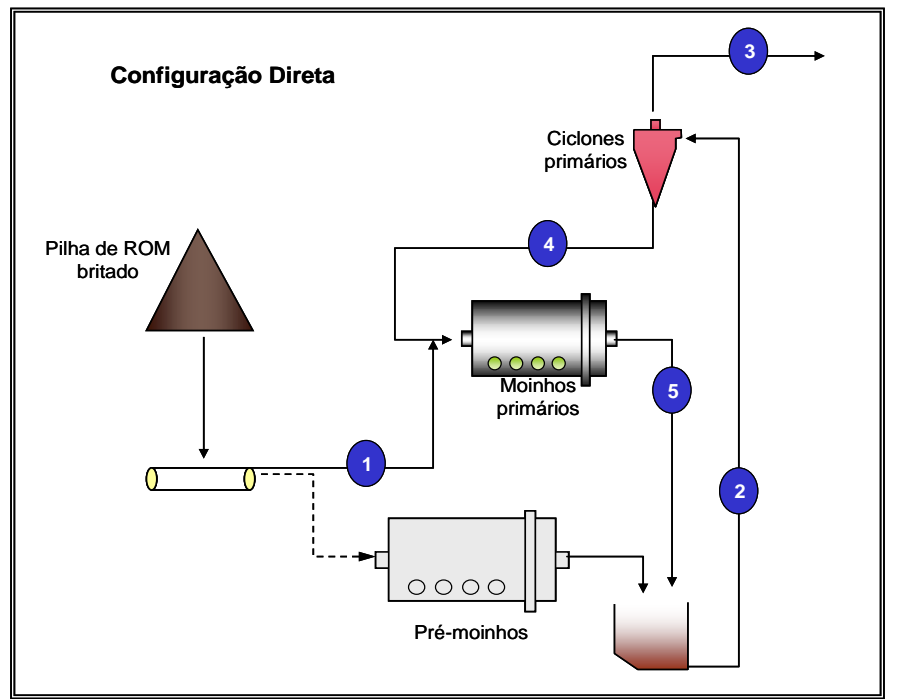

Figura 5.6 - Pontos de amostragem no circuito industrial para a configuração direta.

Conforme mostram a Figura 5.5 e a Figura 5.6 foram amostrados, em cada caso: Configuração inversa:

1 - alimentação nova do circuito (amostras retiradas nas correias de alimentação dos moinhos);

2 - descarga do pré-moinho;

3 - alimentação da etapa de classificação (ciclones primários);

4 - produto final do circuito (overflow dos ciclones primários);

5 - carga circulante dos moinhos primários (underflow dos ciclones primários);

6 - descarga dos moinhos primários.

Configuração direta:

1 - alimentação nova do circuito (amostras retiradas nas correias de alimentação dos moinhos);

2 - alimentação da etapa de classificação (ciclones primários);

3 - produto final do circuito (overflow dos ciclones primários);

4 - carga circulante dos moinhos primários (underflow dos ciclones primários);

5 - descarga dos moinhos primários.

As amostras correspondentes ao underflow dos ciclones primários foram obtidas por incrementos tomados em cada ciclone pertencente à bateria amostrada. As amostras correspondentes ao overflow, por sua vez, foram tomadas na bacia de coleta do fluxo de todos os respectivos ciclones.

Durante a tomada das amostras, os seguintes dados industriais foram registrados a partir do sistema de controle da planta: 
- energia no motor dos moinhos (kWh); a correção para a potência aplicada no eixo pinhão foi calculada utilizando-se o fator de $6 \%$ de perdas entre motor e engrenagem;

- pressão de operação dos ciclones (psi);

- vazão mássica do produto, em cada linha de operação (t/h), assumidas como iguais às vazões da alimentação nova do circuito: obtida a partir dos medidores de vazão (vazão volumétrica) e densímetros, instalados no overflow dos ciclones primários; o cálculo para as vazões mássicas são efetuados e disponibilizados pelo sistema de controle da planta; conforme já mencionado, os instrumentos instalados nestes pontos (medidores de fluxo e densímetros) são calibrados semanalmente, já que seus dados são utilizados para o fechamento do balanço de massas do Concentrador I.

Para todas as amostras coletadas foram realizadas análises de percentagem de sólidos em massa (amostras em polpa), umidade (amostras de minério granulado) e granulométrica. Todas as análises foram realizadas no Laboratório de Controle de Processos - LCP, na Unidade de Germano, em Mariana - MG. Os procedimentos utilizados seguiram os mesmos padrões estabelecidos para as análises rotineiras da empresa, pois, desta forma, seria possível sua comparação direta com os dados históricos dos Concentradores I e II.

O procedimento para as análises granulométricas consistiu em:

a) deslamagem: toda a amostra é deslamada (lavagem manual) em peneira com malha de 0,044 mm (325 \#, série Tyler);

b) peneiramento da fração acima de $0,044 \mathrm{~mm}$ : esta fração da amostra é filtrada, secada em estufa e peneirada a seco, por um período de 20 minutos, em peneirador do tipo vibratório.

c) análise da fração abaixo de 0,044 mm: esta fração é analisada com um granulômetro a laser - modelo Malvern MSS.

O peneiramento a seco da fração acima de $0,044 \mathrm{~mm}$ é o procedimento padrão do LCP, conforme já discutido. Como a amostra é deslamada previamente ao peneiramento, há boa correlação entre os resultados obtidos por este procedimento com os resultados obtidos por peneiramento a úmido. Historicamente, os desvios encontrados são inferiores a $2 \%$. Para exemplificar esta correlação, o Apêndice B mostra uma comparação entre peneiramento a úmido, realizado no laboratório físico de Germano e o procedimento adotado pelo LCP, para uma mesma amostra. 
O procedimento para análise da percentagem de sólidos consistiu:

a) Homogeneização da polpa por agitação manual;

b) Pesagem de proveta graduada;

c) Preenchimento da mesma proveta com a amostra homogeneizada;

d) Pesagem da proveta com a polpa;

e) Cálculo da massa de polpa na proveta por meio da equação:

$$
M_{\text {polpa }}=M_{\text {provetachéa }}-M_{\text {provetavaia }}
$$

f) Secagem da amostra contida na proveta em estufa;

g) Pesagem da amostra seca;

h) Cálculo da percentagem de sólidos da amostra, por meio da equação:

$$
\% \text { sólidos }=\frac{\text { Mamostrasec } a}{\text { Mamostrapopa }}
$$

O procedimento para análise de umidade consistiu:

a) Pesagem da amostra global;

b) Secagem da amostra em estufa;

c) Pesagem da amostra seca;

d) Cálculo da umidade da amostra, por meio da equação:

$$
\text { \%umidade }=\frac{\text { Mamostrasec } a}{\text { Mamostrapopa }}
$$

A Figura 5.7 mostra o fluxograma adotado para as análises das amostras coletadas no circuito industrial: 


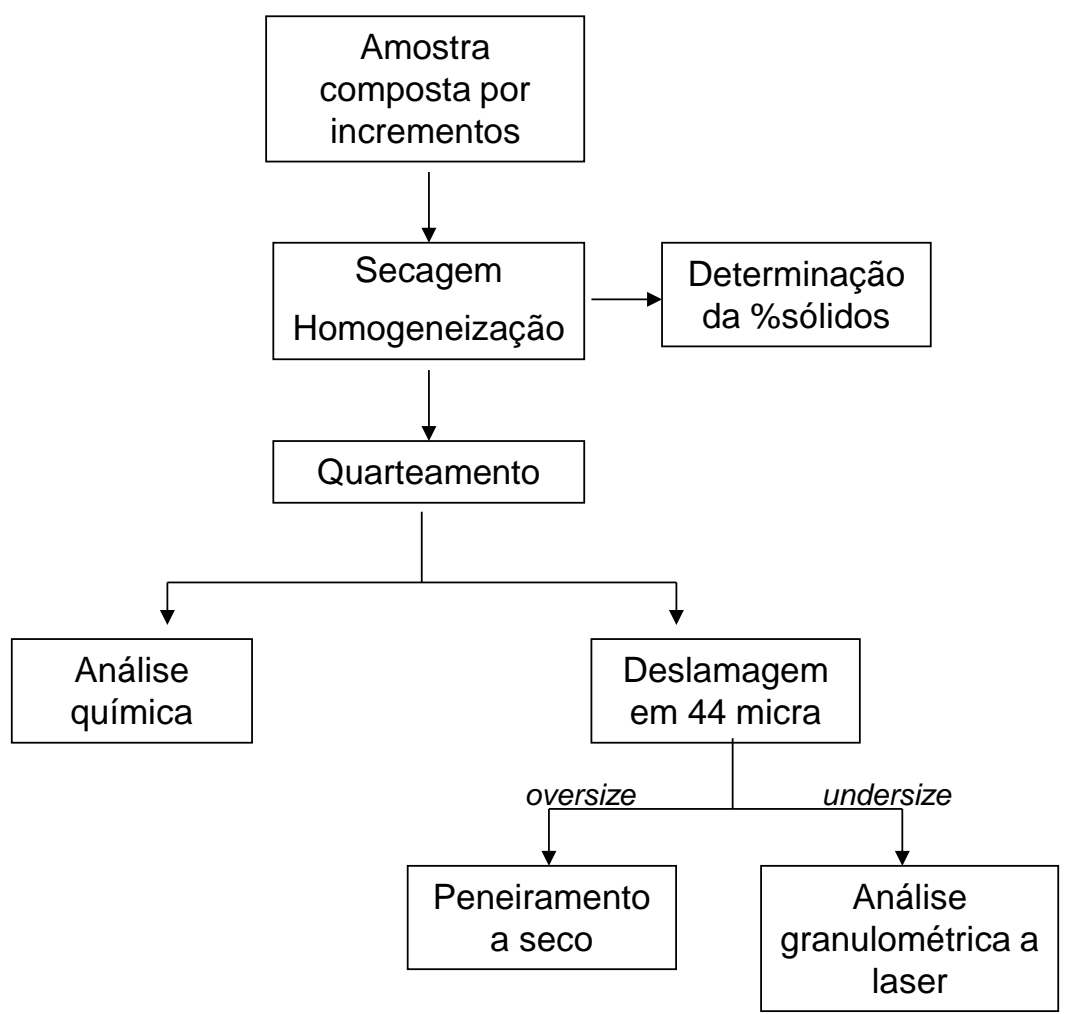

Figura 5.7 - Fluxograma para tratamento das amostras coletadas em circuito industrial.

As amostras oriundas de transportadores de correia foram homogeneizadas e quarteadas em pilhas alongadas. As amostras em polpa foram homogeneizadas por agitação manual e divididas com o uso de um sifão.

Os dados referentes a cada amostragem estão disponíveis no Apêndice A.

\subsubsection{Cálculo dos parâmetros utilizados para análise dos circuitos industriais}

Os parâmetros escolhidos para a análise dos circuitos industriais amostrados no Concentrador I foram os seguintes:

- Work Index operacional $\left(\mathrm{Wi}_{\mathrm{o}}\right)$, ou seja, o Work Index, proposto pela "Terceira Lei" de Bond, calculado a partir dos dados industriais;

- Consumo específico pela percentagem de material gerado na malha de controle, "kWh/t-100\#".

O Work Index operacional $\left(\mathrm{Wi}_{\circ}\right)$ foi calculado segundo a equação: 


$$
\text { Wio }=\frac{W \times \sqrt{F} \times \sqrt{P}}{10 \times 1,102 \times(\sqrt{F}-\sqrt{P})}
$$

onde:

W: consumo específico de energia $(\mathrm{kWh} / \mathrm{st})$ do circuito, calculado a partir da energia no eixo pinhão do moinho e na vazão de sólidos da alimentação do circuito;

F: malha em que passam $80 \%$ da alimentação nova $(\mu \mathrm{m})$;

P: malha em que passam $80 \%$ do produto final do circuito $(\mu \mathrm{m})$.

Quando pertinentes, os fatores de correção expostos no capítulo 3.2.3 foram aplicados.

Por sua vez, o parâmetro denominado "kWh/t_-100\#" é calculado a partir da equação:

$$
\mathrm{kWh} / \mathrm{t}-100 \#=\frac{W}{(\% P-\% F)}
$$

onde:

\%P: percentagem passante em 0,149 mm (100 \#, série Tyler) no produto final do circuito;

\%F: percentagem passante em 0,149 mm na alimentação nova.

\subsection{ENSAIOS DE MOAGEM}

Os ensaios de moagem em laboratório buscaram simular as condições industriais relativas às configurações direta e inversa.

O procedimento dos ensaios foi o mesmo descrito no capítulo 3.5, uma vez que ele é realizado rotineiramente em Germano, com uma amostra composta mensal da alimentação dos concentradores, para avaliação dos circuitos industriais. A Figura 5.8 mostra a relação entre os dados industriais e os resultados destes ensaios para os anos de 2010 e 2011. 


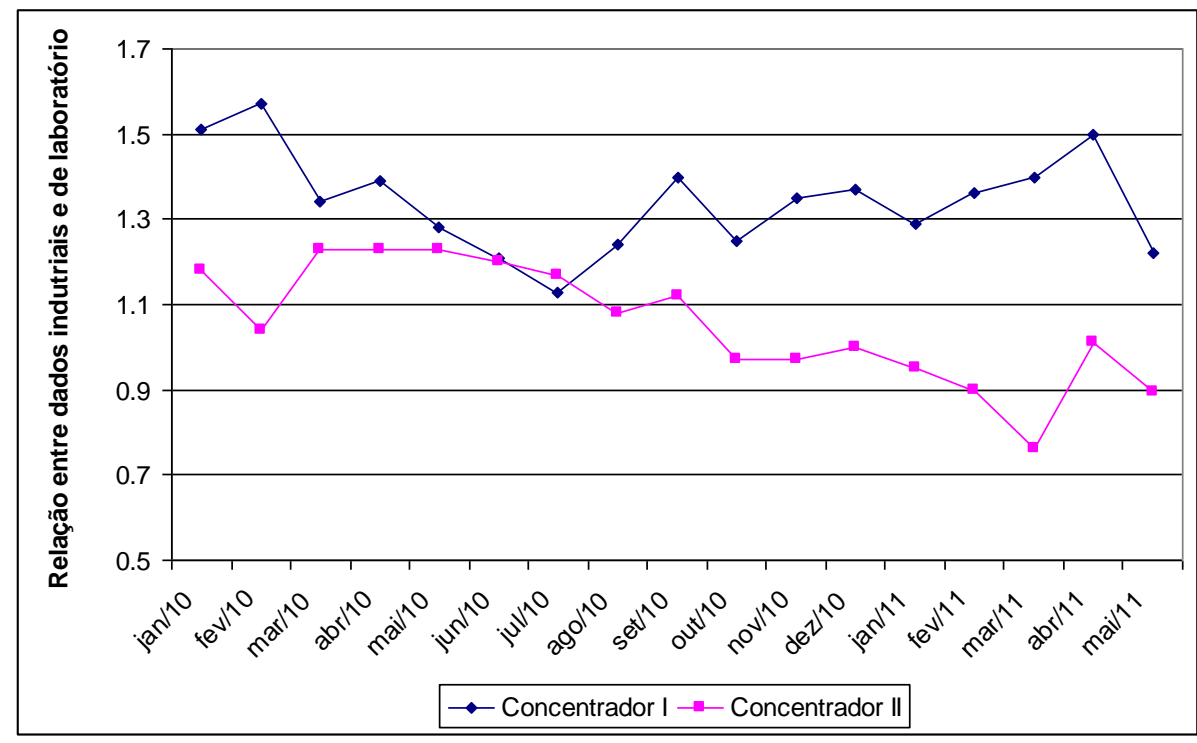

Figura 5.8 - Relação entre dados de moagem industriais e de laboratório.

Tal como mencionado anteriormente, os resultados dos ensaios de moagem são comparados com os dados industriais, para cada concentrador. Razões acima de 1 alertam para possíveis deficiências no circuito industrial enquanto razões abaixo de 1 sinalizam operação eficiente do circuito. Nota-se que o circuito de moagem do Concentrador I tem mostrado um consumo energético consistentemente superior ao previsto em laboratório, o que alerta para possíveis problemas, mas também reflete a condição operacional deste concentrador, cuja capacidade está no limite. Atualmente, está em andamento uma investigação para identificar possíveis pontos de melhoria nos circuitos de moagem primária e secundária do Concentrador I. Por outro lado, a eficiência do circuito de moagem do Concentrador II aumenta gradativamente, como mostra a Figura 5.8, razão pela qual este circuito foi tomado por referência, nos ensaios de moagem deste trabalho. Cabe ressaltar que os pontos da curva apresentada na Figura 5.8, referentes aos meses de junho e julho de 2010, quando a eficiência observada no Concentrador II foi inferior ao constatado no Concentrador I, se devem às grandes restrições de produção causadas por problemas apresentados nos revestimentos dos moinhos do Concentrador II.

Neste trabalho, foram realizados ensaios com uma amostra composta por incrementos diários coletados nas correias de alimentação dos circuitos de moagem primária do Concentrador II, sob duas diferentes condições:

- moagem da amostra "padrão" (apenas britada, conforme procedimento); 
- moagem da fração maior que $0,210 \mathrm{~mm}$ (65\#, série Tyler), ou seja, excluindose os finos da alimentação nova do moinho.

A malha de $0,210 \mathrm{~mm}$ foi escolhida por ser a abertura imediatamente superior à malha de controle do circuito industrial $(0,149 \mathrm{~mm})$, na série Tyler de peneiras - a qual é utilizada nas análises granulométricas dos laboratórios de Germano. Conforme mencionado anteriormente, os ensaios buscaram simular as condições dos circuitos industriais. Peneirando-se a amostra em 0,210 mm, obteve-se, no undersize da peneira, um material cuja percentagem passante em 0,149 mm é semelhante ao observado no produto do circuito industrial do Concentrador II, ou seja, próximo a $90 \%$. Os resultados comprobatórios da metodologia aqui descrita foram apresentados na Figura 6.1, da seção 6.2.

A Figura 5.9 mostra o fluxograma para a preparação de amostra e execução dos ensaios de moagem:

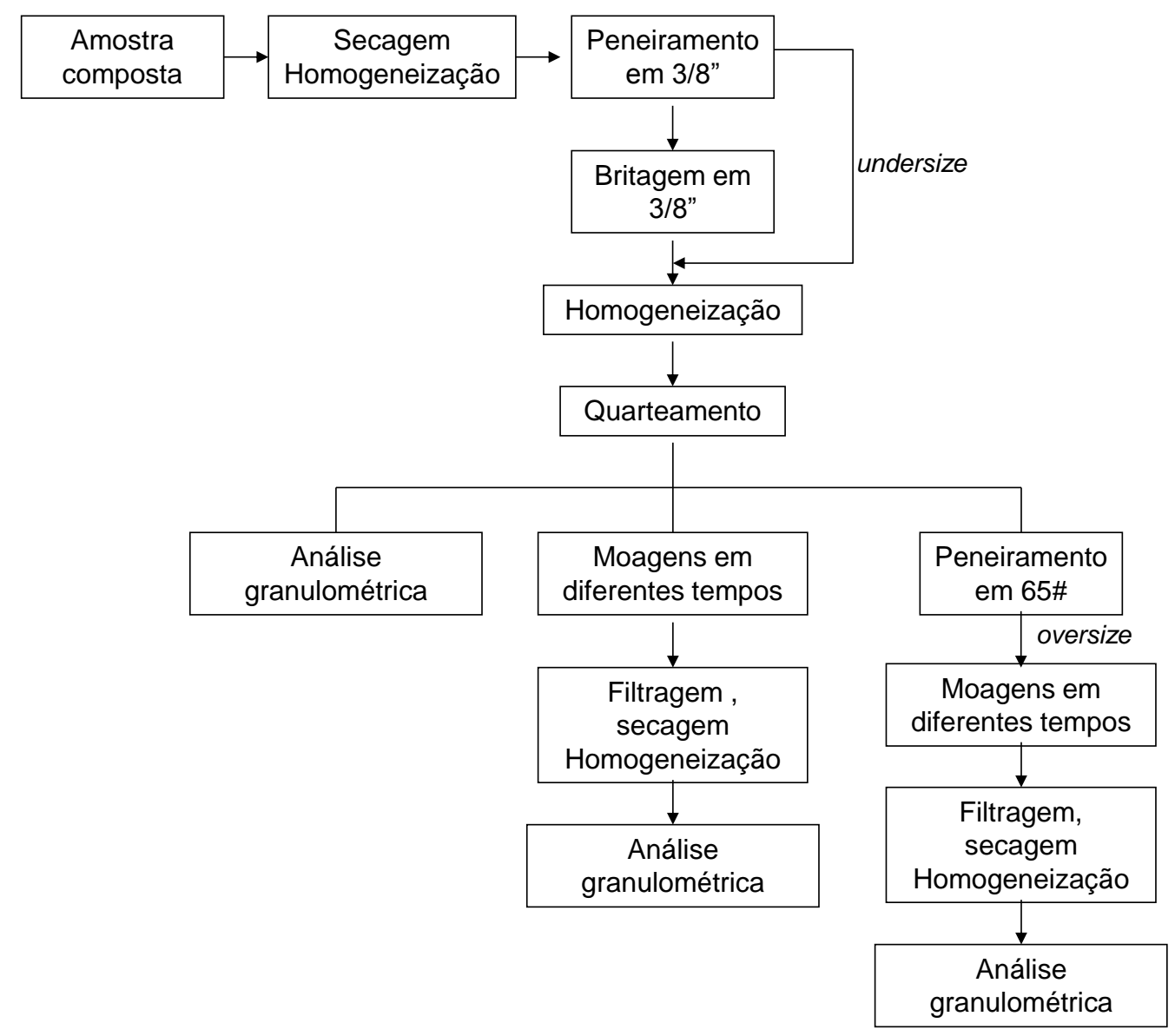

Figura 5.9 - Fluxograma das etapas de preparação de amostras e execução dos ensaios de moagem. 


\section{RESULTADOS}

\subsection{AMOSTRAGENS NO CIRCUITO INDUSTRIAL}

\subsubsection{Consumo de energia}

A Tabela 6.1 resume os resultados obtidos a partir das amostragens industriais, realizadas no circuito industrial de moagem primária do Concentrador I.

Tabela 6.1 - Resultados das amostragens em circuito industrial.

\begin{tabular}{|c|c|c|c|c|c|c|c|c|c|c|}
\hline & \multirow{2}{*}{$\begin{array}{l}\text { Amostragem } \\
\text { Linha de produção }\end{array}$} & \multirow{2}{*}{$\begin{array}{l}1 \\
1\end{array}$} & \multicolumn{2}{|c|}{2} & \multicolumn{2}{|c|}{3} & \multicolumn{2}{|c|}{4} & \multicolumn{2}{|c|}{5} \\
\hline & & & 1 & 2 & 3 & 4 & 3 & 4 & 1 & 2 \\
\hline \multirow{7}{*}{$\begin{array}{l}\text { Circuito } \\
\text { direto }\end{array}$} & $\mathrm{F} 80(\mu \mathrm{m})$ & 4368 & 3870 & 3870 & 3453 & 3525 & 2498 & 2979 & 4652 & 4763 \\
\hline & $\mathrm{P} 80(\mu \mathrm{m})$ & 117 & 91 & 87 & 108 & 105 & 90 & 97 & 125 & 132 \\
\hline & Razão de redução & 37 & 42 & 44 & 32 & 34 & 28 & 31 & 37 & 36 \\
\hline & $\begin{array}{l}\text { Work Index } \\
\text { operacional sem } \\
\text { fatores (kWh/st) }\end{array}$ & 4,1 & 3,7 & 3,6 & 4,0 & 3,9 & 3,9 & 3,9 & 4,1 & 3,9 \\
\hline & $\begin{array}{l}\text { Work Index } \\
\text { operacional com } \\
\text { fatores (kWh/st) }\end{array}$ & 4,5 & 4,2 & 4,0 & 4,5 & 4,4 & 4,4 & 4,4 & 4,6 & 4,4 \\
\hline & $\mathrm{kWh} / \mathrm{t}<100 \#$ & 9,3 & 8,3 & 8,2 & 8,7 & 8,3 & 10,5 & 10,3 & 8,5 & 8,5 \\
\hline & $\begin{array}{l}\% \text { - 0,149 } \mathrm{mm} \text { na } \\
\text { descarga do moinho } \\
\text { primário }\end{array}$ & 48,8 & 43,9 & 56,5 & 51,7 & 44,5 & 50,0 & 50,7 & 46,4 & 50,5 \\
\hline \multirow{8}{*}{$\begin{array}{l}\text { Circuito } \\
\text { inverso }\end{array}$} & $\mathrm{F} 80(\mu \mathrm{m})$ & 281 & 200 & 200 & 431 & 431 & 255 & 255 & 287 & 287 \\
\hline & $\mathrm{P} 80(\mu \mathrm{m})$ & 132 & 113 & 121 & 115 & 123 & 115 & 113 & 140 & 142 \\
\hline & Razão de redução & 2,1 & 1,8 & 1,6 & 3,8 & 3,5 & 2,2 & 2,3 & 2,0 & 2,0 \\
\hline & $\begin{array}{l}\text { Work Index } \\
\text { operacional sem } \\
\text { fatores }(\mathrm{kWh} / \mathrm{st})\end{array}$ & 5,9 & 6,5 & 7,2 & 2,9 & 3,5 & 4,8 & 5,2 & 5,3 & 5,6 \\
\hline & $\begin{array}{l}\text { Work Index } \\
\text { operacional com } \\
\text { fatores (kWh/st) }\end{array}$ & 5,6 & 5,6 & 5,6 & 3,1 & 3,7 & 4,7 & 5,1 & 4,9 & 5,2 \\
\hline & $\begin{array}{l}\text { Work Index } \\
\text { operacional ajustado } \\
\text { (kWh/st) }\end{array}$ & 3,3 & 3,0 & 2,9 & 2,3 & 2,8 & 2,9 & 3,1 & 2,8 & 2,9 \\
\hline & $\mathrm{kWh} / \mathrm{t}<100 \#$ & 10,7 & 10,1 & 11,1 & 5,8 & 7,2 & 8,4 & 9,1 & 8,4 & 9,0 \\
\hline & $\begin{array}{l}\% \text { - 0,149 } \mathrm{mm} \text { na } \\
\text { descarga do moinho } \\
\text { primário }\end{array}$ & 59,4 & 40,5 & 39,5 & 40,6 & 45,6 & 46,8 & 46,5 & 35,8 & 40,0 \\
\hline
\end{tabular}


$\mathrm{Na}$ tabela anterior, o termo "Work Index operacional com fatores" refere-se aos valores industriais corrigidos a partir dos fatores propostos por Bond-Rowland, conforme exposto na seção 3.2.3. Nos dados aqui apresentados, apenas os fatores EF3, referente ao diâmetro do moinho, e EF7, referente à razão de redução para moinhos de bolas, foram aplicáveis. O termo "Work Index operacional ajustado" refere-se aos dados industriais ajustados pelo fator proposto por Bond para alimentações escalpadas, conforme descrito na seção 3.3.3.

\subsubsection{Geração de lamas}

No circuito de moagem primária de Germano, as lamas são identificadas como as partículas abaixo de $10 \mu \mathrm{m}$. A Tabela 6.2 mostra os percentuais abaixo desta granulometria para as amostras das descargas dos moinhos primários e do overflow dos ciclones primários.

Tabela 6.2 - Percentual de lamas obtido nas amostragens.

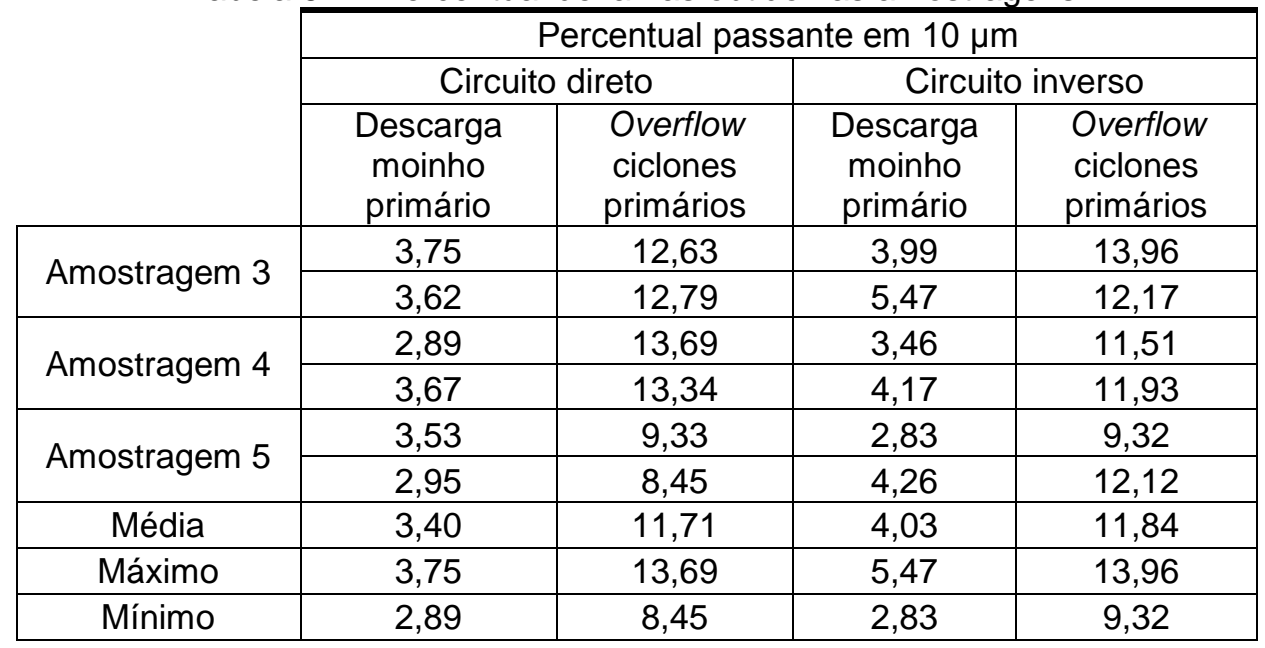

\subsection{Ensaios de moagem em laboratório}


A Figura 6.1 mostra as distribuições granulométricas da amostra obtida na alimentação do circuito de moagem primária do Concentrador II, para as seguintes condições:

- alimentação do concentrador, proveniente da pilha de minério britado (britada a - 9,52 mm, segundo a metodologia do ensaio);

- frações maior e menor que $0,210 \mathrm{~mm}$, conforme procedimento exposto no capítulo 5.4 .

A Figura 6.2 mostra o gráfico com as curvas de cinética de moagem, para as mesmas amostras. Os dados completos sobre os ensaios de moagem estão apresentados no Apêndice B.

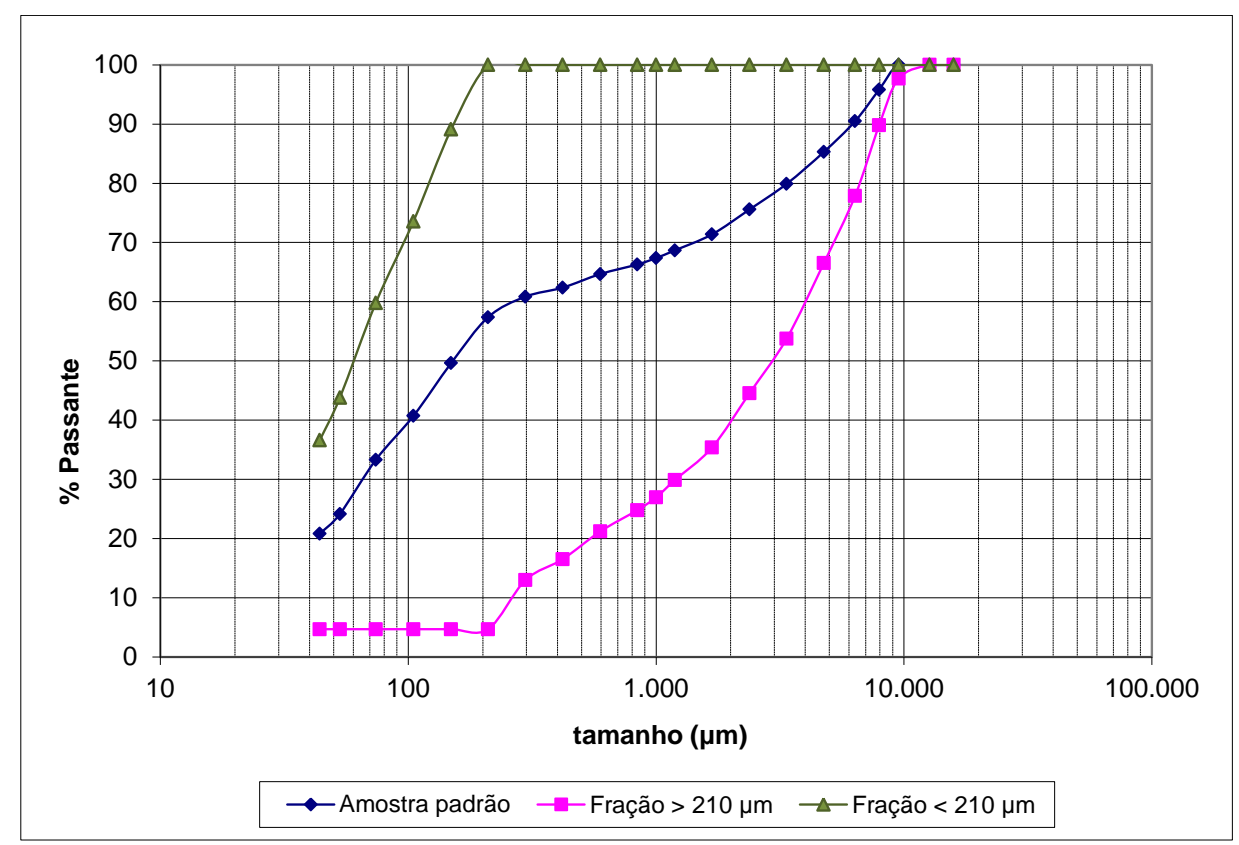

Figura 6.1 - Distribuições granulométricas para as alimentações dos ensaios de moagem. 


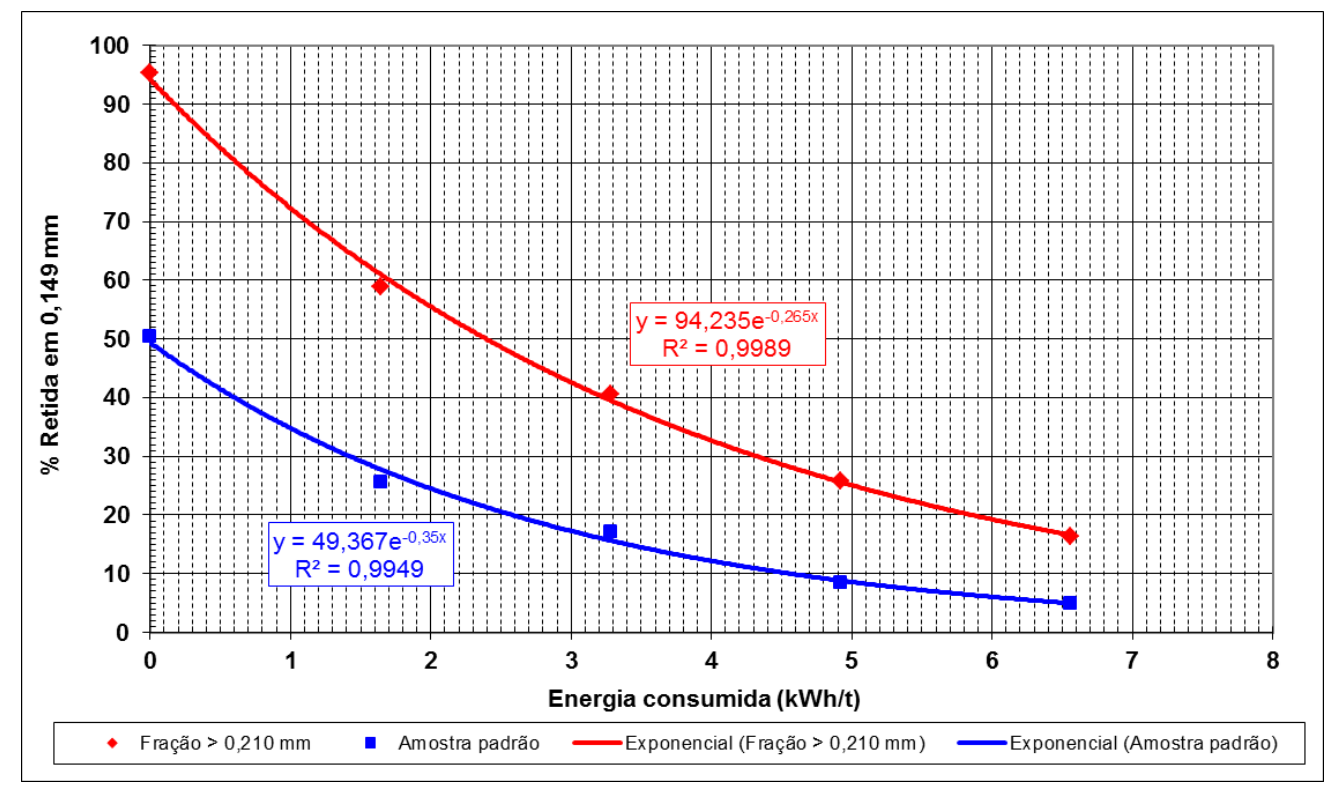

Figura 6.2 - Resultados dos ensaios de moagem.

Conforme a Figura 6.1, a amostra padrão possui 49,6\% de material passante em $0,149 \mathrm{~mm}$; o oversize da mesma amostra peneirada em $0,210 \mathrm{~mm}$ possui $4,7 \%$ passante em 0,149 $\mathrm{mm}$ e o undersize $89 \%$. Nota-se, ainda, que a amostra padrão possui $57,4 \%$ de material passante em 0,210 $\mathrm{mm}$.

Estes dados confirmam a metodologia apresentada na seção 5.4 quanto à malha escolhida para o peneiramento da amostra padrão. $O$ peneiramento da amostra em $0,210 \mathrm{~mm}$ gerou uma fração fina cuja percentagem passante em 0,149 $\mathrm{mm}$ (89\%) é semelhante ao produto do circuito industrial (90\%).

Por outro lado a Figura 6.2 mostra que:

- são necessários 4,4 kWh/t para moer a amostra padrão até que se obtenha um produto com $11 \%$ retido em $0,149 \mathrm{~mm}$ (89\% passante, tal como o undersize da amostra peneirada);

- são necessários 8,0 kWh/t para moer a fração + 0,210 mm da amostra até a mesma especificação. 


\section{DISCUSSÕES}

\subsection{ANÁLISE DOS DADOS INDUSTRIAIS}

\subsubsection{Consumo de energia}

Nota-se pela Tabela 6.1 que, além do Work Index operacional, índice cuja aplicação é frequente em um grande número de operações, foi também utilizado o parâmetro "kWh/t_-100\#", ou seja, a energia consumida por tonelada de material abaixo da malha de controle.

Há uma dificuldade ao se comparar as configurações de circuito direto e inverso, para os moinhos primários do Concentrador I, em razão da diferença entre as granulometrias de alimentação para ambos os casos:

- quando os moinhos operam sob a configuração inversa, a alimentação nova do circuito consiste na descarga dos pré-moinhos, com $\mathrm{P}_{80}$ aproximado de $0,350 \mathrm{~mm}$;

- quando os moinhos operam sob a configuração direta, são alimentados por material da pilha de ROM britado, com $\mathrm{P}_{80}$ aproximado de $3,5 \mathrm{~mm}$.

O parâmetro $\mathrm{P}_{80}$, contudo, traz poucas informações sobre a natureza do minério tratado no circuito. Particularmente, o ROM Samarco tem uma grande quantidade de finos naturais, fator importante quando se avalia os benefícios da retirada das frações menores que a malha de controle da alimentação do moinho.

Em uma primeira análise, a vantagem do circuito inverso sobre o direto consiste em retirar do moinho, a parcela da alimentação nova composta por partículas "prontas", ou seja, dentro da especificação para o produto do circuito, evitando-se assim, consumo de energia desnecessário e a sobremoagem. Sob tal enfoque, não importa o quão diferentes sejam os $\mathrm{F}_{80}$ de ambos os circuitos industriais estudados, desde que se avalie a quantidade efetiva de finos gerada por energia aplicada, para cada caso.

Em outras palavras, considerou-se necessário avaliar se a energia aplicada em cada circuito de moagem foi empregada na quebra das frações mais grosseiras que a malha de controle do circuito ou "desperdiçada" nas frações de "finos". Este é o conceito do parâmetro "kWh/t_-100\#", razão pela qual ele foi utilizado neste trabalho. 
Conforme mostrado na Tabela 6.1, o Work Index operacional foi calculado, em cada amostragem, em três etapas:

1. Work Index operacional sem fatores $\left(\mathrm{Wi}_{\mathrm{o}}\right)$ : aplicando-se, para os dados operacionais, a equação de Bond:

$$
\text { Wio }=\frac{W \times \sqrt{F} \times \sqrt{P}}{10 \times 1,102 \times(\sqrt{F}-\sqrt{P})}
$$

2. Work Index operacional com fatores: Wi operacional calculado pela equação anterior, aplicando-se os fatores de correção propostos por Bond-Rowland.

Para os circuitos industriais amostrados, apenas os fatores referentes ao diâmetro do moinho - EF3 - e à relação de redução para moinhos de bolas - EF7 - são aplicáveis. Conforme explicado no item 3.2.3, o fator EF7 é aplicado quando a razão de redução for inferior a 6 . Em todas as amostragens, a razão de redução foi superior a 6 nos períodos de operação sob a configuração direta. Deste modo, 0 fator de correção EF7 só foi aplicado para os dados referentes à configuração inversa.

Exemplo:

Amostragem 1 - Linha 1:

Circuito direto:

- $\mathrm{F}_{80}=4368 \mu \mathrm{m}$;

- $\mathrm{P}_{80}=117 \mu \mathrm{m}$;

- Razão de redução $=4368 / 117=37,3$

- Energia específica consumida: 3,46 kWh/t;

$$
W i_{o}=\frac{3,46 \times(\sqrt{117}) \times(\sqrt{4368})}{1,102 \times 10 \times(\sqrt{4368}-\sqrt{117})}=4,06 \mathrm{kWh} / \mathrm{st} .
$$

Fatores de correção EF1 e EF2 - não e aplicam;

Fator de correção EF3 $=\left(\frac{2,44}{4,27}\right)^{0,2}=0,89$

Fator de correção EF4:

Fo $=4000 \times \sqrt{\frac{13}{5,7}}=6026 \mu \mathrm{m}$.

Como $F o>F_{80}$, o fator EF4 não é aplicável. 
Fatores de correção EF5, EF6, EF7 e EF8 - não se aplicam.

$$
W i_{o}=\frac{4,06}{0,89}=4,54 \mathrm{kWh} / \mathrm{st} \text {. }
$$

Circuito inverso:

- $\mathrm{F}_{80}=281 \mu \mathrm{m}$;

- $\mathrm{P}_{80}=132 \mu \mathrm{m}$;

- Razão de redução = 281/132 = 2,12

- Energia específica consumida: 1,77 kWh/t;

$$
W i_{o}=\frac{1,77 \times(\sqrt{132}) \times(\sqrt{281})}{1,102 \times 10 \times(\sqrt{281}-\sqrt{132})}=5,90 \mathrm{kWh} / \mathrm{st} .
$$

Fatores de correção EF1 e EF2 - não e aplicam;

Fator de correção EF3 = 0,89;

Fatores de correção EF4, EF5, EF6, e EF8 - não se aplicam.

Fator de correção EF7 $=\frac{(2,12-1,22)}{(2,12-1,35)}=1,17$

$$
W i_{o}=\frac{5,90}{(1,17 * 0,89)}=5,64 \mathrm{kWh} / \mathrm{st} .
$$

3. Work Index operacional ajustado: os dados industriais relativos à operação em circuito inverso foram ajustados, aplicando-se o fator proposto por Bond ${ }^{20}$ para alimentações escalpadas. Para os mesmos dados relativos ao exemplo anterior, o Work Index ajustado, será:

- $\mathrm{F}_{80}(\mathrm{~F})=281 \mu \mathrm{m}$;

- $\mathrm{P}_{80}=132 \mu \mathrm{m}$;

- Energia específica consumida: $1,77 \mathrm{kWh} / \mathrm{t}$.

A classificação da alimentação nova é realizada, neste caso, nos ciclones primários. Deste modo, a malha em que a alimentação foi classificada corresponde à malha de corte dos ciclones, ou seja, ao $\mathrm{D}_{95}$ do overflow dos ciclones primários. Portanto, para este exemplo:

- $\mathrm{Fc}=248 \mu \mathrm{m}$; 
Deste modo: $\mathrm{Fe}=\frac{281}{\left(\frac{2-(248 / 281)^{1 / \sqrt{2}}}{2}\right)^{\sqrt{2}}}=668 \mu \mathrm{m}$.

E o Wi é obtido por:

$W i_{o}=\frac{1,77 \times(\sqrt{132}) \times(\sqrt{668})}{1,102 \times 10 \times(\sqrt{668}-\sqrt{132})}=3,33 \mathrm{kWh} / \mathrm{st}$.

A seguir, os resultados relativos a cada índice foram discutidos em maiores detalhes.

A Figura 7.1 mostra a comparação entre o Work Index operacional, sem fatores, $\left(\mathrm{Wi}_{\mathrm{o}}\right)$ para os dados relativos às configurações direta e inversa.

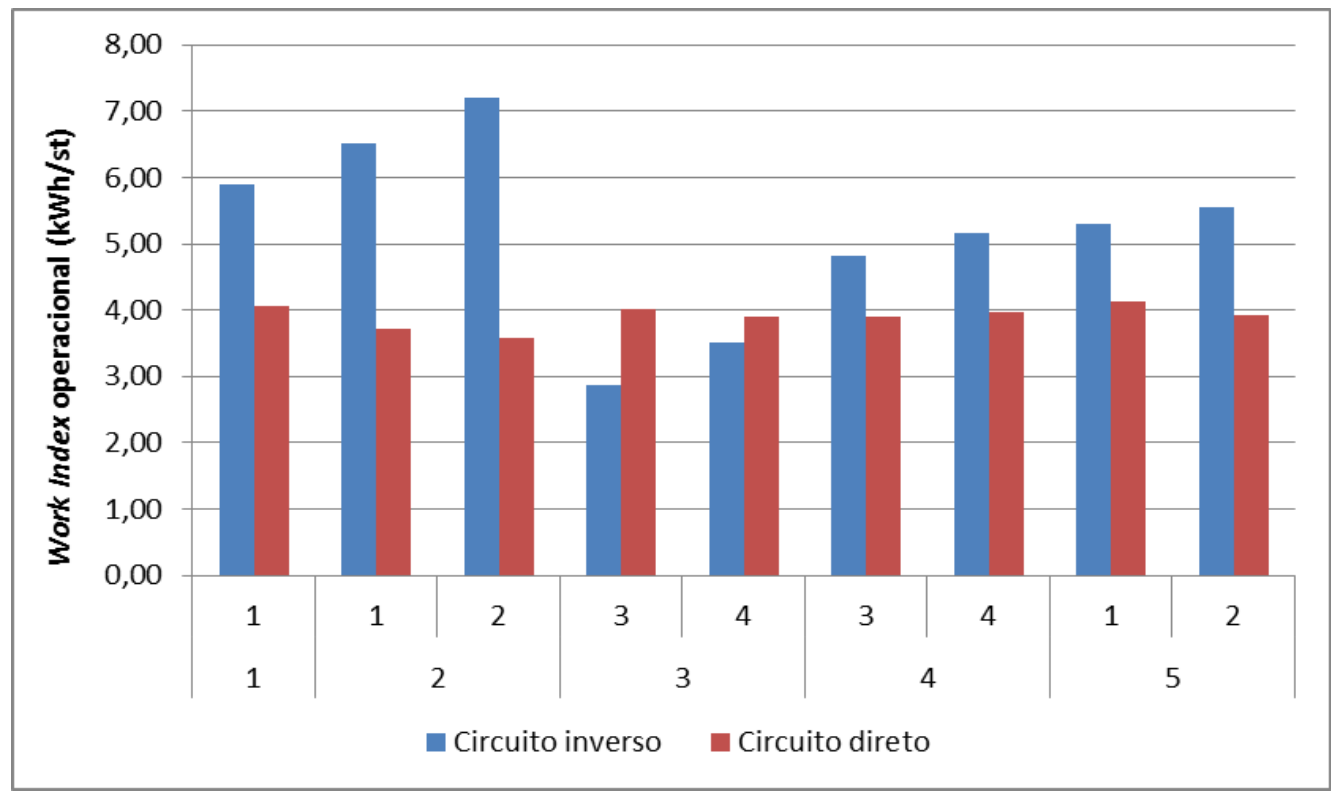

Figura 7.1 - Comparação entre Work Index operacional para os circuitos direto e inverso.

Nota-se que, à exceção dos dados relativos à terceira amostragem, o Work Index operacional para o circuito direto foi, em média, 30\% inferior ao circuito inverso.

É preciso observar, contudo, as diferenças para as operações sob cada configuração: tanto as granulometrias de alimentação quanto as razões de redução para o circuito direto, foram superiores às da operação sob o circuito inverso.

O consumo específico de energia na moagem tende a aumentar à medida que a granulometria de alimentação diminui. Bond ${ }^{13}$ observou que o Wi é alterado à medida que a malha do produto muda e atribui estas mudanças à heterogeneidade 
natural do minério. A curva de cinética de moagem oriunda do ensaio proposto por Donda $^{22}$ demonstra este fato:

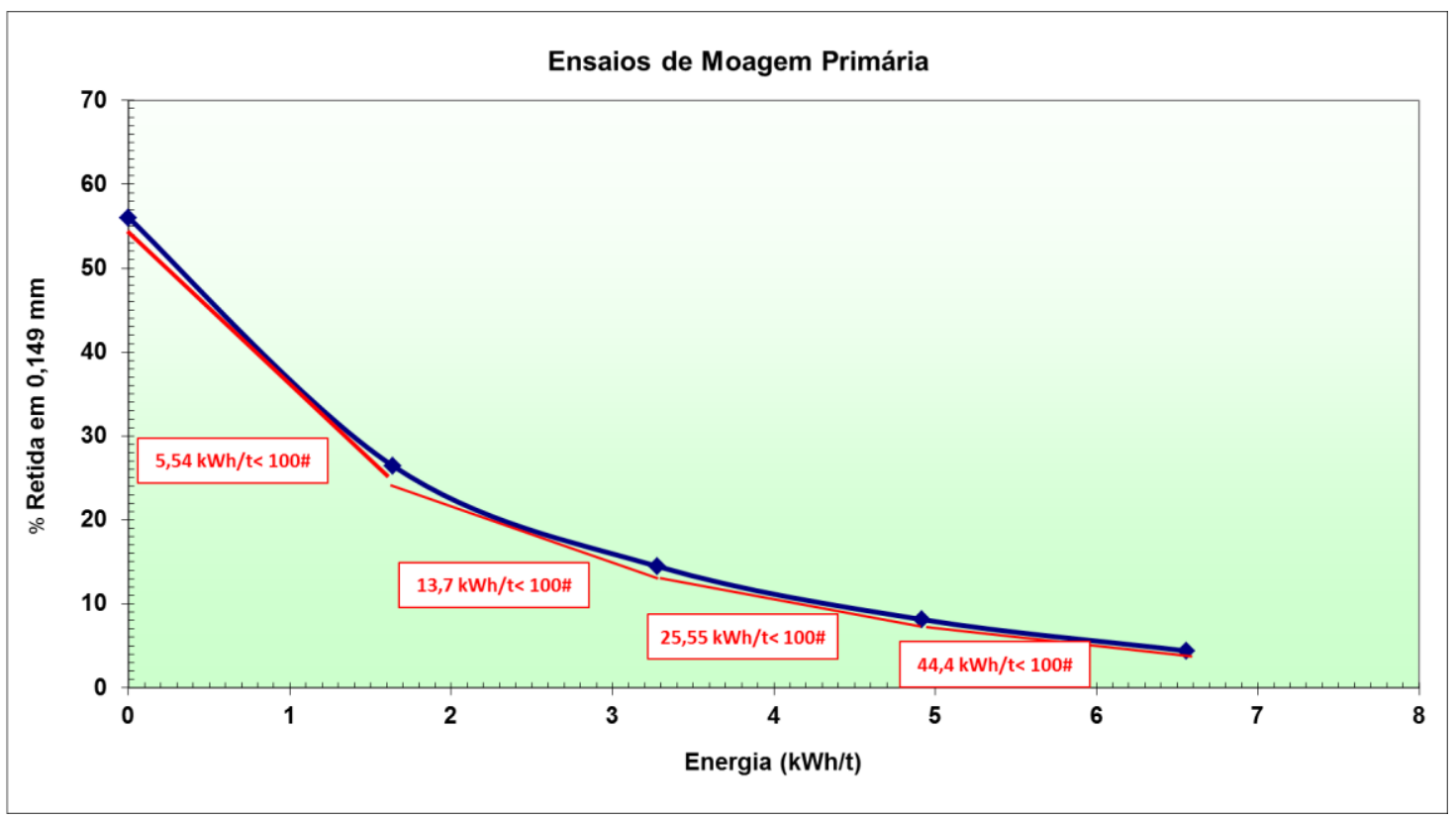

Figura 7.2 - Perfil da curva de cinética de moagem.

Nota-se que as curvas de cinética de moagem, em geral, possuem um perfil assintótico, ou seja, para cada etapa, na medida em que a granulometria de alimentação e a razão de redução diminuem, o consumo de energia por tonelada de material gerado abaixo da malha de controle aumenta.

Os dados das amostragens relativos à operação sob o circuito direto correspondem à primeira fração da curva, em que o requerimento energético do minério é menor. Por sua vez, os dados relativos à operação sob o circuito inverso correspondem à segunda fração, ou seja, a um ponto em que o minério oferece maior dificuldade para a quebra. Deste modo, os dados para ambos os circuitos não podem ser comparados diretamente pelo parâmetro Wi. É preciso ajustar o Work Index operacional para o circuito inverso, de maneira a desonerar a perda relativa de eficiência devida à menor razão de redução.

Bond-Rowland sugeriram um fator de correção para o Work Index operacional que leva em consideração a razão de redução - o fator EF7, de acordo com 0 exposto no item 3.2.3. Conforme já explicado, a razão de redução para o circuito inverso ficou abaixo da considerada ideal, o que não ocorre na operação sob a configuração direta. O fator EF7 foi aplicado, portanto, apenas nos dados relativos 
ao circuito inverso. A Figura 7.3 mostra a comparação dos resultados após a aplicação dos fatores sugeridos por Bond-Rowland.

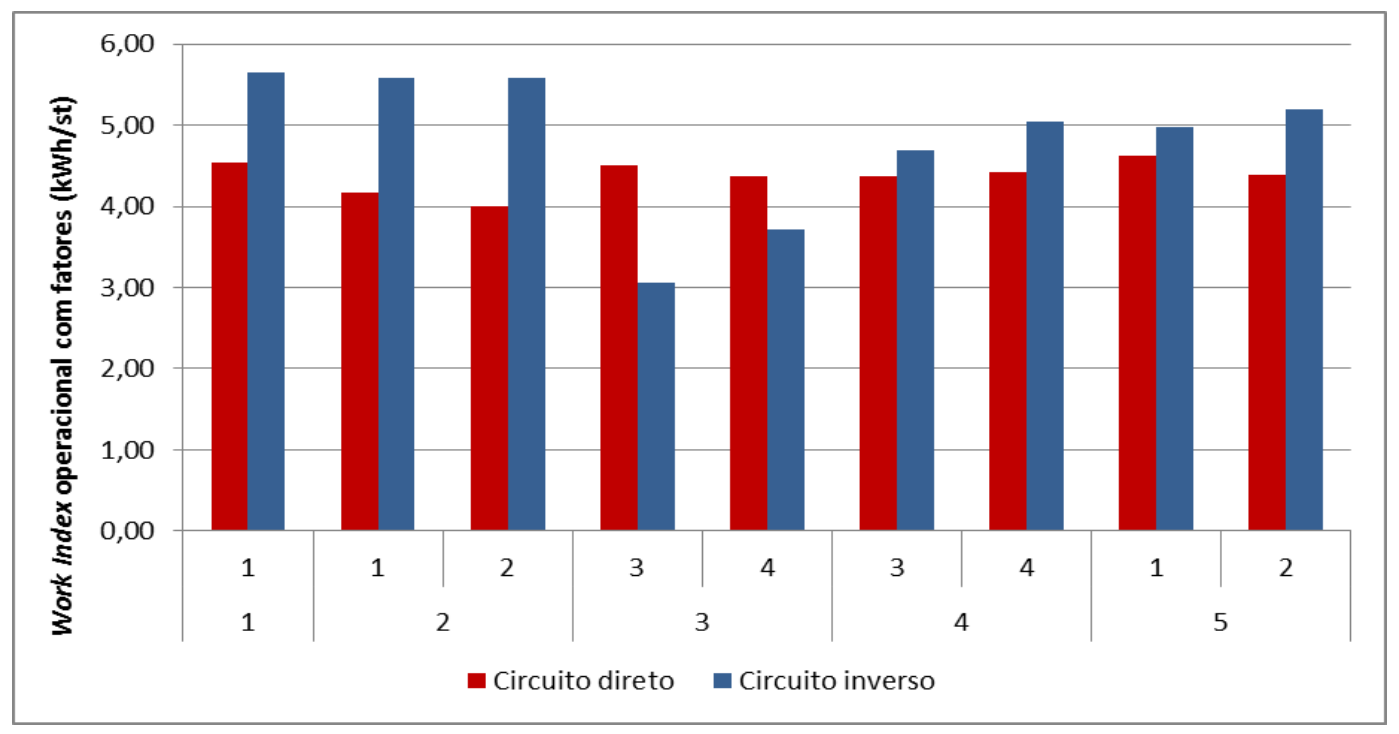

Figura 7.3 - Comparação entre os Work Indexes operacionais corrigidos.

De acordo com a Figura 7.3, descontando-se a parcela devida à baixa relação de redução, a diferença entre o Work Index operacional para o circuito inverso e direto diminui, embora os índices para este último continuem, em média, 8\% inferiores.

Por outro lado, no período relativo à terceira amostragem, o produto dos prémoinhos - que corresponde à alimentação nova dos moinhos primários - foi mais grosseiro que o habitual, como mostra a Figura 7.4. Em consequência, a razão de redução neste período foi maior, ou seja, a operação dos moinhos primários se deu em uma faixa granulométrica correspondente a um menor consumo específico de energia. Este fato pode explicar porque, durante a terceira amostragem, o Work Index operacional para os dados relativos ao circuito inverso foi inferior aos dados para o circuito direto, ao contrário do que foi constatado nos demais períodos. 


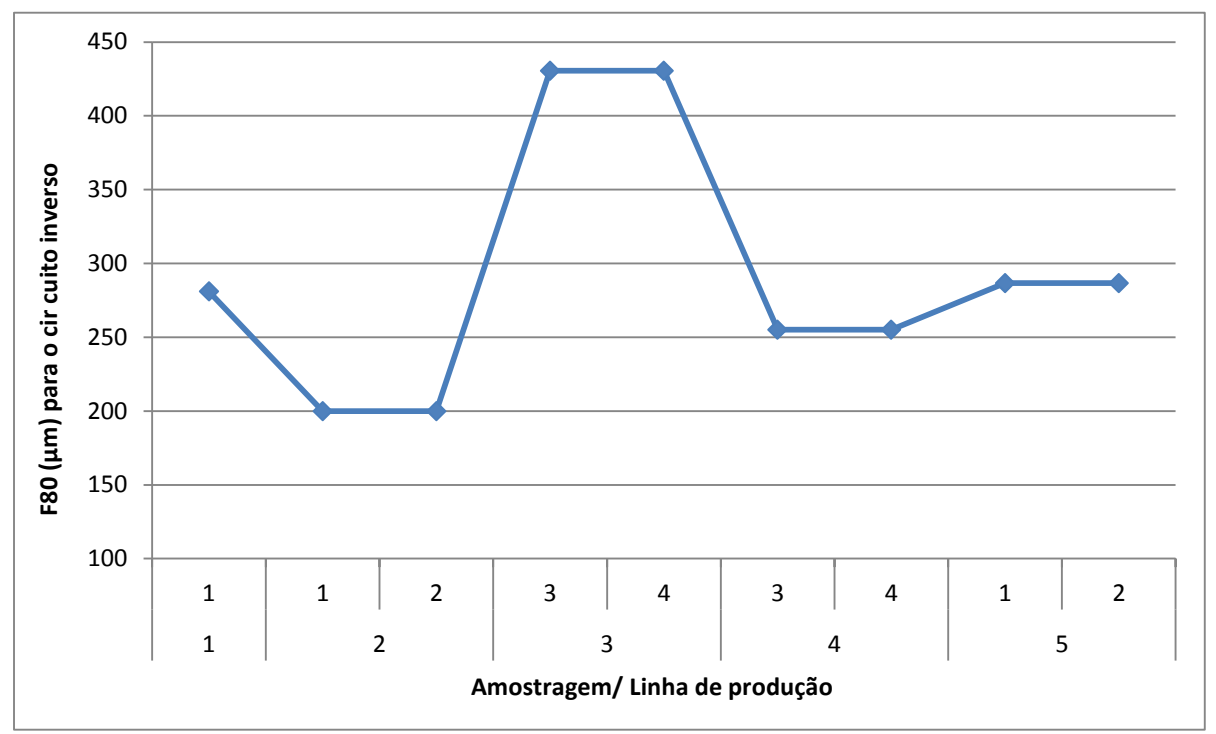

Figura 7.4 - Granulometria para a alimentação nova do circuito inverso durante as amostragens.

Por último, a Figura 7.5 mostra a comparação entre os Work Indexes operacionais para os circuitos direto e inverso, após o ajuste dos dados relativos ao circuito inverso, com o fator para alimentações escalpadas, conforme explicado anteriormente.

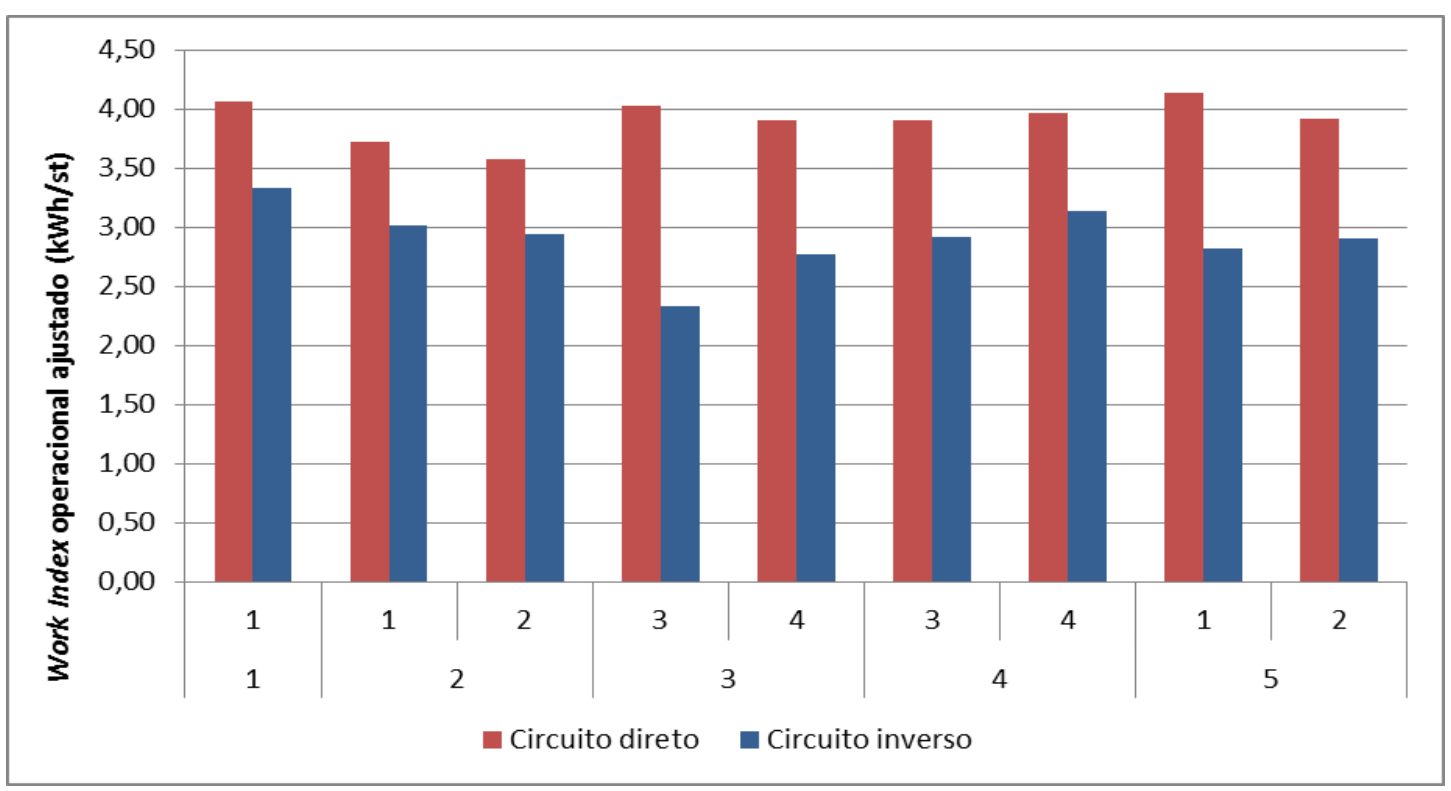

Figura 7.5 - Comparação entre os Work Indexes ajustados para os circuitos inverso e direto.

De acordo com a Figura 7.5, após o ajuste proposto por Bond para alimentações escalpadas, o Work Index operacional para o circuito inverso se manteve, consistentemente, inferior ao direto. Em princípio, a Figura 7.5 demonstra resultados opostos às análises anteriores, ou seja: o circuito inverso demonstrou um consumo 
específico de energia inferior ao circuito direto. Para uma melhor análise, contudo, é necessário considerar os demais resultados deste trabalho.

A Figura 7.6 mostra a comparação entre os dados industriais para os circuitos direto e inverso, de acordo com o parâmetro "kWh/t $<100 \#$ ".

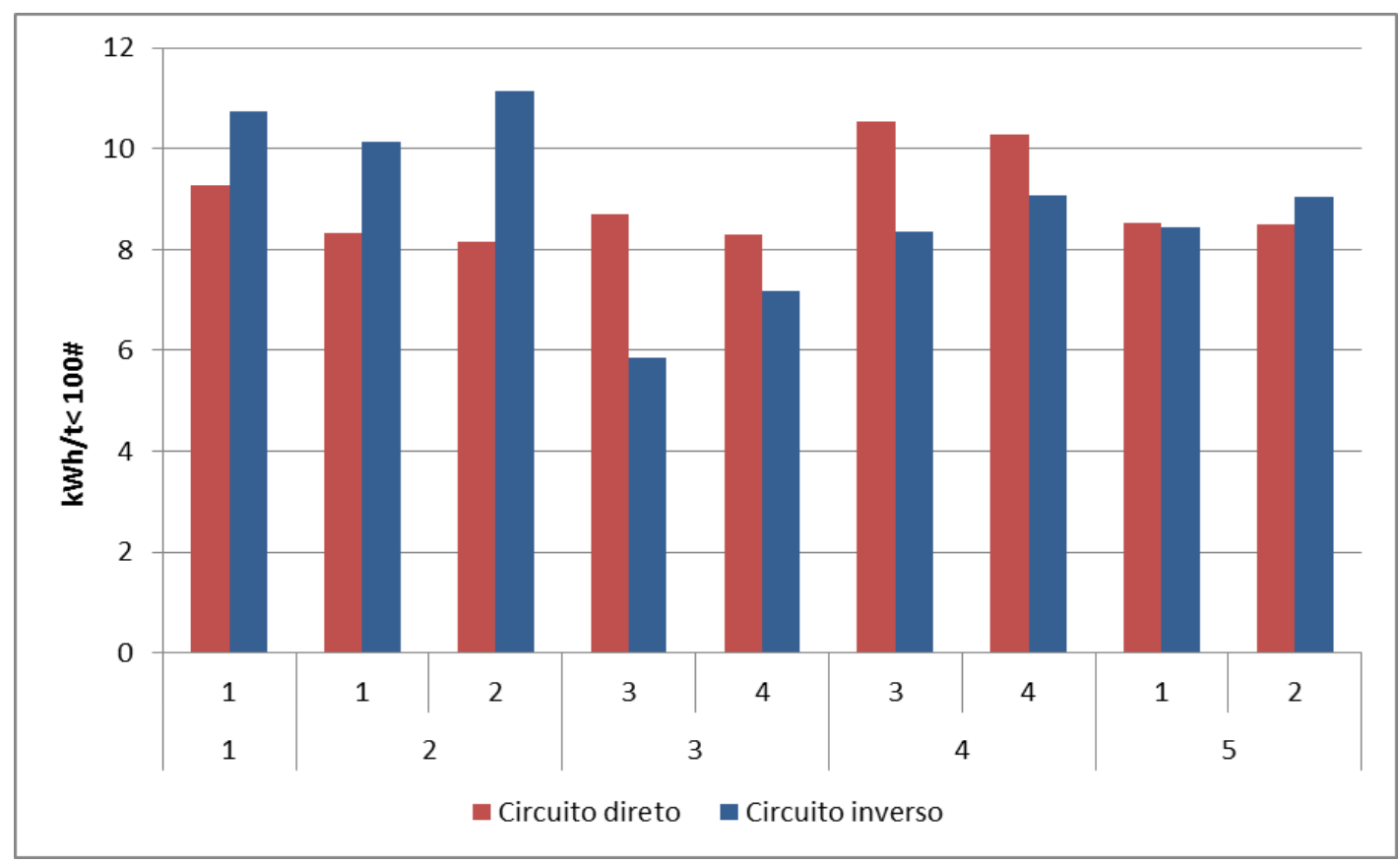

Figura 7.6 - Comparação entre o parâmetro "kWh/t <100"” para os circuitos inverso e direto.

De acordo com a Figura 7.6, o parâmetro "kWh/t<100\#" não mostrou nenhuma tendência entre as duas configurações, ou seja, o consumo específico de energia foi inferior hora para o circuito direto, hora para o circuito inverso.

Contudo, para enriquecer a análise, outros fatores operacionais devem ser avaliados, de forma a consolidar as observações feitas até o momento. Cada um dos fatores aqui considerados relevantes é analisado a seguir.

- Percentagem de enchimento dos moinhos - este parâmetro é controlado diariamente nos concentradores, de modo a manter a potência dos moinhos relativamente constante. No Concentrador I, em especial, tanto os pré-moinhos quanto os moinhos primários se encontram em seu limite de capacidade de processamento. Ambas as linhas de pré-moagem operam com cerca de $35 \%$ de enchimento; para os quatro moinhos primários esta percentagem é de, aproximadamente, $38 \%$; 
- Tipo de corpos moedores e revestimentos - estes parâmetros também são semelhantes entre os moinhos. Embora materiais de diferentes fornecedores possam ser utilizados em cada linha de produção, ambos os pré-moinhos são operados com bolas cujos "top sizes" (diâmetros de reposição da carga) são de 3 polegadas. Para os quatro moinhos primários, o diâmetro da bola de reposição é de 2,5 polegadas.

Do mesmo modo, os perfis de revestimento dos moinhos são os mesmos, ainda que fornecidos por fabricantes distintos. Os pré-moinhos operam com revestimentos metálicos e os moinhos primários com revestimentos de borracha;

- Velocidade de rotação - todos os pré-moinhos operam com $74 \%$ da velocidade crítica e, os moinhos primários, com $71,5 \%$;

- Potência dos moinhos primários - suposto a manutenção dos parâmetros anteriores constantes durante um mesmo "par de amostragens", as diferenças observadas nas potências dos moinhos primários podem ser atribuídas, sobretudo, à densidade de polpa no interior dos mesmos. A diluição da polpa no interior do moinho corresponde a um aumento da potência, uma vez que a densidade de polpa está relacionada à viscosidade da mesma e este último fator altera o movimento das diversas camadas de bolas entre si, alterando o movimento total da carga e o baricentro da mesma.

A Figura 7.7 comprova este fato com base em dados industriais coletados durante a lavagem de um moinho secundário para manutenção.

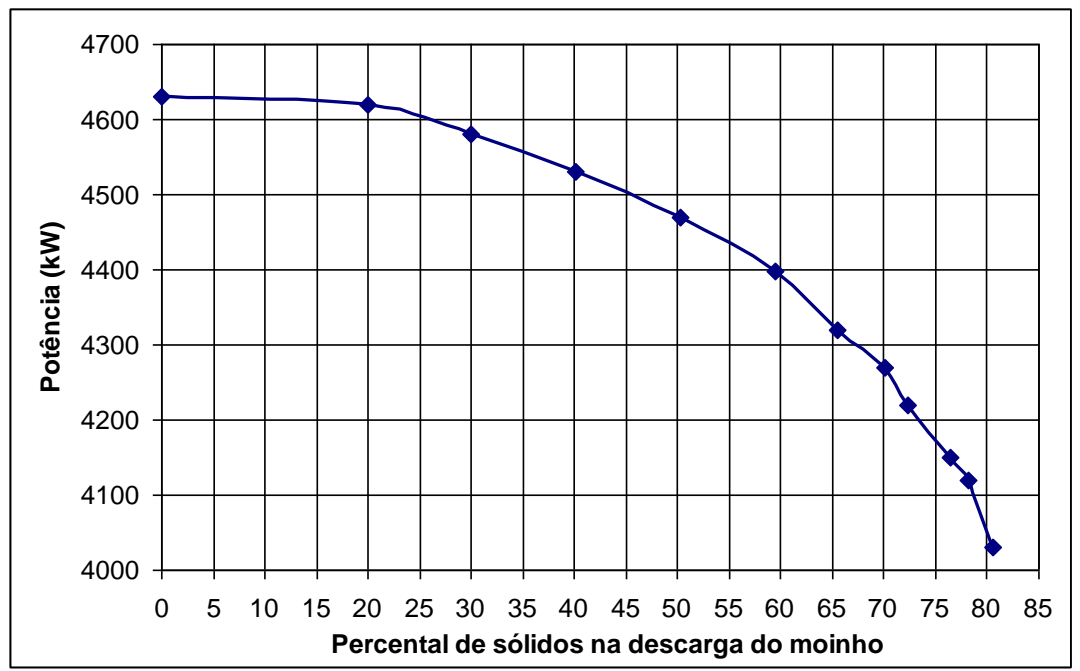

Figura 7.7 - Relação entre potência do moinho e a percentagem de sólidos na descarga. 
- Vazão de alimentação dos circuitos - em média, a vazão alimentada durante a operação sob circuito direto foi a metade vazão para o circuito inverso. Este fato está ligado à limitação da energia disponível nos moinhos primários, como já mencionado.

O objetivo primordial do circuito de moagem primária é entregar o material na granulometria e liberação adequadas ao melhor desempenho da etapa de flotação. Por este motivo, as especificações para o produto da moagem são mantidas inalteradas, mesmo sob condições operacionais adversas.

No momento da parada de um pré-moinho, o minério britado é direcionado para as duas linhas de moagem primária correspondentes, alterando a granulometria de alimentação dos mesmos. Nestes casos, a prática operacional é a diminuição da quantidade alimentada nos moinhos primários, para compensar o aumento na granulometria da alimentação do circuito. Em outras palavras, como a razão de redução necessária aumenta, e a energia disponível no circuito é constante, faz-se necessário diminuir a vazão alimentada nos moinhos, de maneira a manter as características do produto inalteradas.

Por este motivo, os dados analisados consideram sempre o consumo específico de energia, ou seja, a razão entre a energia consumida e a quantidade alimentada em cada moinho.

- Configurações dos hidrociclones - as quatro linhas de moagem primárias operam com uma bateria de seis hidrociclones de 26 polegadas de diâmetro, todos de mesmo modelo, denominados de ciclones primários. Durante o ano de 2010, porém, as equipes responsáveis pelo controle de processo e operação do Concentrador I, realizaram estudos de configuração nestes equipamentos, buscando a melhor qualidade da classificação. Deste modo, os diâmetros do vortex e apex podem ter variado entre diferentes linhas de produção e mesmo entre períodos distintos de amostragem, influenciando nas partições de sólidos e água para o overflow e underflow e, em consequência, na percentagem de material recirculado para o moinho. Esta é uma das razões pelas quais os resultados apresentados nas Figuras 7.1, 7.3, 7.5 e 7.6 foram agrupados de acordo com a linha amostrada.

Por outro lado, é importante frisar que durante um ciclo de amostragem, ou seja, durante a coleta de amostras para os dois tipos de circuito, as configurações adotadas nas respectivas baterias de hidrociclones 
permaneceram inalteradas, não constituindo, portanto, um fator de divergência entre os dados para ambos os circuitos analisados.

- Carga circulante: a percentagem de carga circulante para o circuito inverso se manteve menor que a carga circulante praticada para o circuito direto. Atribuise a este fato a diferença entre as granulometrias de alimentação dos dois circuitos, ou seja, com alimentação nova mais grosseira, a quantidade de material "pronto" na descarga do moinho diminui, tornando necessária uma maior taxa de recirculação de partículas quando na operação em circuito direto. A carga circulante, por outro lado, modula a quantidade de finos presentes no interior do moinho. Quanto maior a carga circulante do circuito, mais bitolada será a alimentação real do moinho e, portanto, menor será a quantidade de finos contida na alimentação do equipamento. Contudo, os dados na Tabela 6.1 mostraram que durante a operação sob o circuito direto, a percentagem de finos na descarga do moinho esteve, em geral, superior ao circuito inverso. Estas observações estão em consonância com as particularidades do ROM Samarco, em que a presença de finos é muito significativa. Deste modo, a classificação dos finos antes da etapa de moagem é mais expressiva do que os efeitos da carga circulante;

- Densidade de polpa na alimentação dos hidrociclones: durante as amostragens foram observadas altas percentagens de sólidos na alimentação dos hidrociclones, com média de $66 \%$ e picos de $70 \%$, conforme mostram os dados presentes no Apêndice $A$. Esta condição é devida às limitações no sistema de manuseio de polpa, o qual foi dimensionado para vazões muito inferiores às praticadas atualmente. Normalmente, foram registrados valores superiores para a operação sob a configuração inversa (média de $70 \%$ ) perante o circuito direto (média de 63\%), devido à diminuição na vazão alimentada no circuito sob esta última condição. Independentemente desta diferença, nota-se que a alta densidade de polpa na alimentação dos ciclones conduziu a altas partições de água, prejudicando a qualidade da classificação, como ilustra a Figura 7.8. 


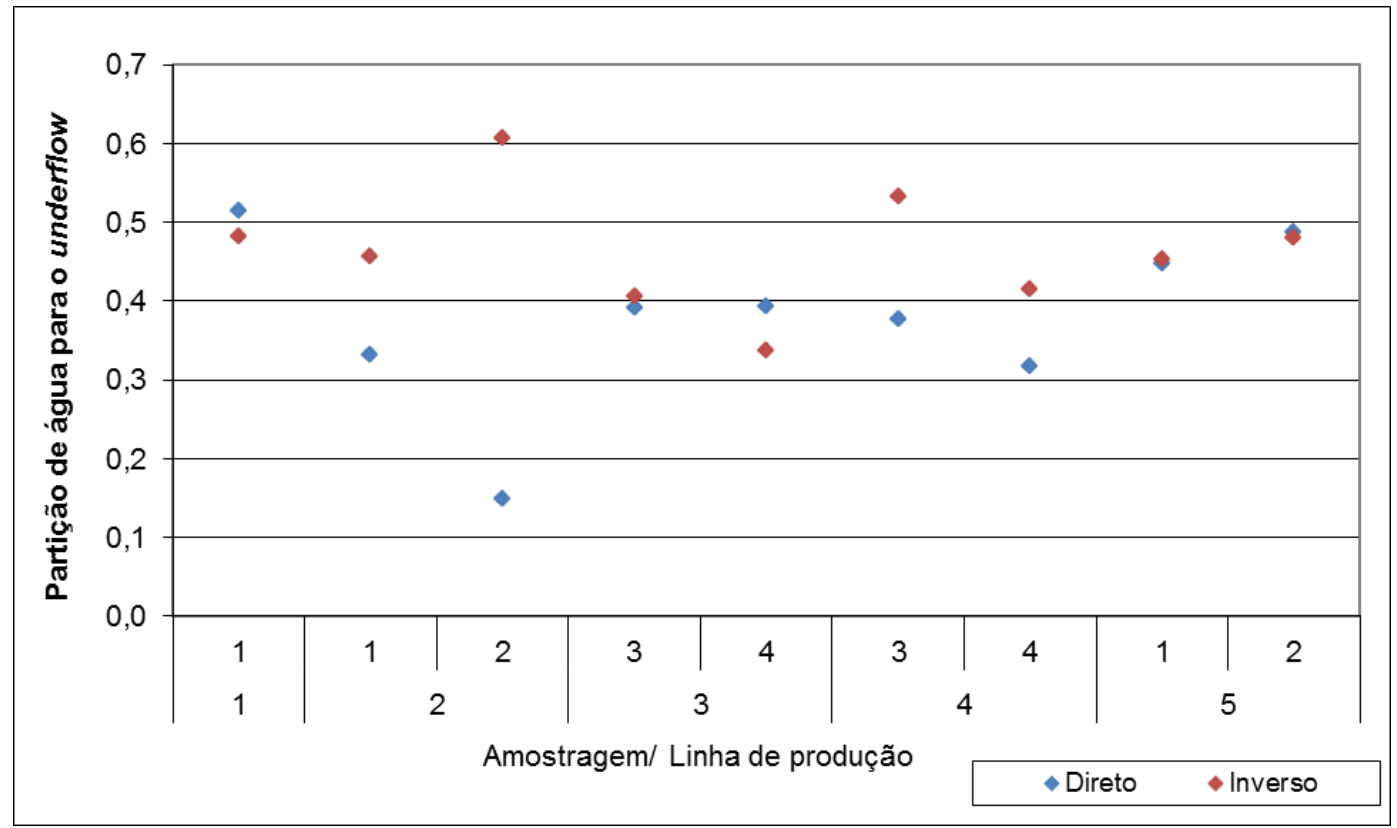

Figura 7.8 - Partições de água para o underflow.

Nota-se, pela Figura 7.8, que não houve uma tendência para os valores observados, embora em muitos dos casos a partição de água para a operação sob circuito inverso tenha sido superior à operação sob circuito direto.

Uma abordagem comparativa entre os dados históricos dos Concentradores I e II de Germano também foi efetuada, para aumentar a abrangência deste estudo. No Concentrador II não há pré-moinhos, ou seja, a etapa de moagem primária é executada em um único estágio, em circuito fechado direto, conforme mostra a Figura 7.9 a seguir:

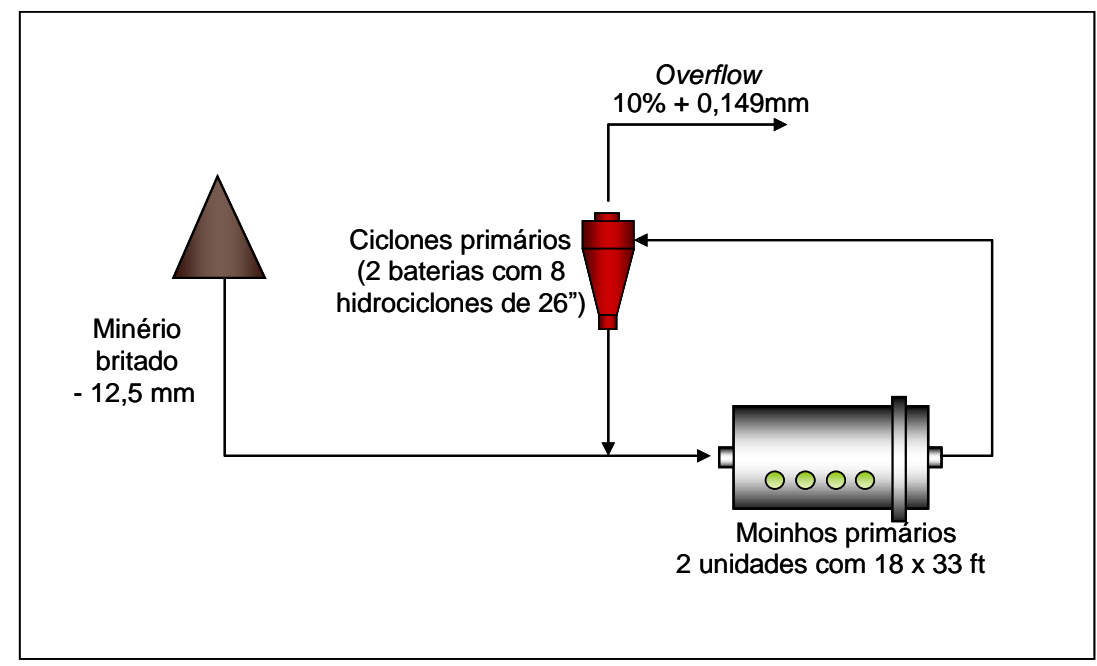

Figura 7.9 - Circuito de moagem primária do Concentrador II. 
Ao se comparar os dados históricos do circuito de moagem primária do Concentrador II (sem pré-moinhos) com os do circuito do Concentrador I (com prémoinhos), é possível avaliar qual a influência da etapa de pré-moagem sobre o desempenho da etapa global de moagem do Concentrador I.

O parâmetro "kWh/t-100\#" está disponível nos sistemas automáticos de controle de ambas as usinas. A Figura 7.10 mostra os dados referentes ao período janeiro de 2010 a maio de 2011 :

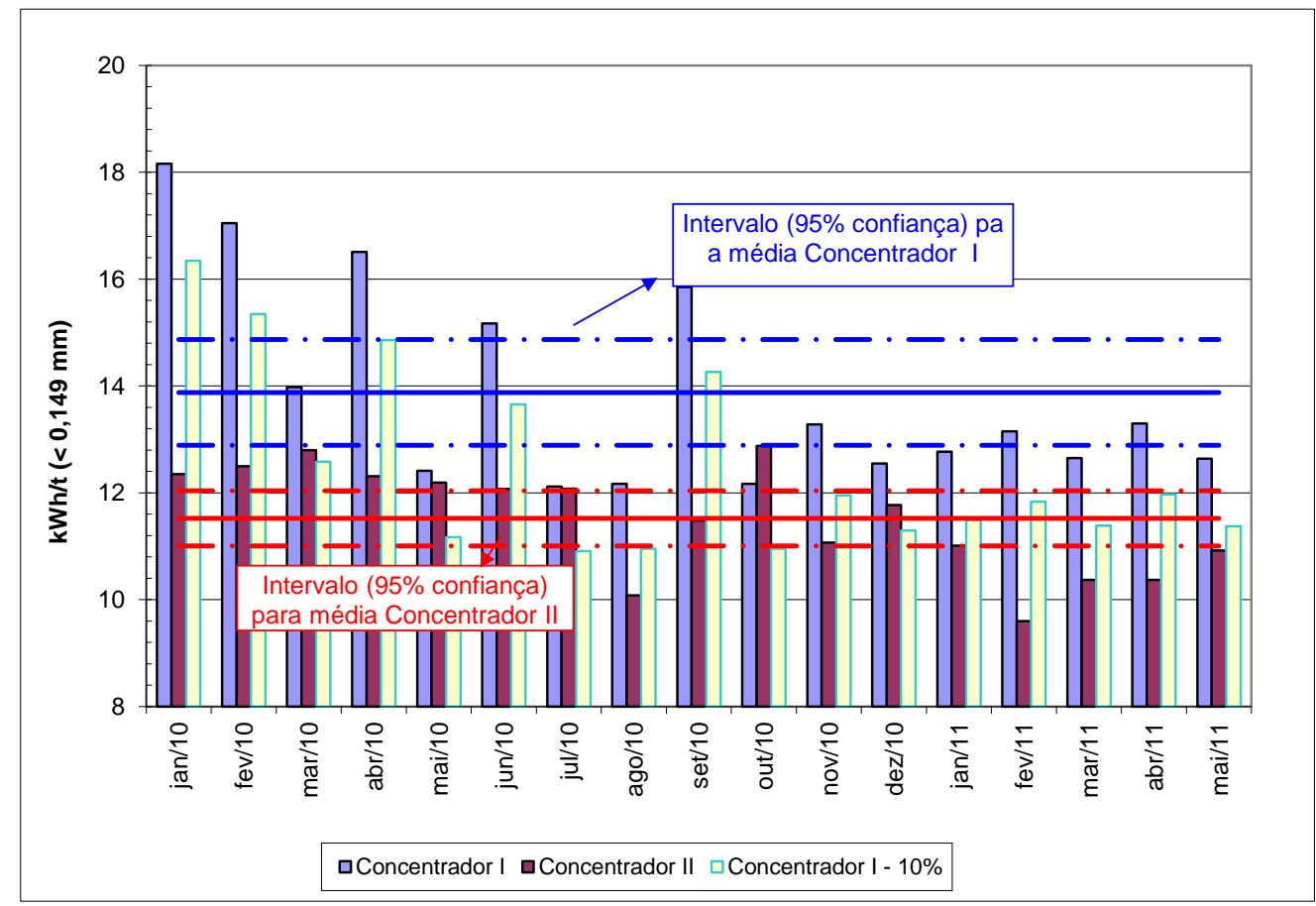

Figura 7.10 - Comparação entre dados industriais dos concentradores I e II.

A Figura 7.10 mostra que, em geral, o circuito de moagem primária do Concentrador II apresenta menor consumo específico de energia que o circuito do Concentrador I. Em outubro de 2010, entretanto, o consumo de energia por tonelada moída abaixo de 0,149 mm no Concentrador II foi superior, devido a restrições de produção, em razão de problemas na calha de alimentação de um moinho primário e a travamentos, por sobrecarga, no espessador de rejeitos.

Excetuando-se este ponto, o gráfico da Figura 7.10 mostra uma maior eficiência do circuito do Concentrador II, que pode ser interpretada pelo fato de que os prémoinhos operam em circuito aberto, configuração tida como menos eficiente que o circuito fechado, conforme referenciado no item 3.3. 
Conforme explicado no capítulo 3.5, em Germano adota-se o fator de eficiência proposto por Rowland ${ }^{7}$ para moinhos operando em circuito aberto, no ajuste do consumo específico de energia da etapa de pré-moagem. Como o produto dos prémoinhos é cerca de $70 \%$ passante na malha de controle $(0,149 \mathrm{~mm})$, adota-se o "fator de ineficiência" de 10\% para este circuito na Samarco.

Deste modo, também foram incluídos na Figura 7.10 os dados relativos ao Concentrador I, descontando-se esta fração. Ainda assim, o circuito do Concentrador II se mostrou mais eficiente, indicando que o fator de ineficiência devido à operação em circuito aberto dos pré-moinhos não é suficiente para explicar tal fato, ou que o fator adequado pode ser superior ao aplicado atualmente.

A comparação entre o histórico para os dados industriais de ambos os concentradores corrobora os resultados apresentados na Figura 7.1 e na Figura 7.3.

\subsubsection{Geração de lamas}

A Figura 7.11 e a Figura 7.12 mostram, respectivamente, o Boxplot para as percentagens de lamas no overflow dos ciclones primários e na descarga dos moinhos primários em cada circuito.

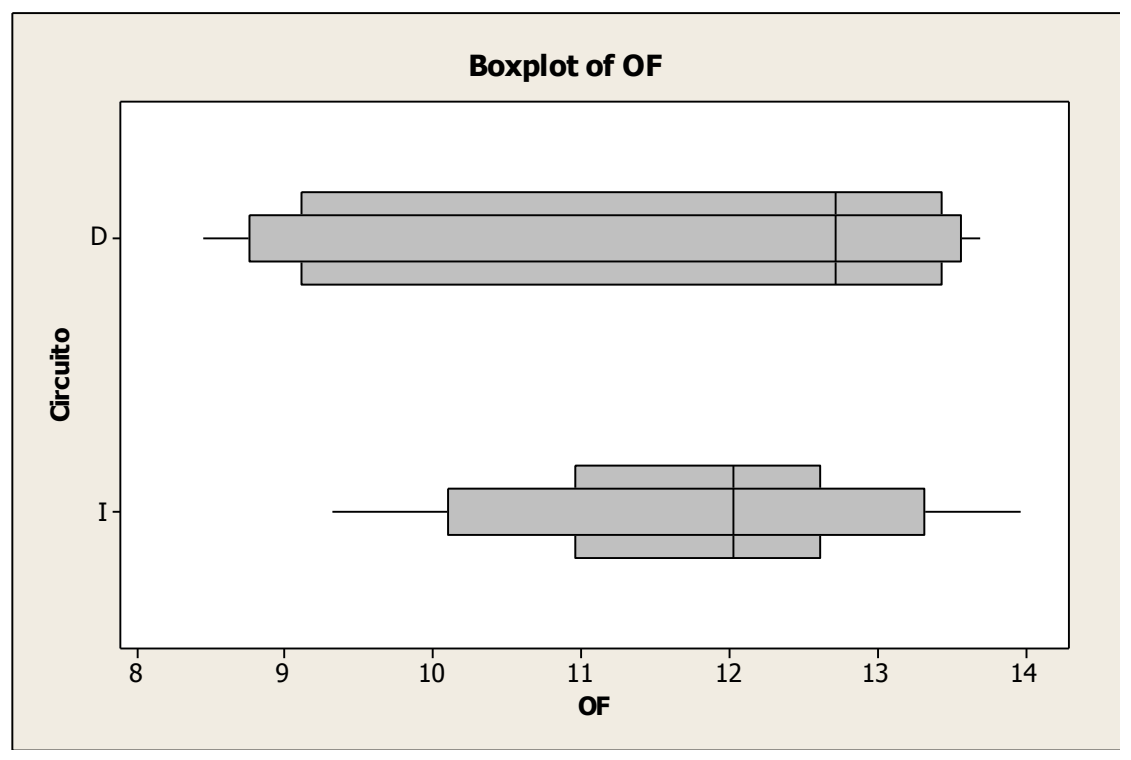

Figura 7.11 - Percentagem de lamas no overflow dos ciclones primários. 


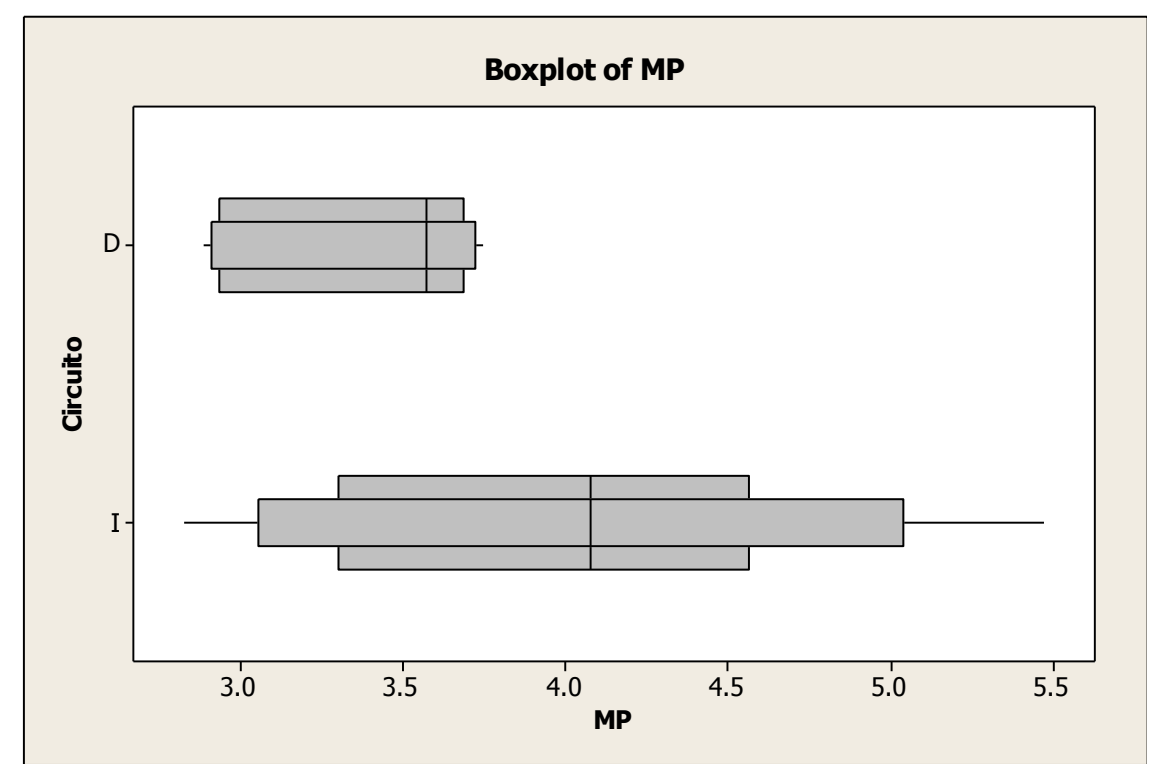

Figura 7.12 - Percentagem de lamas para a descarga dos moinhos primários.

Pela Figura 7.11 nota-se que não houve diferenças significativas (valores médios e medianos semelhantes) entre os percentuais de lama no produto final de cada circuito, embora a variância dos dados relativos ao circuito inverso tenha sido menor.

Por outro lado, a Figura 7.12 indica maior percentual de lamas na descarga dos moinhos primários (MP) quando operando em circuito inverso. O maior percentual de carga circulante, observado durante a operação sob o circuito direto explica este fato: conforme já discutido, a carga circulante aumenta a granulometria da alimentação do moinho, evitando a maior geração de ultrafinos.

\subsection{ANÁLISE DOS ENSAIOS DE LABORATÓRIO}

Para a análise adequada das curvas de moagem apresentadas na Figura 6.2 é preciso considerar que, no circuito inverso, parte da alimentação nova é classificada antes da alimentação do moinho, ou seja, parte da alimentação nova não é enviada à etapa de moagem e a energia não consumida por esta fração de material deve ser considerada.

Pela Figura 6.1 pode-se observar que a amostra padrão utilizada para os ensaios, ou seja, o material que constitui a alimentação nova do circuito simulado em 
laboratório, apresentou 57,4\% passante em 0,210 $\mathrm{mm}$ (a malha em que a amostra foi classificada).

Supondo uma classificação "ideal", ou seja, admitindo que todas as frações abaixo de 0,210 $\mathrm{mm}$ se reportaram ao undersize da peneira, o percentual em massa da amostra padrão que será direcionado ao moinho será:

$$
\% \text { massa }=100-57,4=42,6 \%
$$

Considerando-se que a energia de moagem só será aplicada nesta fração da amostra, e como o consumo específico de energia para a fração maior que $0,210 \mathrm{~mm}$ da amostra foi de $8,0 \mathrm{kWh} / \mathrm{t}$ (Figura 6.2), o consumo de energia para o circuito indireto será:

$$
E=0,426 \times 8,0=3,45 \mathrm{kWh} / t
$$

Ainda segundo a Figura 6.1, pode-se notar que a fração mais fina que 0,210 mm da amostra padrão apresentou $89 \%$ passante em $0,149 \mathrm{~mm}$ (qual seja a malha de controle do circuito de moagem).

Para comparar os resultados de ambos os circuitos é preciso determinar a energia necessária para moer a amostra padrão (ou seja, a amostra sem a retirada dos finos), até a mesma especificação: $89 \%$ passante em 0,149 mm. Em outras palavras, determina-se o consumo de energia para se obter o mesmo produto final em ambas as configurações.

O consumo específico de energia necessário para moer a amostra padrão até $89 \%$ passante em 0,149 $\mathrm{mm}$ foi $4,4 \mathrm{kWh} / \mathrm{t}$ (Figura 6.2), ou seja, $27 \%$ superior ao consumo de energia apresentado pelo oversize da classificação (3,45 kWh/t). Neste caso, a classificação dos finos naturais antes da moagem representaria uma economia de $27 \%$ em relação ao circuito direto.

Deve-se considerar, contudo, a eficiência relativa entre a separação feita por hidrociclones (normalmente empregados em circuitos industriais) e o peneiramento método utilizado nos ensaios.

Nota-se, pela Figura 6.1, que a fração referente ao oversize do peneiramento continha $4,7 \%$ de finos presentes. Suposto o uso de hidrociclones, admite-se uma presença consideravelmente maior de finos retornando ao moinho, o que diminuiria os benefícios atribuídos à configuração inversa. 
Para ilustrar este fato, foram estimadas as granulometrias para o overflow e underflow da classificação da mesma amostra utilizada nos ensaios, por meio de simulação computacional, utilizando-se o modelo proposto por Nageswararao, exposto na seção 3.4. As dimensões adotadas para os diâmetros do hidrociclone, apex e vortex foram as mesmas utilizadas no circuito de moagem do Concentrador II, bem como os parâmetros operacionais, tais como percentagem de sólidos na alimentação e pressão. O objetivo foi reproduzir, no overflow do hidrociclone, a mesma percentagem passante em $0,149 \mathrm{~mm}$ obtida no oversize da amostra peneirada em laboratório.

A Tabela 7.1 resume constantes utilizadas na simulação. Elas correspondem às condições operacionais do Concentrador II.

Tabela 7.1 - Dados utilizados para a calibração do modelo de Nageswararao.
\begin{tabular}{|l|c|}
\hline Diâmetro dos hidrociclones & $26^{\prime \prime}(0,660 \mathrm{~mm})$ \\
\hline Diâmetro do vórtex & $12^{\prime \prime}(0,305 \mathrm{~mm})$ \\
\hline Diâmetro do ápex & $5^{\prime \prime}(0,127 \mathrm{~mm})$ \\
\hline Diâmetro equivalente do inlet & $0,192 \mathrm{~mm}$ \\
\hline Comprimento da porção cilíndrica & $0,500 \mathrm{~mm}$ \\
\hline Ângulo da porção cônica & $20^{\circ}$ \\
\hline Pressão na alimentação dos hidrociclones & $82 \mathrm{kPa}$ \\
\hline Percentagem de sólidos na alimentação & $65 \%$ \\
\hline
\end{tabular}

A Figura 7.13 mostra o balanço de massas obtido; a Figura 7.14 mostra as granulometrias estimadas para alimentação, underflow e overflow dos ciclones na simulação.

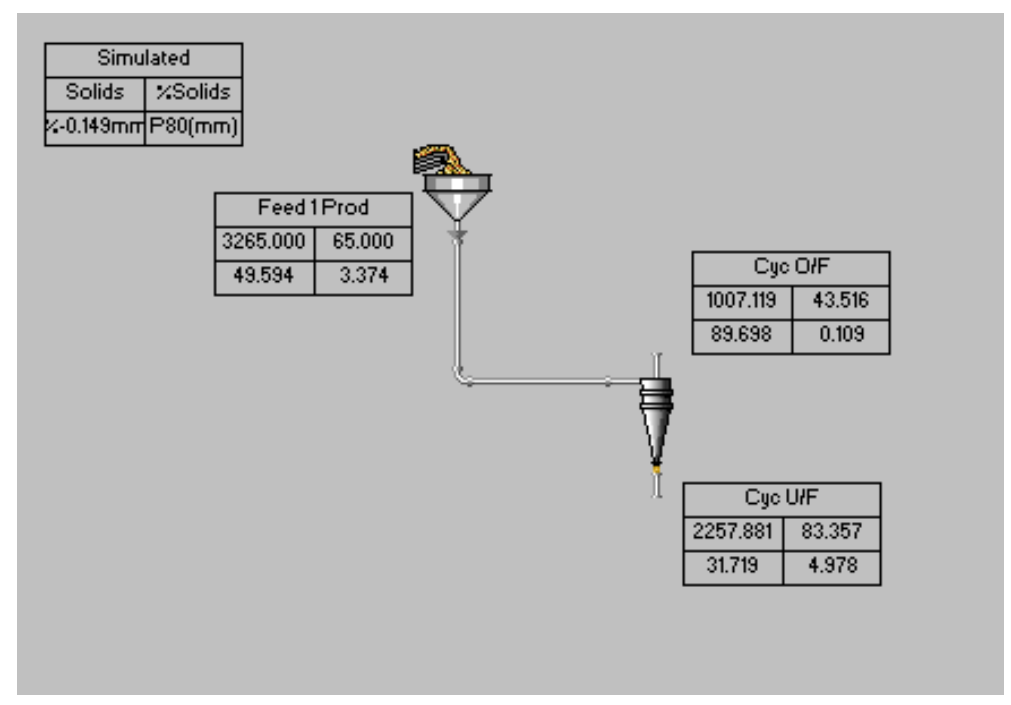

Figura 7.13 - Resultados da simulação: balanço de massas. 


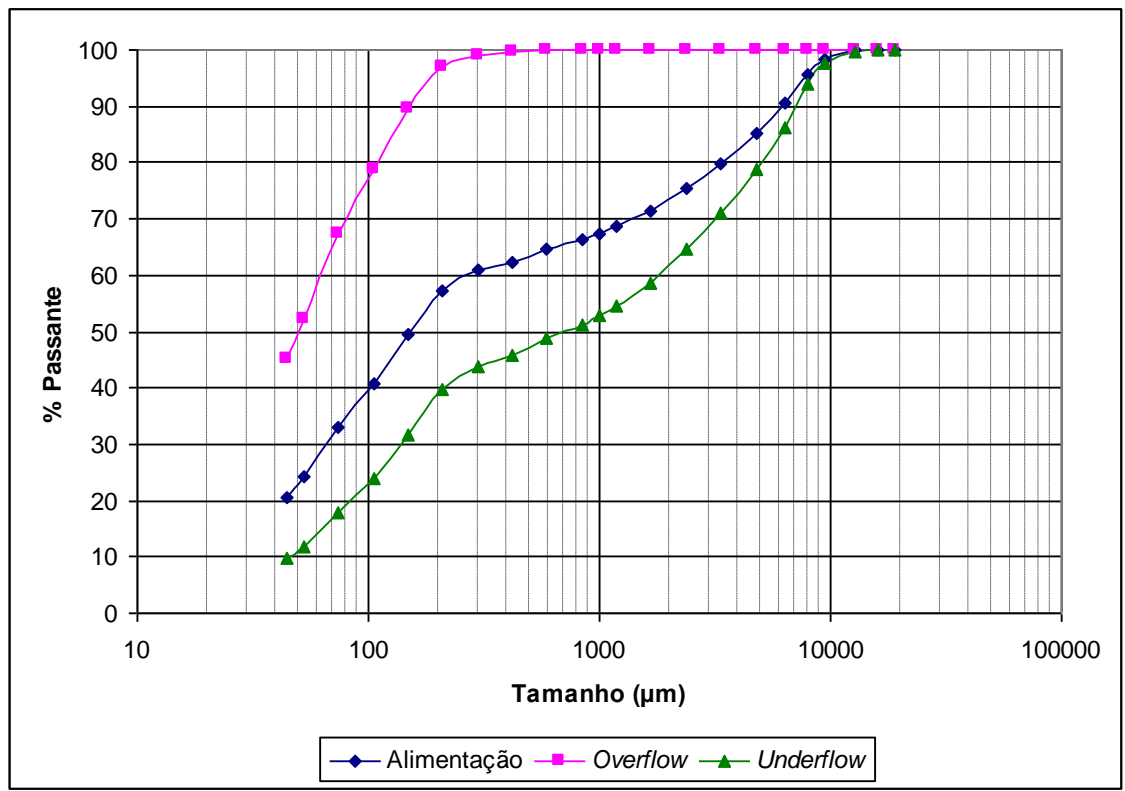

Figura 7.14 - Granulometrias estimadas para produtos da classificação com hidrociclones.

Conforme mostra a Figura $7.14,32 \%$ do material que se reportou ao underflow dos hidrociclones está abaixo de $0,149 \mathrm{~mm}$, fração muito superior aos 4,7\% observados no oversize da amostra peneirada em laboratório.

Pela Figura 7.13 é possível observar que a partição para o underflow foi:

$$
\text { Partição }=2258 / 3265=69 \%
$$

ou seja, $69 \%$ da alimentação nova do circuito é direcionado ao moinho.

Se o mesmo raciocínio seguido anteriormente for aplicado, o consumo específico de energia para o circuito inverso, neste caso, será:

$$
E=0,69 \times 8,0=5,6 k W h / t
$$

Deste modo, o circuito inverso não representaria vantagem sobre o direto, mediante o consumo de $4,4 \mathrm{kWh} / \mathrm{t}$ para este último.

Este exercício mostra que os benefícios da retirada dos finos da alimentação de um circuito são dependentes da etapa da classificação.

Os hidrociclones são, em geral, o equipamento mais utilizado para este fim e possuem, sabidamente, menor eficiência em relação ao peneiramento, embora apresentem outras vantagens, tais como alta capacidade e facilidade de instalação e operação. 
Este é um dos motivos pelos quais os dados das amostragens não são uniformes, ou seja, a diferença entre os resultados para o circuito inverso e direto varia de acordo com as flutuações operacionais típicas da etapa de classificação em escala industrial. Estas variações consistem em uma limitação inerente a trabalhos com base em dados industriais, os quais estão sempre sujeitos a maiores dispersões, se comparados a resultados obtidos em ambientes controlados, como laboratórios e plantas piloto. Os dados oriundos de ambientes industriais são os únicos que refletem, contudo, em escala real, o comportamento de um dado minério em um circuito e, portanto, não devem ser desprezados.

Pela mesma razão, os dados históricos referentes ao Concentrador II revelaram, em sua maioria, um circuito de moagem primária mais eficiente (menor consumo específico de energia). O Concentrador II possui hidrociclones de modelo mais modernos que os utilizados no Concentrador I. Além disto, o sistema de manuseio de polpa da planta II permite a operação dos ciclones primários com uma menor densidade de polpa ( 50\% de sólidos), diferentemente do que ocorre no Concentrador I, como já discutido. Deste modo, o by pass médio nesta etapa de classificação é de $30 \%$ para o Concentrador II, valor significativamente inferior à média de $46 \%$, observados nos momentos de operação regular do Concentrador I (apresentados na Figura 7.8). A maior eficiência da classificação no circuito de moagem do Concentrador II é um dos fatores que contribui para a menor presença de finos no moinho, em relação do circuito do Concentrador I.

\subsubsection{Utilização de peneiras para fechamento de circuitos de moagem}

Com base nas observações descritas na seção anterior, decidiu-se investigar em maior detalhe os possíveis benefícios que uma classificação com peneiras de alta frequência, em substituição aos tradicionais hidrociclones, proporcionasse ao circuito de moagem.

Alguns estudos mostram ganhos efetivos com esta substituição, em especial:

- Albuquerque et al. ${ }^{28}$, Valine, Wheeler e Albuquerque ${ }^{29}$ e Aquino e Torres $^{30}$ afirmam que em circuitos de moagem com estágio único, a capacidade do circuito tende a ser maior com a utilização de peneiras (a recirculação de 
material para o moinho é menor), além de ser observada a redução da geração de ultrafinos;

- Weller, Stewart e Sterns ${ }^{31}$ afirmam que as "caudas das curvas granulométricas" (para os produtos das peneiras) são menores, ou seja, os produtos das peneiras se concentram em uma faixa granulométrica mais estreita que os produtos dos hidrociclones;

- Weller, Stewart e Sterns ${ }^{31}$ e Valine, Wheeler e Albuquerque ${ }^{29}$ alegam que, em minérios com grandes diferenças entre as densidades do mineral de interesse e os de ganga, o produto das peneiras apresenta menores discrepâncias entre os $\mathrm{P}_{80}$ para os diversos minerais.

Contudo, alguns pontos precisam ser observados com cautela:

- há uma tendência natural a se julgar que o desempenho das peneiras será mais eficiente porque elas oferecem um obstáculo físico à passagem de partículas grosseiras para o undersize. Na prática, porém, a própria carga sobre a tela constitui um obstáculo para a passagem de finos e uma percentagem deste material sempre se reportará ao oversize;

- para o funcionamento adequado das peneiras de alta frequência é necessária uma grande diluição da polpa em sua alimentação. Como a água tende a se reportar, preferencialmente, para o undersize, este produto apresenta percentagens de sólidos muito baixas, o que pode prejudicar as operações subsequentes, além de requerer sistemas de manuseio de polpa mais robustos;

- na maioria dos estudos de caso apresentados, não fica claro qual era a eficiência da classificação antes da mudança para peneiras, ou seja, não foi evidenciada se a comparação dos resultados do circuitos com peneiras foi realizada com circuitos (com hidrociclones) bem calibrados e operados. Por outro lado, os dados operacionais de dois circuitos $^{29}$ utilizados como exemplos, revelam uma alta partição de água para o underflow dos hidrociclones:

- OJSC Apatit: 46\%;

- Mina Colquijirca: $40 \%$;

sugerindo que haveria possibilidade de melhoria na classificação dos circuitos "tradicionais"; 
- a separação mais eficiente, para minérios com espécies de densidades distintas, nem sempre é verdadeira, tal como relatam Edwards e Dick ${ }^{32}$, em estudos feitos na usina de beneficiamento de minério de urânio de McArthur River. As peneiras foram escolhidas no projeto do segundo circuito de moagem, pois esperava-se que a diferença entre a densidade dos minerais de ganga e os de urânio causaria segregação e moagem diferencial das partículas, caso fossem adotados hidrociclones. Após a operação, contudo, observou-se o contrário: o mineral de urânio era sobremoído, a diluição dos produtos era excessiva e a frequência de manutenção das peneiras expunha os operadores a riscos de contaminação. A substituição das peneiras por hidrociclones possibilitou a resolução destes problemas, embora a capacidade total do circuito de moagem tenha diminuído;

- o volume de polpa manuseado no circuito é um importante fator restritivo a aplicação de peneiras. Em circuitos com altas capacidades de processamento e de carga circulante elevada - caso típico de operações com minério de ferro - o grande número de peneiras necessárias dificulta não somente as soluções de arranjo da planta, como traz dificuldades operacionais, especialmente em distribuição de fluxo.

Conforme lembrado por Donda ${ }^{19}$, o conceito de um concentrador deve ser o mais simples possível, de maneira a garantir facilidade de fluxo e operação. Caso contrário, eventuais ganhos de processo podem ser suprimidos pelas dificuldades de operação. A substituição de hidrociclones por peneiras deve ser, portanto, analisada à luz destes conceitos.

\subsection{VANTAGENS PRÁTICAS DA CONFIGURAÇÃO DIRETA}

Os circuitos de moagem primária de Germano foram projetados, em princípio, para a operação em circuito fechado direto, a despeito da grande percentagem de finos em sua alimentação. Três argumentos de ordem prática vão ao encontro desta escolha:

1 - Facilidade de operação: tal como já citado antes, o conceito de um concentrador deve se basear, sobretudo, na facilidade de fluxo e operação. Em circuitos de 
moagem primária, este aspecto reduz bastante as possibilidades de configuração; para incluir a etapa de classificação antes do moinho seria necessário "empolpar" (adicionar água) o minério britado, uma operação bastante difícil devido à granulometria e, no caso da Samarco, também a elevada densidade do minério. $O$ moinho de bolas constitui o "misturador" ideal para o empolpamento e, por isto, é comum iniciar as operações a úmido com a etapa de moagem;

2 - Os benefícios da configuração inversa podem ser diluídos em circuitos industriais, devido à ineficiência da classificação, tal como mostraram os resultados deste trabalho. É importante avaliar, portanto, se os ganhos reais possibilitados pela retirada de finos da alimentação do circuito serão compensados pelas dificuldades operacionais geradas por esta configuração. No caso de Germano, entende-se desde a concepção do primeiro concentrador, em 1977, que as dificuldades causadas pelo empolpamento de minério antes do moinho anulariam as vantagens da retirada de finos, mesmo com a condição muito peculiar do ROM;

3 - Operações subsequentes à moagem: o impacto das características do produto do circuito de moagem nas operações subsequentes, especialmente de concentração, deve ser primordial na escolha do "melhor" circuito uma vez que eventuais ganhos no consumo energético raramente compensam perdas em recuperação. São diversos ${ }^{(32-36)}$ os estudos que atestam os efeitos da granulometria, forma e rugosidade das partículas nos processos de concentração.

Em Germano, Santos e Donda ${ }^{37}$ analisaram as implicações de se incluir uma etapa de classificação anterior à pré-moagem no desempenho das operações posteriores de deslamagem e flotação: embora os índices de recuperação no circuito de deslamagem tenham sido superiores, a seletividade dos reagentes na flotação diminuiu, causando perdas superiores aos benefícios obtidos nas etapas de moagem e deslamagem. Concluiu-se que, a passagem dos finos naturais pelo moinho era um importante fator na preparação da superfície das partículas e, por este motivo, a etapa de classificação antes da pré-moagem não foi concretizada.

O debate sobre o melhor circuito de moagem deve ser, portanto, mais amplo, visto que uma série de fatores precisa ser ponderada. Como Kjos ${ }^{38}$ afirmou, há mais de trinta anos: "Não há regra ou fatores em geral que podem ser aplicados, pois estes fatores e sua importância relativa, dependem de cada estudo em particular e de sua localização." 


\section{CONCLUSÕES}

- O parâmetro Work Index operacional não se mostrou adequado para a análise comparativa de dados industriais, uma vez que a aplicação de fatores de ajuste para a normalização dos dados muda os benefícios entre ambas as configurações;

- Por outro lado, o parâmetro "consumo de energia por tonelada de material gerado abaixo da malha de controle" permite a comparação direta entre os dados industriais, sem a necessidade de aplicação de fatores de ajuste;

- Os dados relativos às amostragens industriais realizadas no âmbito deste trabalho não demonstraram diferenças significativas entre os desempenhos para ambas as configurações;

- Por outro lado, os dados históricos dos Concentradores I e II de Germano demonstraram que a configuração direta, utilizada no circuito de moagem primária do Concentrador II de Germano, apresenta consumo específico de energia inferior configuração inversa, utilizado no circuito de moagem primária do Concentrador I;

- A diferença entre os resultados das amostragens e os históricos da Samarco foi atribuída ao desempenho da etapa de classificação, considerada determinante. Simulações adicionais demonstraram que variações de desempenho da etapa de classificação alteram, e podem até anular, as vantagens da configuração inversa;

- Além da qualidade da etapa de classificação a facilidade operacional deve ser um fator determinante na escolha da configuração do circuito fechado de moagem. 


\section{REFERÊNCIAS}

1. TAGGART, A. Handbook of Mineral Dressing. John Wiley and Sons, 1945.

2. WILLS, B.A. Mineral Processing Technology: an introduction to the practical aspects of ore treatment and mineral recovery. 7 th ed. Oxford: Elservier, 2007.

3. BERALDO, J.L. Moagem de minérios em moinhos tubulares. São Paulo: Edgard Blücher LTDA, 1987.

4. CHAVES, A.P; PERES, A.E.C. Teoria e prática do tratamento de minérios: britagem, peneiramento e moagem. São Paulo: Signus Editora, 2009. v. 3.

5. KELLY, G.K.; SPOTTISWOOD, D.J. Introduction to Mineral Processing. New York: John Wiley \& Sons Inc., 1982.

6. PRYOR, E.J. Mineral Processing. 3th ed. New York: Elservier, 1965.

7. ROWLAND JR, C.A. The Tools of Power Power: the Bond Work Index, a tool to measure grinding efficiency. In: Selection Circuits to Prepare Beneficiation Feeds. Allis Chalmers Bulletin,1983.

8. $\mathrm{LYNCH}, \mathrm{A} . J$. Mineral Crushing and grinding circuits: their simulation, optimization, design and control. Amsterdam: Elservier, 1979.

9. BOND, F.C. More accurate grinding calculations. AIME Transactions, 1961.

10. NAPIER-MUNN, T.J et al. Mineral comminution circuits: their operation and optimization. JKMRC, 2005.

11. SEPÚLVEDA, J.E. La cuarta ley de la molienda/ clasificación: I Formulación y verificación experimental. Revista Rocas y Minerales, $\mathrm{n}$. 460, p. 50-62, 2010. 
12. . La cuarta ley de la molienda/ clasificación: II - Implicaciones prácticas de sua correcta aplicación. Revista Rocas y Minerales, n. 460, p. 64-74, 2010.

13. BOND, F.C. Crushing and grinding calculations. Allis-Chalmers Publication, 1961.

14. DONDA, J.D. Curso de moagem de itabiritos compactos. Belo Horizonte, ABM, 22 set. 2010. Curso proferido por ocasião do 11온 Simpósio de Minério de Ferro, Belo Horizonte, 2010.

15. McIVOR, R.E. Classification effects in wet ball milling circuits. AIME Transactions: Littleton, 1985.

16. NAPIER-MUNN; ASOMAH, I.K. Rheological effects in grinding and classification. Mineral Processing and Extractive Metallurgy Review, n. 20, p. 123-131, 2000.

17. SCHLEPP, D.D.; TURNER, P.A. Influence of circulating load and classification efficiency on mill throughput. AIME transactions, Littleton, 1990.

18. CHAVES, A.P. Teoria e prática do tratamento de minérios. São Paulo: Signus Editora, 2006. v. 1.

19. DONDA, J.D. Considerações gerais sobre o Concentrador do Projeto da Terceira Usina de Pelotização (Segundo Concentrador de Germano). In: Relatório Interno - Samarco Mineração S.A., 2005.

20.BOND, F.C. Confirmation of the third theory. AIME transactions: San Francisco, 1960.

21. JKTECH. JKSimMet steady state mineral processing simulator - version 5.1. Indooroopilly, 2003. Disponível em: https://downloads.jktech.com.au/JKSimMetV5.2.01Release/JKSimMet\%20V5. $2.01 \% 20$ Basic\%20Install\%20Files/JKSimMet\%20V5.1\%20Manuals/. Acesso em 14. dez. 2009.

22. DONDA, J.D. Um método para prever o consumo específico de energia na (re)moagem de concentrados de minérios de ferro em moinhos de 
bolas. 2003. Tese (doutorado) - Universidade Federal de Minas Gerais, Belo Horizonte, 2003.

23. ROWLAND, C. A. Testing for the selection of comminution circuits to prepare concentration feed. Australasian Institute of Mining and Metallurgy, n. 289,1984 .

24. ROWLAND, C.A. Selection of of Rod Mills, Ball Mills, Peble Mills and Regrind Mills. In: MULAR, A. L.; GERALD II, V. J. Design and Installation of Comminution Circuits. New York, AIMME, 1982. p. 393- 438.

25.DONDA, J.D.; GALINARI C.M.; RABELO, P.J.B. O Controle da Eficiência Energética nos Circuitos de Pré-moagem e Moagem Primária da Samarco Mineração. In: Simpósio Brasileiro de Minério de Ferro - ABM, 2., 1999. Anais: São Paulo, ABM, 1999. p. 144-150.

26. PITARD, F.F. Pierre Gy's sampling theory and sampling practice: heterogeneity, sampling, correctness and statistical process control. CRC Press, 1993.

27. ASSOCIAÇÃO BRASILEIRA DE NORMAS TÉCNICAS. NBR ISO 3082 : minérios de ferro - procedimentos de amostragem e preparação de amostras. Rio de Janeiro, 2003.

28. ALBUQUERQUE, L. et al. Application of high frequency screens in closing grinding circuits. In: International Mineral Processing Seminar Gecamin, 5., 2008. Anais: Santiago, Gecamin, 2008. p. 257-265.

29. VALINE, S.B.; WHEELER, J. E.; ALBUQUERQUE, L.G. Fine Sizing with the Derrick Stack Sizer Screen. In: Mineral Processing Plant Design - SME, 2009.

30. AQUINO, B.G.A.; TORRES, J.E.V. Reingeniería de los processos metalúrgicos em la mina Colquijira. In: Convecíon Minería, 28., 2007.

31. WELLER, K.R. STEWART, P.S.B. STERNS, U.J. A comparison of DSM screens and cyclones in grinding circuits treating complex sulphide ores. In: Comminution - theory and practice. Littleton: AIME, 1992. p. 465480. 
32. EDWARDS, C.; DYCK, K. Replacement of classification screens with cyclones in the McArthur River Uranium Mine grinding circuit. In: Annual Meeting of the Canadian Mineral Processors, 36., 2004, Ottawa. Anais. Ottawa: CIM, 2004.

33. AHMED, M.M. Effect of comminution on particle shape and surface roughness and their relation to flotation process. International Journal of Mineral Processing, n. 94, p. 180-191, 2010.

34. BAZIN, C.; HODOUIN, D.; COOPER, M. Interactions between grinding and flotation. In: Interactions in Mineral Processing. COM, 2001. p. 3-16.

35. BANISI, S. et al. Effect of ball size change on the performance of grinding and flotation circuits of the Sarcheshmeh copper mine. In: Annual Meeting of the Canadian Mineral Processors, 34., 2002, Ottawa. Anais. Ottawa: CIM, 2002.

36. KIMPLEL, R.R. Some industrial experiences in modifying fine grinding environments for improved downstream product performance. International Journal of Mineral Processing, n. 44, p. 133-142, 1996.

37. SANTOS, I.J.; DONDA, J.D. Estudo da introdução de etapa de classificação na pré-moagem. Correspondência interna Samarco Mineração, n. GBEN-025/01, 2001.

38. KJOS, D.M. Grinding circuits: current status and projected future development. In: Annual Meeting of Minnesota Section, 52., 1979, Duluth. Anais. Minnesota: AIME, 1979. 


\section{APÊNDICE A - Dados relativos às amostragens no circuito industrial do Concentrador I}

\section{Amostragem 1:}

- Data coleta: julho de 2010.

- Linhas amostradas:

- Pré-moagem: linha 1

- Moagem primária: linha $1^{*}$

* ocorreu um problema operacional na linha 2 durante a amostragem e as amostras relativas a linha 2 foram descartadas.

Balanços de massa dos circuitos:

a) Circuito direto:

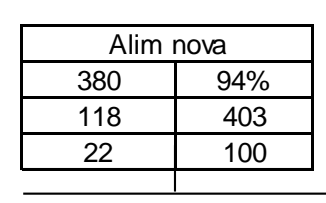

\begin{tabular}{|c|c|}
\hline t/h sólidos & $\%$ solidos \\
\hline$m^{3} / h$ polpa & t/h polpa \\
\hline$m^{3} / h$ água & $\%$ massa \\
\hline
\end{tabular}
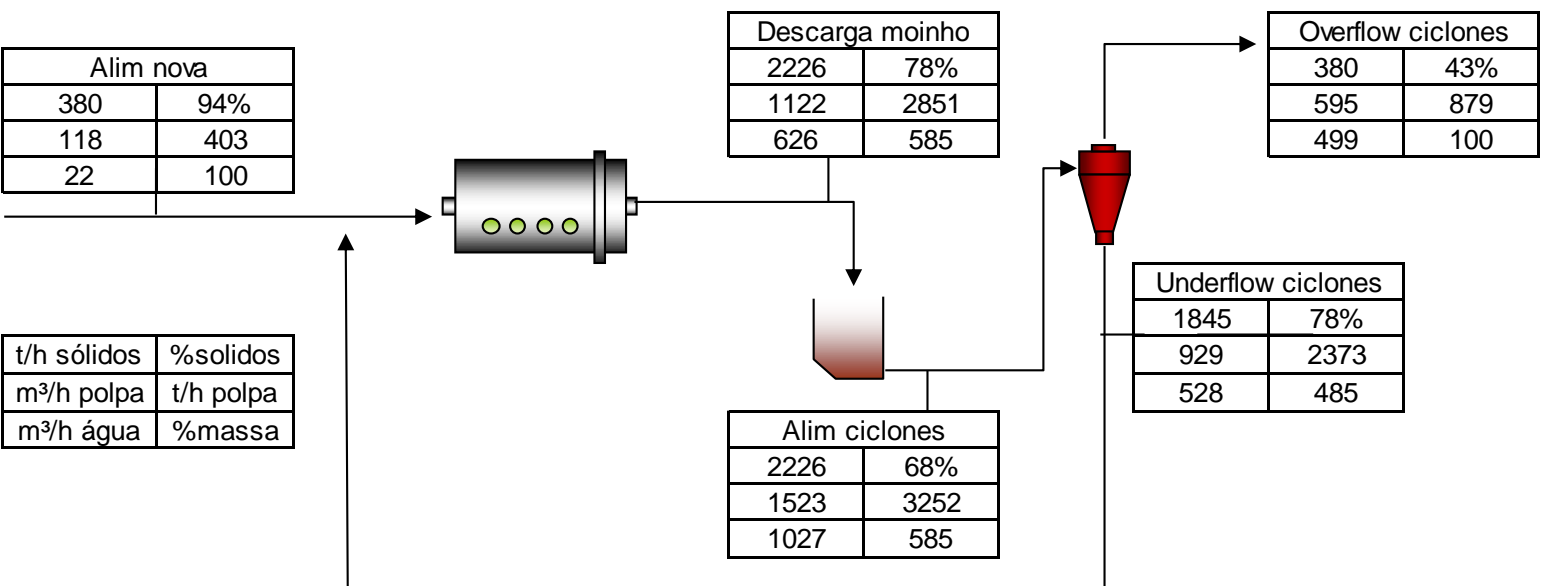

b) Circuito inverso: 


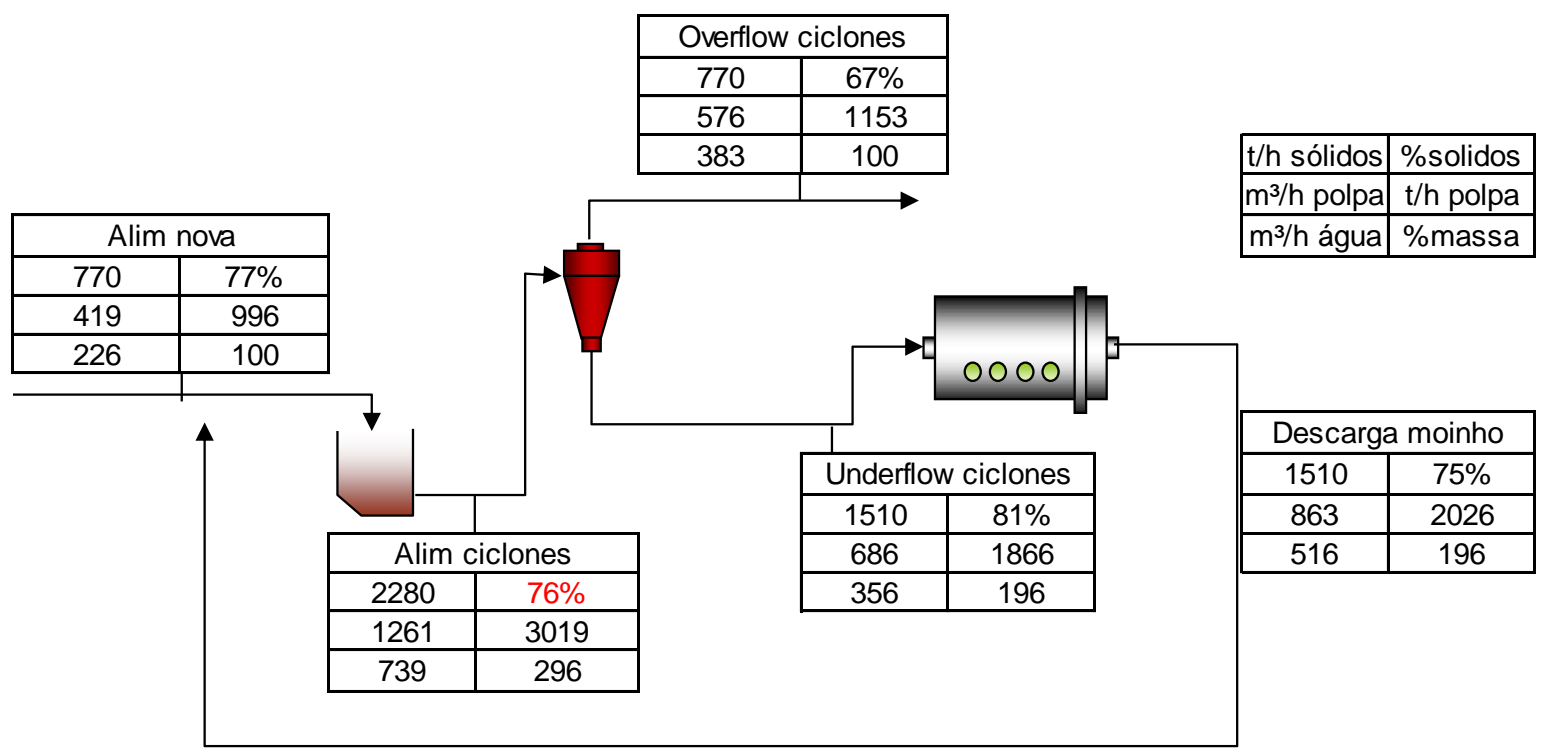

Dados industriais coletados durante a amostragem:

\begin{tabular}{|c|c|c|c|c|c|c|c|c|c|}
\hline \multirow{2}{*}{ Parâmetros } & \multicolumn{10}{|c|}{ Circuito direto } \\
\cline { 2 - 12 } & Linha & $\mathbf{1}$ & $\mathbf{2}$ & $\mathbf{3}$ & $\mathbf{4}$ & $\mathbf{5}$ & $\mathbf{6}$ & $\mathbf{7}$ & Média \\
\hline Pressão ciclones (psi) & $\mathbf{1}$ & 7,0 & 7,0 & 6,9 & 6,5 & 7,0 & 7,0 & 7,0 & 6,9 \\
\hline $\begin{array}{c}\text { Potência Moinho } \\
\text { primário (kW) }\end{array}$ & $\mathbf{1}$ & 1365 & 1418 & 1430 & 1359 & 1384 & 1423 & 1411 & 1399 \\
\hline Vazão (t/h) & $\mathbf{1}$ & 378 & 377 & 403 & 387 & 380 & 365 & 373 & 380 \\
\hline \multicolumn{10}{|c|}{ Circuito inverso } \\
\hline \multicolumn{1}{|c|}{} & Linha & $\mathbf{1}$ & $\mathbf{2}$ & $\mathbf{3}$ & $\mathbf{4}$ & $\mathbf{5}$ & $\mathbf{6}$ & $\mathbf{7}$ & Média \\
\hline Pressão ciclones (psi) & $\mathbf{1}$ & 11,06 & 11,23 & 14,71 & 15,19 & 14,42 & 14,89 & 14,88 & 13,8 \\
\hline $\begin{array}{c}\text { Potência pré-moinho } \\
\text { (kW) }\end{array}$ & $\mathbf{1}$ & 3838 & 3820 & 3779 & 3796 & 3702 & 3584 & 3769 & 3755 \\
\hline $\begin{array}{c}\text { Potência Moinho } \\
\text { primário }\end{array}$ & $\mathbf{1}$ & 1434 & 1431 & 1387 & 1487 & 1484 & 1440 & 1484 & 1450 \\
\hline Vazão (t/h) & $\mathbf{1}$ & 723 & 804 & 727 & 803 & 797 & 795 & 743 & 770 \\
\hline
\end{tabular}

Dados analisados em laboratório:

a) Percentagem de sólidos e densidades:

\begin{tabular}{|c|c|c|c|}
\hline \multicolumn{4}{|c|}{ Circuito direto } \\
\hline Linha & Fluxo & \% Sólidos & ds $\left(\mathrm{g} / \mathrm{cm}^{3}\right)$ \\
\hline \multicolumn{2}{|r|}{ Alimentação nova } & 94,44 & 3,98 \\
\hline \multirow{3}{*}{1} & Descarga Moinho primário & 78,05 & 4,49 \\
\hline & Underflow ciclones & 77,74 & 4,61 \\
\hline & Overflow ciclones & 43,28 & 3,96 \\
\hline \multicolumn{4}{|c|}{ Circuito inverso } \\
\hline Linha & Fluxo & \% Sólidos & ds $\left(\mathrm{g} / \mathrm{cm}^{3}\right)$ \\
\hline \multicolumn{2}{|c|}{ Descarga Pré Moinho 01} & 77,30 & 3,99 \\
\hline \multirow{3}{*}{1} & Descarga Moinho primário & 74,52 & 4,36 \\
\hline & Underflow ciclones & 80,91 & 4,58 \\
\hline & Overflow ciclones & 66,80 & 4,00 \\
\hline
\end{tabular}


b) Análises granulométricas:

\begin{tabular}{|c|c|c|c|c|c|c|c|}
\hline \multicolumn{7}{|c|}{ Circuito direto } \\
\hline \multirow{2}{*}{ Malha ( $\boldsymbol{\mu m}$ ) } & \multicolumn{7}{|c|}{ \% Passante } \\
\hline AN (CV20) & Desc MP1 & Desc MP 2 & OF linha 1 & OF linha 2 & UF linha 1 & UF linha 2 \\
\hline 63.500 & 100,00 & 100,00 & 100,00 & 100,00 & 100,00 & 100,00 & 100,00 \\
\hline 50.800 & 100,00 & 100,00 & 100,00 & 100,00 & 100,00 & 100,00 & 100,00 \\
\hline 38.100 & 99,73 & 100,00 & 100,00 & 100,00 & 100,00 & 100,00 & 100,00 \\
\hline 31.700 & 99,64 & 100,00 & 100,00 & 100,00 & 100,00 & 100,00 & 100,00 \\
\hline 25.400 & 99,19 & 100,00 & 100,00 & 100,00 & 100,00 & 100,00 & 100,00 \\
\hline 22.200 & 98,77 & 100,00 & 100,00 & 100,00 & 100,00 & 100,00 & 100,00 \\
\hline 19.100 & 98,41 & 100,00 & 100,00 & 100,00 & 100,00 & 100,00 & 100,00 \\
\hline 15.875 & 96,80 & 100,00 & 100,00 & 100,00 & 100,00 & 100,00 & 100,00 \\
\hline 12.700 & 93,73 & 99,79 & 99,97 & 100,00 & 100,00 & 99,57 & 99,94 \\
\hline 9.525 & 90,57 & 99,32 & 99,90 & 100,00 & 100,00 & 98,84 & 99,65 \\
\hline 7.938 & 87,34 & 98,88 & 99,83 & 100,00 & 100,00 & 98,23 & 99,36 \\
\hline 6.350 & 84,15 & 98,28 & 99,68 & 100,00 & 100,00 & 97,07 & 98,81 \\
\hline 4.750 & 81,09 & 97,63 & 99,49 & 100,00 & 100,00 & 95,90 & 98,12 \\
\hline 3.360 & 76,68 & 96,36 & 99,12 & 100,00 & 100,00 & 94,02 & 97,04 \\
\hline 2.380 & 73,53 & 95,07 & 98,80 & 100,00 & 100,00 & 92,11 & 95,90 \\
\hline 1.680 & 70,58 & 93,70 & 98,24 & 100,00 & 100,00 & 89,79 & 94,36 \\
\hline 1.190 & 68,61 & 92,41 & 97,65 & 100,00 & 100,00 & 87,66 & 92,89 \\
\hline 1.000 & 67,82 & 91,63 & 97,27 & 100,00 & 100,00 & 86,35 & 91,88 \\
\hline 840 & 66,32 & 90,29 & 96,65 & 100,00 & 100,00 & 84,80 & 90,74 \\
\hline 595 & 64,90 & 87,98 & 95,35 & 99,99 & 99,99 & 82,12 & 88,51 \\
\hline 420 & 63,04 & 83,19 & 92,50 & 99,69 & 99,91 & 76,95 & 83,51 \\
\hline 297 & 61,45 & 78,12 & 88,90 & 99,04 & 99,68 & 70,93 & 78,11 \\
\hline 210 & 57,97 & 66,23 & 78,12 & 96,32 & 98,13 & 57,65 & 65,07 \\
\hline 149 & 51,23 & 48,81 & 59,00 & 88,47 & 93,20 & 38,40 & 43,29 \\
\hline 105 & 42,17 & 35,29 & 39,45 & 76,40 & 84,60 & 23,53 & 24,94 \\
\hline 74 & 34,03 & 26,77 & 26,66 & 64,46 & 74,57 & 16,16 & 15,25 \\
\hline 53 & 25,05 & 19,64 & 16,82 & 49,65 & 60,48 & 10,50 & 8,71 \\
\hline 44 & 21,81 & 17,28 & 14,30 & 43,59 & 54,68 & 8,98 & 7,43 \\
\hline 37 & 19,80 & 16,13 & 13,27 & 39,92 & 50,40 & 8,25 & 6,70 \\
\hline & & & & & & & \\
\hline
\end{tabular}

\begin{tabular}{|c|c|c|c|c|c|c|c|}
\hline \multicolumn{8}{|c|}{ Circuito inverso } \\
\hline \multirow[b]{2}{*}{$\begin{array}{c}\text { Malha } \\
(\mu \mathrm{m})\end{array}$} & \multicolumn{7}{|c|}{ \% Passante } \\
\hline & $\begin{array}{c}\text { AN (desc } \\
\text { PM1) }\end{array}$ & $\begin{array}{l}\text { Desc } \\
\text { MP1 }\end{array}$ & $\begin{array}{c}\text { Desc MP } \\
2\end{array}$ & $\begin{array}{c}\text { OF linha } \\
1\end{array}$ & $\begin{array}{c}\text { OF linha } \\
2\end{array}$ & $\begin{array}{c}\text { UF linha } \\
1\end{array}$ & $\begin{array}{c}\text { UF linha } \\
2\end{array}$ \\
\hline 15.875 & 100,00 & 100,00 & 100,00 & 100,00 & 100,00 & 100,00 & 100,00 \\
\hline 12.700 & 100,00 & 100,00 & 100,00 & 100,00 & 100,00 & 100,00 & 100,00 \\
\hline 9.525 & 99,93 & 100,00 & 99,96 & 100,00 & 100,00 & 99,97 & 99,94 \\
\hline 7.938 & 99,76 & 99,98 & 99,78 & 100,00 & 100,00 & 99,89 & 99,72 \\
\hline 6.350 & 99,18 & 99,92 & 99,26 & 100,00 & 100,00 & 99,70 & 99,28 \\
\hline 4.750 & 98,50 & 99,81 & 98,43 & 100,00 & 100,00 & 99,29 & 98,53 \\
\hline 3.360 & 97,25 & 99,52 & 97,02 & 100,00 & 100,00 & 98,30 & 97,15 \\
\hline 2.380 & 95,82 & 99,09 & 95,48 & 100,00 & 100,00 & 96,88 & 95,41 \\
\hline 1.680 & 93,82 & 98,08 & 93,11 & 100,00 & 100,00 & 94,60 & 92,68 \\
\hline 1.190 & 92,05 & 96,81 & 90,67 & 100,00 & 100,00 & 92,13 & 89,82 \\
\hline 1.000 & 90,93 & 95,79 & 88,86 & 100,00 & 100,00 & 90,38 & 87,69 \\
\hline 840 & 89,33 & 94,24 & 85,88 & 99,85 & 99,94 & 87,63 & 84,62 \\
\hline 595 & 87,30 & 91,45 & 80,73 & 99,62 & 99,84 & 83,21 & 79,36 \\
\hline
\end{tabular}




\begin{tabular}{|c|c|c|c|c|c|c|c|}
\hline \multirow[b]{2}{*}{$\begin{array}{c}\text { Malha } \\
(\mu \mathrm{m})\end{array}$} & \multicolumn{7}{|c|}{ \% Passante } \\
\hline & $\begin{array}{c}\text { AN (desc } \\
\text { PM1) }\end{array}$ & $\begin{array}{l}\text { Desc } \\
\text { MP1 }\end{array}$ & $\begin{array}{c}\text { Desc MP } \\
2\end{array}$ & $\begin{array}{c}\text { OF linha } \\
1\end{array}$ & $\begin{array}{c}\text { OF linha } \\
2\end{array}$ & $\begin{array}{c}\text { UF linha } \\
1\end{array}$ & $\begin{array}{c}\text { UF linha } \\
2\end{array}$ \\
\hline 420 & 83,86 & 85,76 & 71,77 & 98,83 & 99,19 & 73,61 & 69,95 \\
\hline 297 & 80,95 & 79,83 & 63,29 & 97,45 & 98,00 & 66,52 & 60,80 \\
\hline 210 & 75,21 & 68,54 & 48,66 & 92,79 & 93,79 & 53,40 & 44,46 \\
\hline 149 & 67,52 & 59,36 & 37,25 & 83,99 & 84,75 & 43,76 & 32,93 \\
\hline 105 & 57,74 & 50,59 & 30,07 & 72,64 & 73,43 & 36,52 & 25,29 \\
\hline 74 & 48,85 & 43,33 & 25,21 & 62,20 & 62,98 & 30,28 & 20,48 \\
\hline 53 & 36,65 & 33,56 & 19,27 & 48,28 & 49,18 & 22,92 & 15,41 \\
\hline 44 & 32,74 & 30,34 & 16,97 & 42,84 & 42,41 & 20,23 & 13,22 \\
\hline 37 & 30,13 & 28,11 & 15,62 & 39,91 & 38,74 & 18,75 & 12,00 \\
\hline
\end{tabular}

\section{Amostragem 2:}

- Data coleta: agosto de 2010.

- Linhas amostradas:

- Pré-moagem: linha 1;

- Moagem primária: linhas 1 e 2 .

Balanços de massa dos circuitos:

a) Circuito direto - linha 1:

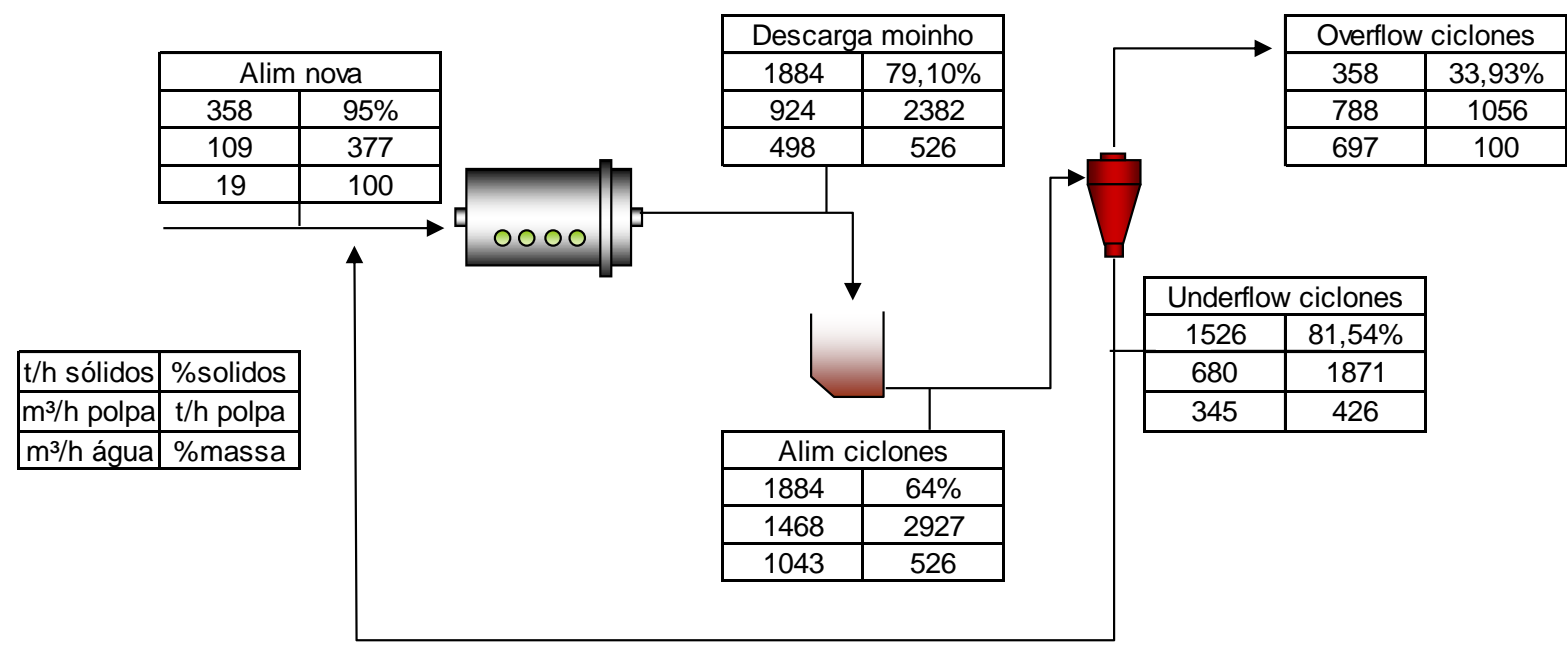

b) Circuito direto - linha 2: 


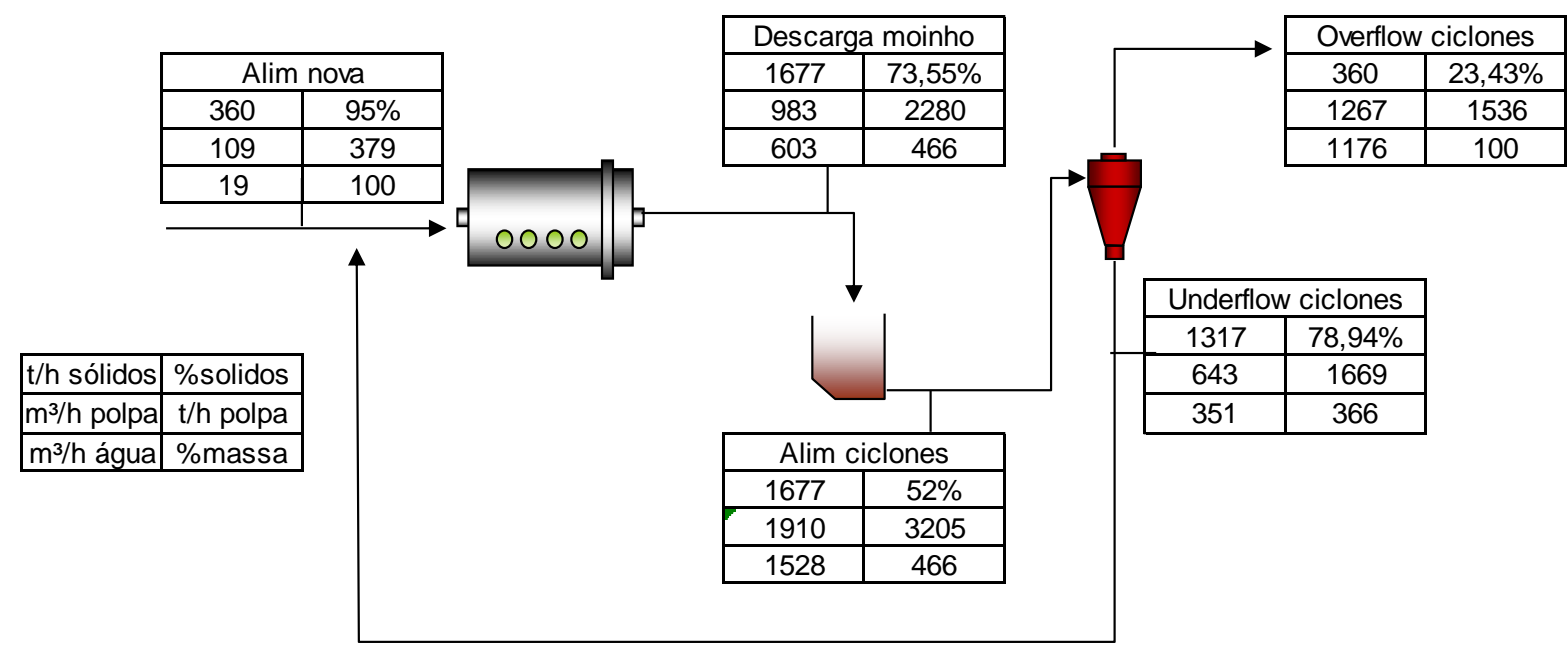

c) Circuito inverso - linha 1:

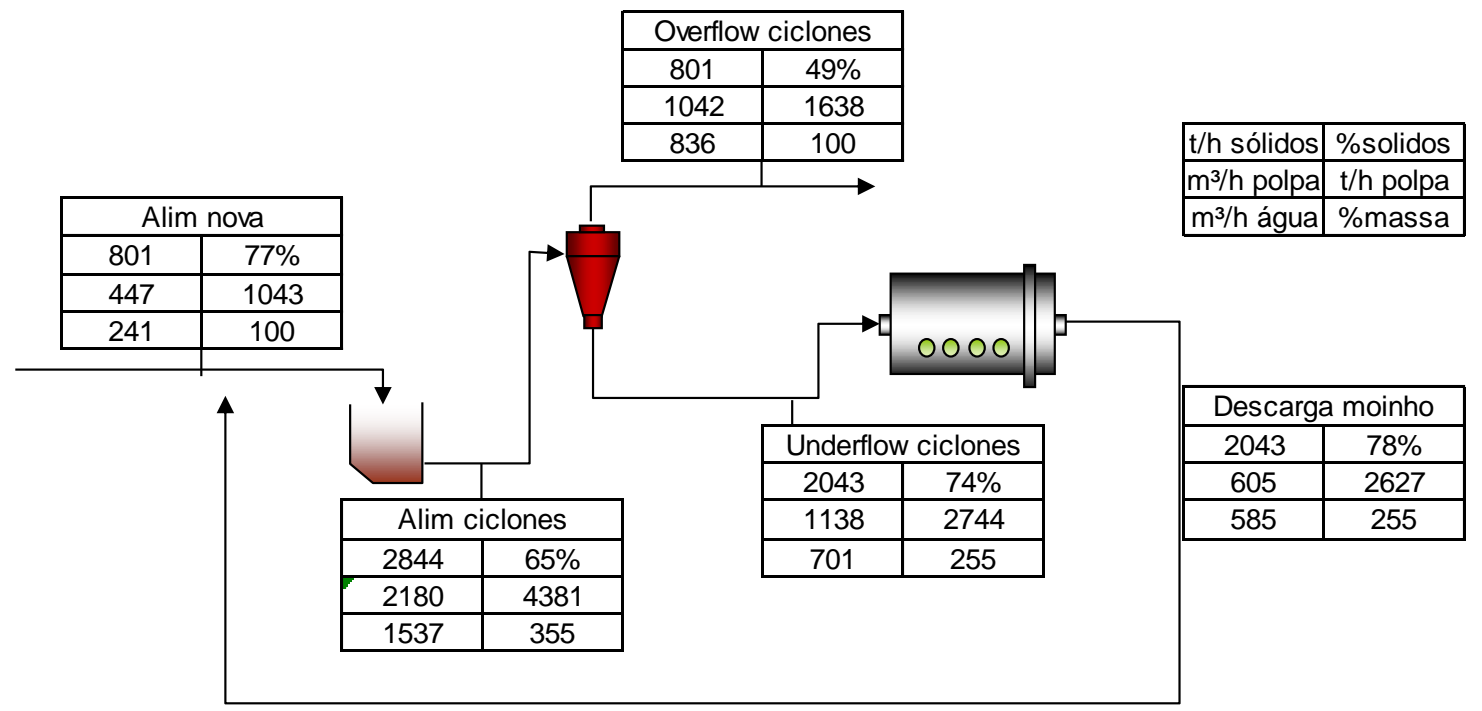

d) Circuito inverso - linha 2: 


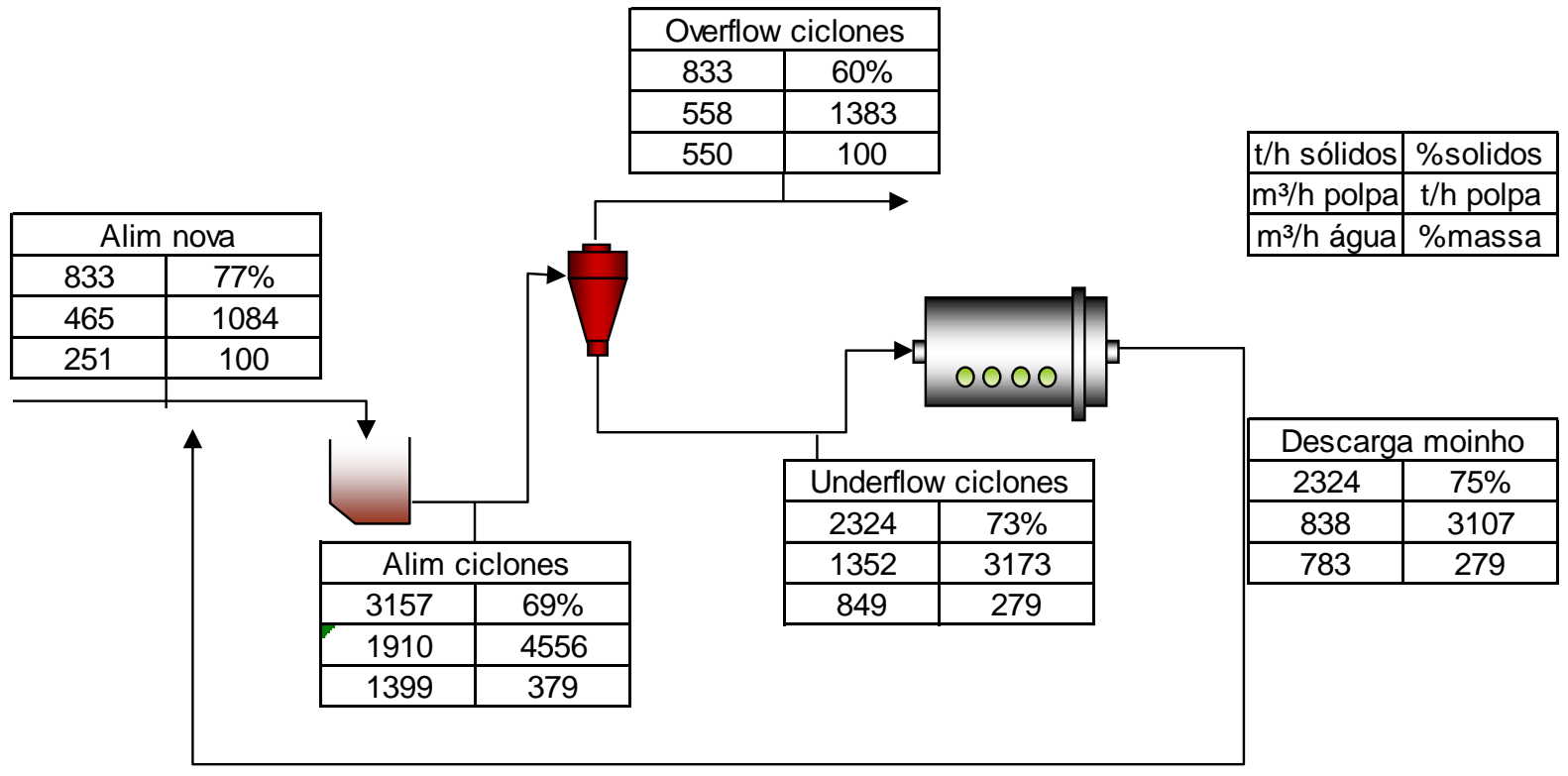

Dados industriais coletados durante a amostragem:

\begin{tabular}{|c|c|c|c|c|c|c|c|c|c|}
\hline \multirow{2}{*}{ Parâmetros } & \multicolumn{9}{|c|}{ Circuito direto } \\
\hline & Linha & 1 & 2 & 3 & 4 & 5 & 6 & 7 & Média \\
\hline \multirow{2}{*}{ Pressão ciclones (psi) } & 1 & 11,24 & 11,15 & 11,04 & 11,01 & 11,11 & 12,08 & 11,23 & 11,3 \\
\hline & 2 & 9,35 & 9,19 & 8,9 & 8,9 & 9,15 & 9,56 & 8,88 & 9,1 \\
\hline \multirow{2}{*}{$\begin{array}{l}\text { Potência moinho primário } \\
(\mathrm{kW})\end{array}$} & 1 & 1381 & 1364 & 1342 & 1368 & 1391 & 1376 & 1467 & 1384 \\
\hline & 2 & 1398 & 1374 & 1337 & 1371 & 1394 & 1354 & 1410 & 1377 \\
\hline \multirow{2}{*}{ Vazão de alimentação (t/h) } & 1 & 368 & 359 & 366 & 366 & 379 & 378 & 291 & 358 \\
\hline & 2 & 342 & 357 & 344 & 351 & 367 & 352 & 407 & 360 \\
\hline \multirow{2}{*}{ Parâmetros } & \multicolumn{9}{|c|}{ Circuito inverso } \\
\hline & \begin{tabular}{|l|} 
Linha \\
\end{tabular} & 1 & 2 & 3 & 4 & 5 & 6 & 7 & Média \\
\hline \multirow{2}{*}{ Pressão ciclones (psi) } & 1 & 11,7 & 11,31 & 11,41 & 11,34 & 11,01 & 11,45 & 11,27 & 11,4 \\
\hline & 2 & 9,57 & 9,28 & 9,45 & 9,43 & 8,72 & 8,53 & 8,07 & 9,0 \\
\hline Potência pré-moinho (kW) & 1 & 3748 & 3699 & 3727 & 3723 & 3627 & 3741 & 3703 & 3710 \\
\hline \multirow{2}{*}{$\begin{array}{c}\text { Potência moinho primário } \\
(\mathrm{kW})\end{array}$} & 1 & 1438 & 1484 & 1391 & 1399 & 1452 & 1467 & 1424 & 1436 \\
\hline & 2 & 1368 & 1434 & 1384 & 1344 & 1462 & 1423 & 1419 & 1405 \\
\hline \multirow{2}{*}{ Vazão de alimentação (t/h) } & 1 & 839 & 811 & 772 & 795 & 840 & 801 & 752 & 801 \\
\hline & 2 & 828 & 869 & 815 & 813 & 857 & 822 & 826 & 833 \\
\hline
\end{tabular}

Dados analisados em laboratório:

a) Percentagem de sólidos e densidades: 


\begin{tabular}{|c|c|c|c|}
\hline \multicolumn{4}{|c|}{ Circuito direto } \\
\hline Linha & Fluxo & \% Sólidos & ds $\left(\mathrm{g} / \mathrm{cm}^{3}\right)$ \\
\hline \multicolumn{2}{|r|}{ Alimentação nova } & 95,00 & 3,98 \\
\hline \multirow{3}{*}{1} & Descarga moinho primário & 79,10 & 4,42 \\
\hline & Underflow ciclones & 81,54 & 4,56 \\
\hline & Overflow ciclones & 33,93 & 3,94 \\
\hline \multirow{3}{*}{2} & Descarga moinho primário & 73,55 & 4,42 \\
\hline & Underflow ciclones & 78,94 & 4,51 \\
\hline & Overflow ciclones & 23,43 & 3,99 \\
\hline \multicolumn{4}{|c|}{ Circuito inverso } \\
\hline Linha & Fluxo & \% Sólidos & ds $\left(\mathrm{g} / \mathrm{cm}^{3}\right)$ \\
\hline \multicolumn{2}{|c|}{ Descarga Pré Moinho 01} & 76,86 & 3,89 \\
\hline \multirow{3}{*}{1} & Descarga moinho primário & 77,75 & 4,63 \\
\hline & Underflow ciclones & 74,44 & 4,68 \\
\hline & Overflow ciclones & 48,94 & 3,89 \\
\hline \multirow{3}{*}{2} & Descarga moinho primário & 74,80 & 4,61 \\
\hline & Underflow ciclones & 73,24 & 4,63 \\
\hline & Overflow ciclones & 60,23 & 3,90 \\
\hline
\end{tabular}

b) Análises granulométricas:

\begin{tabular}{|c|c|c|c|c|c|c|c|}
\hline \multicolumn{7}{|c|}{$\begin{array}{c}\text { Malha } \\
(\boldsymbol{\mu m})\end{array}$} & \multicolumn{7}{|c|}{ \% Passante } \\
\cline { 2 - 8 } & AN (CV20) & Desc MP1 & Desc MP 2 & OF linha 1 & OF linha 2 & UF linha 1 & UF linha 2 \\
\hline 63.500 & 100,00 & 100,00 & 100,00 & 100,00 & 100,00 & 100,00 & 100,00 \\
\hline 50.800 & 100,00 & 100,00 & 100,00 & 100,00 & 100,00 & 100,00 & 100,00 \\
\hline 38.100 & 100,00 & 100,00 & 100,00 & 100,00 & 100,00 & 100,00 & 100,00 \\
\hline 31.700 & 100,00 & 100,00 & 100,00 & 100,00 & 100,00 & 100,00 & 100,00 \\
\hline 25.400 & 100,00 & 100,00 & 100,00 & 100,00 & 100,00 & 100,00 & 100,00 \\
\hline 22.200 & 99,96 & 100,00 & 100,00 & 100,00 & 100,00 & 100,00 & 100,00 \\
\hline 19.100 & 99,81 & 100,00 & 100,00 & 100,00 & 100,00 & 100,00 & 100,00 \\
\hline 15.875 & 99,33 & 100,00 & 100,00 & 100,00 & 100,00 & 100,00 & 100,00 \\
\hline 12.700 & 97,72 & 100,00 & 100,00 & 100,00 & 100,00 & 99,91 & 99,89 \\
\hline 9.525 & 93,63 & 99,67 & 99,89 & 100,00 & 100,00 & 99,28 & 99,61 \\
\hline 7.938 & 90,13 & 99,07 & 99,75 & 100,00 & 100,00 & 98,80 & 99,19 \\
\hline 6.350 & 86,83 & 98,00 & 99,24 & 100,00 & 100,00 & 97,64 & 98,44 \\
\hline 4.750 & 82,74 & 96,69 & 98,71 & 100,00 & 100,00 & 96,46 & 97,49 \\
\hline 3.360 & 78,17 & 94,51 & 97,66 & 100,00 & 100,00 & 93,80 & 95,83 \\
\hline 2.380 & 74,76 & 92,80 & 96,52 & 100,00 & 100,00 & 92,17 & 94,38 \\
\hline 1.680 & 71,52 & 90,65 & 95,25 & 100,00 & 100,00 & 89,77 & 92,56 \\
\hline 1.190 & 69,23 & 88,72 & 94,22 & 100,00 & 100,00 & 87,70 & 90,83 \\
\hline 1.000 & 68,18 & 84,47 & 93,67 & 100,00 & 100,00 & 86,58 & 89,96 \\
\hline 840 & 66,97 & 83,24 & 92,59 & 100,00 & 100,00 & 84,99 & 88,56 \\
\hline 595 & 65,37 & 80,82 & 90,60 & 99,99 & 99,89 & 81,84 & 86,11 \\
\hline 420 & 63,22 & 75,92 & 86,68 & 99,98 & 99,85 & 75,34 & 80,93 \\
\hline 297 & 61,39 & 70,49 & 82,33 & 99,88 & 99,75 & 68,94 & 74,82 \\
\hline 210 & 57,47 & 59,07 & 71,61 & 98,82 & 98,88 & 53,74 & 61,10 \\
\hline 149 & 50,70 & 43,88 & 56,51 & 94,32 & 94,77 & 35,78 & 42,07 \\
\hline 105 & 41,74 & 30,96 & 41,91 & 84,56 & 86,10 & 22,27 & 24,86 \\
\hline 74 & 33,61 & 23,54 & 32,46 & 73,59 & 75,12 & 14,99 & 14,34 \\
\hline
\end{tabular}




\begin{tabular}{|c|c|c|c|c|c|c|c|}
\hline \multirow{2}{*}{$\begin{array}{c}\text { Malha } \\
(\boldsymbol{\mu m})\end{array}$} & \multicolumn{7}{|c|}{ \% Passante } \\
\cline { 2 - 8 } & AN (CV20) & Desc MP1 & Desc MP 2 & OF linha 1 & OF linha 2 & UF linha 1 & UF linha 2 \\
\hline 53 & 24,39 & 16,96 & 24,68 & 57,39 & 59,97 & 9,42 & 7,85 \\
\hline 44 & 21,18 & 14,63 & 22,18 & 50,73 & 53,69 & 7,96 & 6,71 \\
\hline 37 & 19,10 & 12,89 & 20,66 & 46,34 & 48,90 & 6,95 & 5,92 \\
\hline
\end{tabular}

\begin{tabular}{|c|c|c|c|c|c|c|c|}
\hline \multicolumn{8}{|c|}{ Circuito inverso } \\
\hline \multirow[b]{2}{*}{$\begin{array}{c}\text { Malha } \\
(\mu \mathrm{m})\end{array}$} & \multicolumn{7}{|c|}{ \% Passante } \\
\hline & $\begin{array}{c}\text { AN (desc } \\
\text { PM1) }\end{array}$ & Desc MP1 & Desc MP 2 & OF linha 1 & OF linha 2 & UF linha 1 & UF linha 2 \\
\hline 15.875 & 100,00 & 100,00 & 100,00 & 100,00 & 100,00 & 100,00 & 100,00 \\
\hline 12.700 & 99,98 & 100,00 & 100,00 & 100,00 & 100,00 & 99,99 & 100,00 \\
\hline 9.525 & 99,98 & 99,95 & 99,92 & 100,00 & 100,00 & 99,97 & 99,97 \\
\hline 7.938 & 99,94 & 99,85 & 99,88 & 100,00 & 100,00 & 99,89 & 99,88 \\
\hline 6.350 & 99,85 & 99,67 & 99,68 & 100,00 & 100,00 & 99,70 & 99,67 \\
\hline 4.750 & 99,69 & 99,33 & 99,48 & 100,00 & 100,00 & 99,32 & 99,37 \\
\hline 3.360 & 99,35 & 98,62 & 99,01 & 100,00 & 100,00 & 98,67 & 98,60 \\
\hline 2.380 & 98,80 & 97,77 & 98,32 & 100,00 & 100,00 & 97,86 & 97,56 \\
\hline 1.680 & 97,75 & 96,74 & 97,13 & 100,00 & 100,00 & 96,49 & 95,76 \\
\hline 1.190 & 96,26 & 95,68 & 95,68 & 100,00 & 100,00 & 94,79 & 93,75 \\
\hline 1.000 & 95,08 & 95,03 & 94,57 & 100,00 & 100,00 & 93,51 & 92,26 \\
\hline 840 & 94,38 & 93,37 & 92,80 & 99,98 & 99,94 & 92,02 & 90,06 \\
\hline 595 & 92,82 & 89,97 & 88,50 & 99,94 & 99,83 & 88,66 & 85,40 \\
\hline 420 & 89,82 & 82,80 & 79,59 & 99,63 & 99,28 & 81,32 & 76,50 \\
\hline 297 & 86,98 & 74,47 & 70,07 & 98,93 & 98,31 & 72,29 & 67,19 \\
\hline 210 & 81,35 & 57,50 & 53,36 & 96,19 & 94,81 & 53,16 & 50,15 \\
\hline 149 & 72,44 & 40,55 & 39,48 & 89,04 & 86,66 & 35,45 & 35,30 \\
\hline 105 & 61,93 & 29,57 & 31,58 & 77,83 & 75,54 & 24,35 & 27,07 \\
\hline 74 & 52,32 & 23,98 & 27,14 & 67,02 & 65,19 & 18,72 & 22,67 \\
\hline 53 & 39,73 & 18,00 & 21,39 & 52,71 & 52,39 & 13,39 & 16,97 \\
\hline 44 & 34,56 & 16,47 & 19,78 & 47,56 & 46,89 & 12,31 & 15,62 \\
\hline 37 & 28,88 & 13,92 & 17,28 & 42,59 & 42,41 & 10,10 & 13,38 \\
\hline
\end{tabular}

\section{Amostragem 3:}

- Data coleta: outubro de 2010

- Linhas amostradas:

- Pré-moagem: linha 2;

- Moagem primária: linhas 3 e 4 .

Balanços de massa dos circuitos:

a) Circuito direto - linha 3: 


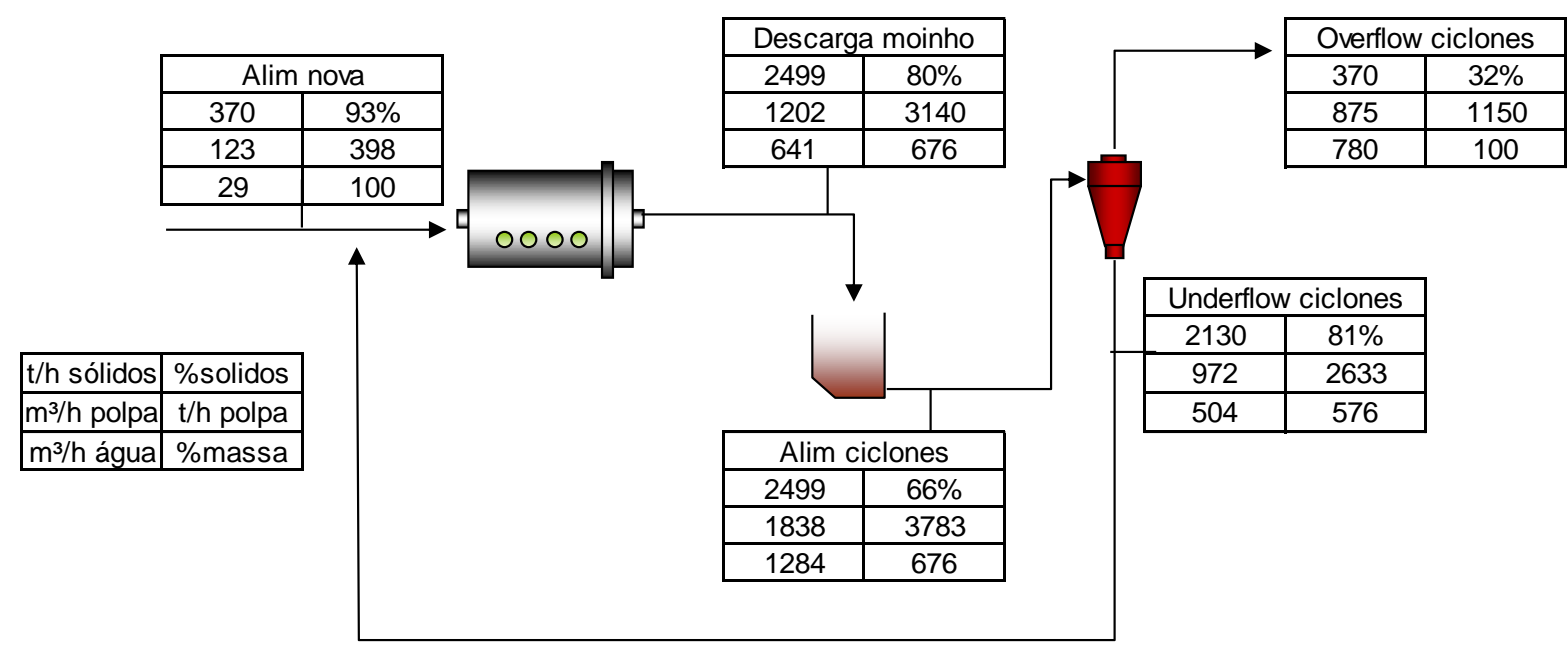

b) Circuito direto - linha 4:

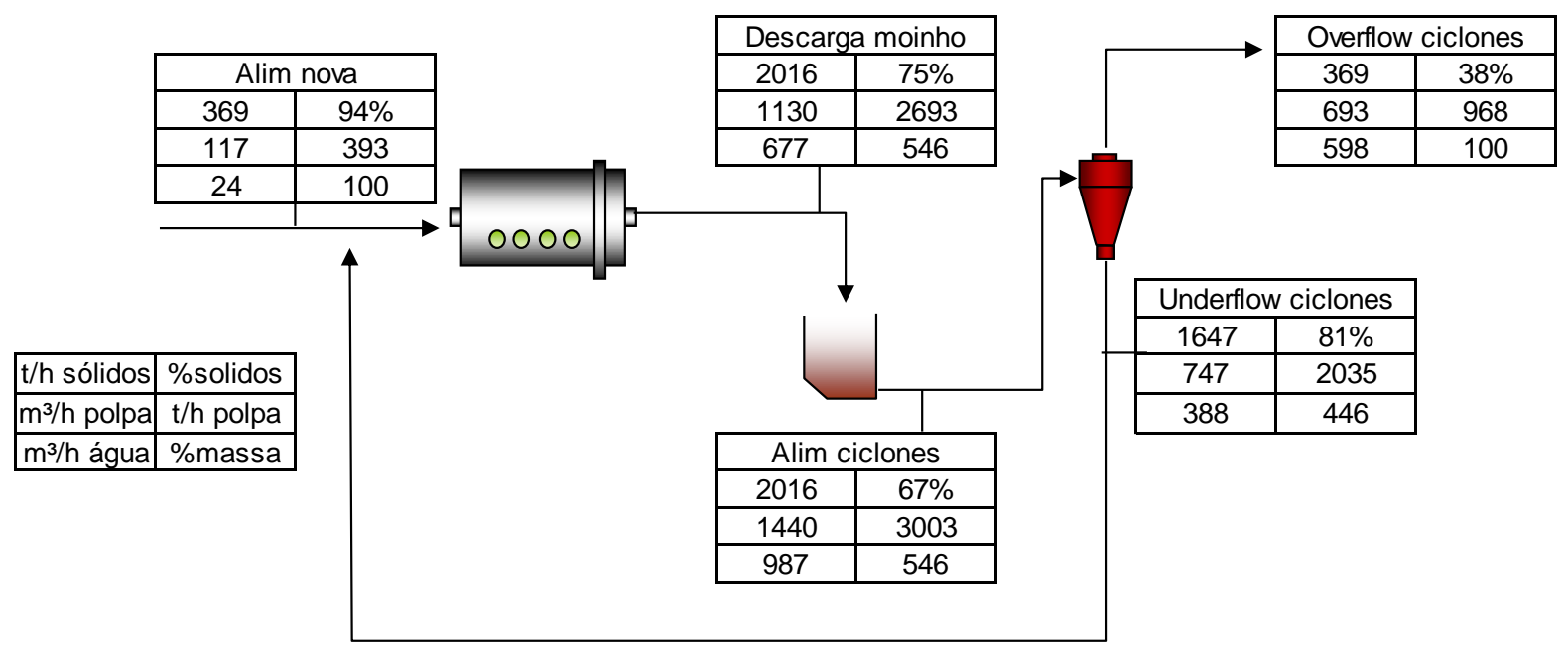

c) Circuito inverso - linha 3: 


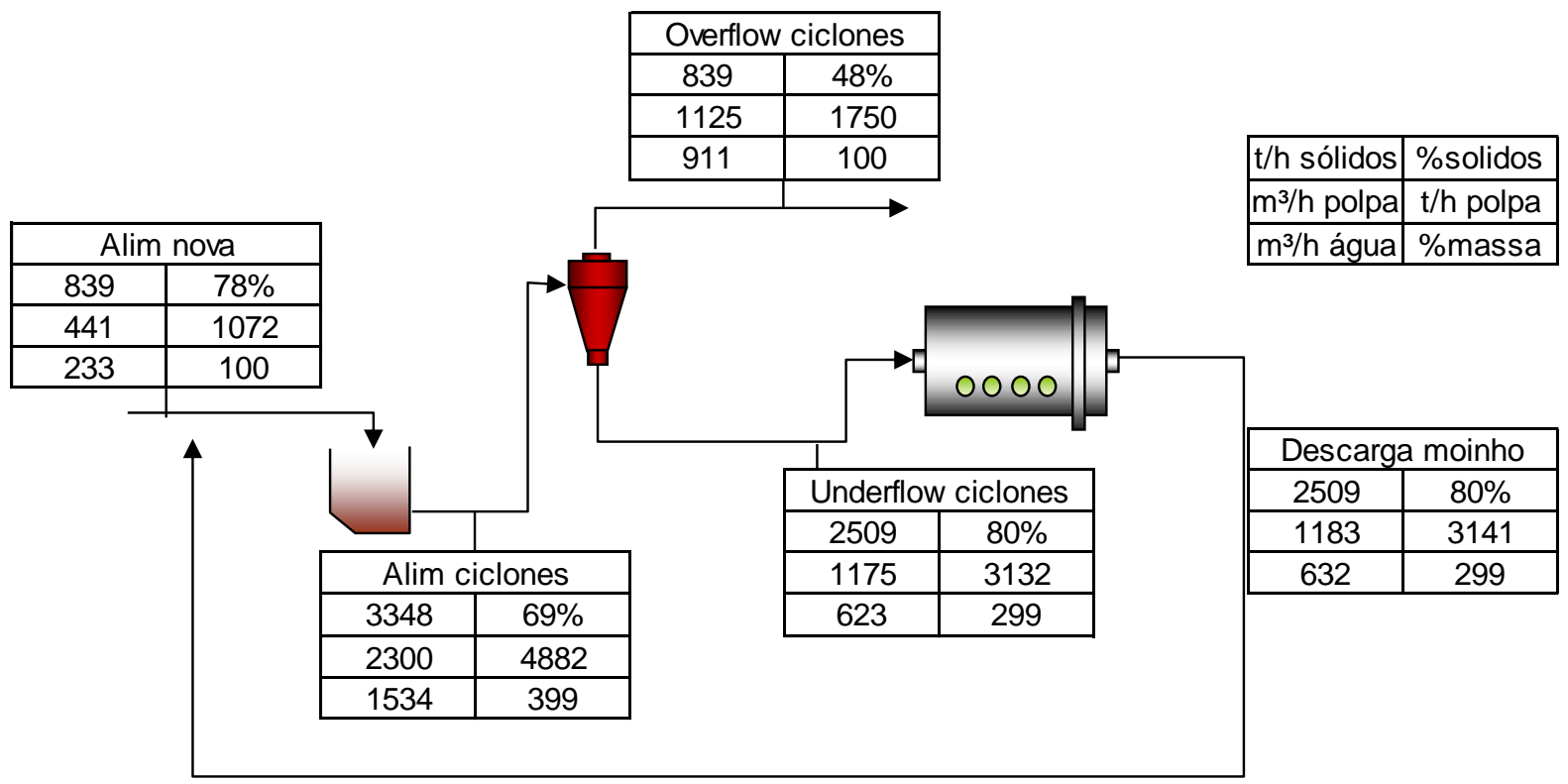

d) Circuito inverso - linha 4:

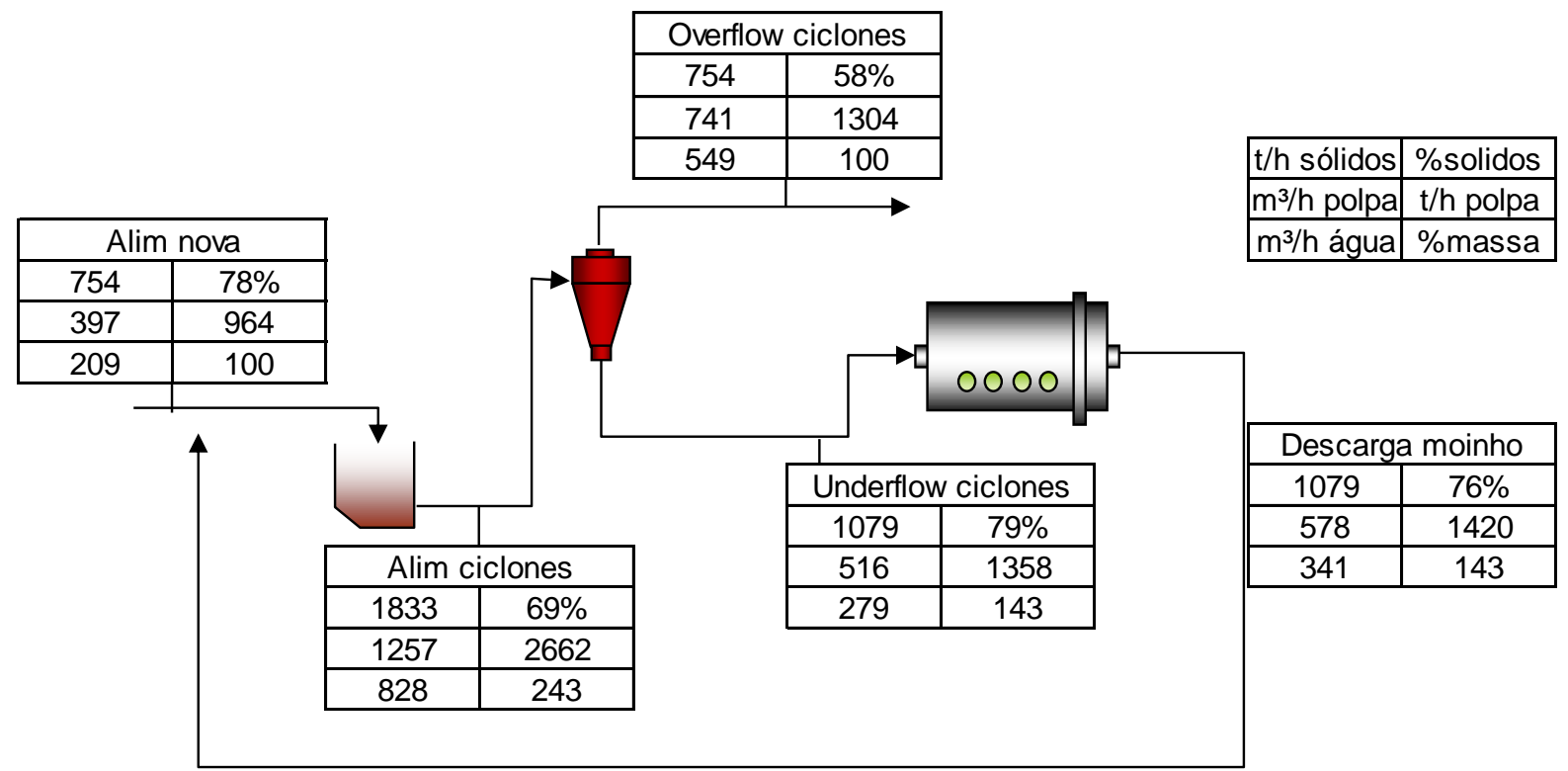


Dados industriais coletados durante a amostragem:

\begin{tabular}{|c|c|c|c|c|c|c|c|c|c|}
\hline \multirow{2}{*}{ Parâmetros } & \multicolumn{9}{|c|}{ Circuito direto } \\
\hline & Linha & 1 & 2 & 3 & 4 & 5 & 6 & 7 & Média \\
\hline \multirow{2}{*}{ Pressão ciclones (psi) } & 3 & 11,39 & 11,18 & 11,2 & 11,47 & 11,57 & 11,73 & 11,96 & 11,5 \\
\hline & 4 & 6,19 & 6,18 & 6,55 & 6,49 & 6,18 & 6,64 & 6,8 & 6,4 \\
\hline \multirow{2}{*}{$\begin{array}{c}\text { Potência moinho primário } \\
(\mathrm{kW})\end{array}$} & 3 & 1413 & 1354 & 1382 & 1365 & 1359 & 1409 & 1373 & 1379 \\
\hline & 4 & 1366 & 1380 & 1379 & 1358 & 1346 & 1347 & 1377 & 1365 \\
\hline \multirow{2}{*}{ Vazão (t/h) } & 3 & 365 & 353 & 356 & 351 & 351 & 405 & 407 & 370 \\
\hline & 4 & 417 & 361 & 401 & 391 & 331 & 342 & 342 & 369 \\
\hline \multirow{2}{*}{ Parâmetros } & \multicolumn{9}{|c|}{ Circuito inverso } \\
\hline & Linha & 1 & 2 & 3 & 4 & 5 & 6 & 7 & Média \\
\hline \multirow{2}{*}{ Pressão ciclones (psi) } & 3 & 10,16 & 10,22 & 10,09 & 10,12 & 10,5 & 10,53 & 10,13 & 10,3 \\
\hline & 4 & 8,26 & 8,22 & 8,28 & 8,77 & 8,63 & 8,43 & 8,17 & 8,4 \\
\hline Potência pré-moinho (kW) & 2 & 3532 & 3443 & 3570 & 3580 & 3551 & 3509 & 3630 & 3545 \\
\hline \multirow{2}{*}{$\begin{array}{c}\text { Potência moinho primário } \\
(\mathrm{kW})\end{array}$} & 3 & 1286 & 1281 & 1261 & 1299 & 1293 & 1222 & 1313 & 1279 \\
\hline & 4 & 1320 & 1287 & 1278 & 1327 & 1297 & 1300 & 1326 & 1305 \\
\hline \multirow{2}{*}{ Vazão (t/h) } & 3 & 836 & 813 & 818 & 884 & 788 & 921 & 813 & 839 \\
\hline & 4 & 753 & 740 & 750 & 755 & 735 & 807 & 741 & 754 \\
\hline
\end{tabular}

Dados analisados em laboratório:

a) Percentagem de sólidos e densidades:

\begin{tabular}{|c|c|c|c|}
\hline \multicolumn{4}{|c|}{ Circuito direto } \\
\hline Linha & Fluxo & \% Sólidos & ds $\left(\mathrm{g} / \mathrm{cm}^{3}\right)$ \\
\hline \multirow{5}{*}{3} & Alimentação nova & 92,80 & 3,90 \\
\hline & Descarga moinho primário & 79,59 & 4,45 \\
\hline & Alimentação ciclones & 66,06 & 4,51 \\
\hline & Underflow ciclones & 80,87 & 4,55 \\
\hline & Overflow ciclones & 32,15 & 3,89 \\
\hline \multirow{5}{*}{4} & Alimentação nova & 93,97 & 3,97 \\
\hline & Descarga moinho primário & 74,86 & 4,45 \\
\hline & Alimentação ciclones & 67,14 & 4,45 \\
\hline & Underflow ciclones & 80,92 & 4,59 \\
\hline & Overflow ciclones & 38,16 & 3,91 \\
\hline \multicolumn{4}{|c|}{ Circuito inverso } \\
\hline Linha & Fluxo & \% Sólidos & ds $\left(\mathrm{g} / \mathrm{cm}^{3}\right)$ \\
\hline \multicolumn{2}{|c|}{ Descarga Pré Moinho 02} & 78,30 & 4,02 \\
\hline \multirow{4}{*}{3} & Alimentação nova & 79,87 & 4,56 \\
\hline & Descarga moinho primário & 68,58 & 4,41 \\
\hline & Alimentação ciclones & 80,10 & 4,55 \\
\hline & Underflow ciclones & 47,94 & 3,93 \\
\hline \multirow{4}{*}{4} & Alimentação nova & 76,00 & 4,55 \\
\hline & Descarga moinho primário & 68,87 & 4,33 \\
\hline & Alimentação ciclones & 79,45 & 4,55 \\
\hline & Underflow ciclones & 57,87 & 3,94 \\
\hline
\end{tabular}

b) Análises granulométricas: 


\begin{tabular}{|c|c|c|c|c|c|c|c|c|c|c|}
\hline \multicolumn{11}{|c|}{ Circuito direto } \\
\hline \multirow[b]{2}{*}{ Malha ( $\mu \mathrm{m})$} & \multicolumn{10}{|c|}{ \% Passante } \\
\hline & AN (CV 14) & AN (CV 15) & Desc MP 3 & $\begin{array}{l}\text { Alim 10 } \\
\text { Linha } 3\end{array}$ & OF linha 3 & UF linha 3 & Desc MP 4 & $\begin{array}{l}\text { Alim 10 } \\
\text { Linha } 4\end{array}$ & OF linha 4 & UF linha 4 \\
\hline 63.500 & 100,00 & 100,00 & 100,00 & 100,00 & 100,00 & 100,00 & 100,00 & 100,00 & 100,00 & 100,00 \\
\hline 50.800 & 100,00 & 100,00 & 100,00 & 100,00 & 100,00 & 100,00 & 100,00 & 100,00 & 100,00 & 100,00 \\
\hline 38.100 & 100,00 & 100,00 & 100,00 & 100,00 & 100,00 & 100,00 & 100,00 & 100,00 & 100,00 & 100,00 \\
\hline 31.700 & 100,00 & 100,00 & 100,00 & 100,00 & 100,00 & 100,00 & 100,00 & 100,00 & 100,00 & 100,00 \\
\hline 25.400 & 100,00 & 100,00 & 100,00 & 100,00 & 100,00 & 100,00 & 100,00 & 100,00 & 100,00 & 100,00 \\
\hline 22.200 & 100,00 & 100,00 & 100,00 & 100,00 & 100,00 & 100,00 & 100,00 & 100,00 & 100,00 & 100,00 \\
\hline 19.100 & 100,00 & 100,00 & 100,00 & 100,00 & 100,00 & 100,00 & 100,00 & 100,00 & 100,00 & 100,00 \\
\hline 15.875 & 100,00 & 100,00 & 100,00 & 100,00 & 100,00 & 100,00 & 100,00 & 100,00 & 100,00 & 100,00 \\
\hline 12.700 & 95,62 & 96,69 & 100,00 & 100,00 & 100,00 & 99,79 & 100,00 & 100,00 & 100,00 & 100,00 \\
\hline 9.525 & 92,50 & 93,20 & 99,66 & 99,17 & 100,00 & 99,48 & 99,74 & 99,77 & 100,00 & 99,55 \\
\hline 7.938 & 90,09 & 91,07 & 98,94 & 98,42 & 100,00 & 98,64 & 99,59 & 99,44 & 100,00 & 99,42 \\
\hline 6.350 & 86,67 & 87,90 & 97,71 & 97,22 & 100,00 & 97,61 & 99,14 & 98,80 & 100,00 & 98,66 \\
\hline 4.750 & 83,76 & 84,34 & 96,55 & 95,73 & 100,00 & 96,07 & 98,54 & 97,32 & 100,00 & 97,58 \\
\hline 3.360 & 79,69 & 79,32 & 94,35 & 93,23 & 100,00 & 94,36 & 97,23 & 95,15 & 100,00 & 95,62 \\
\hline 2.380 & 76,09 & 75,77 & 92,77 & 90,96 & 100,00 & 92,85 & 95,60 & 93,07 & 100,00 & 93,85 \\
\hline 1.680 & 72,36 & 71,93 & 91,00 & 88,22 & 100,00 & 91,03 & 93,21 & 90,54 & 100,00 & 91,36 \\
\hline 1.190 & 69,73 & 69,29 & 89,49 & 85,79 & 100,00 & 89,30 & 91,02 & 88,17 & 100,00 & 88,97 \\
\hline 1.000 & 68,43 & 68,00 & 88,60 & 84,36 & 100,00 & 88,26 & 89,48 & 86,65 & 100,00 & 87,41 \\
\hline 840 & 67,59 & 66,89 & 87,66 & 83,05 & 100,00 & 87,21 & 87,81 & 84,81 & 100,00 & 85,59 \\
\hline 595 & 65,93 & 65,11 & 85,89 & 80,12 & 100,00 & 85,09 & 84,37 & 81,52 & 100,00 & 82,22 \\
\hline 420 & 63,51 & 62,64 & 82,55 & 74,93 & 99,96 & 80,57 & 78,30 & 75,65 & 99,84 & 75,81 \\
\hline 297 & 61,30 & 60,25 & 78,29 & 69,22 & 99,72 & 74,96 & 71,92 & 69,70 & 99,39 & 68,58 \\
\hline 210 & 56,25 & 54,96 & 67,35 & 57,25 & 96,77 & 61,21 & 59,22 & 57,85 & 96,45 & 54,20 \\
\hline 149 & 49,15 & 47,72 & 51,74 & 41,79 & 89,48 & 42,21 & 44,55 & 43,76 & 89,59 & 37,28 \\
\hline 105 & 41,64 & 40,19 & 36,58 & 28,08 & 79,16 & 24,82 & 32,31 & 31,95 & 79,93 & 23,75 \\
\hline 74 & 35,31 & 33,96 & 27,36 & 20,30 & 68,25 & 15,17 & 25,01 & 24,82 & 70,15 & 16,32 \\
\hline 53 & 27,64 & 26,44 & 19,87 & 14,33 & 54,01 & 8,95 & 18,51 & 18,49 & 57,00 & 10,85 \\
\hline 44 & 25,57 & 22,71 & 16,92 & 12,02 & 47,22 & 7,41 & 15,95 & 16,73 & 50,20 & 9,16 \\
\hline 37 & 22,91 & 19,65 & 15,06 & 10,69 & 41,35 & 6,07 & 13,95 & 14,17 & 44,24 & 7,86 \\
\hline
\end{tabular}


Circuito inverso

\begin{tabular}{|c|c|c|c|c|c|c|c|c|c|}
\hline \multicolumn{9}{|c|}{ Circuito inverso } \\
\hline \multirow{2}{*}{$\begin{array}{c}\text { Malha } \\
(\boldsymbol{\mu m})\end{array}$} & \multicolumn{9}{|c|}{ \% Passante } \\
\hline & AN (Desc PM 2) & Desc MP 3 & Alim 10 Linha 3 & OF linha 3 & UF linha 3 & Desc MP 4 & Alim 10 Linha 4 & OF linha 4 & UF linha 4 \\
\hline 15.875 & 100,00 & 100,00 & 100,00 & 100,00 & 100,00 & 100,00 & 100,00 & 100,00 & 100,00 \\
\hline 12.700 & 100,00 & 100,00 & 100,00 & 100,00 & 100,00 & 100,00 & 100,00 & 100,00 & 100,00 \\
\hline 9.525 & 100,00 & 100,00 & 100,00 & 100,00 & 100,00 & 100,00 & 100,00 & 100,00 & 100,00 \\
\hline 7.938 & 99,27 & 99,86 & 99,87 & 100,00 & 99,66 & 100,00 & 99,94 & 100,00 & 99,68 \\
\hline 6.350 & 98,40 & 99,45 & 99,23 & 100,00 & 99,45 & 99,92 & 99,78 & 100,00 & 98,50 \\
\hline 4.750 & 97,37 & 98,94 & 98,41 & 100,00 & 98,73 & 99,66 & 99,42 & 100,00 & 97,72 \\
\hline 3.360 & 95,50 & 97,92 & 97,14 & 100,00 & 97,54 & 99,16 & 98,50 & 100,00 & 96,37 \\
\hline 2.380 & 93,21 & 96,81 & 95,80 & 100,00 & 96,15 & 98,30 & 97,49 & 100,00 & 94,66 \\
\hline 1.680 & 90,64 & 95,40 & 94,04 & 100,00 & 94,02 & 96,98 & 95,99 & 100,00 & 92,33 \\
\hline 1.190 & 88,28 & 93,65 & 92,29 & 100,00 & 91,74 & 95,27 & 94,25 & 100,00 & 89,99 \\
\hline 1.000 & 86,93 & 92,53 & 91,06 & 100,00 & 90,25 & 92,33 & 93,08 & 100,00 & 88,15 \\
\hline 840 & 85,64 & 91,37 & 89,47 & 100,00 & 89,03 & 91,23 & 91,71 & 99,97 & 86,42 \\
\hline 595 & 83,25 & 88,36 & 86,40 & 99,92 & 85,13 & 88,22 & 88,62 & 99,92 & 82,87 \\
\hline 420 & 79,76 & 81,55 & 80,22 & 99,59 & 77,02 & 81,43 & 82,59 & 99,45 & 75,00 \\
\hline 297 & 76,57 & 73,60 & 73,76 & 98,84 & 68,57 & 74,15 & 76,31 & 98,46 & 66,56 \\
\hline 210 & 70,85 & 57,41 & 60,84 & 95,44 & 52,84 & 59,78 & 64,49 & 94,27 & 49,51 \\
\hline 149 & 63,34 & 40,58 & 46,76 & 87,87 & 37,79 & 45,58 & 52,22 & 86,01 & 32,53 \\
\hline 105 & 54,89 & 29,99 & 36,86 & 77,48 & 28,45 & 36,12 & 43,03 & 75,28 & 22,46 \\
\hline 74 & 47,34 & 24,15 & 30,56 & 67,61 & 23,01 & 30,25 & 36,55 & 65,26 & 17,28 \\
\hline 53 & 37,65 & 18,34 & 23,74 & 54,78 & 17,42 & 23,86 & 29,09 & 52,33 & 12,50 \\
\hline 44 & 32,66 & 15,75 & 20,97 & 48,40 & 15,80 & 21,05 & 26,06 & 46,00 & 10,82 \\
\hline 37 & 29,38 & 14,22 & 18,33 & 43,46 & 13,54 & 18,96 & 22,97 & 40,90 & 9,37 \\
\hline
\end{tabular}




\section{Amostragem 4:}

- Data coleta: novembro de 2010

- Linhas amostradas:

- Pré-moagem: linha 2;

- Moagem primária: linhas 3 e 4 .

Balanços de massa dos circuitos:

a) Circuito direto - linha 3:

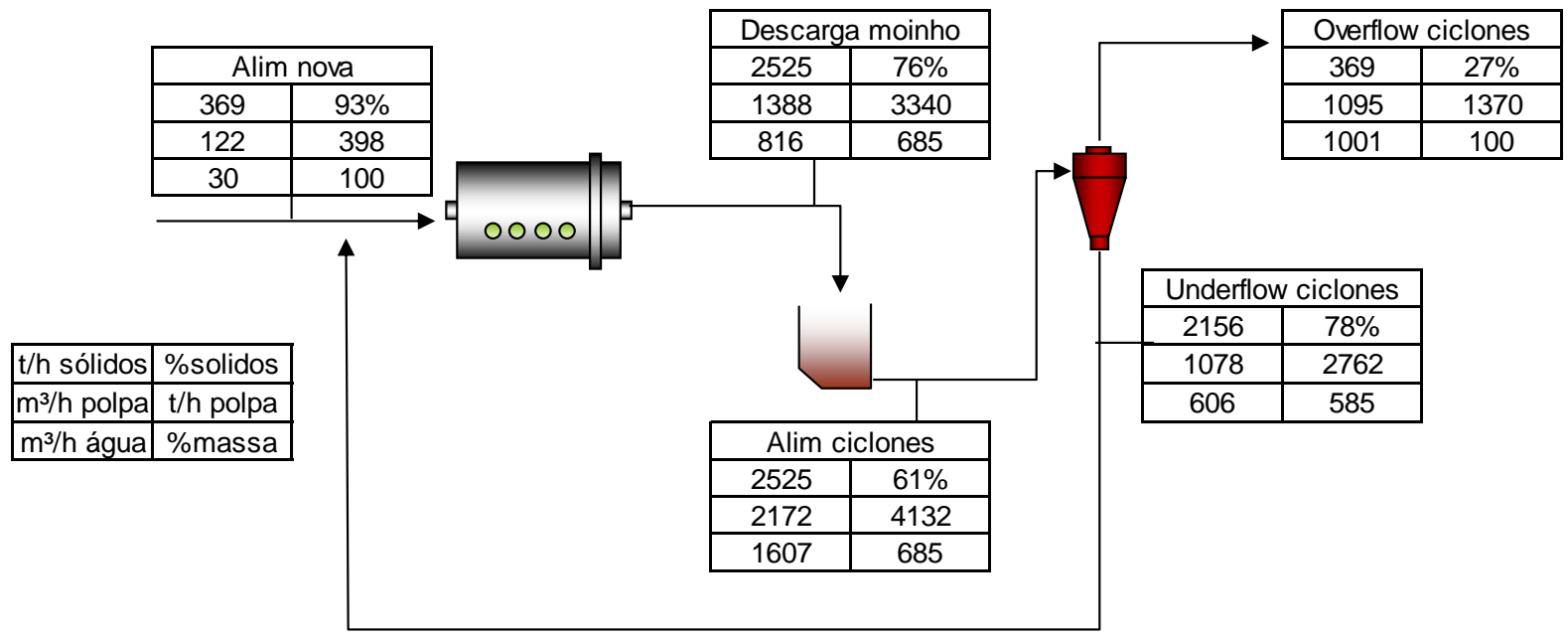

b) Circuito direto - linha 4:

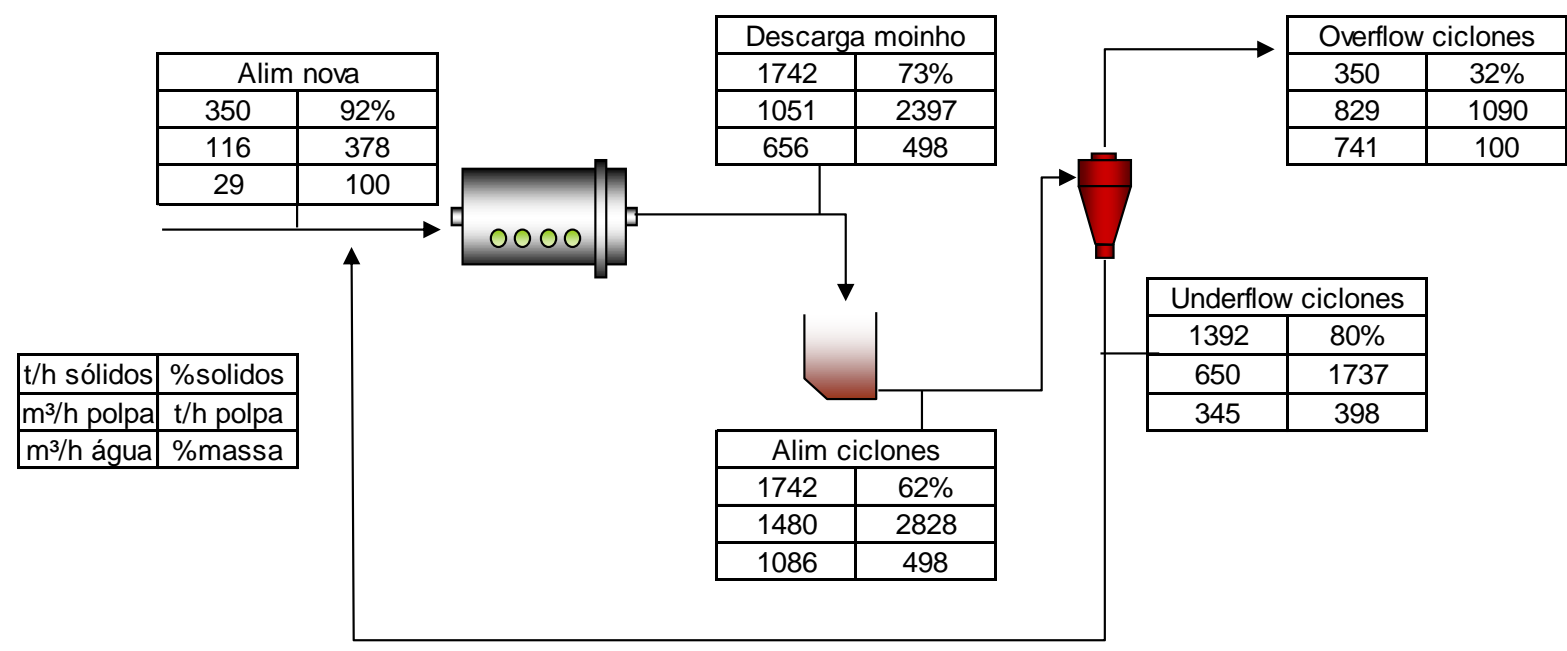

c) Circuito inverso - linha 3: 


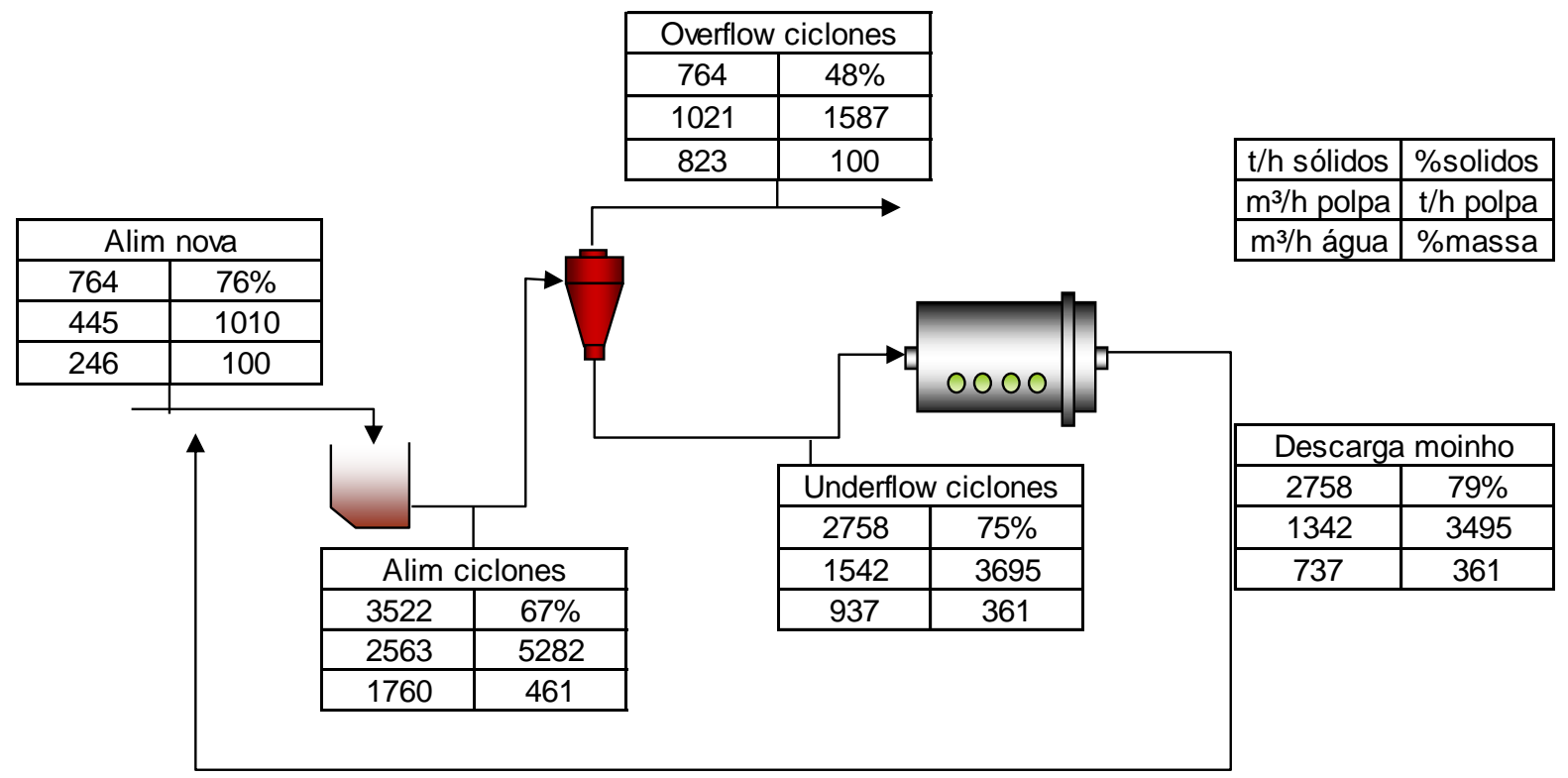

d) Circuito inverso - linha 4:

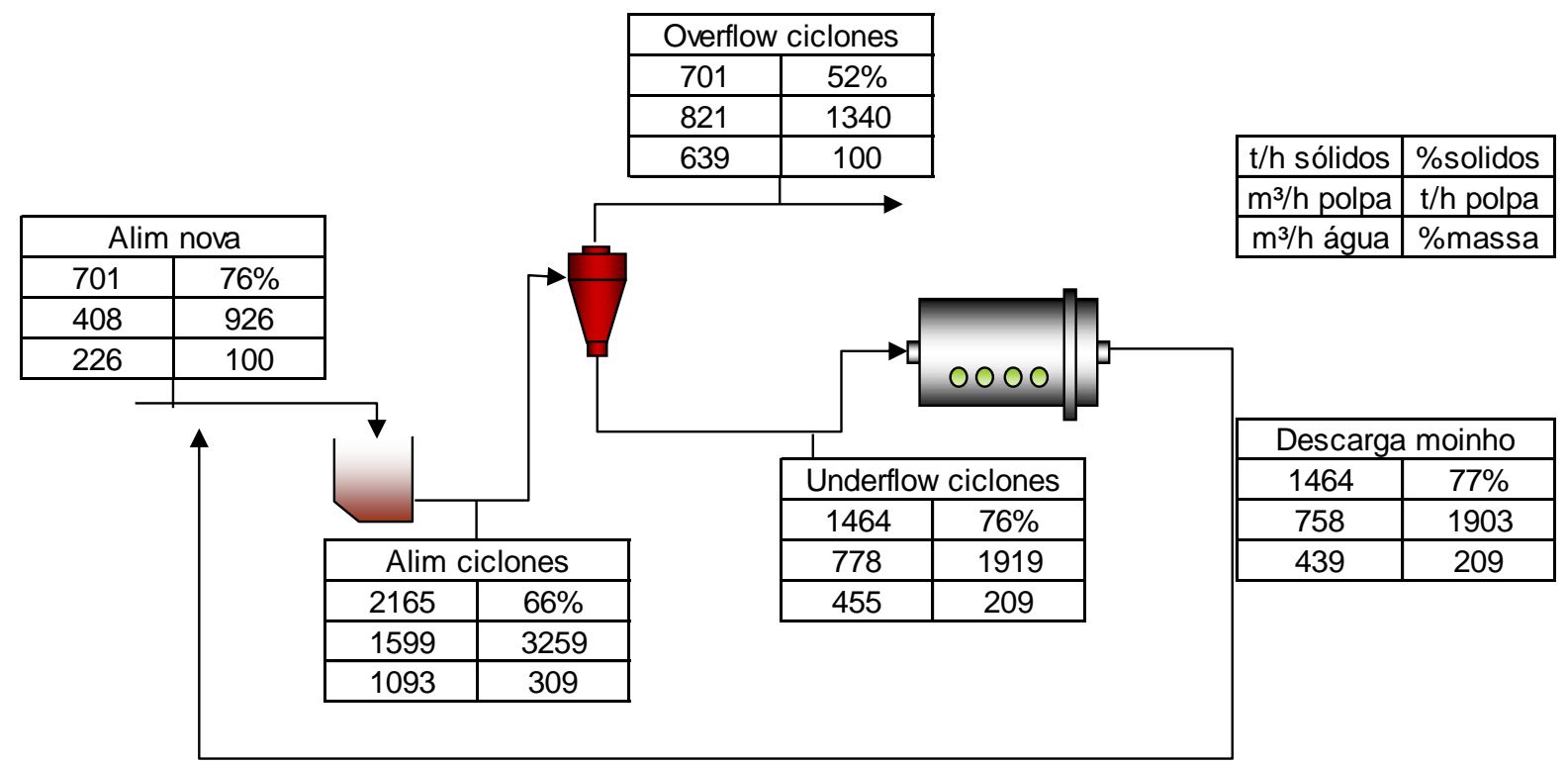


Dados industriais coletados durante a amostragem:

\begin{tabular}{|c|c|c|c|c|c|c|c|c|c|}
\hline \multirow{2}{*}{ Parâmetros } & \multicolumn{9}{|c|}{ Circuito direto } \\
\hline & Linha & 1 & 2 & 3 & 4 & 5 & 6 & 7 & Média \\
\hline \multirow{2}{*}{ Pressão ciclones (psi) } & 3 & 9,16 & 9,59 & 9,71 & 9,76 & 9,73 & 9,84 & 9,84 & 9,7 \\
\hline & 4 & 7,57 & 7,15 & 7,38 & 7,38 & 7,4 & 7,58 & 7,45 & 7,4 \\
\hline \multirow{2}{*}{$\begin{array}{c}\text { Potência moinho primário } \\
(\mathrm{kW})\end{array}$} & 3 & 1426 & 1412 & 1471 & 1435 & 1467 & 1416 & 1464 & 1442 \\
\hline & 4 & 1357 & 1374 & 1364 & 1368 & 1305 & 1352 & 1338 & 1351 \\
\hline \multirow{2}{*}{$\begin{array}{c}\text { Vazão de alimentação } \\
(\mathrm{t} / \mathrm{h})\end{array}$} & 3 & 347 & 353 & 389 & 356 & 392 & 380 & 363 & 369 \\
\hline & 4 & 350 & 356 & 338 & 362 & 347 & 348 & 347 & 350 \\
\hline \multirow{2}{*}{ Parâmetros } & \multicolumn{9}{|c|}{ Circuito inverso } \\
\hline & Linha & 1 & 2 & 3 & 4 & 5 & 6 & 7 & Média \\
\hline \multirow{2}{*}{ Pressão ciclones (psi) } & 3 & 10,45 & 10,04 & 10,45 & 10,53 & 10,76 & 10,82 & 10,60 & 10,5 \\
\hline & 4 & 8,90 & 8,67 & 8,84 & 8,74 & 8,38 & 8,50 & 8,63 & 8,7 \\
\hline Potência pré-moinho (kW) & 2 & 3601 & 3656 & 3573 & 3589 & 3621 & 3603 & 3555 & 3600 \\
\hline \multirow{2}{*}{$\begin{array}{c}\text { Potência moinho primário } \\
(\mathrm{kW})\end{array}$} & 3 & 1318 & 1326 & 1360 & 1361 & 1299 & 1314 & 1323 & 1329 \\
\hline & 4 & 1353 & 1294 & 1297 & 1311 & 1385 & 1297 & 1364 & 1329 \\
\hline \multirow{2}{*}{$\begin{array}{c}\text { Vazão de alimentação } \\
(\mathrm{t} / \mathrm{h})\end{array}$} & 3 & 859 & 778 & 740 & 698 & 551 & 834 & 888 & 764 \\
\hline & 4 & 767 & 689 & 696 & 666 & 516 & 790 & 781 & 701 \\
\hline
\end{tabular}

Dados analisados em laboratório:

a) Percentagem de sólidos e densidades:

\begin{tabular}{|c|c|c|c|}
\hline \multicolumn{4}{|c|}{ Circuito direto } \\
\hline Linha & Fluxo & \% Sólidos & ds $\left(\mathrm{g} / \mathrm{cm}^{3}\right)$ \\
\hline \multirow{5}{*}{3} & Alimentação nova & 92,58 & 3,97 \\
\hline & Descarga moinho primário & 75,58 & 4,41 \\
\hline & Alimentação ciclones & 61,10 & 4,47 \\
\hline & Underflow ciclones & 78,07 & 4,57 \\
\hline & Overflow ciclones & 26,91 & 3,93 \\
\hline \multirow{5}{*}{4} & Alimentação nova & 92,45 & 4,00 \\
\hline & Descarga moinho primário & 72,65 & 4,40 \\
\hline & Alimentação ciclones & 61,59 & 4,42 \\
\hline & Underflow ciclones & 80,12 & 4,59 \\
\hline & Overflow ciclones & 32,07 & 3,94 \\
\hline \multicolumn{4}{|c|}{ Circuito inverso } \\
\hline Linha & Fluxo & \% Sólidos & ds $\left(\mathrm{g} / \mathrm{cm}^{3}\right)$ \\
\hline \multicolumn{2}{|c|}{ Descarga Pré Moinho 02} & 75,65 & 3,84 \\
\hline \multirow{4}{*}{3} & Alimentação nova & 78,91 & 4,56 \\
\hline & Descarga moinho primário & 66,68 & 4,35 \\
\hline & Alimentação ciclones & 74,64 & 4,56 \\
\hline & Underflow ciclones & 48,14 & 3,85 \\
\hline \multirow{4}{*}{4} & Alimentação nova & 76,95 & 4,59 \\
\hline & Descarga moinho primário & 66,44 & 4,30 \\
\hline & Alimentação ciclones & 76,31 & 4,53 \\
\hline & Underflow ciclones & 52,31 & 3,85 \\
\hline
\end{tabular}

b) Análises granulométricas: 


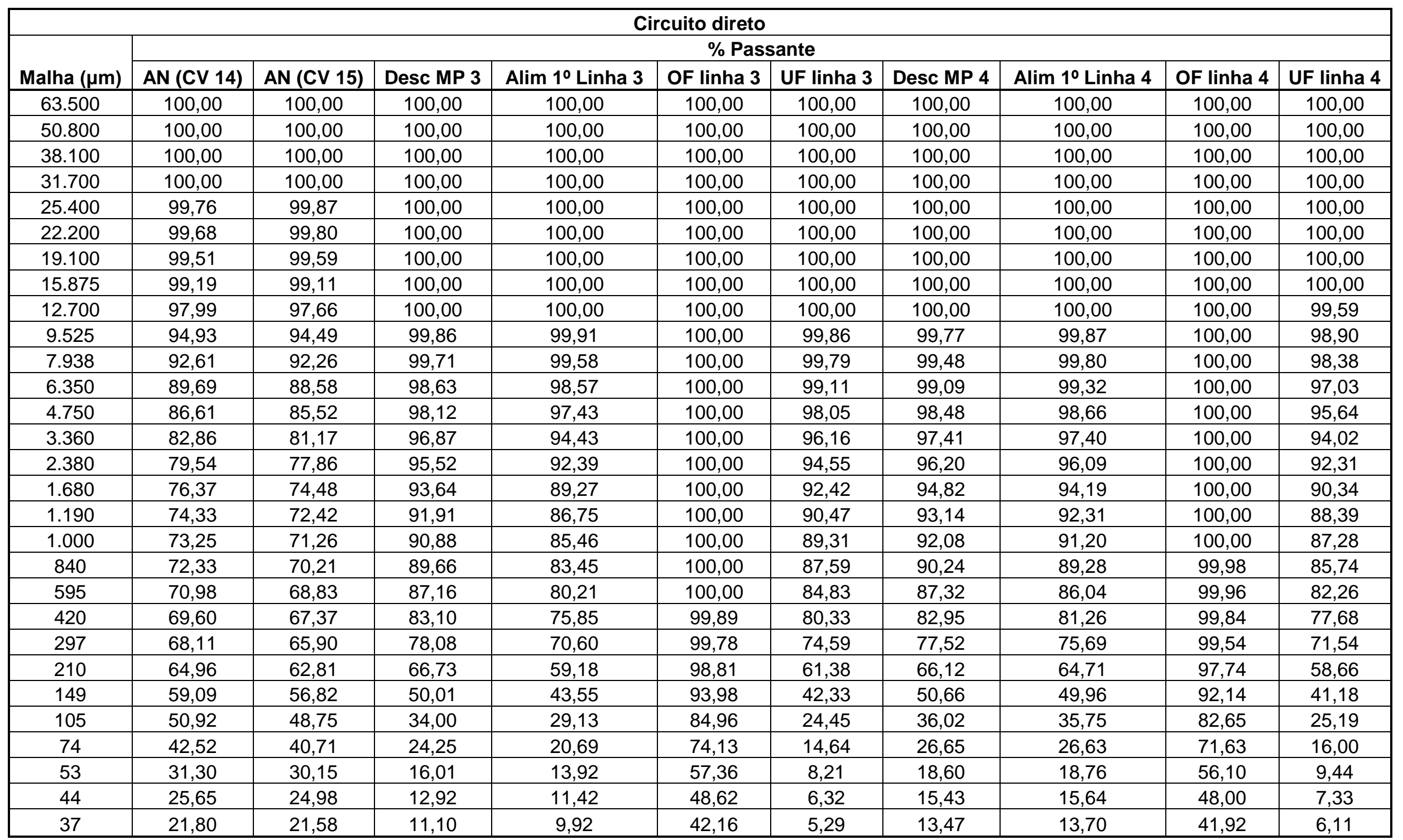




\begin{tabular}{|c|c|c|c|c|c|c|c|c|c|}
\hline \multicolumn{10}{|c|}{ Circuito direto } \\
\hline \multirow[b]{2}{*}{ Malha $(\mu \mathrm{m})$} & \multicolumn{9}{|c|}{ \% Passante } \\
\hline & AN (Desc PM 2) & Desc MP 3 & Alim 1ํㅡㄴ Linha 3 & OF linha 3 & UF linha 3 & Desc MP 4 & Alim $1^{\circ}$ Linha 4 & OF linha 4 & UF linha 4 \\
\hline 15.875 & 100,00 & 100,00 & 100,00 & 100,00 & 100,00 & 100,00 & 100,00 & 100,00 & 100,00 \\
\hline 12.700 & 100,00 & 100,00 & 100,00 & 100,00 & 100,00 & 100,00 & 100,00 & 100,00 & 100,00 \\
\hline 9.525 & 100,00 & 100,00 & 100,00 & 100,00 & 100,00 & 100,00 & 100,00 & 100,00 & 100,00 \\
\hline 7.938 & 99,86 & 99,95 & 99,96 & 100,00 & 99,93 & 100,00 & 100,00 & 100,00 & 99,94 \\
\hline 6.350 & 99,36 & 99,87 & 99,74 & 100,00 & 99,57 & 99,96 & 99,86 & 100,00 & 99,57 \\
\hline 4.750 & 98,67 & 99,76 & 99,39 & 100,00 & 98,94 & 99,90 & 99,70 & 100,00 & 99,30 \\
\hline 3.360 & 97,53 & 99,38 & 98,71 & 100,00 & 97,84 & 99,62 & 99,34 & 100,00 & 98,53 \\
\hline 2.380 & 96,15 & 98,74 & 97,68 & 100,00 & 96,53 & 99,16 & 98,74 & 100,00 & 97,67 \\
\hline 1.680 & 94,22 & 97,65 & 96,21 & 100,00 & 94,42 & 98,14 & 97,88 & 100,00 & 96,07 \\
\hline 1.190 & 92,50 & 96,37 & 94,74 & 100,00 & 92,10 & 96,90 & 96,87 & 100,00 & 94,34 \\
\hline 1.000 & 91,42 & 95,45 & 93,65 & 100,00 & 90,31 & 95,99 & 96,09 & 100,00 & 93,14 \\
\hline 840 & 90,29 & 94,31 & 92,55 & 100,00 & 87,19 & 94,80 & 94,58 & 100,00 & 91,20 \\
\hline 595 & 87,97 & 91,52 & 89,61 & 99,96 & 83,15 & 91,86 & 91,65 & 99,97 & 87,98 \\
\hline 420 & 85,14 & 86,29 & 84,96 & 99,73 & 77,75 & 85,87 & 87,08 & 99,73 & 82,41 \\
\hline 297 & 82,39 & 79,69 & 79,36 & 99,15 & 70,89 & 78,44 & 81,36 & 99,11 & 75,01 \\
\hline 210 & 77,04 & 64,88 & 67,48 & 96,14 & 56,16 & 63,39 & 69,67 & 95,97 & 60,12 \\
\hline 149 & 68,88 & 46,81 & 52,82 & 88,43 & 38,54 & 46,52 & 55,82 & 88,52 & 42,83 \\
\hline 105 & 59,03 & 33,38 & 40,84 & 77,37 & 25,77 & 34,40 & 44,54 & 77,78 & 30,33 \\
\hline 74 & 50,37 & 26,31 & 33,38 & 66,94 & 19,33 & 27,70 & 37,12 & 67,63 & 23,66 \\
\hline 53 & 39,34 & 19,76 & 25,52 & 53,32 & 13,75 & 21,19 & 29,02 & 54,25 & 17,51 \\
\hline 44 & 33,61 & 16,82 & 21,75 & 46,26 & 11,37 & 18,21 & 25,00 & 46,99 & 14,80 \\
\hline 37 & 29,27 & 14,93 & 19,10 & 40,56 & 9,84 & 16,23 & 22,10 & 41,43 & 13,00 \\
\hline
\end{tabular}




\section{Amostragem 5:}

- Data coleta: maio de 2011

- Linhas amostradas:

- Pré-moagem: linha 1;

- Moagem primária: linhas 1 e 2 .

Balanços de massa dos circuitos:

a) Circuito direto - linha 1:

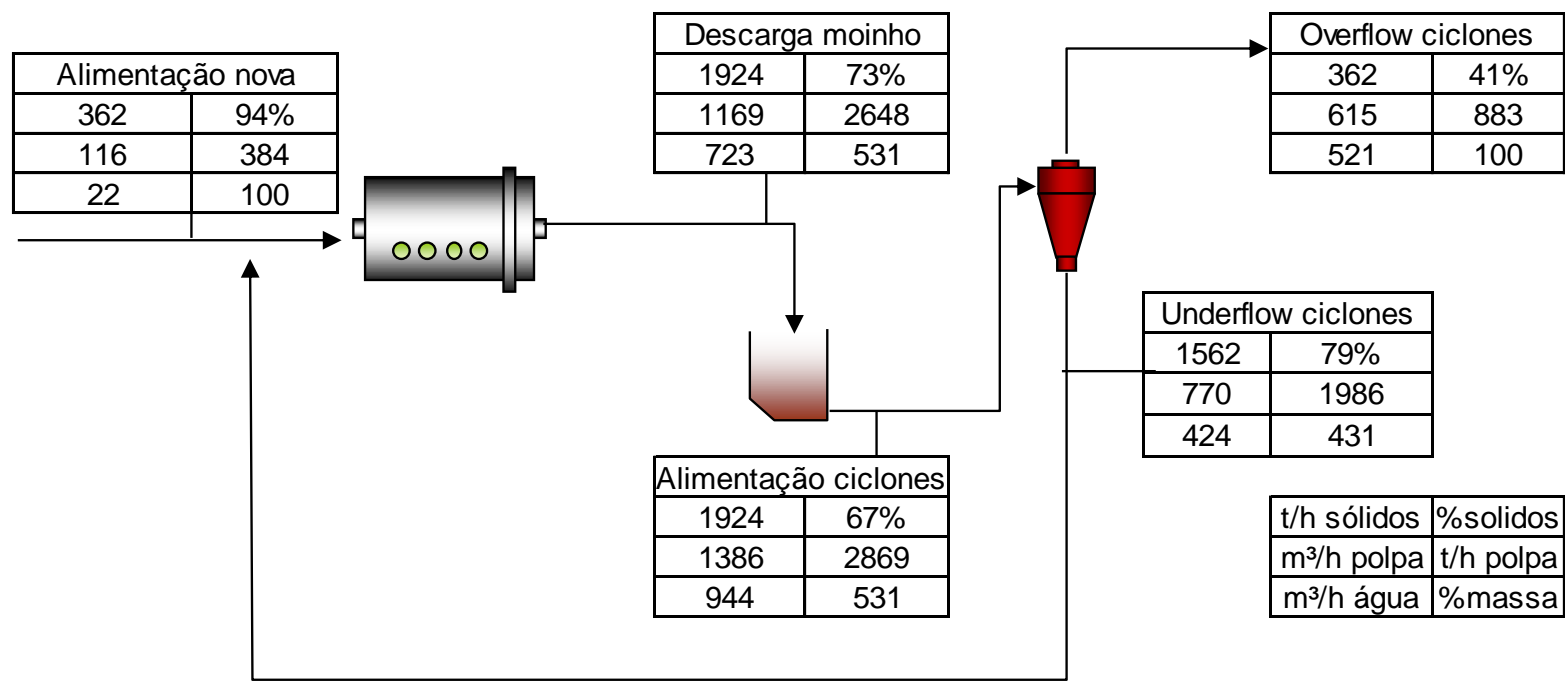

b) Circuito direto - linha 2:

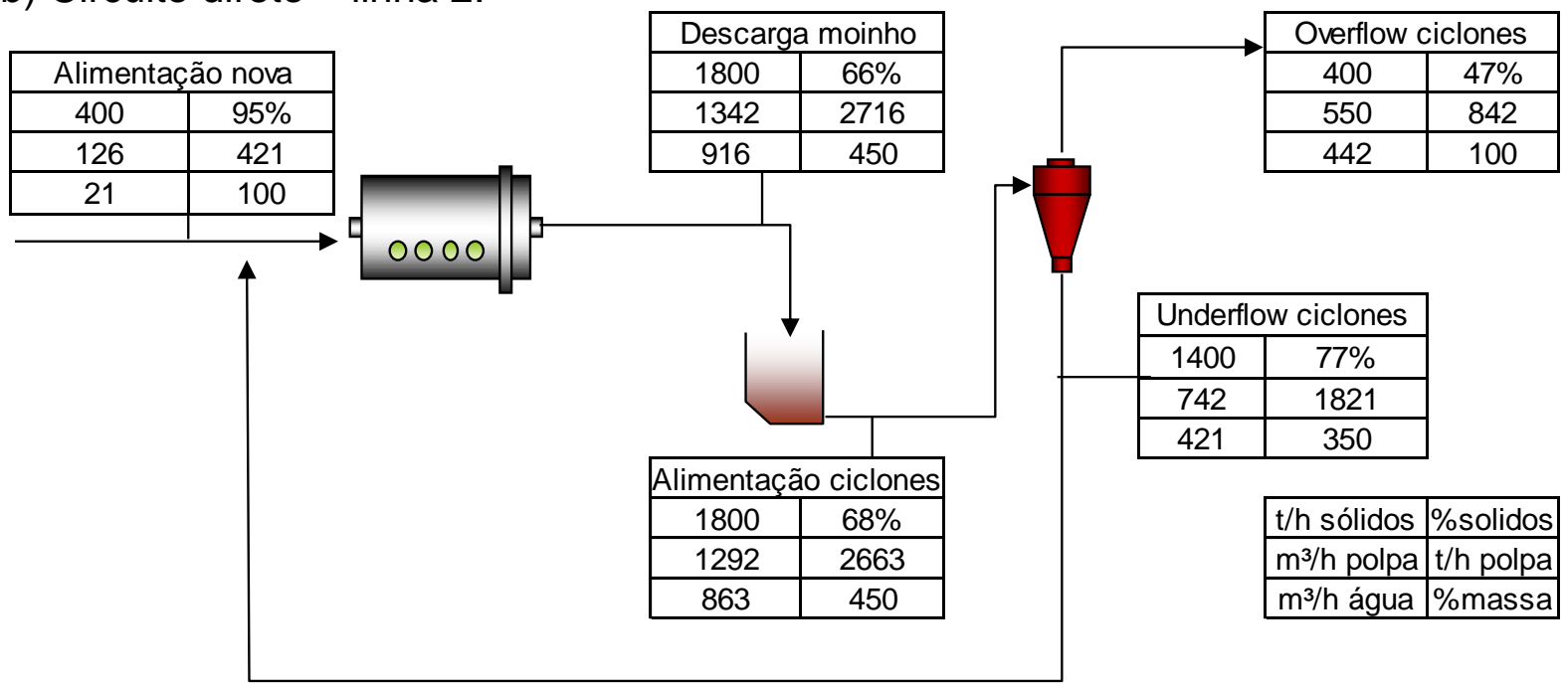

c) Circuito inverso - linha 1: 


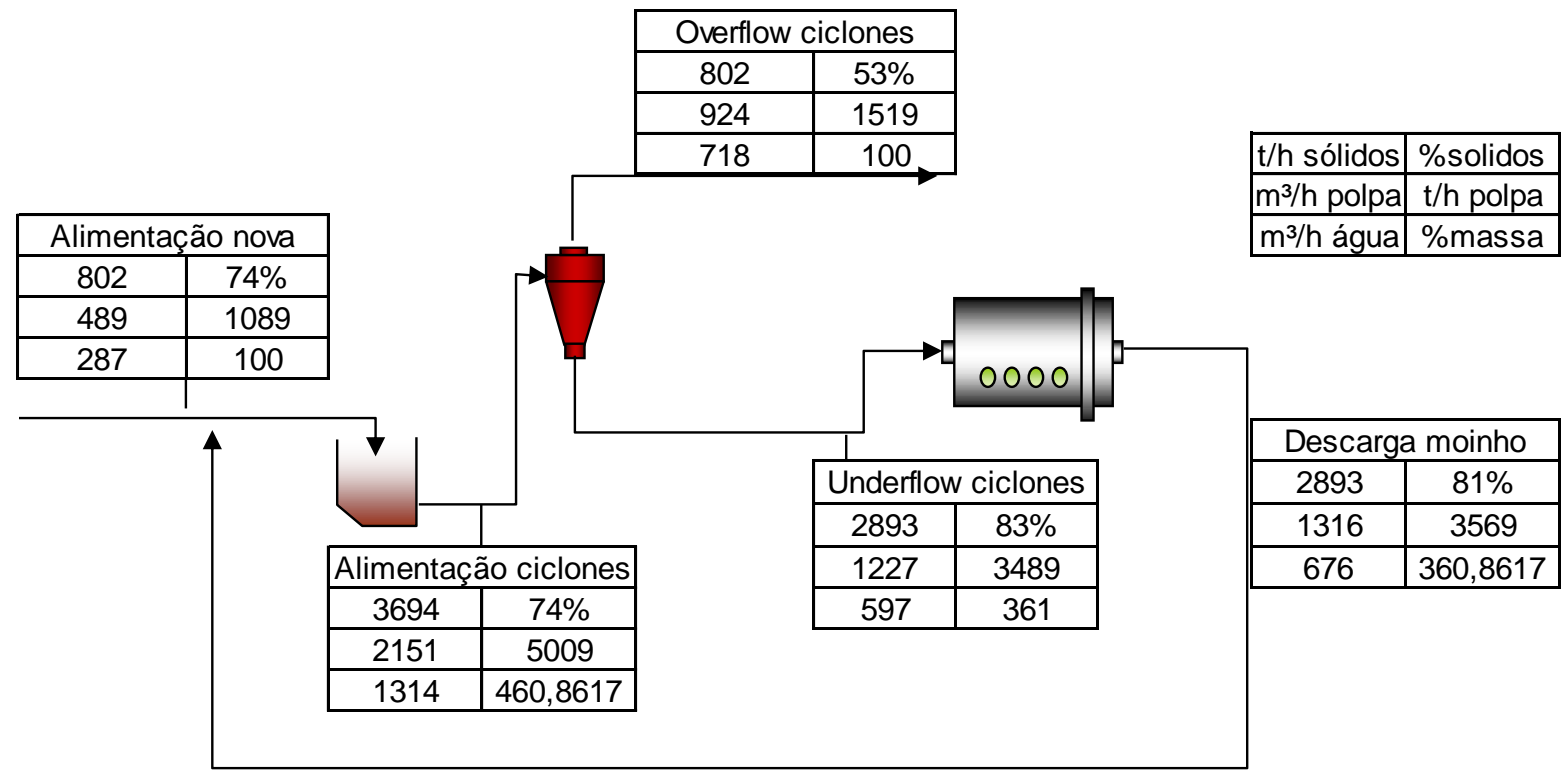

d) Circuito inverso - linha 2:

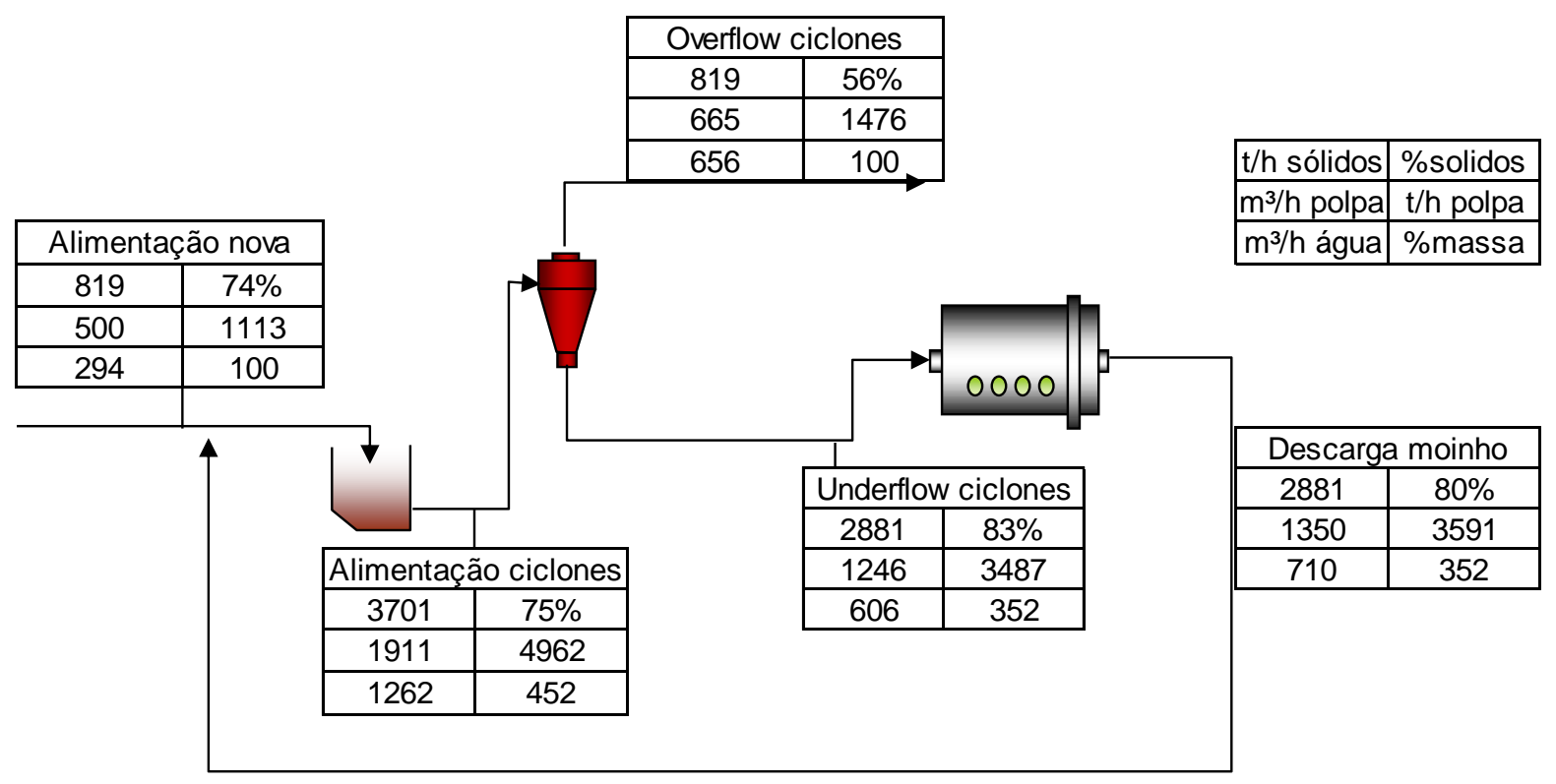


Dados industriais coletados durante a amostragem:

\begin{tabular}{|c|c|c|c|c|c|c|c|c|c|}
\hline \multirow{2}{*}{ Parâmetros } & \multicolumn{9}{|c|}{ Circuito direto } \\
\hline & Linha & 1 & 2 & 3 & 4 & 5 & 6 & 7 & Média \\
\hline \multirow{2}{*}{ Pressão ciclones (psi) } & 1 & 7,16 & 7,02 & 6,66 & 7,02 & 6,52 & 4,64 & 4,55 & 6,2 \\
\hline & 2 & 7,35 & 6,95 & 7,14 & 7,19 & 6,75 & 8,72 & 9,08 & 7,6 \\
\hline \multirow{2}{*}{$\begin{array}{l}\text { Potência moinho primário } \\
(\mathrm{kW})\end{array}$} & 1 & 1292 & 1289 & 1276 & 1270 & 1353 & 1338 & 1378 & 1314 \\
\hline & 2 & 1324 & 1361 & 1372 & 1317 & 1326 & 1287 & 1359 & 1335 \\
\hline \multirow{2}{*}{ Vazão de alimentação (t/h) } & 1 & 359 & 356 & 363 & 370 & 361 & 360 & 368 & 362 \\
\hline & 2 & 392 & 381 & 413 & 395 & 425 & 402 & 392 & 400 \\
\hline \multirow{2}{*}{ Parâmetros } & \multicolumn{9}{|c|}{ Circuito inverso } \\
\hline & Linha & 1 & 2 & 3 & 4 & 5 & 6 & 7 & Média \\
\hline \multirow{2}{*}{ Pressão ciclones (psi) } & 1 & 11,54 & 11,26 & 11,49 & 11,83 & 11,27 & 11,56 & 11,66 & 11,5 \\
\hline & 2 & 9,5 & 9,8 & 9,59 & 9,34 & 9,76 & 9,65 & 9,61 & 9,6 \\
\hline Potência pré-moinho (kW) & 1 & 3747 & 3728 & 3748 & 3766 & 3760 & 3741 & 3774 & 3752 \\
\hline \multirow{2}{*}{$\begin{array}{c}\text { Potência moinho primário } \\
(\mathrm{kW})\end{array}$} & 1 & 1255 & 1284 & 1249 & 1270 & 1258 & 1258 & 1260 & 1262 \\
\hline & 2 & 1319 & 1308 & 1303 & 1349 & 1317 & 1343 & 1294 & 1319 \\
\hline \multirow[t]{2}{*}{ Vazão de alimentação (t/h) } & 1 & 801 & 782 & 799 & 798 & 823 & 815 & 793 & 802 \\
\hline & 2 & 847 & 812 & 813 & 802 & 816 & 823 & 823 & 819 \\
\hline
\end{tabular}

Dados analisados em laboratório:

a) Percentagem de sólidos e densidades:

\begin{tabular}{|c|c|c|c|}
\hline \multicolumn{4}{|c|}{ Circuito direto } \\
\hline Linha & Fluxo & \% Sólidos & ds $\left(\mathrm{g} / \mathrm{cm}^{3}\right)$ \\
\hline \multirow{4}{*}{1} & Alimentação nova & 94,33 & 3,85 \\
\hline & Descarga moinho primário & 72,68 & 4,31 \\
\hline & Underflow ciclones & 78,67 & 4,51 \\
\hline & Overflow ciclones & 41,04 & 3,82 \\
\hline \multirow{4}{*}{2} & Alimentação nova & 95,05 & 3,82 \\
\hline & Descarga moinho primário & 66,28 & 4,22 \\
\hline & Underflow ciclones & 76,90 & 4,36 \\
\hline & Overflow ciclones & 47,48 & 3,70 \\
\hline \multicolumn{4}{|c|}{ Circuito inverso } \\
\hline Linha & Fluxo & \% Sólidos & ds $\left(\mathrm{g} / \mathrm{cm}^{3}\right)$ \\
\hline \multicolumn{2}{|c|}{ Descarga Pré Moinho 01} & 73,62 & 3,97 \\
\hline \multirow{3}{*}{1} & Descarga moinho primário & 81,05 & 4,52 \\
\hline & Underflow ciclones & 82,90 & 4,59 \\
\hline & Overflow ciclones & 52,76 & 3,89 \\
\hline \multirow{3}{*}{2} & Descarga moinho primário & 80,23 & 4,49 \\
\hline & Underflow ciclones & 82,63 & 4,50 \\
\hline & Overflow ciclones & 55,53 & 3,95 \\
\hline
\end{tabular}

b) Análises granulométricas: 


\begin{tabular}{|c|c|c|c|c|c|c|c|c|}
\hline \multicolumn{9}{|c|}{ Circuito direto } \\
\hline \multirow[b]{2}{*}{$\begin{array}{c}\text { Malha } \\
(\mu \mathrm{m})\end{array}$} & \multicolumn{8}{|c|}{$\%$ Passante } \\
\hline & $\begin{array}{c}\text { AN } \\
\text { (CV12) }\end{array}$ & $\begin{array}{c}\text { AN } \\
\text { (CV13) }\end{array}$ & $\begin{array}{l}\text { Desc } \\
\text { MP1 }\end{array}$ & $\begin{array}{l}\text { Desc } \\
\text { MP } 2 \\
\end{array}$ & $\begin{array}{c}\text { OF } \\
\text { linha } 1\end{array}$ & $\begin{array}{c}\text { OF } \\
\text { linha } 2\end{array}$ & $\begin{array}{c}\text { UF } \\
\text { linha } 1\end{array}$ & $\begin{array}{c}\text { UF } \\
\text { linha } 2\end{array}$ \\
\hline 63.500 & 100,00 & 100,00 & 100,00 & 100,00 & 100,00 & 100,00 & 100,00 & 100,00 \\
\hline 50.800 & 100,00 & 100,00 & 100,00 & 100,00 & 100,00 & 100,00 & 100,00 & 100,00 \\
\hline 38.100 & 100,00 & 100,00 & 100,00 & 100,00 & 100,00 & 100,00 & 100,00 & 100,00 \\
\hline 31.700 & 99,78 & 100,00 & 100,00 & 100,00 & 100,00 & 100,00 & 100,00 & 100,00 \\
\hline 25.400 & 99,14 & 99,35 & 100,00 & 100,00 & 100,00 & 100,00 & 100,00 & 100,00 \\
\hline 22.200 & 98,82 & 99,18 & 100,00 & 100,00 & 100,00 & 100,00 & 100,00 & 100,00 \\
\hline 19.100 & 98,21 & 98,99 & 100,00 & 100,00 & 100,00 & 100,00 & 100,00 & 100,00 \\
\hline 15.875 & 97,47 & 98,20 & 100,00 & 100,00 & 100,00 & 100,00 & 100,00 & 100,00 \\
\hline 12.700 & 95,55 & 96,04 & 100,00 & 99,89 & 100,00 & 100,00 & 100,00 & 99,96 \\
\hline 9.525 & 91,97 & 91,13 & 99,46 & 99,80 & 100,00 & 100,00 & 99,81 & 99,79 \\
\hline 7.938 & 88,87 & 87,99 & 99,10 & 99,61 & 100,00 & 100,00 & 99,50 & 99,47 \\
\hline 6.350 & 84,46 & 83,54 & 97,91 & 99,08 & 100,00 & 100,00 & 98,81 & 98,74 \\
\hline 4.750 & 80,34 & 79,97 & 96,48 & 98,50 & 100,00 & 100,00 & 97,66 & 97,38 \\
\hline 3.360 & 79,80 & 75,43 & 94,15 & 97,26 & 100,00 & 100,00 & 95,91 & 95,39 \\
\hline 2.380 & 75,85 & 71,95 & 91,82 & 96,03 & 100,00 & 100,00 & 94,01 & 92,95 \\
\hline 1.680 & 71,84 & 68,40 & 88,81 & 94,23 & 100,00 & 100,00 & 91,32 & 89,90 \\
\hline 1.190 & 69,36 & 66,13 & 86,67 & 92,66 & 100,00 & 100,00 & 88,97 & 87,36 \\
\hline 1.000 & 68,05 & 64,94 & 85,31 & 91,81 & 100,00 & 100,00 & 87,53 & 86,01 \\
\hline 840 & 67,21 & 63,97 & 84,21 & 88,29 & 99,94 & 99,95 & 84,11 & 84,58 \\
\hline 595 & 65,56 & 62,38 & 81,29 & 85,77 & 99,49 & 99,70 & 80,42 & 81,27 \\
\hline 420 & 63,56 & 60,47 & 76,40 & 81,51 & 98,93 & 99,30 & 75,36 & 75,83 \\
\hline 297 & 61,84 & 58,78 & 71,31 & 76,68 & 98,12 & 98,88 & 69,42 & 69,83 \\
\hline 210 & 58,02 & 55,13 & 60,48 & 66,32 & 95,50 & 97,41 & 57,41 & 57,25 \\
\hline 149 & 50,13 & 47,59 & 46,38 & 50,51 & 86,50 & 84,55 & 39,76 & 39,17 \\
\hline 105 & 40,16 & 38,22 & 34,00 & 36,75 & 73,92 & 72,22 & 26,82 & 24,98 \\
\hline 74 & 32,22 & 30,81 & 27,03 & 28,63 & 62,18 & 62,16 & 20,02 & 17,55 \\
\hline 53 & 22,61 & 21,97 & 18,79 & 19,90 & 45,96 & 45,66 & 13,69 & 10,64 \\
\hline 44 & 18,22 & 18,37 & 16,55 & 17,18 & 39,58 & 37,71 & 11,49 & 8,28 \\
\hline 37 & 16,18 & 16,06 & 14,27 & 14,56 & 34,72 & 33,92 & 9,79 & 6,88 \\
\hline
\end{tabular}

\begin{tabular}{|c|c|c|c|c|c|c|c|}
\hline \multicolumn{8}{|c|}{ Circuito inverso } \\
\hline \multirow{2}{*}{$\begin{array}{c}\text { Malha } \\
(\boldsymbol{\mu m})\end{array}$} & $\begin{array}{c}\text { AN (desc } \\
\text { PM1) }\end{array}$ & $\begin{array}{c}\text { Desc } \\
\mathbf{M P 1}\end{array}$ & $\begin{array}{c}\text { Desc MP } \\
\mathbf{2}\end{array}$ & $\begin{array}{c}\text { OF linha } \\
\mathbf{1}\end{array}$ & $\begin{array}{c}\text { OF linha } \\
\mathbf{2}\end{array}$ & $\begin{array}{c}\text { UF linha } \\
\mathbf{1}\end{array}$ & $\begin{array}{c}\text { UF linha } \\
\mathbf{2}\end{array}$ \\
\hline 15.875 & 100,00 & 100,00 & 100,00 & 100,00 & 100,00 & 100,00 & 100,00 \\
\hline 12.700 & 100,00 & 100,00 & 100,00 & 100,00 & 100,00 & 100,00 & 100,00 \\
\hline 9.525 & 100,00 & 99,99 & 99,91 & 100,00 & 100,00 & 99,82 & 99,83 \\
\hline 7.938 & 99,89 & 99,72 & 99,54 & 100,00 & 100,00 & 99,52 & 99,46 \\
\hline 6.350 & 99,61 & 99,06 & 98,89 & 100,00 & 100,00 & 98,83 & 98,70 \\
\hline 4.750 & 99,10 & 98,24 & 98,04 & 100,00 & 99,95 & 97,95 & 97,70 \\
\hline 3.360 & 97,75 & 96,98 & 96,53 & 100,00 & 99,92 & 96,44 & 96,00 \\
\hline 2.380 & 96,35 & 95,73 & 95,03 & 100,00 & 99,86 & 94,64 & 94,17 \\
\hline 1.680 & 94,28 & 93,92 & 92,65 & 100,00 & 99,67 & 92,18 & 91,49 \\
\hline 1.190 & 92,34 & 92,21 & 91,00 & 100,00 & 99,32 & 90,01 & 88,77 \\
\hline 1.000 & 91,33 & 90,96 & 90,02 & 100,00 & 99,10 & 88,95 & 87,30 \\
\hline 840 & 89,96 & 89,44 & 88,70 & 99,82 & 98,88 & 87,03 & 85,28 \\
\hline
\end{tabular}




\begin{tabular}{|c|c|c|c|c|c|c|c|}
\hline \multirow{2}{*}{$\begin{array}{c}\text { Malha } \\
(\boldsymbol{\mu m})\end{array}$} & $\begin{array}{c}\text { AN (desc } \\
\text { PM1) }\end{array}$ & $\begin{array}{c}\text { Desc } \\
\text { MP1 }\end{array}$ & $\begin{array}{c}\text { Desc MP } \\
\mathbf{2}\end{array}$ & $\begin{array}{c}\text { OF linha } \\
\mathbf{1}\end{array}$ & $\begin{array}{c}\text { OF linha } \\
\mathbf{2}\end{array}$ & $\begin{array}{c}\text { UF linha } \\
\mathbf{1}\end{array}$ & $\begin{array}{c}\text { UF linha } \\
\mathbf{2}\end{array}$ \\
\hline 595 & 87,51 & 85,82 & 84,67 & 98,83 & 98,28 & 82,63 & 80,78 \\
\hline 420 & 83,93 & 78,64 & 77,22 & 97,34 & 97,25 & 74,14 & 72,53 \\
\hline 297 & 80,67 & 69,94 & 69,10 & 95,94 & 95,63 & 65,13 & 63,12 \\
\hline 210 & 74,36 & 52,84 & 53,83 & 91,56 & 91,07 & 47,41 & 46,79 \\
\hline 149 & 64,79 & 35,76 & 40,01 & 82,31 & 81,57 & 29,80 & 32,54 \\
\hline 105 & 54,51 & 25,84 & 31,39 & 69,96 & 70,25 & 20,43 & 24,27 \\
\hline 74 & 45,62 & 20,60 & 26,32 & 60,29 & 61,18 & 15,85 & 19,40 \\
\hline 53 & 34,76 & 14,89 & 20,06 & 46,39 & 48,50 & 10,82 & 13,95 \\
\hline 44 & 29,43 & 12,51 & 17,41 & 40,34 & 43,45 & 9,02 & 11,74 \\
\hline 37 & 26,07 & 11,01 & 15,67 & 35,01 & 39,23 & 7,88 & 10,08 \\
\hline
\end{tabular}




\section{APÊNDICE B - Validação do método de análise granulométrica utilizado pelo Laboratório de Controle de Processos (LCP) de Germano}

Amostra: overflow dos ciclones primários, linha 1, coletada no dia 23/07/12. Amostra coletada em polpa. Após secagem e quarteamento, foram realizadas análises granulométricas em dois métodos distintos:

a) Peneiramento a úmido: amostra peneirada a úmido, em peneirador do tipo vibratório, por 20 minutos.

b) Método padrão do LCP:

- deslamagem: toda a amostra é deslamada (lavagem manual) em peneira com malha de 0,044 mm (325 \#, série Tyler);

- peneiramento da fração acima de 0,044 mm: esta fração da amostra é filtrada, secada em estufa e peneirada a seco, por um período de 20 minutos, em peneirador do tipo vibratório.

\begin{tabular}{|c|c|c|}
\hline \multirow{2}{*}{$\begin{array}{c}|c| \\
\text { Peneiramento }\end{array}$} & \multicolumn{2}{|c|}{ Passante } \\
\hline $\begin{array}{c}\text { Abertura } \\
\text { (micrômetros) }\end{array}$ & Peneiramento a úmido & Método padrão do LCP \\
\hline 840 & 100,00 & 100,00 \\
\hline 595 & 100,00 & 100,00 \\
\hline 420 & 100,00 & 100,00 \\
\hline 297 & 100,00 & 100,00 \\
\hline 210 & 100,00 & 100,00 \\
\hline 149 & 83,50 & 82,98 \\
\hline 105 & 72,40 & 71,66 \\
\hline 74 & 60,06 & 58,59 \\
\hline 53 & 47,99 & 45,63 \\
\hline 44 & 42,86 & 40,29 \\
\hline
\end{tabular}




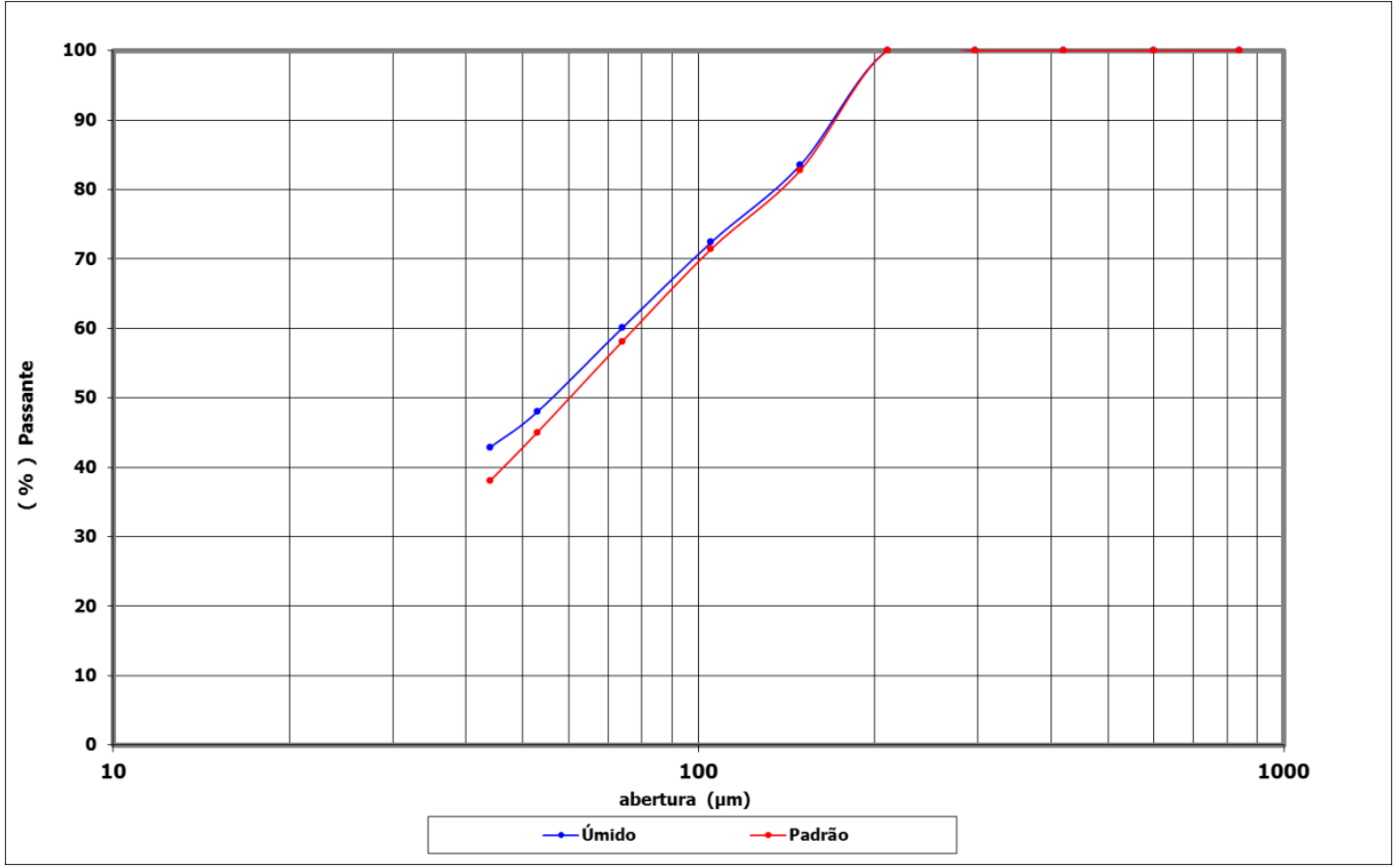




\section{APÊNDICE C - Ensaios de moagem}

a) Amostra coletada nas correias de alimentação dos moinhos primários - usina II:

\begin{tabular}{|c|c|c|c|c|c|}
\hline \multirow{2}{*}{$\begin{array}{c}\text { Peneiramento } \\
\begin{array}{c}\text { Abertura } \\
\text { (micrômetros) }\end{array}\end{array}$} & \multicolumn{5}{|c|}{$\%$ Passante } \\
\hline & $\begin{array}{l}\text { Alimentação } \\
\text { da moagem }\end{array}$ & $\begin{array}{l}\text { Primeira } \\
\text { moagem }\end{array}$ & $\begin{array}{l}\text { Segunda } \\
\text { moagem }\end{array}$ & $\begin{array}{l}\text { Terceira } \\
\text { moagem }\end{array}$ & $\begin{array}{c}\text { Quarta } \\
\text { moagem }\end{array}$ \\
\hline 15.875 & 100,00 & 100,00 & 100,00 & 100,00 & 100,00 \\
\hline 12.700 & 100,00 & 100,00 & 100,00 & 100,00 & 100,00 \\
\hline 9.525 & 100,00 & 100,00 & 100,00 & 100,00 & 100,00 \\
\hline 7.938 & 95,82 & 99,46 & 99,62 & 99,74 & 99,84 \\
\hline 6.350 & 90,48 & 98,58 & 99,35 & 99,64 & 99,79 \\
\hline 4.750 & 85,30 & 98,02 & 99,17 & 99,57 & 99,75 \\
\hline 3.360 & 79,89 & 97,28 & 99,01 & 99,54 & 99,69 \\
\hline 2.380 & 75,57 & 96,86 & 98,93 & 99,52 & 99,68 \\
\hline 1.680 & 71,36 & 96,42 & 98,86 & 99,51 & 99,66 \\
\hline 1.190 & 68,67 & 96,07 & 98,81 & 99,49 & 99,65 \\
\hline 1.000 & 67,37 & 95,87 & 98,78 & 99,49 & 99,65 \\
\hline 840 & 66,29 & 95,58 & 98,75 & 99,49 & 99,65 \\
\hline 595 & 64,66 & 94,90 & 98,66 & 99,47 & 99,63 \\
\hline 420 & 62,38 & 93,28 & 98,35 & 99,42 & 99,61 \\
\hline 297 & 60,85 & 90,82 & 97,81 & 99,33 & 99,58 \\
\hline 210 & 57,37 & 84,89 & 94,50 & 98,46 & 99,26 \\
\hline 149 & 49,63 & 74,31 & 82,78 & 91,49 & 95,04 \\
\hline 105 & 40,71 & 62,16 & 69,28 & 78,22 & 83,67 \\
\hline 74 & 33,28 & 50,99 & 58,10 & 65,19 & 70,74 \\
\hline 53 & 24,14 & 38,05 & 43,03 & 49,14 & 54,61 \\
\hline 44 & 20,80 & 32,96 & 38,54 & 43,53 & 48,49 \\
\hline $\begin{array}{l}\text { Tempo de moagem } \\
\text { (min) }\end{array}$ & 0 & 5 & 10 & 15 & 20 \\
\hline $\begin{array}{c}\text { Consumo de energia } \\
(\mathrm{kWh} / \mathrm{t})\end{array}$ & 0 & 1,64 & 3,28 & 4,92 & 6,56 \\
\hline
\end{tabular}


b) Amostra peneirada em 0,210 $\mathrm{mm}$ (fração grosseira):

\begin{tabular}{|c|c|c|c|c|c|}
\hline Peneiramento & $\begin{array}{l}\text { Alimentação } \\
\text { da moagem }\end{array}$ & $\begin{array}{l}\text { Primeira } \\
\text { moagem }\end{array}$ & $\begin{array}{l}\text { Segunda } \\
\text { moagem }\end{array}$ & $\begin{array}{l}\text { Terceira } \\
\text { moagem }\end{array}$ & $\begin{array}{c}\text { Quarta } \\
\text { moagem }\end{array}$ \\
\hline $\begin{array}{c}\text { Abertura } \\
\text { (micrômetros) }\end{array}$ & $\%$ Passante & \% Passante & \% Passante & \% Passante & $\%$ Passante \\
\hline 15.875 & 100,00 & 100,00 & 100,00 & 100,00 & 100,00 \\
\hline 12.700 & 100,00 & 100,00 & 100,00 & 100,00 & 100,00 \\
\hline 9.525 & 97,70 & 100,00 & 100,00 & 100,00 & 100,00 \\
\hline 7.938 & 89,80 & 96,72 & 98,56 & 99,26 & 99,57 \\
\hline 6.350 & 77,89 & 92,32 & 96,80 & 98,83 & 99,15 \\
\hline 4.750 & 66,53 & 88,62 & 95,39 & 98,43 & 98,97 \\
\hline 3.360 & 53,74 & 84,90 & 94,11 & 98,10 & 98,78 \\
\hline 2.380 & 44,53 & 82,27 & 93,31 & 97,92 & 98,70 \\
\hline 1.680 & 35,36 & 79,72 & 92,60 & 97,75 & 98,64 \\
\hline 1.190 & 29,86 & 77,61 & 92,04 & 97,63 & 98,59 \\
\hline 1.000 & 26,94 & 76,36 & 91,71 & 97,56 & 98,57 \\
\hline 840 & 24,78 & 74,54 & 91,28 & 97,49 & 98,55 \\
\hline 595 & 21,19 & 71,47 & 90,29 & 97,32 & 98,51 \\
\hline 420 & 16,50 & 65,63 & 87,48 & 96,79 & 98,40 \\
\hline 297 & 12,96 & 60,61 & 83,44 & 95,32 & 98,02 \\
\hline 210 & 4,68 & 50,24 & 72,22 & 88,00 & 94,85 \\
\hline 149 & 4,68 & 41,04 & 59,44 & 74,20 & 83,56 \\
\hline 105 & 4,68 & 34,78 & 50,25 & 62,71 & 70,77 \\
\hline 74 & 4,68 & 29,92 & 43,27 & 54,08 & 60,90 \\
\hline 53 & 4,68 & 23,07 & 33,72 & 42,42 & 47,63 \\
\hline 44 & 4,68 & 20,54 & 30,02 & 37,51 & 42,63 \\
\hline $\begin{array}{c}\text { Tempo de moagem } \\
\text { (min) }\end{array}$ & 0 & 5 & 10 & 15 & 20 \\
\hline $\begin{array}{c}\text { Consumo de energia } \\
\text { (kWh/t) }\end{array}$ & 0 & 1,64 & 3,28 & 4,92 & 6,56 \\
\hline
\end{tabular}

